\title{
Assistive technology service delivery for children with multiple disabilities : a family-centred approach to assure quality
}

Citation for published version (APA):

Desideri, L. (2015). Assistive technology service delivery for children with multiple disabilities : a familycentred approach to assure quality. [Doctoral Thesis, Maastricht University]. Datawyse / Universitaire Pers Maastricht. https://doi.org/10.26481/dis.20151021ld

Document status and date:

Published: 01/01/2015

DOI:

10.26481/dis.20151021ld

Document Version:

Publisher's PDF, also known as Version of record

\section{Please check the document version of this publication:}

- A submitted manuscript is the version of the article upon submission and before peer-review. There can be important differences between the submitted version and the official published version of record.

People interested in the research are advised to contact the author for the final version of the publication, or visit the DOI to the publisher's website.

- The final author version and the galley proof are versions of the publication after peer review.

- The final published version features the final layout of the paper including the volume, issue and page numbers.

Link to publication

\footnotetext{
General rights rights.

- You may freely distribute the URL identifying the publication in the public portal. please follow below link for the End User Agreement:

www.umlib.nl/taverne-license

Take down policy

If you believe that this document breaches copyright please contact us at:

repository@maastrichtuniversity.nl

providing details and we will investigate your claim.
}

Copyright and moral rights for the publications made accessible in the public portal are retained by the authors and/or other copyright owners and it is a condition of accessing publications that users recognise and abide by the legal requirements associated with these

- Users may download and print one copy of any publication from the public portal for the purpose of private study or research.

- You may not further distribute the material or use it for any profit-making activity or commercial gain

If the publication is distributed under the terms of Article $25 \mathrm{fa}$ of the Dutch Copyright Act, indicated by the "Taverne" license above, 


\section{Assistive Technology \\ Service Delivery for Children \\ with Multiple Disabilities}

A Family-Centred Approach to Assure Quality

LORENZO DESIDER I 



\author{
Lorenzo Desideri
}

\title{
Assistive Technology Service Delivery for Children with Multiple Disabilities
}

A Family-Centred Approach to Assure Quality 
(C) copyright Lorenzo Desideri, Maastricht 2015

Printing: Datawyse | Universitaire Pers Maastricht ISBN 978-94-6159-473-0 


\title{
Assistive Technology Service Delivery for Children with Multiple Disabilities
}

\author{
A Family-Centred Approach to \\ Assure Quality
}

\section{DISSERTATION}

to obtain the degree of Doctor at Maastricht University, on the authority of the Rector Magnificus, Prof. Dr. L.L.G. Soete in accordance with the decision of the Board of Deans, to be defended in public on Wednesday 21 October 2015, at 10.00 hours

by

Lorenzo Desideri

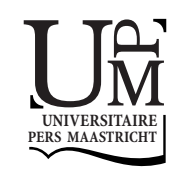


SUPERVISOR

Prof. dr. L.P. de Witte

Co-supervisors

Dr. G.J. Gelderblom $\dagger$ (Zuyd University of Applied Sciences, Heerlen)

Dr. U.R. Roentgen (Zuyd University of Applied Sciences, Heerlen)

Assessment Committee

Prof. dr. C.M. van Heugten (chair)

Dr. R. Andrich (Fondazione Don Gnocchi, Italy)

Prof. dr. M. Hawley (University of Sheffield, United Kingdom)

Dr. H.J.L. van Rossum

Prof. dr. G.D.E.M. van der Weijden 
Contents

Chapter 1

Chapter 2

Chapter 3

Chapter 4

Chapter 5

Chapter 6

Chapter 7

Chapter 8
General Introduction

9

Recommending assistive technology (AT) for children with multiple disabilities: A systematic review and qualitative synthesis of models and instruments for AT professionals

Assessing children with multiple disabilities for assistive technology: A framework for quality assurance

Development of a team-based method for assuring the quality of assistive technology documentation

Satisfaction of users with assistive technology service delivery: An exploratory analysis of experiences of parents of children with physical and multiple disabilities

Implementing a routine outcome assessment procedure to evaluate the quality of assistive technology service delivery for children with physical or multiple disabilities: perceived effectiveness, social cost, and user satisfaction

General Discussion

Valorization of Research Results

Summary

Samenvatting

Sommario

Abbreviations

Aknowledgments 195

About the Author 

Chapter I

General Introduction 

Children living in Europe are surviving more than ever, and the diseases and disabilities they suffer from are changing ${ }^{1}$. The burden of disease in the $0-18$ age group has shifted from infants and children to newborn babies and adolescents, and from infectious diseases to disabilities and non-communicable diseases which may require multiple longterm care interventions ${ }^{1}$. To further complicate the picture, health services in Europe and worldwide are facing the challenge associated to the management of multiple chronic conditions both in elderly people and in children ${ }^{2}$. Today, it is estimated that 50 million people in the European Union live with multiple chronic diseases, which in turn deeply impact quality of life in the person experiencing multiple functional limitations ${ }^{3}$.

The focus of this thesis is on children with multiple problems such as eating, breathing, mobility, congenital malformations and intellectual disabilities ${ }^{2}$, and on interventions aimed at creating developmental and learning opportunities by modifying the context in which they live. These types of interventions are denoted under the umbrella term assistive technology (AT).

A serious issue to consider when thinking of the needs of children with disabilities is the level of access to and provision of AT that they have available to them. Empirical research has documented that children are often less likely than adults to access $\mathrm{AT}^{4}$. In addition, children with more severe disabilities are more likely to report having unmet AT needs $s^{5}$. Research also highlights that in Western countries the average of non-use or abandonment of AT is usually estimated as one-third after one year from provision ${ }^{6}$. Non-use rates of provided AT among children are reported as up to $23 \%{ }^{7}$.

The increased probability of survival even among children with multiple disabilities means that adequate services and interventions, including AT, will need to be provided for children at any point of their life ${ }^{8}$. Therefore, this thesis will focus on the development and implementation of a quality assurance approach that can support AT professionals measuring and assessing the quality of AT service delivery (ATSD) provided to children and their families.

This introductory chapter will first give an overview of the research-topic context in relation to general health policy and a description of children with disabilities in terms of who they are and the role of AT. It will then offer an explanation of ATSD organization, with particular attention to the Italian system, this being the context in which the research project described in this thesis took place. The last paragraphs will better define the concept and objectives of quality measurement, and will specify the research questions addressed in this thesis.

\section{Major Developments in Health Service Delivery}

Over the last decade, two major social and economic changes have affected health service delivery. The first concerns the recognition that, since children with disabilities are living longer, there is a critical need to increase their autonomy and to reduce the demand on health services and caregivers ${ }^{4,9}$. The Convention on the Rights of Persons with Disabilities ${ }^{10}$ and the Convention on the Rights of the Child ${ }^{11}$ challenge charitable approaches that regard children with disabilities as passive recipients of care and pro- 
tection. Instead, the Conventions demand recognition of each child as a full member of her or his family, community and society. This entails a focus that is not on traditional notions of 'rescuing' the child, but on the investment in removing the physical, cultural, economic, communication, mobility and attitudinal barriers that impede the realization of the child's rights - including the right to active involvement in decision-making that affects the child's daily life. Evidence exists to demonstrate that AT can reduce children's activity limitations, improve their participation ${ }^{12}$, and have a positive socio-economic effect by improving access to education and increasing achievement ${ }^{13}$. For this, Articles 4, 9, 20, 21, 24, 26, 29 and 32 of the Convention on the Rights of Persons with Disabilities make explicit mention of $\mathrm{AT}^{14}$.

The second change regards the current economic downturn which has forced governments in many countries to reduce public funding ${ }^{15}$. As far as the Italian situation is concerned, if cuts to the healthcare system are not compensated by research on how to improve quality in service delivery systems and their efficiency, providers may have to reduce their service supply and quality, with negative consequences for the health outcomes ${ }^{16}$.

\section{A Focus on Quality}

The social impact of childhood disability involves both the present, through health care and other social costs, and the future, through growing demand in public support for basic needs as well as health care ${ }^{17}$. AT interventions may play a fundamental role in tertiary prevention, this being the limitation of the consequences of disabilities ${ }^{18}$. Implementing the AT-related measures of the Convention on the Rights of Persons with Disabilities among children implies ensuring that products and services are 'available, affordable and well suited to all who need them' ${ }^{14}$.

The growing rate of children with chronic health conditions and the switch towards interventions aimed at improving their autonomy have increased government interest in many countries in measuring and improving healthcare quality for that population ${ }^{17}$. There is a number of definitions of the term 'quality' in health care. The Institute of Medicine (IOM) has defined quality as the degree to which health services for individuals and populations increase the likelihood of desired health outcomes and are consistent with current professional knowledge ${ }^{19}$.

In the field of AT, a recent position paper published by the Association for the Advancement of Assistive Technology in Europe (AAATE) clearly recommends that 'service delivery systems should include quality assurance procedures for self-correcting quality control of the process, of the devices provided, and the outcomes ${ }^{20}$ (p. 20). In this view, the ultimate goal of quality assurance is to use measurements in order to support actions guiding the improvement of service delivery ${ }^{17,21}$. Furthermore, measuring ATSD quality may fulfil a number of associated purposes:

- $\quad$ it can identify differences in service delivery practices or processes, programmes and policies, as well as the outcomes associated with these differences; 
- $\quad$ it provides a basis for determining whether the care received by users from specific providers is consistent with evidence and professional standards;

- $\quad$ it facilitates assessment and monitoring of the overall functioning of the service delivery system over time.

To date, relatively little research has been conducted on ATSD quality, and that on service delivery targeting children with disabilities is almost inexistent. Possible reasons for the scarce attention paid by the AT field to this topic may be associated with the complexities related to the characteristics of both the target group and organization of the service delivery systems.

\section{Defining Children with Disabilities}

Notions of child disability have evolved over the past century in concert with changing conceptions of health and illness, and in relation to changing demands and expectations for child functioning ${ }^{22}$. In the last decade, the International Classification of Functioning, Disability and Health - Children and Youth Version (ICF-CY) ${ }^{23}$ has attempted to integrate the two existing models of disability that are usually seen as antithetical to each other - the medical model and the social one - into a unified model of disability, providing a multi-perspective approach to the classification of health, functioning and disability as the result of interactive and evolutionary processes ${ }^{24}$. In this view, the ICFCY regards disability as neither purely biological nor social but instead as the interaction between health conditions and environmental and personal factors. According to the ICF-CY, disability can occur at three levels ${ }^{25}$ :

- an impairment in body function or structure, such as a cataract which prevents the passage of light and the sensing of form, shape, and size of visual stimuli;

- a limitation in activity, such as the inability to read or move around;

- a restriction in participation, such as exclusion from school or other community activities.

According to this model, the term 'children with disabilities' refers to children up to the age of 18 who have 'long-term physical, mental, intellectual, or sensory impairments which in interaction with various barriers may hinder their full and effective participation in society on an equal basis with others' ${ }^{10}$.

The spectrum of impairments that may affect activity and participation in children is wide and comprises many congenital and acquired conditions (e.g. cerebral palsy, traumatic brain injury, neuromuscular disease, genetic disorders and other developmental disorders ${ }^{26}$. The term 'children with multiple disabilities' will be used throughout this thesis. This term identifies a highly variable group which includes children having any combination of a number of concomitant impairments such as neuromuscular dysfunctions, cognitive and intellectual disabilities and other physical and sensory impairments, with different degrees of severity. 
Estimating the prevalence of children with multiple disabilities is a difficult task. In general, there are currently no reliable and representative estimates based on actual measurement of the number of children with disabilities ${ }^{25}$. The varying nature and severity of disabilities, together with the fact that having multiple disabilities is not related to a specific diagnosis, further complicate data collection efforts ${ }^{27}$.

As far as the European Union is concerned, current health information systems are focusing mainly on mortality and acute morbidity, while the development dimension and the ability to perform functions, which would be more useful in estimating rates of multiple disabilities, are not systematically addressed ${ }^{28}$. Recent estimates show an increase in developmental disabilities and mental health disorders. In particular, estimated prevalence of neurological and developmental disorders are $4-5 \%$ of the total population (80 million under age 15 in 2006) ${ }^{28}$.

Cerebral palsy may be considered a neurological condition which can lead to multiple disabilities. It is the commonest cause of physical disability in early childhood, beginning in early childhood and persisting throughout lifespan. In addition to physical disability, cerebral palsy describes a group of permanent disorders in movement development, often accompanied by disturbances of sensation, perception, cognition, communication, and behaviour ${ }^{29}$. Overall, the rate of cerebral palsy in Europe is between 2 and 3 per 1000 live births. This rate increases to $40-100$ per 1000 live births among babies born very early or with very low birth-weight ${ }^{30}$. Cerebral palsy is one of the most severe disabilities in childhood and makes heavy demands on health, educational and social services as well as on families and children themselves ${ }^{8}$. In Italy, available data ${ }^{31}$ show that the percentage of children and young adults (age 6-24 years) with more than one disability and living within their families is $0.3 \%$ (approximately 165,000) of the total population (55 million). Rates of Italian pupils with at least one disability and attending compulsory school (until age 15) increased in the decade from 2000 to 2011. In the academic year 2010-2011, the total number of pupils with disabilities was 165,000 , of which $7.8 \%$ in primary school and 5.2\% in secondary school, and presenting more than one disability in the areas including autonomous eating, mobility and self-care ${ }^{32}$.

\section{The Role of Assistive Technology}

Any restriction to participation in social, physical and communication activities reduces the extent to which the child interacts with his/her environment, thus limiting the opportunities for the child to reach important developmental and learning goals. Children with multiple disabilities require extensive or pervasive supports in their daily lives and pose special healthcare needs. In particular, they are at increased risk of participation restrictions in a wide array of age-appropriate activities, including communication, mobility, self-care, household tasks, family relationships, education, recreation and leisure in a variety of contex$\mathrm{ts}^{33,34}$. Empirical data from research conducted in Europe targeting children with cerebral palsy, for example, document that children with disabilities have lower participation than children in the general population ${ }^{33,35,36}$. In addition, children with more types of impairment and with more severe impairments have lower participation across most domains ${ }^{37}$. 
ICF-CY conceptualizes disability as resulting from the interaction between the person and his/her environment. In this view, children with disabilities may have reduced participation, partly because of their intrinsic impairments, partly because of the social, physical and attitudinal environment in which they live ${ }^{38}$. Thus, one of the most important consequences for children with disabilities derived by the ICF-CY model is recognition of the role of context: it can facilitate or obstruct the functioning of a child, and a child can function in different ways in different contexts. This is especially important for children and young people with neurodevelopmental disorders and, in general, experiencing multiple disabilities which are relatively unchanging and in which therapy, even if helpful, rarely eliminates impairment ${ }^{39}$.

The ICF-CY considers AT solutions as facilitators and classifies them among the environmental factors, which are external to an individual. There are several definitions of the term 'assistive technology'. In this thesis, the definition provided by the International Organization for Standardization (ISO) is adopted, which, in its standard ISO 9999, classifies such technologies as 'any product, instrument, equipment or technical system used by a disabled person, especially produced or generally available, preventing, compensating, monitoring, relieving or neutralizing disability' ${ }^{30}$. As such, AT refers to rather a broad and varied array of products that are directed towards a very diverse population of device users and for a wide variety of scopes. For example, AT may be used to change body structure in an effort to correct it and promote normal functioning (e.g. software to provide training in specific cognitive functions which are lacking, or the use of an orthotic splint). Alternatively, AT may serve to accommodate for children's disabilities, thus providing an alternative means of functioning in order to reduce activity limitations and participation restrictions (e.g. text-to-speech software for those that struggle to read, or powered wheelchairs for those with motor disabilities). For the purposes of the present thesis, AT includes technologies that help children compensate for their disabilities in order to provide them with an alternative means of functioning. Some have suggested that such technologies should be named 'enabling technologies', highlighting the fact that they allow forms of activity that could not previously take place ${ }^{41}$; however, throughout this thesis the term AT will be employed, since it is the most common and widely used.

\section{Organization of Assistive Technology Service Delivery in Europe}

A large variety of AT is available to children and their families to choose from, and one of the main challenges to healthcare concerns is the provision of the most adequate AT to the child. An important mediator between the child and the most appropriate AT or set of assistive devices is the AT service provider. The main function of such services is to evaluate, together with the child and the other stakeholders (e.g. parents, teachers, health professionals), which AT best fits his/her specific needs, and help guide towards informed decisions on appropriateness of the technology. Furthermore, AT services have the important function of assisting users throughout the period of usage and of evaluating the effects of the AT. 
There is no standard organization of the process establishing which AT services are delivered. ATSD varies broadly within and between countries and may vary in relation to each country's disability policy, socio-economic context and history. It follows that there exists a variety of service delivery systems and models, each with its own characteristics and mechanisms ${ }^{20}$.

In the 1993-1994 period, the study by Horizontal European Activities in Rehabilitation Technology (HEART) gathered information from 16 European countries in order to improve collaboration among professionals and researchers in the AT field ${ }^{42}$. The structure of each country's system was described within this HEART study. From a comparison of the different systems, essential steps in the ATSD process emerged, and these embrace a variety of activities (Figure 1): Access to service provider (Initiative); Assessment of the user's and stakeholders' needs and resources (Assessment); Identification and selection of the most adequate assistive solution, adaptation, modification and fitting of the product to the child (Selection); Access to public funding to obtain the recommended assistive solution (Authorization); Implementation of the technology in the user's context(s), training of the user (Implementation); and, Follow-up, maintenance and repair of the device (Management and Follow-up).

\section{Organization of Assistive Technology Service Delivery in Italy}

Italy has a tax-funded national health service (Servizio Sanitario Nazionale, SSN) that guarantees the universal provision of comprehensive care throughout the country ${ }^{16}$. Responsibility for the organization and delivery of services, including AT provision, is attributed to its 20 regional authorities. The provision of AT and prostheses is regulated by the 'Tariffs Nomenclature' (Nomenclatore Tariffario): a law by the Italian state (Ministerial Decree 332/1999) establishing the provisional norms and tariffs for assistance performances within the SSN. Roughly described, the decree includes a list of AT (organized by category, code and tariff) that can be financed by the SNN.

The first step in the process of AT acquisition consists in contacting the person's local health authority. The general practitioner can prescribe some devices and/or directly activate the relative operators: specialized doctors, experts in that type of impairment/ disability (depending on the case, these may be physiatrists, child psychiatrists, geriatrists, and so forth), and rehabilitation operators such as physiotherapists and occupational therapists. The task of these operators involves elaborating, together with the person with disabilities and his/her family, the project to result in provision of the device. Following evaluation of the person's 'disability' and 'functioning', by considering bodily functions and structure but also activities and environmental factors, conditions are set for the specialist doctor and the competent operators to identify the most adequate devices, working alongside the subjects involved in the case (first and foremost, the person directly concerned).

Once the AT has been identified, the specialized doctor employed by the local health authority takes charge of prescription, activating the path which will allow provision of the device, paid (totally or partially) by the SSN. The device acquisition procedure is 
managed by the Prostheses and Assistive Devices Service of the local health authority of reference, which evaluates prescription authorization and, subsequently, provides payment to the supplier.

As previously mentioned, each code in the Nomenclature corresponds to a type of AT and to a maximum amount that can be paid by the SSN; therefore, the Nomenclature covers the expenses, totally or partially, depending on the cost of the solutions. Should the appropriate device not appear on the Nomenclature lists, but may correspond with a similar item specified by the prescribing doctor, the excess of expense is covered by the person with disabilities.

In the event that the AT is neither provided by the Nomenclature nor corresponds to one of its items, and the person concerned presents an extremely severe disability, a particular survey (Art. 1, Paragraph 6, Ministerial Decree 322/99) provides for the authorization and supply of devices even when not included in the Nomenclature lists. An alternative to this possibility consists in considering whether the AT cost, which exceeds the amount funded by the Nomenclature, may fall within some financing clauses provided for by regional laws. Also in this latter case, the Italian situation appears as somewhat non-homogeneous.

\section{The Role of Centres for Assistive Technology}

The growing availability of solutions implies that particular knowledge of the AT devices present on the market, as well as of the most recent and sophisticated technologies, is necessary for the individualization of some solution typologies. For this reason, health professionals may take advantage of the expertise of professionals working in specialized AT centres. The acronym GLIC refers to the Italian association of independent AT centres, which groups together the centres specialized in AT for people with disabilities. The GLIC network was founded in 1997 and now includes almost all the active independent centres for AT in Italy (30 at present). From the perspective of the GLIC network, a centre for AT is an organization that presents the following characteristics: (1) it has no commercial interest; (2) it provides information, evaluation, assessment, support, training and research; (3) it draws on the services of a multi-disciplinary team of highly specialized professionals; (4) it possesses its own AT resources.

These centres constitute a point of reference for professional operators and for people with disabilities. They offer a variety of AT-related services (see Figure 1, grey area), in collaboration with professionals from the relative local health authority, social services and, in the case of children, the school system. The centres for AT are managed at a local and regional level, with the objective of helping the users and the professionals to identify the most suitable AT. Usually, centres for AT belong to a more complex network of public services, and are part of the rehabilitation, education and assistance pathway which is addressed to the person with disabilities and which provides the involvement of different, but mutually integrated, professional profiles. 


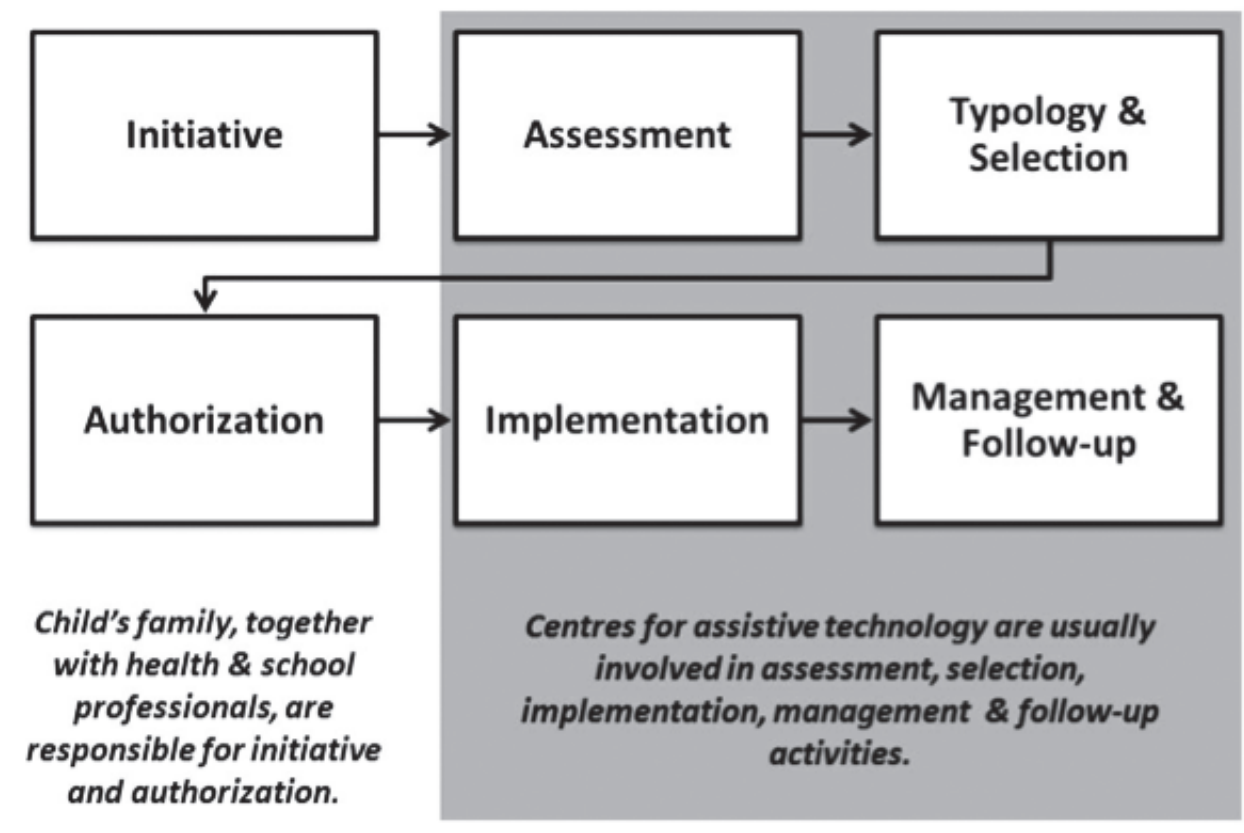

Figure 1. Steps in the assistive technology service delivery as described by the HEART study ${ }^{42}$. Boxes within the grey area represent the steps in which centres for AT are usually involved in Italy.

\section{The AIAS Centre for Assistive Technology}

This thesis focuses on the activities of one of the Italian AT centres which are members of the GLIC network. The Centre for AT (hereafter, CAT) is located in the city of Bologna, which is the capital of the Emilia-Romagna region. The CAT is managed by the AIAS Bologna ONLUS, a non-profit organization with approximately 100 staff members. The CAT was founded in 1987 and was followed by the opening of the Regional Centre for AT (CRA) in 2000. Its AT team manages, on behalf of the local health authority, an AT area that has become a leader and model of its kind in Italy, serving the needs of users from a large geographical area (Emilia-Romagna and beyond). The AT area functions as a key hub in the Regional Council's strategy for the provision of quality services aimed at fostering and supporting the independence of disabled people and of the elderly. As of 2005, and on behalf of the Local City Council, the AT team has also been operating the Centre for Home Adaptation (CAAD). The AT team (22 professionals) is multi-disciplinary and comprises experts with specialized experience in one among a wide range of areas, such as information and communication technologies, education, social issues, health and architecture. The Centre is entirely funded by public means and has no commercial interest. It is thus in a position to provide independent informed advice to people for whom the right technology, adaptation or strategy can make the difference between exclusion and participation. 


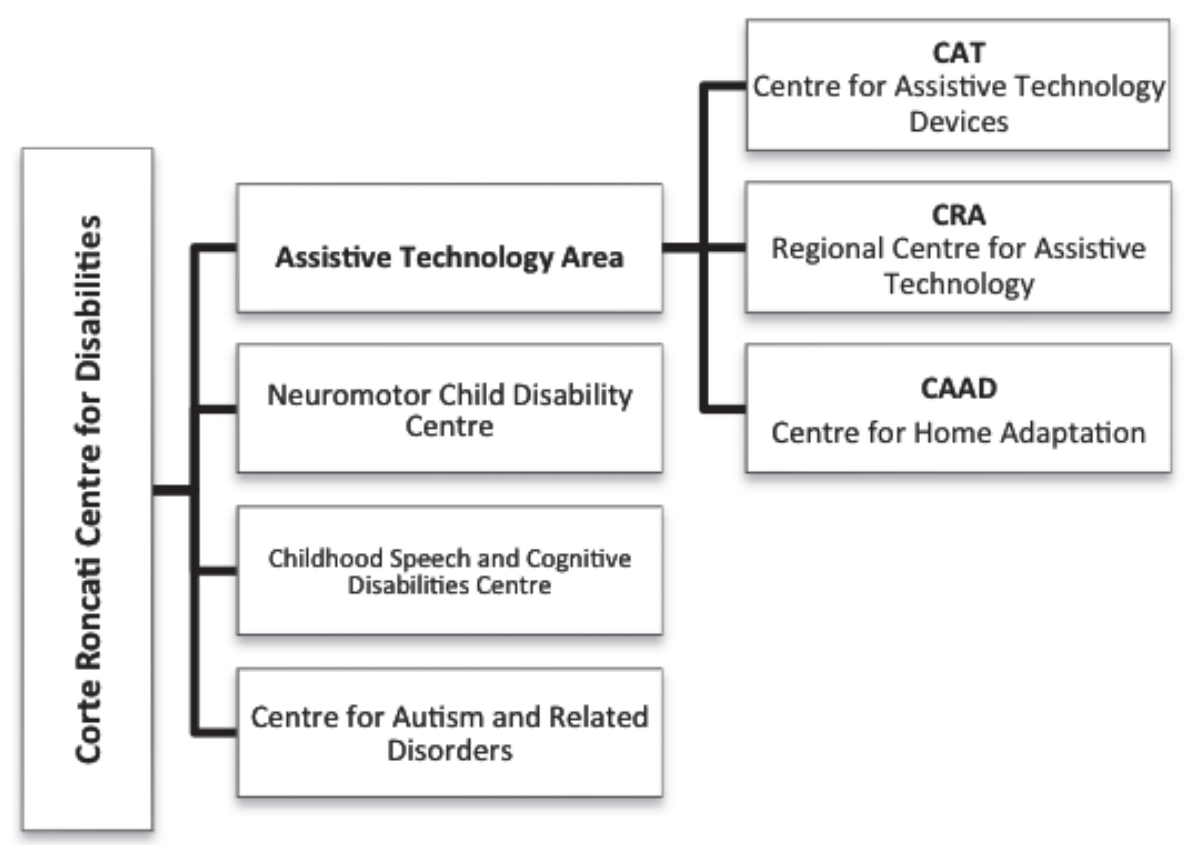

Figure 2. Diagram of the services present on the premises at the Corte Roncati Centre for Disabilities.

In June 2007, these three services in the AT area relocated to Corte Roncati, a new expressly designed centre. By moving to Corte Roncati, the AT services have become part of a more complex structure entirely dedicated to disabilities. In fact, besides the AT area, Corte Roncati hosts three other centres: the Neuromotor Child Disability Centre, the Childhood Speech and Cognitive Disabilities Centre, and the Centre for Autism and Related Disorders (Figure 2). Each centre is designed to be autonomous and to operate according to its own working procedures and rhythms for most of the time, but is organized to allow cooperation, when required. This is the case when the need is to select an AT, especially for children with intellectual or multiple disabilities. In such cases, each service places its competence at the disposal of all three, which become a single team composed of different professionals, who together evaluate and select the AT best fitting the user's needs.

Though working together, the three services in the AT area have different functions and funding resources. For the purposes of the present research project, this thesis will focus on the CAT. This service is primarily oriented to provide technologies addressing learning, play and communication goals. AT for children with multiple disabilities considered in this thesis includes both low-tech devices such as switches, adapted equipment and picture boards, and high-tech devices such as electronic communication devices, educational software and environmental controls. AT also includes adapted or specially designed toys that not only are entertaining and usable but that also make a contribution to the child's physical and emotional development ${ }^{43}$. 


\section{Stakeholders in Assistive Technology Service Delivery}

Other than the child and his/her family, the involvement of all groups of stakeholders in service delivery is crucial for the achievement of positive results through the AT intervention. As far as the Italian system is concerned, other groups involved in AT service delivery may include (Figure 3): professionals working in AT centres; school professionals; health professionals from the local health authority. Each group has a unique role in service delivery and may provide useful information from a unique perspective. Professionals at centres for AT work mainly as consultants to the educational and rehabilitation team composed of professionals from the school system and the local health authority, respectively, and each has distinct roles and responsibilities within each step of the ATSD process. Following the consecutive steps depicted in Figure 1, professionals from the local health authority (e.g. child psychiatrist, physiotherapist, psychologist) - usually in collaboration with the school professionals (e.g. teacher aide, social educator), professionals from the social care system (e.g. social educator) and the child's family - are responsible for considering the need for an assistive solution and take the initiative to contact the professionals at the AT centre. AT professionals support the professionals from the local health authority and the school system, the child and his/her family in the process of identifying the most appropriate AT. Once the AT solution has been selected, the child's family and the local health authority are responsible for applying for the public funding to obtain the device. Once obtained, AT professionals may be involved in the implementation of the solution within the child's context, which is usually the child's home and the classroom, and in evaluation of its effects.

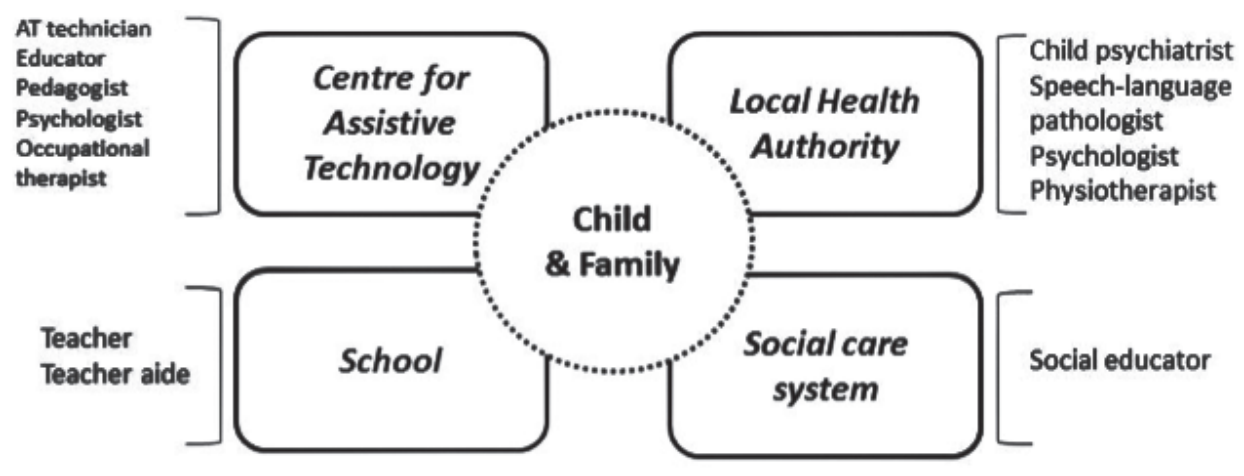

Figure 3. Stakeholders in assistive technology service delivery.

\section{Who Can Provide Information on Service Delivery Quality?}

As illustrated in Figure 3, there are different stakeholders in ATSD. In this thesis, the focus is particularly on the roles of the child's family and AT professionals, whose partnership plays a pivotal role throughout the whole service delivery process ${ }^{44}$. 
In the specific case of health services targeting children with disabilities, health professionals have started to recognize that the way in which professionals consider and support the children's families has the potential to enhance or hinder the child and family outcomes $^{45}$. Family-centred services draw on an approach and a service delivery method that emphasize partnership between parents and service providers, focus on the family's role in decision making about their child, and recognize parents as the experts on their child's status and needs ${ }^{34}$. In the AT context, this approach highlights the importance of involving families and their children in any aspect of the ATSD process, emphasizing the importance of considering parents' opinions, together with those of AT professionals, as a driver of service delivery planning, implementation and evaluation ${ }^{45}$.

\section{What Should Be Measured?}

According to a well-established framework, healthcare evaluation may be defined by distinguishing between structure, process and outcome ${ }^{46}$. Structure refers to the organizational factors that define the health system under which care is provided ${ }^{46}$ (e.g. health facilities, staff characteristics). Process refers to interactions between users and the healthcare structure, this being what is done to or with users ${ }^{46,47}$ (e.g. diagnosis, treatment, referral, interpersonal communication). Outcome refers to the consequences of interaction between individuals and a healthcare system, this being structure and process ${ }^{46,47}$.

An ongoing debate exists on the relative usefulness of process versus outcome measures to evaluate healthcare quality ${ }^{48,49}$. In this thesis, it will be assumed that process measures may offer a direct tool for describing and measuring the current quality of care being delivered by an ATSD system. Conversely, outcome measures are not a direct measure of healthcare quality in the same way that process measures are ${ }^{49}$. Though important, it should be recognized that ATSD process quality is only one determinant of AT intervention. AT outcome may vary not only in relation to ATSD quality, but also in relation to several factors that are independent from the ATSD process, such as the child's type and severity of disability, socio-economic status, family structure and well-being ${ }^{50}$. It follows that process measures may be more sensitive than outcome measures in detecting differences in the quality of ATSD systems $s^{48,49}$, provided that a link has been demonstrated between a given process (e.g. easy access to AT services) and outcome (e.g. AT use). For these reasons, improving the care process has been described as the primary objective of quality measurement ${ }^{46,51,52,53}$. For instance, a robust finding in the literature on early childhood is that care process quality is associated with a variety of positive outcomes for young children ${ }^{54,55}$. Process variables are assumed to have a direct impact on children's development, whereas structural variables are assumed to have an indirect impact, via process quality ${ }^{54,56}$.

Thus, improvement of ATSD must follow from the active use of service delivery process measurement, to identify promising process-related targets for changing and improving outcomes ${ }^{17}$. Indicators are usually adopted to measure service delivery process quality ${ }^{51}$. An indicator may be defined as a 'measurable element of practice performance for which there is evidence or consensus that it can be used to assess the quality, and hence change the quality, of care provided'51 (p. 359). A wide variety of quality indicators have been develo- 
ped to assess care in different contexts (e.g. hospitals, primary care). In the specific context of AT, the HEART study identified a set of process indicators which belong to six quality dimensions developed to evaluate quality of the service delivery systems in Europe ${ }^{42}$. The criteria identified have recently been reviewed and are still considered valid today ${ }^{20,57}$.

\section{Which Measures Should Be Used?}

When measuring healthcare quality, a distinction is often made between objective and subjective measures. At a basic level, the distinction is purely methodological. Subjective methods refer to procedures for obtaining information about individuals' perspectives or experiences, usually by questionnaires or interviews; objective methods refer to procedures based on directly observable behaviour (e.g. adherence to treatment) or physiological parameters (e.g. blood pressure). Choosing one or both of the methodologies depends on the research goal.

Increasingly, quality measurement is required for providers to be sensitive to the complexities of users' expectations and preferences ${ }^{58,59}$. Nowadays, users' perception (or experience) has a central role in research into quality of healthcare. In this context, satisfaction is an example of a perception. User satisfaction has been widely used in research studies on healthcare quality, and its measurement is important for public policy analysts, healthcare managers, health professionals and users ${ }^{60}$. There is not a widely accepted definition of satisfaction. For the purpose of this thesis, it can be defined as 'fulfilling expectations, needs, and desires' ${ }^{60}$ (p. 518) of the users. Studies on user satisfaction have contributed to our understanding of how users' perceptions affect user behaviour: for example, users who report being more satisfied with the care received are more compliant and cooperative, and are more likely to participate in their treatment procedures ${ }^{60}$.

However, there have also been several critiques of the use of satisfaction as a comprehensive measure of quality. According to Crow and colleagues ${ }^{61}$ satisfaction does not imply superior services, only adequate or acceptable services. In addition, satisfaction is a relative concept; therefore, what satisfies one person may dissatisfy another ${ }^{60,61}$. It follows from these considerations that being satisfied is only one way to characterize users' perception of quality. Indeed, reports on patients' experience are increasingly replacing assessments of patient satisfaction ${ }^{58,62}$. In this thesis, the understanding of users' perception is conceived as recognizing that feelings, subjective experiences, emotions and responses are a crucial part of service delivery ${ }^{63}$. The goal is to try to find ways to capture and measure these experiences in order to assess and improve ATSD process quality.

\section{Specification of the Research Questions and Thesis Content}

The present research project is an attempt to measure the quality of the ATSD process and outcomes from the perspectives of both children's parents and AT professionals. To achieve this aim, the following research questions are addressed: 
- Which instruments and models are available to AT professionals to guide them during the service delivery process?

- How can quality assurance in the context of ATSD targeting children be defined?

- What is the quality of the service delivery process at the CAT from both professionals' and users' perspectives?

- How can AT professionals turn results from stakeholders' perspectives into practical forms of knowledge that may be used to implement a quality assurance procedure in the service delivery process?

Chapter 2 aims to answer the first research question. It presents a systematic literature review of AT assessment models and instruments specifically developed for children with multiple disabilities.

Chapter 3 responds to the second research question. It gives a detailed description of the CAT and the service delivery system in which it operates. The study further presents a framework for quality assurance, specifically developed for measuring the quality of AT systems when children with multiple disabilities are considered. Within the quality framework, a comprehensive battery of instruments, aiming to detect the quality of the entire service delivery process, is proposed.

The third question was tackled by two distinct studies. Chapter 4 presents a study aimed at measuring the quality of one important aspect of the service delivery process, this being documentation of AT assessment, through the development of specific quality indicators. From analysis of the documentation, it was possible to identify weaknesses related to different aspects of the service delivery process from a professionals' perspective. In Chapter 5, the quality of the whole ATSD process was evaluated from the perspective of parents to children with multiple disabilities who were assessed by the CAT. The aim of this study was to identify shortcomings in the service delivery process from a user perspective.

Chapter 6 provides an example of how to translate the information gathered from the previous studies on service delivery quality into changes in the service delivery process.

Chapter 7 discusses the main findings of this thesis and addresses their implications for AT professionals and health policies. Lastly, in Chapter 8 the scopes for valorization of the knowledge gained during the research project presented in this thesis is explored. 


\section{References}

1. Wolfe I, Thompson M, Gill P, Tamburlini G, Blair M, van den Bruel A et al. Health services for children in western Europe. The Lancet. 2013;381(9873):1224-1234.

2. Wolfe I, McKee M. European Child Health Services and Systems. Maidenhead: McGraw-Hill Education; 2014.

3. Rijken M, Struckmann V, Dyakova, Melchiorre M, Rissanen S, van Ginneken E. ICARE4EU: Improving care for people with multiple chronic conditions in Europe. Eurohealth. 2013;19(3):29-31.

4. Lindsay S, Tsybina I. Predictors of unmet needs for communication and mobility assistive devices among youth with a disability: the role of socio-cultural factors. Disability \& Rehabilitation: Assistive Technology. $2011 ; 6(1): 10-21$.

5. Dusing S, Skinner A, Mayer M. Unmet Need for Therapy Services, Assistive Devices, and Related Services: Data From the National Survey of Children With Special Health Care Needs. Ambulatory Pediatrics. 2004; $4(5): 448$.

6. Federici S, Scherer M. Assistive technology assessment handbook. Boca Raton: CRC Press; 2012.

7. Østensjø, S, Carlberg E, VÃ sllestad N. The use and impact of assistive devices and other environmental modifications on everyday activities and care in young children with cerebral palsy. Disabil Rehabil. 2005;27(14):849-861.

8. Cans C. Surveillance of cerebral palsy in Europe: a collaboration of cerebral palsy surveys and registers. Developmental Medicine \& Child Neurology. 2000;42(12):816-824.

9. Wise P. Emerging Technologies and Their Impact on Disability. The Future of Children. 2012;22(1):169-191.

10. Convention on the Rights of Persons with Disabilities [Internet]. 2015 [cited 19 June 2015]. Available from: http://www.un.org/disabilities/convention/conventionfull.shtml

11. Convention on the Rights of the Child [Internet]. 2015 [cited 19 June 2015]. Available from: http:// www.ohchr.org/en/professionalinterest/pages/crc.aspx

12. Henderson S, Skelton H, Rosenbaum P. Assistive devices for children with functional impairments: impact on child and caregiver function. Developmental Medicine \& Child Neurology. 2008;50(2):89-98.

13. Parette H, Peterson-Karlan G. Facilitating Student Achievement with Assistive Technology. Education and Training in Developmental Disabilities 2007, 42(4): 387-397.

14. The State of the World's Children 2013 - Assistive technology for children [Internet]. 2015 [cited 19 June 2015]. Available from: http://www.unicef.org/sowc2013/focus_assistive_technology.html

15. Karanikolos M, Mladovsky P, Cylus J, Thomson S, Basu S, Stuckler D et al. Financial crisis, austerity, and health in Europe. The Lancet. 2013;381(9874):1323-1331.

16. de Belvis A, Ferrè F, Specchia M, Valerio L, Fattore G, Ricciardi W. The financial crisis in Italy: Implications for the healthcare sector. Health Policy. 2012;106(1):10-16.

17. Perrin J. How Can Quality Improvement Enhance the Lives of Children with Disabilities?. The Future of Children. 2012;22(1):149-168.

18. Rauch S, Lanphear B. Prevention of Disability in Children: Elevating the Role of Environment. The Future of Children. 2012;22(1):193-217.

19. Lohr K. Medicare. Washington, D.C.: National Academy Press; 1990.

20. Association for the Advancement of Assistive Technology in Europe (AAATE). Service Delivery Systems for Assistive Technology in Europe: Position Paper [Internet]. 2012 [cited 19 June 2015]. Available from: http://www.aaate.net/sites/default/files/ATServiceDelivery_PositionPaper.pdf

21. Derose S, Petitti D. Measuring Quality of Care and Performance from a Population Health Care Perspective. Annu Rev Public Health. 2003;24(1):363-384.

22. Halfon N, Houtrow A, Larson K, Newacheck P. The Changing Landscape of Disability in Childhood. The Future of Children. 2012;22(1):13-42.

23. World Health Organization. International classification of functioning, disability and health: children and youth version. Geneva: World Health Organization; 2007.

24. Simeonsson R, Leonardi M, Lollar D, Bjorck-Akesson E, Hollenweger J, Martinuzzi A. Applying the International Classification of Functioning, Disability and Health (ICF) to measure childhood disability. Disabil Rehabil. 2003;25(11-12):602-610. 
25. World Health Organization. Early Childhood Development and Disabilities: A Discussion Paper. Geneva: World Health Organization; 2012.

26. Michaud L. Prescribing Therapy Services for Children with Motor Disabilities. PEDIATRICS. 2004;113(6):1836-1838.

27. The State of the World's Children 2013 - Homepage [Internet]. 2013 [cited 19 June 2015]. Available from: http://www.unicef.org/sowc2013/

28. Cattaneo A, Cogoy L, Macaluso A, Tamburlini G. Child Health in the European Union. 1st ed. European Union; 2012.

29. A report: the definition and classification of cerebral palsy April 2006. Developmental Medicine \& Child Neurology. 2007;49:8-14.

30. Krägeloh-Mann I, Cans C. Cerebral palsy update. Brain and Development. 2009;31(7):537-544.

31. ISTAT. La disabilità in Italia. [Disability in Italy. An Overview of the Official Statistics] [Internet]. 2009 [cited 19 June 2015]. Available from: http://www3.istat.it/dati/catalogo/20100513_00/arg_09_37_la_ disabilita_in_Italia.pdf

32. ISTAT. L'integrazione degli alunni con disabilità nelle scuole primarie e secondarie di primo grado, statali e non statali [The integration of pupils with disabilities in primary and secondary schools] [Internet]. 2013 [cited 19 June 2015]. Available from: http://www.istat.it/it/files/2013/01/Statisticareport_alunnicondisabilit\%C3\%A0.pdf

33. Michelsen S, Flachs E, Damsgaard M, Parkes J, Parkinson K, Rapp M et al. European study of frequency of participation of adolescents with and without cerebral palsy. European Journal of Paediatric Neurology. 2014;18(3):282-294.

34. Law M, King G, King S, Kertoy M, Hurley P, Rosenbaum P et al. Patterns of participation in recreational and leisure activities among children with complex physical disabilities. Developmental Medicine \& Child Neurology. 2006;48(05):337.

35. Schenker R, Coster W, Parush S. Participation and activity performance of students with cerebral palsy within the school environment. Disabil Rehabil. 2005;27(10):539-552.

36. Michelsen S, Flachs E, Uldall P, Eriksen E, McManus V, Parkes J et al. Frequency of participation of 8-12-year-old children with cerebral palsy: A multi-centre cross-sectional European study. European Journal of Paediatric Neurology. 2009;13(2):165-177.

37. Fauconnier J, Dickinson H, Beckung E, Marcelli M, McManus V, Michelsen S et al. Participation in life situations of 8-12 year old children with cerebral palsy: cross sectional European study. BMJ. 2009;338(apr23 2):b1458-b1458.

38. Colver A, Thyen U, Arnaud C, Beckung E, Fauconnier J, Marcelli M et al. Association Between Participation in Life Situations of Children With Cerebral Palsy and Their Physical, Social, and Attitudinal Environment: A Cross-Sectional Multicenter European Study. Archives of Physical Medicine and Rehabilitation. 2012;93(12):2154-2164.

39. RICHEProject.Reporton theroadmapsforthefutureofEuropeanchildhealthresearch-ChildHealthResearch [Internet]. Childhealthresearch.eu. 2013 [cited 19 June 2015]. Available from: http://www.childhealthresearch.eu/Members/jkilroe/report-on-the-roadmaps-for-the-future-of-european-child-health-research/ view

40. International Organization for Standardization. ISO 9999 Assistive products for persons with disability: Classification and terminology. Geneva: International Organization for Standardization; 2007.

41. Abbott C. Defining assistive technologies: a discussion. Jnl of Assistive Technologies. 2007;1(1):6-9.

42. HEART. European Service Delivery System in Rehabilitation Technology: A Comprehensive Description of Service Delivery Systems of 16 European Countries. HEART (Horizontal European Activities of Rehabilitation Technology) Line C [Internet]. 1994 [cited 19 June 2015]. Available from: http://portale. siva.it/files/doc/library/a416_1_ATServiceDelivery_HEART_ReportC51.pdf

43. Field M, Jette A. The future of disability in America. Washington, DC: National Academies Press; 2007.

44. Parette P, VanBiervliet A, Hourcade J. Family-centered decision-making in assistive technology. Journal of Special Education Technology. 2000;15(1):45-55.

45. Dempsey I, Keen D. A Review of Processes and Outcomes in Family-Centered Services for Children With a Disability. Topics in Early Childhood Special Education. 2008;28(1):42-52.

46. Donabedian A. An introduction to quality assurance in health care. New York: Oxford University Press; 2003. 
47. Campbell S, Roland M, Buetow S. Defining quality of care. Social Science \& Medicine. 2000;51(11):1611-1625.

48. Mant J. Process versus outcome indicators in the assessment of quality of health care. International Journal for Quality in Health Care. 2001;13(6):475-480.

49. Nolte E. International benchmarking of healthcare quality: A review of the literature | RAND [Internet]. Rand.org. 2010 [cited 23 June 2015]. Available from: http://www.rand.org/pubs/technical_reports/ TR738.html

50. Fuhrer M, Jutai J, Scherer M, DeRuyter F. A framework for the conceptual modelling of assistive technology device outcomes. Disabil Rehabil. 2003;25(22):1243-1251.

51. Campbell S, Braspenning J, Hutchinson A, Marshall M. Improving the quality of health care: Research methods used in developing and applying quality indicators in primary care. BMJ. 2003;326(7393):816-819.

52. Eddy D. Performance measurement: problems and solutions. Health Affairs. 1998;17(4):7-25.

53. Parast L, Doyle B, Damberg C, Shetty K, Ganz D, Wenger N et al. Challenges in Assessing the Process-Outcome Link in Practice. J Gen Intern Med. 2015;30(3):359-364.

54. NICHD Early Child Care Research Network. Child-Care Structure $\rightarrow$ Process $\rightarrow$ Outcome: Direct and Indirect Effects of Child-Care Quality on Young Children's Development. Psychological Science. 2002;13(3):199-206.

55. King G, King S, Rosenbaum P, Goffin R. Family-centered caregiving and well-being of parents of children with disabilities: linking process with outcome. Journal of Pediatric Psychology. 1999;24(1):41-53.

56. NICHD Early Child Care Research Network. Child outcomes when child care center classes meet recommended standards for quality. NICHD Early Child Care Research Network. Am J Public Health. 1999;89(7):1072-1077.

57. Steel E, de Witte L. Advances in European Assistive Technology service delivery and recommendations for further improvement. Technology and Disability. 2011;23(3):131-138.

58. Elwyn G, Buetow S, Hibbard J, Wensing M. Respecting the subjective: quality measurement from the patient's perspective. BMJ. 2007;335(7628):1021-1022.

59. Wensing M, Elwin G. Methods for incorporating patients' views in health care. BMJ. 2003;326(7394):877-879.

60. Sofaer S, Firminger K. Patient perceptions of the quality of health services. Annu Rev Public Health. 2005;26(1):513-559.

61. Crow R, Gage H, Hampson S, Hart J, Kimber A, Storey L et al. The measurement of satisfaction with healthcare: implications for practice from a systematic review of the literature. Health Technology Assessment. 2002;6(32).

62. Williams B, Coyle J, Healy D. The meaning of patient satisfaction: An explanation of high reported levels. Social Science \& Medicine. 1998;47(9):1351-1359.

63. SKAPE. What is the patient experience? | SKAPE [Internet]. 2014 [cited 23 June 2015]. Available from: http://blogs.sps.ed.ac.uk/skape/2014/09/30/what-is-the-patient-experience/ 
Chapter 2

Recommending assistive technology (AT) for children with multiple disabilities: A systematic review and qualitative synthesis of models and instruments for AT professionals

This Chapter was published as: Desideri, L., Roentgen, U., Hoogerwerf, E. J., \& de Witte, L. (2013). Recommending assistive technology (AT) for children with multiple disabilities: A systematic review and qualitative synthesis of models and instruments for AT professionals, 


\begin{abstract}
Purpose: To review the AT specific assessment models and instruments that have been developed for children with multiple disabilities in order to provide an overview of the strategies to be employed in interdisciplinary rehabilitation. Method: A systematic review was conducted utilizing the MEDLINE, CINAHL, PsycINFO, ERIC and ISI databases covering the period January 1990-September 2011. In addition, 4 conference proceedings, 35 journals and various web resources were hand searched. Papers were reviewed in three steps by three independent investigators according to specific inclusion and exclusion criteria. Results: The search resulted in the finding of 25 papers. Only one model for structuring the AT assessment process and four instruments developed to support decisions about AT solutions for children with multiple disabilities were found. The validity and reliability of the models and instruments found are not documented in the literature reviewed. Conclusions: We argue that there is a need to develop validated models and instruments to guide AT professionals in the process of AT assessment for children with multiple disabilities.
\end{abstract}




\section{Introduction}

A key factor determining the development of motor, cognitive and communication abilities in children is activity and participation in a range of contexts ${ }^{1}$. When the co-occurrence of different disabilities prevents a child from completing a range of tasks, the resulting functional limitations reduce the extent to which helshe interacts with the surrounding environment, thus limiting the opportunities for the child to reach important developmental and learning goals ${ }^{2}$.

Children who are limited in this way are referred to as children with multiple disabilities (hereafter, children with MD) and are characterized by any combination of a number of concomitant impairments such as neuromuscular dysfunctions, cognitive and intellectual disabilities and other physical and sensory impairments ${ }^{3}$. Interventions employing assistive technology (AT) can compensate for functional limitations and improve participation in the activities of everyday life by offering children alternative strategies for the accomplishment of certain tasks ${ }^{4}$. Appropriate kinds of AT in this context include both low-tech devices such as switches, adapted equipment and picture boards, and high-tech devices such as electronic communication devices, educational software, powered mobility and environmental controls ${ }^{2}$.

While the literature demonstrates that the provision of AT devices can produce beneficial outcomes for children in terms of participation ${ }^{4,5}$, it also shows that the use of this kind of technology is far from always being successful ${ }^{6,7}$. Unsuccessful outcomes are associated with the abandonment of assistive solutions or inadequate adaptation to the situation and routines of the child ${ }^{6,8}$, failings which are often the consequence of ineffective strategies for the provision of $\mathrm{AT}^{6,7,8}$. Assessing children for AT and providing useful technological recommendations is a process which requires an interdisciplinary approach and the collaboration of highly qualified practitioners with particular fields of expertise, ${ }^{9,10}$. AT professionals working in interdisciplinary teams can support educators, teachers and families in relating developmental and educational goals to the specific areas in which AT can compensate for functional limitations or enhance the skills of children with $\mathrm{MD}^{11,12}$. In order to make appropriate recommendations, AT professionals need assessment models and instruments ${ }^{13,14}$ to guide them in the process of understanding the complex interrelationship between the child's physical, sensory and cognitive abilities, the available environmental resources, the goals that the educational team, the family and the child want to achieve, and the child's interaction with AT.

Research findings have shown that the assessment approach adopted by AT professionals affects the effectiveness of the recommendations made ${ }^{15}$. Bernd and colleagues ${ }^{16}$ have recently provided an extensive description of models and instruments for AT provision. However, though comprehensive, this study did not adopt a developmental perspective, and did not provide any indication about the compatibility between the models and instruments in question and factors contingent to ongoing child development. If they are to understand how technological interventions might benefit child development, AT professionals cannot afford to ignore the possible impact of developmental changes. Treating children as young adults ${ }^{17}$, and basing AT recommendations on models not specifically developed for them, might lead to an oversimplification of the ob- 
jectives sought, since, where children are concerned, AT interventions should not only compensate for functional impairments, but also stimulate skill development ${ }^{18}$. The aim of the present study is to review and synthesize the assessment models and instruments developed for making AT recommendations in case of children with MD.

\section{Method}

A systematic review of the literature published in English between January 1990 and September 2011 was conducted. For the purpose of the present study, a practice-oriented approach was followed, and working definitions were adopted a priori for the terms 'model' and 'instrument'. A model was defined as a framework that makes the organization of the different elements and phases involved in the AT assessment process more systematic $^{19}$. An instrument was defined as a tool (e.g., observation scales, questionnaires, checklists, forms, etc.) employed during the assessment process and developed for the collection of data ${ }^{20}$. Though the meaning of these terms may overlap, this distinction was made in order to clarify the difference between the organization or structure of the assessment process and the tools employed for documenting the process. With the term 'children', we refer to children and young people from birth to age 17. Every study satisfying the outlined inclusion criteria was analyzed in terms of: (a) study-design; (b) number of participants involved in the study; (c) models mentioned; (d) assessment instruments mentioned.

\section{Literature search}

Table 1 provides a summary of the sources consulted. In total, four different types of sources were searched. The academic databases investigated included: MEDLINE, consulted through the free electronic access PubMed; CINAHL, PsycINFO and ERIC, consulted through EBSCOHost, and ISI Web of Knowledge. Combinations of terms defined a priori and targeting specific populations (e.g. toddlers, infants, children, adolescents, students) and different types of disability (e.g. multiple, complex, profound, functional, cognitive, motor, physical, developmental) were used as search terms. Searches were carried out combining population type and disability type as search terms, with subsequent refinement through combination with a specific technology type (e.g. assistive technology, devices, self-help devices) and with terms concerning the typology of the interventions targeted in this study (e.g. interdisciplinary, delivery, advise, decision making, assessment).

The search terms were combined by means of two Boolean logical operators (AND, $\mathrm{OR}$ ) in order to reduce the number of non-pertinent results. Alternative spellings and abbreviations were employed. MeSH terms and MeSH equivalents were used as well as free-text words. Electronic data retrieval from the academic databases was supplemented by a hand search of a selection of relevant academic journals, books and four conference proceedings. A broad investigation of the resources available on the World Wide Web (WWW) was also conducted. 


\section{Review method}

The search for relevant papers to be included in the review was undertaken in three steps. During the first step, the titles of the papers retrieved were reviewed by three independent researchers and scored as not relevant (0), probably relevant (1) or relevant (2). For this first step, broad inclusion criteria were used in order to include any possible article referring to AT assessment practices. The scores were added to make a sum score ranging from 0 to 6 . All publications above the cut-off score of 2 were selected for the next step. The cut-off score employed allowed the papers scored as probably relevant by two reviewers or as relevant by one reviewer to be included in the next step. Articles were excluded if mentioning only specific disorders or disabilities like dyslexia, autism spectrum disorder/ASD, attention deficit and hyperactivity disorder/ADHD, blindness, deafness, hard of hearing, or if they identified the target population using general terms like individual, persons, people, adults.

In the course of the second step, the abstracts of the selected papers were read and scored by two reviewers according to more specific criteria than that utilized in the preceding step. To be included in the next step, the abstracts had to mention at least a model and the working practices adopted by specialized AT centres or assessment instruments related to the selection of any type of AT device. No restrictions were made regarding the type of publication. The scores given by each reviewer were added to make a sum score ranging from 0 to 4 . All publications above the cut-off score of 2 were included in the next step. An inter-rater reliability analysis using the weighted kappa statistic was performed to determine consistency among raters in the first and second steps. Finally, in the third step, the selected articles were read in full and judged by one reviewer according to their relevance in addressing the topic of AT assessment in case of children or adolescents with any combination of sensory, cognitive, physical or communicational impairments. The references retrieved from the WWW were judged by the first author of the paper. 
Table 1. List of the sources searched for the systematic review.

\begin{tabular}{lll}
\hline Sources & Source name & Periods $\backslash$ Editions \\
\hline Academic databases & & \\
\hline & MEDLINE & \\
CINAHL & January 1990 to \\
& PsycINFO & September 2011 \\
ERIC & \\
ISI Web of Knowledge &
\end{tabular}

Academic Journals*

Assistive Assistive Technology; Augmentative and Alternative Com-

Technology munication; Disability and Rehabilitation: AT; Journal of Assistive Technologies; Technology and Disability.

Development American Journal on Mental Retardation $\backslash$ American Journal on Intellectual and Developmental Disabilities; Developmental Neurorehabilitation; Early Childhood Education Journal; European Journal of Special Needs Education; Exceptional Children; Focus on Autism and Other Developmental Disabilities; Infants and Young Children; Intellectual and Developmental Disabilities; International Journal of Disability, Development and Education; Journal of Developmental and Physical Disabilities; Journal of Intellectual and Developmental Disability; Journal of Special Education; Mental Retardation and Developmental Disabilities Research Reviews\ Developmental Disabilities Research Reviews; Pediatric Physical Therapy; Research in Developmental Disabilities; Topics in Early Childhood Special Education.

Rehabilitation American Journal of Occupational Therapy; Archives of Physical Medicine and Rehabilitation; Canadian Journal of Occupational Therapy; Disability and Rehabilitation; International Journal of Language and Communication Disorders; International Journal of Rehabilitation Research; Journal of Head Trauma Rehabilitation; Journal of Intellectual Disability Research; Journal of Learning Disabilities; NeuroRehabilitation; Occupational Therapy International; Canadian Journal of Occupational Therapy.

Other Assessment for Effective Intervention; Cochrane Database of Systematic Reviews

Conference Proceedings**

AAATE

ARATA
$1990-2011$

1997, 1999, 2001, 2003, 2005, 2007, 2009, 2011

2004, 2006, 2008, 2010 


\begin{tabular}{lll}
\hline Sources & Source name & Periods $\backslash$ Editions \\
\hline EASPD & $2007,2008,2009$, \\
& 2010,2011 \\
& & Editions indexed in \\
& the ERIC database \\
& available in full text, \\
& from 1990 to $2002 ;$ \\
& editions from 2003 to \\
& 2010 retrieved from \\
& AbleData
\end{tabular}

World Wide Web ***

AbleData; TeachingAT; EASTIN; SIVA; WHO - World report on disability; CIRRIE (Center for International Rehabilitation Research Information and Exchange); International Encyclopedia of Rehabilitation; Closing the Gap; The National Center to Improve Practice (NCIP); Google Scholar and Google Blog; Atoms Project; INFOMINE; no time restrictions SCIRUS; National Center for the Dissemination of Disability Research; National Assistive Technology in Education (NATE) Network; Rehabdata; Swedish Institute of Assistive Technology (SIAT)

Notes: * Journals were searched with the terms "assistive technology", "multiple disabilities"; ** AAATE, Association for Advancement of Assistive Technology in Europe; ARATA, Australian Rehabilitation \& Assistive Technology Association; EASPD, European Association of Service Providers for Persons with Disabilities; RESNA, Rehabilitation Engineering \& Assistive Technology Society of North America: *** For the Rehabdata database, the Thesaurus terms "Multiple disabilities" and "Assistive Technology" were employed; for the Google Scholar and the Google Blog search engines, the search strategy employed was: "multiple disability" AND children OR adolescence AND "assistive technology"; for the Infomine search engine, the search terms employed were: "multiple disabilities", "assistive technology"; for the SCIRUS search engine, the search strategy employed was: "assistive technology (multiple disabilities) (children)". 


\section{Results}

\section{Overview of the references found}

A total of twenty five references satisfying our criteria were included in the review (see figure 1). The inter-rater agreement was fair to moderate in the first step with kappa ranging from .36 to .52 (with standard errors ranging from .02 to .37 ), and substantial between the two reviewers in the second step (kappa .61; standard error .05)21. The relatively low inter-rater agreement found in the first step was due to the employment of broad criteria for the inclusion of the relevant titles. This prevented the exclusion of any possible relevant paper while at the same time allowing the authors to exclude those which were not relevant. According to the definitions provided in the method section, twelve models (see next section) and seven instruments (see table 3) were found.

1981 titles identified through database searches

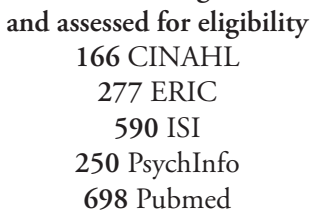

Step 1

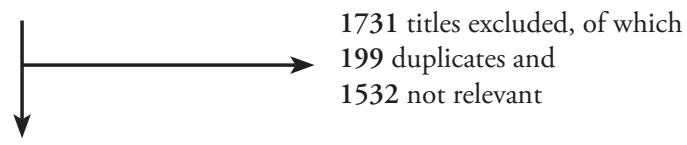

Abstract screening

285 abstracts assessed for eligibility, of which

35 titles identified through other sources:

11 target journals

19 web resources

5 conference proceedings

Step 2

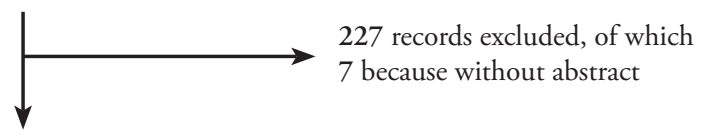

Full text assessment

63 records assessed for eligibility, of which

5 identified through hand search of books

Step 3

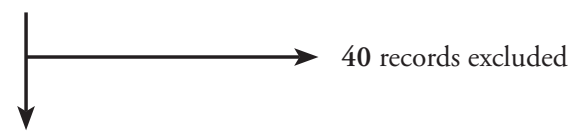

25 records included in qualitative synthesis, of which

2 identified from reference lists

Figure 1. Synthesis of the review search process 


\section{Models found}

Of the models included in the review, only those focusing on children were analyzed (see table 2). Only one model specifically targeted children with $\mathrm{MD}^{22}$. How closely the assessment process is detailed and defined by the different models varies in terms of the identification of target users (e.g. students, children), the specification of context (e.g. schools, homes), the terminology employed (process, model or approach) and the level of abstraction: some models focus on practice and systematize the different activities of the AT assessment and decision making processes (models 1-9), while the remainder only deal with the whole process of service delivery (models 10-12) at a conceptual level. The twelve models are:

- $\quad$ Of the models examined, the Technology Team Assessment Process (TTAP) model $^{22,23}$ is the only one which was developed not only for adults but also for children with MD. It forms part of a system composed of different AT related models developed within the framework of the Early Childhood Comprehensive Technology System (ECCTS ${ }^{23}$ ). The TTAP model forms the component in the ECCTS system that deals with the AT selection process, targeting children from birth to eight with moderate to severe disabilities (including children with MD). The face and content validity of this model were assessed and critiqued by experts during the review process with a $98 \%$ score for inter-rater agreement ${ }^{22}$. The TTAP model is based on an approach requiring two teams: a Core Team of professionals with AT expertise and a Support Team composed of family members and any others who can provide information about the child's performance, characteristics and educational goals. The model distinguishes three distinct phases with specific activities to be performed before, during, and after the assessment.

- The Matching Person and Technology (MPT) model ${ }^{24,25,26}$ is the most tried and tested client-centred approach to AT provision found in the literature. Central to this model is the idea that the use as well as the non-use of any AT solution is mainly influenced by three interrelated factors: (i) the milieu/ environment(s) in which the user interacts with the technology; (ii) personal factors unique to the user, like preferences, predisposition to use the AT solution and his/her needs and (iii) the characteristics of the technology. This model accordingly defines a five step process for identifying and selecting the most appropriate technology. In the first step the user, together with the AT practitioner, identifies the goals of the AT intervention and the user's strengths and difficulties are determined. Step two is recommended for reviewing the user's past experience and satisfaction with previously used AT solutions as well as the user's attitude towards those desired/needed but not yet available. In steps three through to five, the user and the AT practitioner assess the user's readiness for AT use, the match between the identified AT and the user's lifestyle, and comfort in use. 
- The ATCoplanner model ${ }^{27,28}$ seeks to provide a comprehensive overview of the AT planning and implementation team processes. It is organized around four stages: Orientation, Assessment and Planning, Implementation and Evaluation, and Reporting. Guiding questions are provided for facilitating teamwork.

- $\quad$ Education TECH Points ${ }^{27,29}$ is a framework for organizing AT provision and addresses AT-related issues at all stages of the AT provision process. Guiding questions are proposed for each stage. The stages identified are Referral, Evaluation and Extended evaluation, Plan development, Implementation and Periodic review.

- $\quad$ The Student, Environment, Task and Technology (SETT) framework ${ }^{30}$ was developed in order to help school-based teams organize and prioritize information regarding a disabled student, his/her environment and the activities or tasks he/she needs to perform by means of an assistive solution or tool. By providing a sequence of guiding questions at every stage of the AT provision process it promotes a collaborative approach and facilitates consensus building among the team members.

- The Consortium model ${ }^{26}$ is a 10 -step model covering all aspects of the AT selection process, from its very beginning, and involves the development of an outcome-driven Individual Family Service Plan (IFSP). The 10 steps are: (1) Problem identification; (2) Definition of the desired outcomes; (3) Assessment and identification of AT and AT services; (4) Development of an AT menu; (5) Matching of AT and AT services to the child and family needs; (6) Selection of a device and identification of AT services, (7) Identification of a supplier; (8) Identification of a funding source; (9) Implementation; (10) Follow-up.

- $\quad$ The Barnsley Provision Framework ${ }^{31}$ employed by the Barnsley Assistive Technology Multidisciplinary Team identifies four stages in AT provision: (1) Assessment of user ability and past experience in using AT; (2) Definition of the user's functional requirements and design of a system and user-interface; (3) Presentation of the system to the user and evaluation of whether or not it matches the user's requirements; (4) Long term monitoring and modification when required.

- $\quad$ The SIVA counseling model mentioned in $^{32}$ is employed by the SIVA interdisciplinary team for the assessment of children with disabilities with regard to computer and toy access.

- $\quad$ Campbell and colleagues describe a 4-step model for making decisions about interventions of an adaptive nature (including the provision of AT devices) which aim to promote the participation of children in activities and routines in their everyday environment ${ }^{33}$. The phases they identify in the AT decision making process are: (1) the gathering of information about family activities; (2) the evaluation of levels of satisfaction in the family with the child's functional abilities; (3) the identification of the most adequate intervention on the basis of a graduated list ranking alternative strategies from the least intru- 
sive (environmental adaptation) to the most (having the child do something outside of the activity context with an adult); and (4) the design of a plan of implementation ${ }^{33}$.

- $\quad$ Parette and Brotherson ${ }^{34}$ have developed a conceptual model for AT assessment focusing on children with mental retardation and developmental disabilities. The model focuses on the involvement of the family system as a key factor for AT success. It is composed of three phases: (1) use of a comprehensive approach to the AT assessment; (2) evaluation of the effect of AT provision on the family system; and (3) provision of information about AT in order to empower family members and professionals in decision-making.

- Brotherson and colleagues ${ }^{35}$ have developed an intervention model targeting how AT can be implemented successfully in the home environment and contribute to family system activities. This model adopts a home-centred approach to AT provision and involves careful analysis of both the physical and the social aspects of the home environment ${ }^{35}$.

- $\quad$ Parette and Brotherson ${ }^{36}$ extended their family-centred model for AT provision to include issues related to cultural diversity. They provide a 4-step model aimed at creating reciprocal understanding between AT professionals and families from different cultures. 


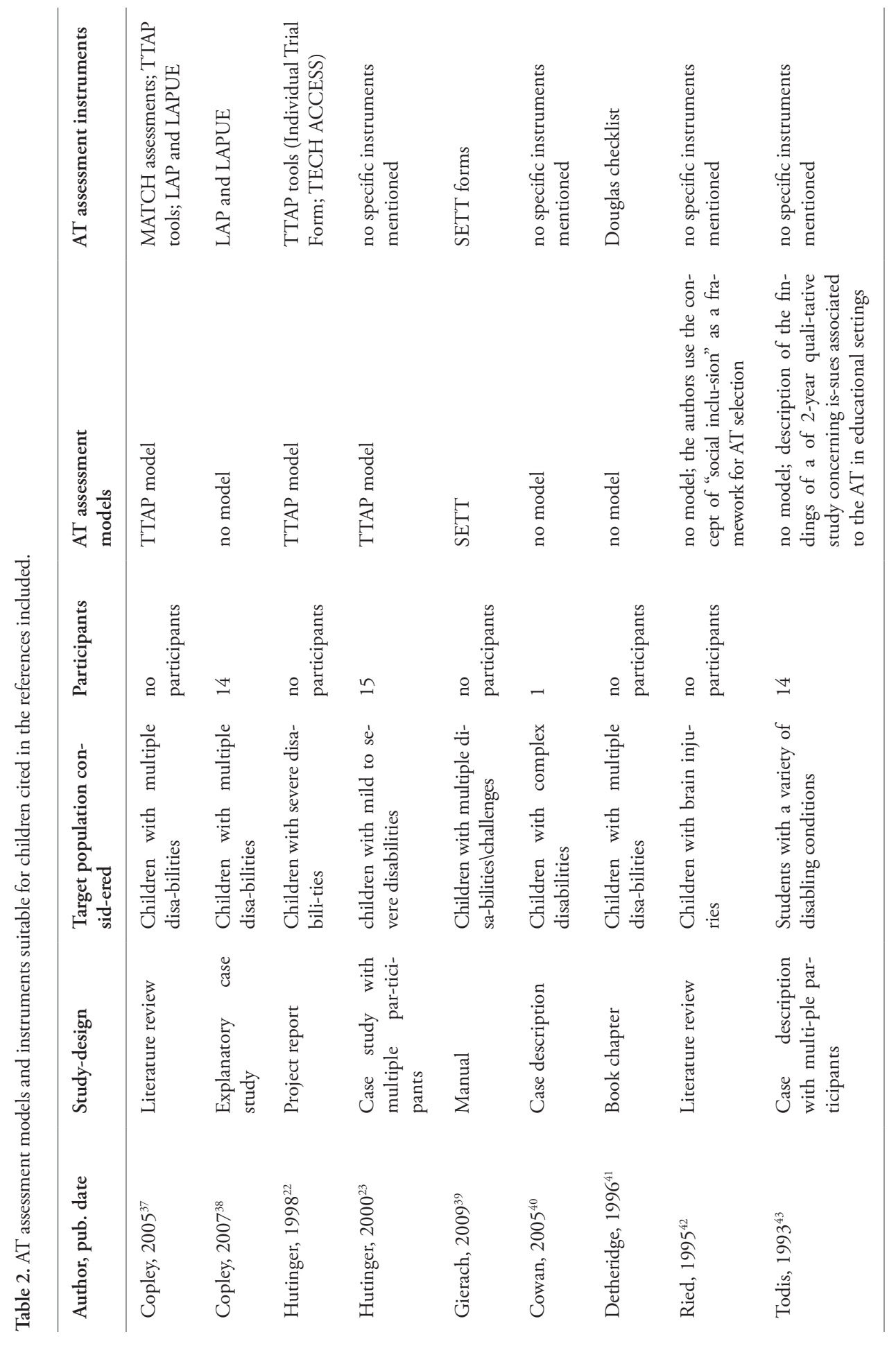




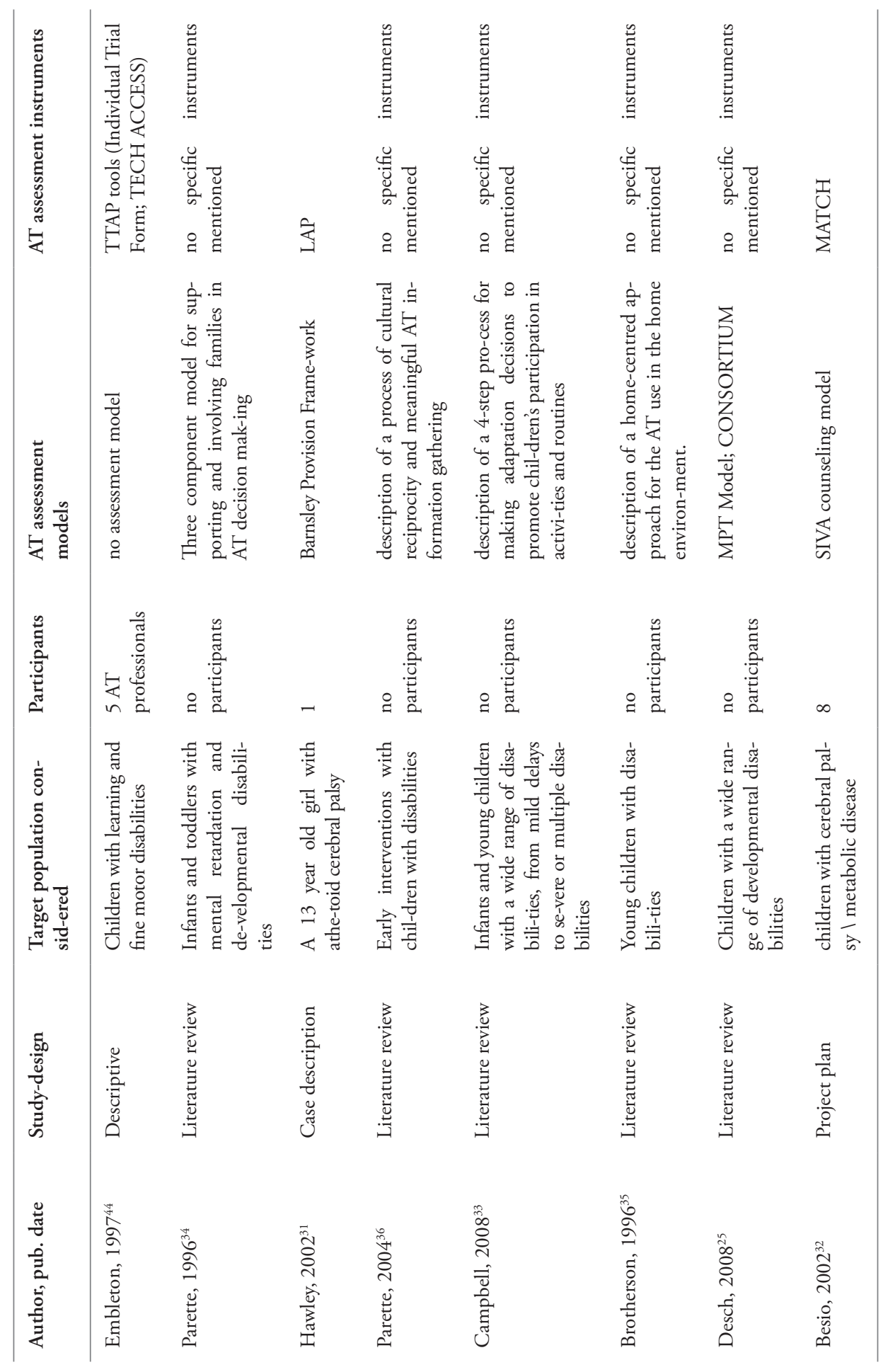




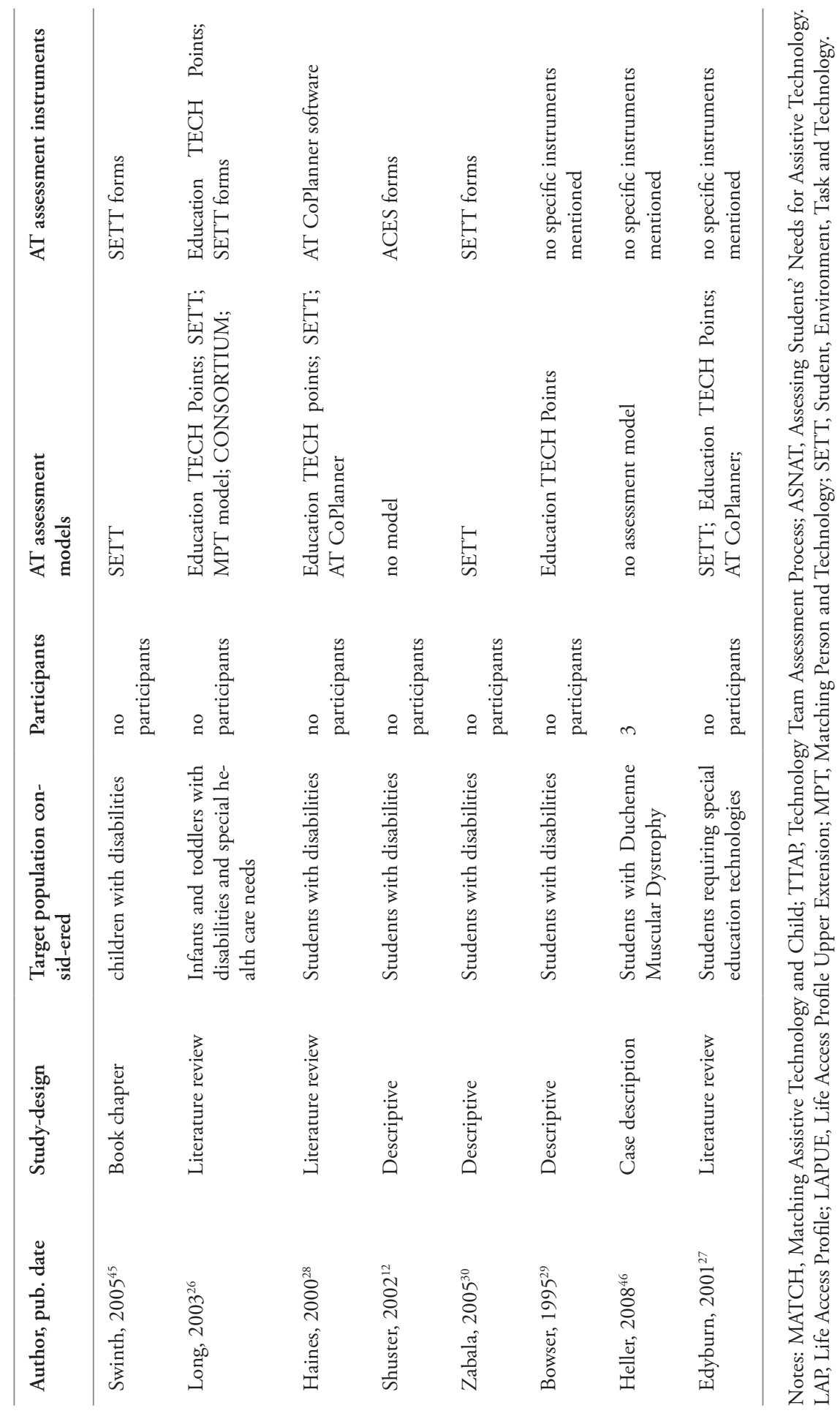




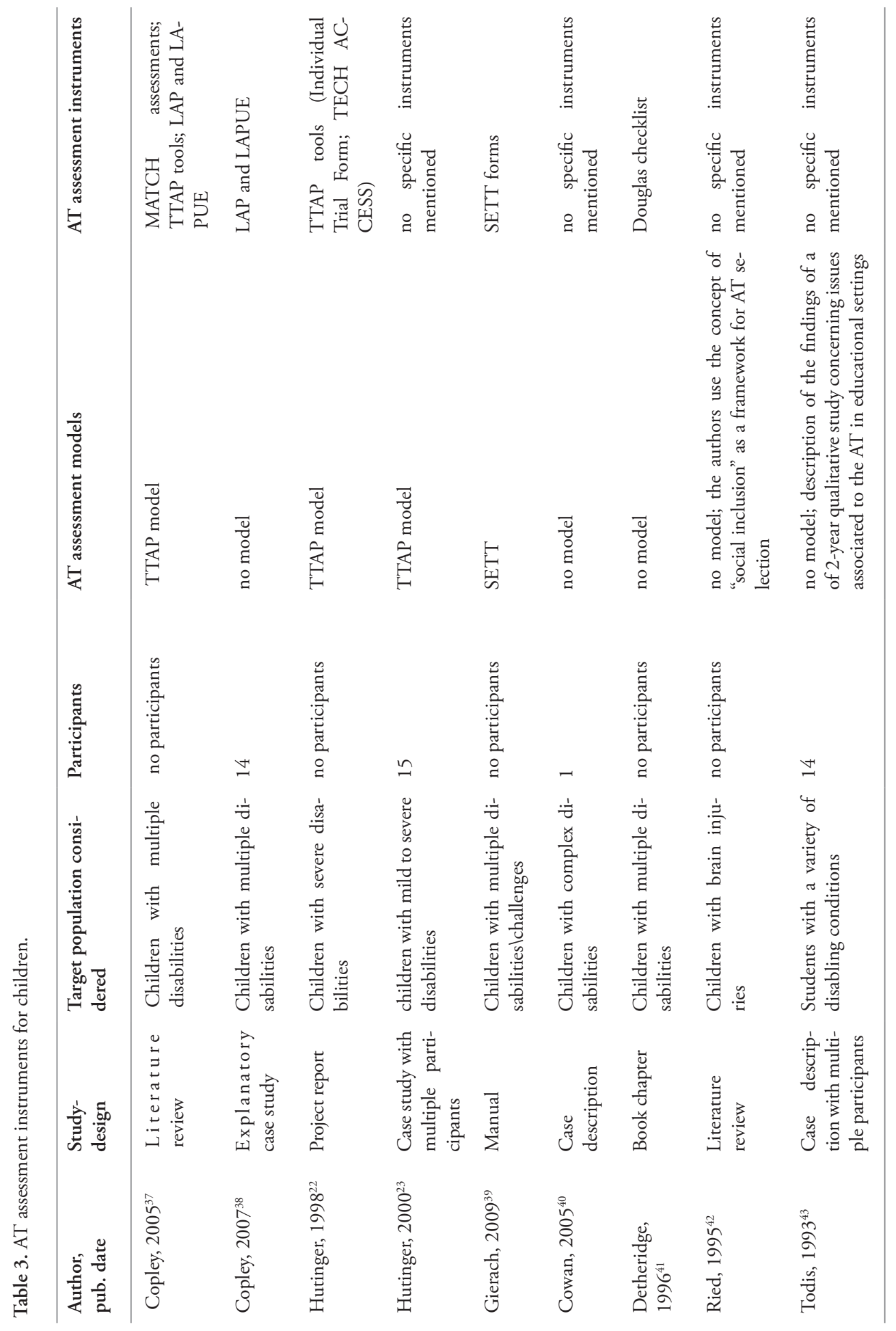




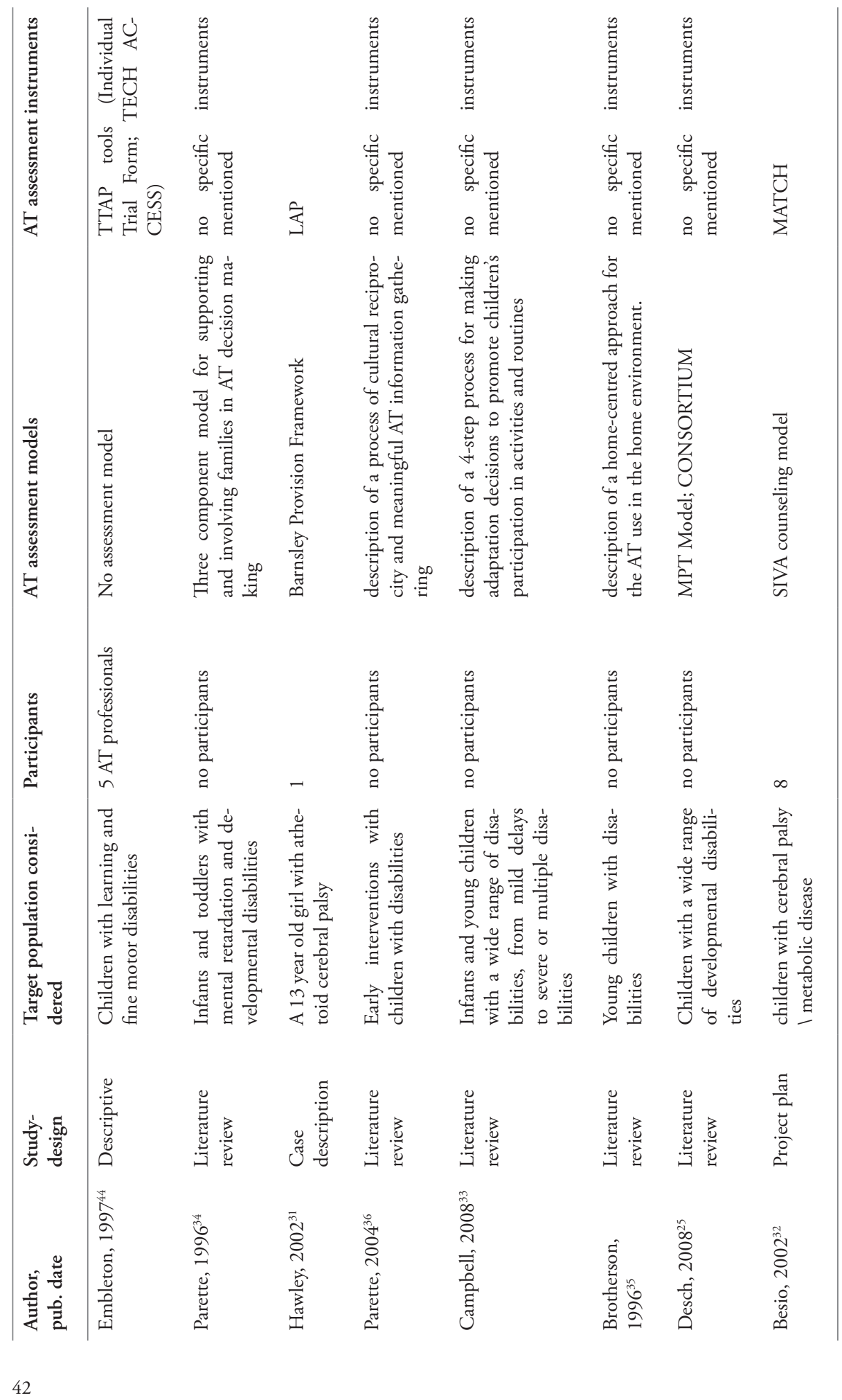




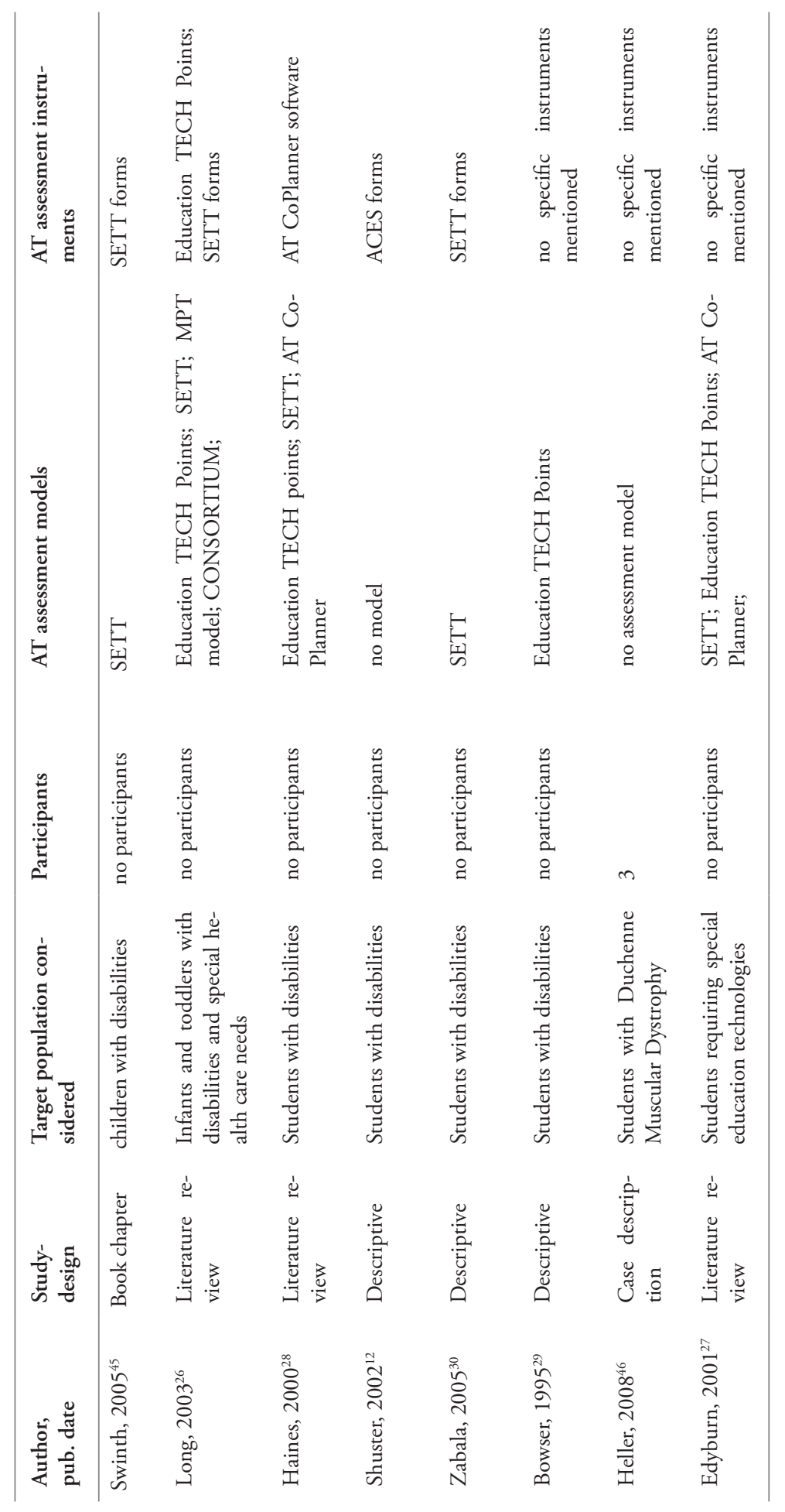


Table 4. AT assessment instruments for children.

\begin{tabular}{|c|c|c|}
\hline $\begin{array}{l}\text { Assessment } \\
\text { Instrument }\end{array}$ & Related model & Description \\
\hline \multicolumn{3}{|l|}{ Suitable for children with MD } \\
\hline LAP and $\mathrm{LAPUE}^{47}$ & no model & $\begin{array}{l}\text { The LAP tool was developed specifically for people } \\
\text { with severe disabilities. It is composed of five sections } \\
\text { each including a series of rating scales: three focusing } \\
\text { on the person and covering user's physical, cognitive } \\
\text { and emotional resources; one related to the support } \\
\text { resources; and the last for the assessment of the envi- } \\
\text { ronmental resources. LAPUE was developed for people } \\
\text { without significant cognitive impairments }\end{array}$ \\
\hline $\begin{array}{l}\text { TECH ACCESS and Indi- } \\
\text { vidual Trial Form }\end{array}$ & TTAP & $\begin{array}{l}\text { The TTAP model was operationalized in two obser- } \\
\text { vational instruments for computer access assessment } \\
\text { which can be administered in any setting familiar to } \\
\text { the child }\end{array}$ \\
\hline ASNAT $^{39}$ & no model & $\begin{array}{l}\text { It is a manual developed by the WATI consultants. } \\
\text { It provides a set of forms for the whole AT selection } \\
\text { process, from the consideration phase to the moni- } \\
\text { toring and evaluation of the AT solution provided. } \\
\text { It was developed also for children with MD (termed } \\
\text { children with multiple challenges). The ASNAT pro- } \\
\text { cess is mainly based on the SETT framework and } \\
\text { adaptations of the SETT forms }\end{array}$ \\
\hline Douglas checklist ${ }^{41}$ & no model & $\begin{array}{l}\text { It is a tool for assessing a child's ability to use a com- } \\
\text { puter. It provides also a hierarchy of skills that may } \\
\text { be used as a guide during the AT assessment. The } \\
\text { checklist identifies a series of steps of progression in } \\
\text { four areas of child-computer interaction: visual at- } \\
\text { tention to the screen, motivation, concentration and } \\
\text { physical control }\end{array}$ \\
\hline
\end{tabular}

Not specific for children with MD

\begin{tabular}{|c|c|c|}
\hline MATCH $^{48}$ & MPT & $\begin{array}{l}\text { The MATCH process is based on the MPT model } \\
\text { and is composed of a set of questionnaires to be com- } \\
\text { pleted by the child or his/her family. }\end{array}$ \\
\hline SETT forms $s^{30}$ & SETT & $\begin{array}{l}\text { These forms help AT professionals documenting the } \\
\text { main aspects of the AT provision process: considera- } \\
\text { tion of AT needs, data gathering, tool selection, and } \\
\text { implementation and effectiveness evaluation }\end{array}$ \\
\hline $\mathrm{ACES}^{12}$ & no model & $\begin{array}{l}\text { It is a set of forms to help AT teams gather informa- } \\
\text { tion about the student with disability, assessing the } \\
\text { effectiveness of his/her currently used technology, } \\
\text { his/her educational needs, and identifying logistical } \\
\text { barriers for the AT implementation }\end{array}$ \\
\hline
\end{tabular}




\begin{tabular}{lll}
\hline $\begin{array}{l}\text { Assessment } \\
\text { Instrument }\end{array}$ & Related model & Description \\
\hline AT CoPlanner $^{28}$ & AT CoPlanner & $\begin{array}{l}\text { The AT CoPlanner model has been implemented in } \\
\text { a software environment which is a synthesis of other } \\
\text { existing AT models and their related instruments } \\
\text { (e.g., SETT). The software provides forms for docu- } \\
\text { menting each aspect of the AT assessment process }\end{array}$ \\
&
\end{tabular}

Notes: MATCH, Matching Assistive Technology and Child; TTAP, Technology Team Assessment Process; ASNAT, Assessing Students' Needs for Assis-tive Technology; WATI, Wisconsin Assistive Technology Initiative; LAP, Life Access Profile; LAPUE, Life Access Profile Upper Extension; MPT, Match-ing Person and Technology; SETT, Student, Environment, Task and Technology.

\section{Discussion}

The present study provides an overview of the models and instruments that have been developed to guide AT professionals working in interdisciplinary rehabilitation in their assessment of children with MD. Specific definitions for the term 'models' and 'instruments' have been provided. The term 'multiple disabilities' has been used for identifying the target population both because of its broad meaning and because our attention was on the co-occurrence of different impairments regardless of the level of severity of these impairments. What emerges from the work reviewed here is that assessing children with MD for AT is a complex process which involves several tasks. These tasks have been extensively described by Copley and Ziviani ${ }^{37}$ and include: adopting both interdisciplinary- and family-centred approaches, establishing shared goals for AT use, evaluating family and contextual resources, and assessment of both access and functions ${ }^{37}$. The role of the family is central at all stages in the assessment process ${ }^{34,37}$ and the main goal of AT professionals is to empower family members so as to enable them to make the final decision regarding the AT solutions proposed ${ }^{34}$. Though most of the models reviewed in the present study address these tasks, data is lacking concerning their effectiveness. Moreover, information about follow-up after AT implementation is also lacking. Regarding the instruments suitable for children with MD (see table 3), Copley and Ziviani ${ }^{37}$ concluded that in comparison with the tools developed within the TTAP model, LAP and LAPUE assessment tools better satisfy the criteria for making AT recommendations for this target population. This conclusion is supported by the work of Embleton and Spencer ${ }^{44}$, who point out that the high inter-rater agreement reported by Hutinger for the TTAP instruments ${ }^{22}$ emerged only for final AT recommendations and not in reference to items or sections in the process conducted using TTAP tools. They also questioned the validity of the TTAP instruments in the case of students with MD who are 9-year-old to 12 -year-old ${ }^{44}$. However, the pilot study conducted by Copley and Ziviani ${ }^{38}$ in order to investigate the consequences of the use of LAP and LAPUE tools by school-based AT teams does not provide any data on the benefits to students after AT implementation ${ }^{38}$. The present study also identified two further instruments suitable for children with MD, 
which are not discussed in the paper by Copley and Ziviani ${ }^{37}$, namely the ASNAT tool ${ }^{39}$ and the Douglas checklist ${ }^{41}$. Once again, data is lacking on their effectiveness.

Due to the lack of reliable information on the effectiveness of the models and the instruments reviewed in this study, it is impossible to draw any evidence-based conclusions concerning key factors that could guide the design of models and instruments able to address in the best possible way the complexities related to the AT assessment of children with $\mathrm{MD}$ in different conditions and contexts and thus to evaluate their applicability in interdisciplinary rehabilitation. Moreover, the work reviewed here leaves it unclear what factors should be considered in evaluating the effectiveness of AT interventions in case of children with MD. Copley and Ziviani ${ }^{37}$ evaluated the benefits of the assessment process for the AT team. In keeping with a user-centred approach to AT provision, other factors to be considered in evaluating outcomes would be the satisfaction of the child and the child's family with both the AT and the AT service, the impact of AT provision on families and caregivers burden, and changes in the child's functional capability. The cost-effectiveness of the AT intervention is also a factor of increasing importance.

\section{Limitations of the present study}

Both our working definitions of the terms 'model' and 'instrument' and the practice-oriented approach employed here might have reduced the number of models found, thus excluding those models that provide a more abstract conceptualization of the interaction between the user and the technology like, for example, the Human Activity Assistive Technology (HAAT) model $^{11}$. Other limitations of our study are the fact that the term 'multiple disabilities' and its definition here employed, though including several related meanings (e.g., 'complex' disabilities), might have reduced the number of references found; only papers published in English were selected; and that the hand search may not have been comprehensive enough of all the documents present on the World Wide Web (e.g., project reports and manuals) and of the books relevant to the topic addressed.

\section{Conclusions}

There is a lack of empirically sound models and instruments for AT assessment focusing on children with MD. In order to make the transition from unsystematic clinical experience and intuition, which seems to characterize the AT field ${ }^{49}$, to more evidence-based practices for AT assessment, AT professionals have to adopt validated intervention models and instruments. This is desirable not only in order to improve AT outcomes for users, but also as a means of reducing the public costs associated with the abandonment and non-use of AT solutions ${ }^{13}$. What emerges from this study is a clear need for further research in order to develop models and instruments for assessing children with MD for AT. 


\section{References}

1. Bronfenbrenner U, Ceci SJ. Nature-nurture reconceptualized in developmental perspective: a bioecological model. Psychol Rev 1994; 101(4): 568-86.

2. Dugan LM, Campbell PH, Wilcox, M J. Making decisions about assistive technology with infants and toddlers. Topics Early Child Spec Educ 2006; 26(1): 25-32.

3. Cass H, Price K, Reilly S, Wisbeach A, McConachie H. A model for the assessment and management of children with multiple disabilities. Child Care Health Dev 1999; 25(3):191-211.

4. Henderson S., Skelton H., Rosenbaum P. Assistive devices for children with functional impairments: impact on child and caregiver function. Dev Med Child Neurol 2008; 50(2): 89-98.

5. Hutinger P, Western Illinois Univ. M, And O. State of Practice: How Assistive Technologies Are Used in Educational Programs of Children with Multiple Disabilities. A Final Report for the Project: Effective Use of Technology To Meet Educational Goals of Children with Disabilities. 1994 [cited 2011 Aug 29]; Available from: http://www.eric.ed.gov/ERICWebPortal/contentdelivery/servlet/ ERICServlet?accno=ED378721.

6. Copley J, Ziviani J. Barriers to the use of assistive technology for children with multiple disabilities. Occup Ther Int 2004; 11(4): 229-243.

7. Østensjø I. Assistive Devices for Children with Disabilities. In: Söderback I, editor. International Handbook of Occupational Therapy Interventions. New York: Springer; 2009. p. 141-146.

8. Judge S. Family-Centered Assistive Technology Assessment and Intervention Practices for Early Intervention. Infants Young Child 2002; 15(1): 60-68.

9. Bain BK, Leger D. Assistive Technology: An interdisciplinary approach. New York: Churchill Livingstone Inc; 1997.

10. Jackson R. Curriculum Access for Students with Low-Incidence Disabilities: The Promise of Universal Design for Learning. Wakefield: National Center on Accessing the General Curriculum; 2005 [cited 2011Sept 21]; Available from: http://www.cast.org/publications/ncac/ncac_lowinc.html.

11. Cook AM, Hussey SM. Assistive Technologies - Principles and Practice . 2nd ed. St. Louis, MO: Mosby; 2002.

12. Shuster NE. The Assistive Technology Assessment: An Instrument for Team Use. Journal Of Special Education Technology 2002; 17(1): 39-46.

13. Federici $S$, Borsci $S$. The use and non-use of assistive technology in Italy: Preliminary data. In: Gelderblom GJ, Soede M, Adriaens L, Miesenberger K, editors. Proceedings of the 11th AAATE Conference: Everyday technology for independence and care. Amsterdam, NL: IOS Press; 2011. p. 979-986.

14. Galvin JC, Scherer MJ. Evaluating, Selecting and Using Assistive Technology. Gaithersburg, MD: Aspen Publishers; 1998.

15. Lahm EA, Sizemore L. Factors that influence Assistive Technology decision making. Journal of Special Education Technology 2002; 17(1), 15-26.

16. Bernd T, Pijl DVD., de Witte LP. Existing models and instruments for the selection of assistive technology in rehabilitation practice. Scand J Occup Ther 2009; 16(3): 146-158.

17. Karmiloff-Smith A. Development itself is the key to understanding developmental disorders. Trends Cogn Sci 1998; 2(10), 389-98.

18. Hammarskiöld G. Assistive devices for children with disabilities. 2005 [cited 2011 Sept 02] http://www. hi.se/Global/Dokument/english/assistive-devices-for-children-GunillaH-2009.pdf.

19. Determining the Need for Assistive Technology [homepage on the Internet]. Consortium for Children and Youth with Disabilities and Special Health Care Need 2005 [cited 2012 Mar 10]. Available from: http://www.teachingat.info/constructs/index.html

20. Lahm EA, Mendonca R. Assistive Technology Assessment Tools. 2008 [cited 2011 Aug 09]. http://www. tamcec.org/pdf/TIA\%20Oct\%202008.pdf

21. Sim J, Wright CC. The kappa statistic in reliability studies: use, interpretation, and sample size requirements. Phys Ther 2005; 85(3), 257-68.

22. Hutinger P, Western Illinois Univ. M. Technology Team Assessment Process (Project TTAP). Final Report, 1998 [cited 2011 Sept 10]; Available from: http://www.eric.ed.gov/PDFS/ED420138.pdf

23. Hutinger P, Johanson J. Implementing and Maintaining an Effective Early Childhood Comprehensive Technology System. Topics Early Child Spec Educ 2000; 20(3). 159-173. 
24. Scherer MJ. Matching person \& technology: A series of assessments for evaluating predispositions to and outcomes of technology use in rehabilitation, education, the workplace $\&$ other settings. Rev. ed. Webster, NY: Institute for Matching Person \& Technology; 1998.

25. Desch L. The spectrum of assistive and augmentative technology for individuals with developmental disabilities. In: Accardo PJ, editor. Capute and Accardo's Neurodevelopmental Disabilities in Infancy and Childhood. 3rd ed. Baltimore, MD: Paul H. Brookes Publishing; 2008. p. 691-719.

26. Long T, Huang L, Woodbridge M, Woolverton M, Minkel J. Integrating Assistive Technology into an Outcome-Driven Model of Service Delivery. Infants Young Child 2003; 16(4), 272-83.

27. Edyburn, DL. Models, theories, and frameworks : Contributions to understanding special education technology. Special Education Technology Practice 2002 [cited 2011 Oct 06]; 4(2): 16-24. Available from: http://www.temple.edu/martec/accessibility/cd/data/assistivetech/brochure_edy_burn.pdf.

28. Haines L, Sanche B. Assessment models and software support for assistive technology teams. Assess Eff Interv 2000; 25(3), 291-306.

29. Bowser G, Reed P. Education Tech Points for Assistive Technology Planning. Journal of Special Education Technology 1995; 12(4): 325-338.

30. Zabala J. Ready, SETT, Go! Getting started with the SETT framework. Closing the Gap 2005 [cited 2011 Sept 19]; 23(6): 12-13. Available from: http://www.joyzabala.com/uploads/Zabala_CTG_SETTing_Up_Staff_and_Supporters.pdf.

31. Hawley MS, O’Neill P, Webb LH., Roast C. A provision framework and data logging tool to aid the prescription of electronic assistive technology. Technol Disabil 2002; 14(2): 43-52.

32. Besio S. An Italian research project to study the play of children with motor disabilities: the first year of activity. Disabil Rehabil 2002; 24(1-3): 72-79.

33. Campbell PH, Milbourne S, Wilcox MJ. Adaptation interventions to promote participation in natural settings. Infants Young Child 2008; 21(2): 94-107.

34. Parette HR, Brotherson M. Family participation in assistive technology assessment for young children with mental retardation and developmental disabilities. Education and Training In Mental Retardation and Developmental Disabilities 1996; 31(1): 29-43.

35. Brotherson MJ, Cook CC, Parette HP. A home-centered approach to assistive technology provision for young children with disabilities. Focus Autism Other Dev Disabl 1996; 11(2):86-95.

36. Parette HR, Brotherson M. Family-centered and culturally responsive assistive technology decision making. Infants Young Child 2004; 17(4): 355-367.

37. Copley J, Ziviani J. Assistive technology assessment and planning for children with multiple disabilities in educational settings. Br J Occup Ther 2005; 68(12): 559-566.

38. Copley J, Ziviani J. Use of a team-based approach to assistive technology assessment and planning for children with multiple disabilities: a pilot study. Assist Technol 2007; 19(3): 109-125.

39. Gierach J, editor. Assessing Students' Needs for Assistive Technology (ASNAT). 5th ed. Milton, WI: WATI; 2009 [cited 2011 Sept 20]; Available from: http://www.wati.org/content/supports/free/pdf/ ASNAT5thEditionJun09.pdf.

40. Cowan D, Khan Y. Assistive technology for children with complex disabilities. Current Paediatrics 2005; 15(3): 207-212.

41. Detheridge T. Developing information technology competencies. In: Bozic N, Murdoch H, editors. Learning through interaction: Technology and children with multiple disabilities. London, UK: David Fulton Publishers; 1996. p. 28-40.

42. Ried S, Strong G, Wright L, Wood A, Goldman A, Bogen D. Computers, assistive devices, and augmentative communication aids: technology for social inclusion. J Head Trauma Rehabil 1995; 10(5): 80-90.

43. Todis B, Walker HM. User Perspectives on Assistive Technology in Educational Settings. Focus Except Child 1993; 26(3): 1-16.

44. Embleton AJ, Spencer KC. Interrater reliability of the Technology Team Assessment. Am J Occup Ther 1997; 51(4), 297-302.

45. Swinth Y. Assistive technology : low technology, computers, electronic aids for daily living, and augmentative communication. In: Case-Smith J, editor. Occupational Therapy for Children. 5th ed. St. Louis, MO: Mosby; 2005. p. 615-656.

46. Heller K, Mezei PJ, Avant M. Meeting the Assistive Technology Needs of Students with Duchenne Muscular Dystrophy. Journal Of Special Education Technology 2009; 23(4): 15-30. 
47. Williams WB, Stemach G, Wolfe S, Stanger C. Lifespace Access Profile: Assistive technology assessment and planning for individuals with severe or multiple disabilities. Revised ed. Irvine, CA: Lifespace; 1995.

48. Scherer MJ. Matching assistive technology and child: A process and series of assessments for selecting and evaluating technologies used by infants \& young children. Webster, NY: Institute for Matching Person \& Technology; 1997.

49. Friederich A, Bernd T., de Witte LP. Methods for the selection of assistive technology in neurological rehabilitation practice. Scand J Occup Ther 2010; 17(4):308-18. 

Chapter 3 Assessing children with multiple
disabilities for assistive technology:
A framework for quality assurance

This Chapter was published as: Desideri, L., Mingardi, A., Stefanelli, B., Tanzini, D., Bitelli, C., Roentgen, U., \& de Witte, L. (2013). Assessing children with multiple disabilities for assistive technology: A framework for quality assurance, “Technology and Disability", 25(3), 159-166. 


\begin{abstract}
The design of public assistive technology (AT) service delivery systems in Europe varies according to each country's culture, disability policy, socio-economic context, health care system organization and history. Though it is recognized by the AT community that it is impossible and not useful to develop a "perfect" or "standard" model for AT service delivery, a way to reduce the fragmentation and increase the collaboration among AT providers has been recently highlighted by the AAATE Position Paper on Service Delivery Systems in Europe. In particular, this document emphasizes the importance for AT providers to share their practices of service delivery in order to "understand to which extent good practices could be exported from one country to another"; and implement common strategies for the evaluation of the quality of the service delivery. In keeping with these recommendations, the present paper illustrates an interdisciplinary AT assessment model targeting children with multiple disabilities which is grounded on the experience of the Centre for Assistive Technology (CAT) operating in the municipality of Bologna, Italy. In addition, a proposal for a conceptual framework for evaluating the quality of service delivery is developed.
\end{abstract}




\section{Introduction}

The achievement of appropriate outcomes for children and their families in the provision of assistive technology (AT) depends to a larger extent on the design of systems, models and practices which can serve both as a guide and as a means of evaluation ${ }^{1,2}$. Researchers in the field of AT delivery have increasingly drawn attention to the need for instruments which can ensure the effectiveness of AT service provision ${ }^{3,4}$ and have called upon AT providers across Europe to share their models of service delivery ${ }^{5}$ and to implement common strategies for quality assessment4. This study focuses on the Centre for Assistive Technology (CAT) which operates in the municipality of Bologna, in Italy, and which targets children with motor or with a combination of intellectual, sensory and motor disabilities (children with multiple disabilities).

\section{Aim of the study}

In this case study of one AT service provider, we describe in depth the activities of the CAT in Bologna (for the first time, as far as the literature regarding children with multiple disabilities is concerned ${ }^{14}$ ) in order:

- $\quad$ to develop a general model for assessing children with multiple disabilities for AT provision;

- to improve transparency in AT service delivery by developing a framework for the assess-ment of quality in AT service delivery.

\section{Model for AT assessment}

\section{Background information}

AT service delivery in Italy is organized at regional level and delivered via local health authorities (ASLs), usually in collaboration with private organizations ${ }^{6}$. The CAT in Bologna was set up in 1987 by the NPISH AIAS Bologna Onlus, an association that was founded by the families of people with motor disabilities. The CAT is a publicly funded non-profit organization, and although its interdisciplinary team works on behalf of the Bologna ASL, its catchment area covers the whole country. The CAT works closely with the Regional Centre for Assistive Technology for independent living (CRA) and the Centre for the adaptation of the home (CAAD), to form an integrated AT Area within the "Corte Roncati" Centre for people with disabilities. Corte Roncati is a complex structure entirely dedicated to disability which houses, in addition to the fore mentioned AT Area dedicated to the provision of AT solutions, three clinical services targeting children and adolescents: the Neuromotor Child Disability Centre (UOCMRI), the Childhood Speech and Cognitive Disabilities Centre (Ceredilico) and the Centre for autistic spectrum disorders. Corte Roncati thus seeks to integrate traditional clinical/ rehabilitation approaches with AT interventions aimed at increasing the independence, 
autonomy and well-being of people with disabilities. The activities of the CAT focus on the provision of assessment, recommendations, training and support to children, families and other stakeholders (e.g., school, health and social professionals) in the following categories of AT: access to information and communication technology in any context (school, play, work, leisure); rehabilitative and educational software; augmentative and alternative communication (AAC); environmental control. Data for the last five years of activity (2007-2012) show that the CAT has conducted AT interventions involving approximately 100 users every year, of whom about $50 \%$ were children or adolescents aged 0-17. Drawing on over thirty years of experience, the CAT has developed through a bottom-up approach the four-step interdisciplinary AT assessment model (Activation, Assessment, Documentation, and Post-assessment) depicted in figures 1 and 2, which will be briefly described below.

\section{Phase 1: Activation}

The assessment process may be triggered by an initiative on the part of the child's family or of a health or educational professional and often begins with a phone call or email. Since the CAT forms part of the local health system, formal referral on the part of a local health system operative is necessary for access to its services. They are required to fill out a form with both open and closed questions concerning four basic dimensions related to the child's capabilities: awareness of situation/context and language comprehension; reading and writing; communication skills; motor abilities and mobility. They are also required to explain why they are asking for an AT consultation and to specify possible objectives and expectations regarding the use of AT. On the basis of the information gathered through the referral form and through preliminary telephone conversations with the parents and/or other stakeholders, the CAT core team (see Figure 1) decides which professionals from Corte Roncati to call upon for the assessment of the child. In other words, each CAT assessment is performed by a team whose composition varies according to the specific characteristics of the child.

\section{Phase 2: Assessment}

The objectives of the AT assessment are: a) to identify AT solutions which could facilitate child's achievement of his/her developmental and educational goals (e.g., communicating, playing, learning, personal autonomy) as described in most cases in the child's PEI (Individualized Education Program) as well as help family members and health and educational professionals seeking to ensure their achievement; b) to assess whether (and how) an AT solution may permit the setting of new developmental goals (i.e the design of a new PEI). To this end, it is vital that all possible stakeholders be actively involved every stage in the assessment process.

The CAT procedure for the AT assessment is centre-based and is illustrated in Figure 2. It is conducted in a customizable setting and lasts approximately half a working day (3-4 hours). The assessment of the child's capabilities and the process of matching capacities to 


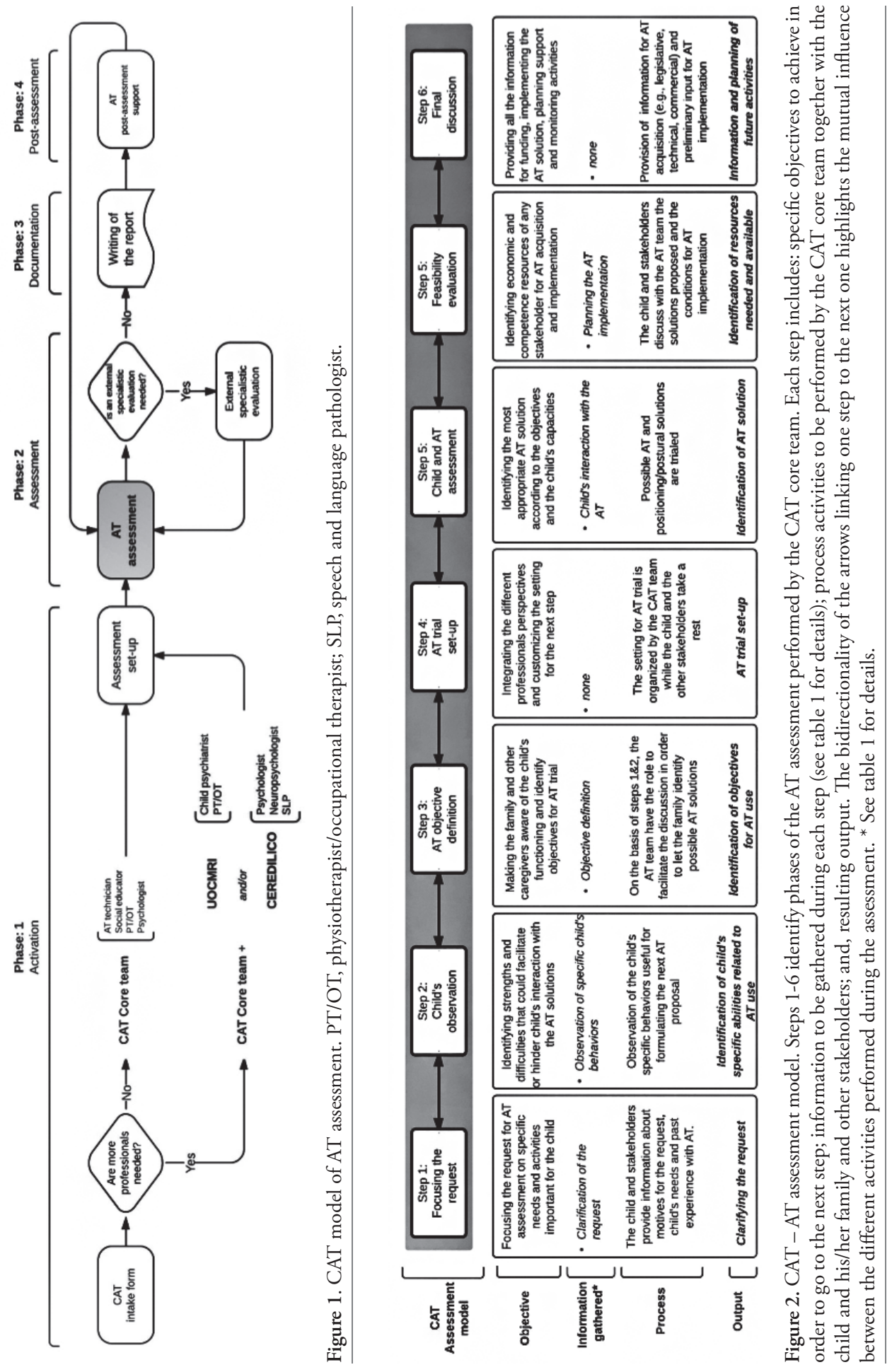


needs is a complex one that requires the participation of professionals from different fields of expertise. Figure 2 depicts the steps of a typical CAT assessment, while table 1 provides an overview of what kinds of contribution are made by different professionals in the CAT core team, together with the instruments employed.

\section{Phase 3: Documentation}

Documentation refers to a structured text record that integrates and summarizes the recommendations made by the AT team for the benefit of all of the stakeholders involved. The aim of the documentation is to provide the child, his/her family and other stakeholders with a summary of the rationale that guided the final AT decision, with a definition of objectives, as well as with information concerning AT acquisition and its implementation in the child's environments. The CAT does not play an active role in purchasing the AT solution, but the report can be used by health and social service professionals to support an application for public funding.

\section{Phase 4: Post-assessment}

Once the AT solution is available to the child, post-assessment activities are mainly life context-based. The CAT provides post-assessment services for users living in the municipality of Bologna. It gives direct support to the child, his/her family and the school staff during and after the implementation of the AT solution, at school, at home, and in day care centres. The objective of post-assessment activities is to provide support and consultation for the child and other AT stakeholders. Support consists of: a) facilitating the implementation of the AT solution (e.g., customization of the AT, adaptation of the workplace); b) training the child and his/her caregivers in the use of the AT solution; c) fine tuning the AT solution with the objectives, resources and expectations of the context of use; d) providing support to professionals so as to render them autonomous in the development of AT related activities. Consultations consist in meetings with parents and/ or professionals in order to monitor AT use through a discussion with AT stakeholders, and deal with any difficulties encountered in the course of use.

Approximately 150 AT support interventions and 500 consultations were provided every year over the period 2007-12. 


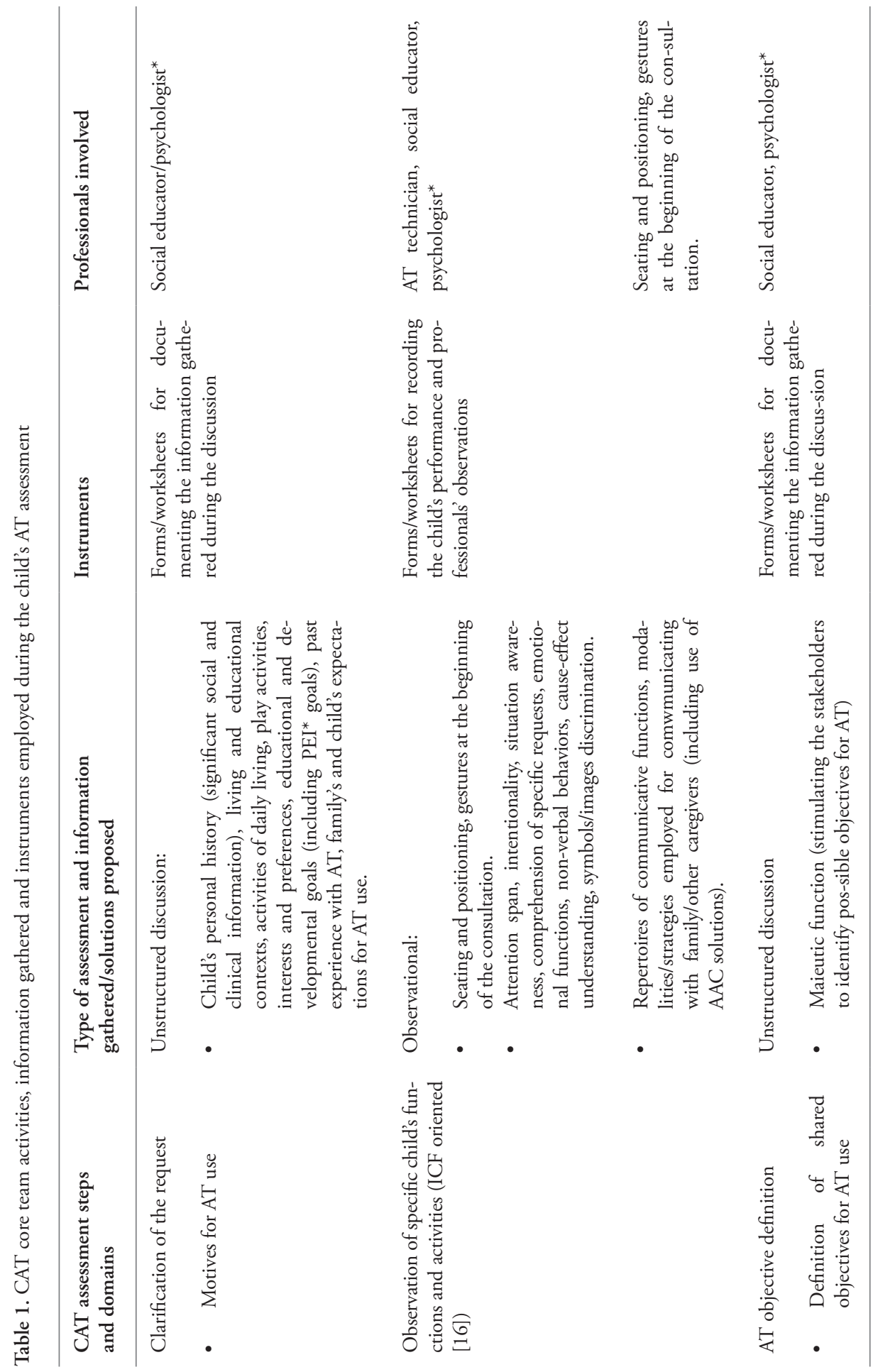




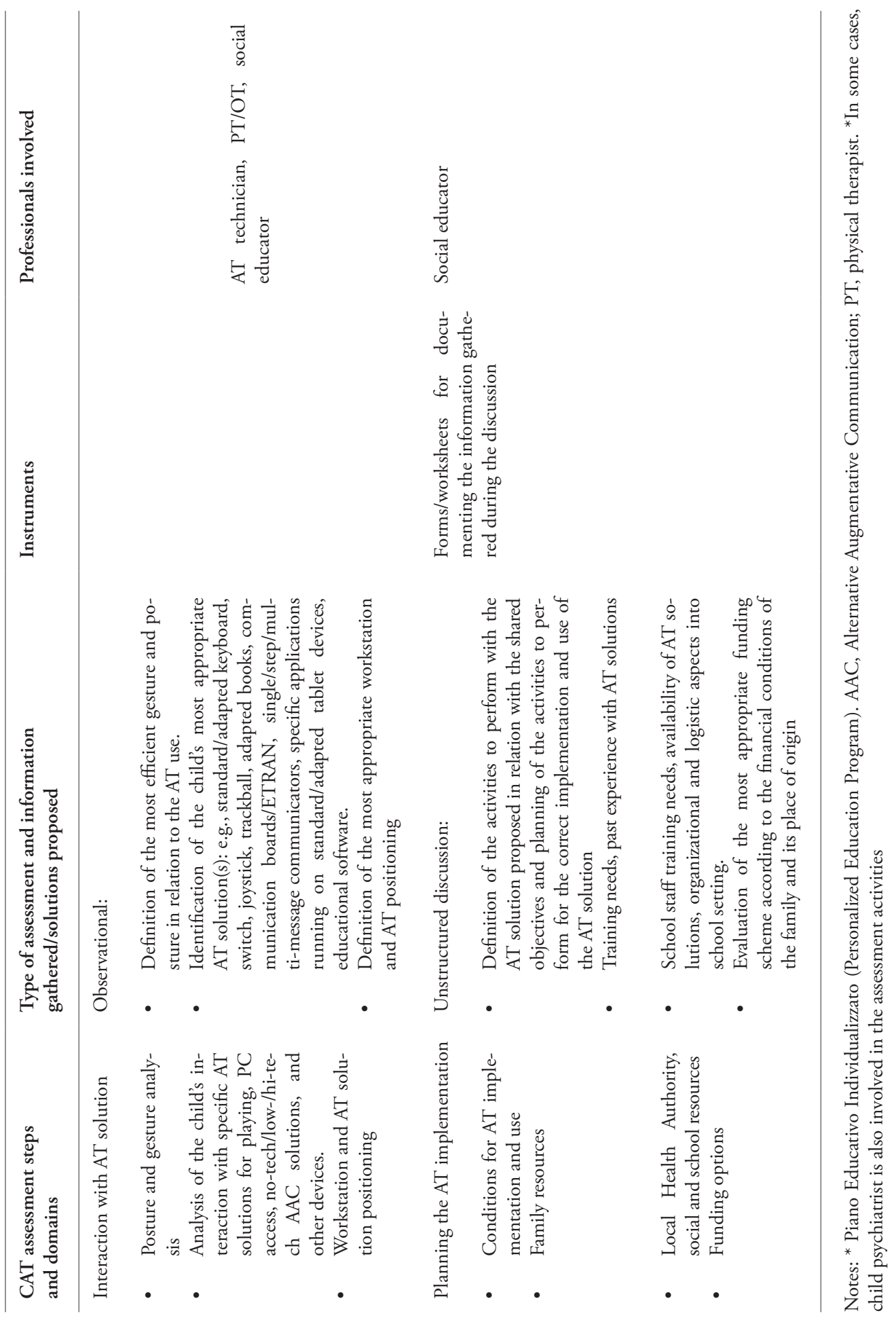




\section{Framework for service quality}

As part of a complex health system, the CAT is not only responsible for its own services, but also has some responsibility for the functioning of the entire AT service delivery system. Assuring the quality of the CAT's interventions is thus a cornerstone for the success of the system as a whole. Quality assurance refers to "all actions taken to establish, protect, promote, and improve the quality of health care"

The project developed by the CAT team, in collaboration with the CAPHRI School for Public Health and Primary Care in Maastricht, The Netherlands, aims to assess the quality of the service provided by the CAT through a conceptual framework which targets the components of the service delivery model delineated above while relating them to the complexities of the global service delivery system within which the CAT operates.

The framework we adopted is based on the Donabedian triadic model [8] for the evaluation of the quality of health care and the quality criteria for service delivery defined by the AAATE Position Paper on AT Service Delivery Systems in Europe [4] and reported in Table 2 .

According to the Donabedian model $^{7,8,9,10,11,12}$, information about quality of care is of three distinct kinds: it concerns the structure, process, or outcomes of health care. Details of the resulting conceptual framework are provided below (see also figure 3):

- Structure refers to "the attributes of the settings in which care occurs" in the context of AT service delivery, it includes financing schemes, legislation and school and health system regulations for obtaining and implementing AT devices. Concurrent interventions made by the Local Health Authority (ASL) or the school (e.g., physical therapy, speech and language therapy, social interventions) should also be viewed as structural in these terms.

- Process refers to "what is actually done in giving and receiving care" 7,8 . It refers to the activities performed by AT professionals in the assessment, selection, implementation, management and follow-up of the AT solution 11. The quality of the process is defined in our framework as the degree to which the process satisfies all or specific target indicators described by the HEART study and illustrated in Table $2^{4}$.

- $\quad$ Outcomes ${ }^{7,8}$ refers to the end results of health care practices and the changes that are produced by AT solutions in the lives of users and in their environments ${ }^{13}$. From a systematic review of the literature14, no clear factors emerged for the evaluation of the effects of the AT interventions on children with multiple disabilities in relation to specific models of AT assessment. In order to account for the complexities of the AT service delivery and the different agencies involved, we distinguish between three different levels of outcomes assessment: effects produced by the AT solution (micro level); effects produced by the CAT (meso level); and effects produced by the AT service delivery system (macro level). 
1. Micro level measures of outcome include: effectiveness of the AT solution, defined as changes in the user's levels of activity and participation $^{13,15}$. The International Classification of Functioning (ICF) defines activities as the execution of a task or action by an individual ${ }^{16}$; while participation is defined as involvement in a life situation 16 and also includes participation on the part of caregivers ${ }^{17}$. In addition, micro level outcome assessment includes: the user's satisfaction with the AT solutions ${ }^{18}$; the child's and caregivers' mental functioning and personal factors ${ }^{19,17}$, caregivers' quality of life $^{17}$ and subjective well-being ${ }^{1,20}$.

2. Meso level measures of outcome include: the user's perception of quality of care received by the CAT (e.g., user's satisfaction); users' compliance with AT recommendation $s^{21}$ (e.g., use and non-use of selected AT).

3. Macro level measures of outcome include: overall users' satisfaction with the service delivery system; efficiency ${ }^{13}$, defined as the evaluation of the resources spent on the AT intervention in comparison with the cost of an alternative intervention ${ }^{22,23}$. In particular, the resources employed for the AT intervention may be analyzed in terms of social cost, referring to the sum of all resources spent by all actors involved in the AT process ${ }^{24,25}$. 
Table 2. Criteria for AT process quality assessment

\begin{tabular}{ll}
\hline Criteria & Indicators* \\
\hline Accessibility & The scope of the system (beneficiaries, age differences, insurance diffe- \\
rences etc.), its simplicity, the availability of information to the public, \\
financial barriers and costs for the user, the duration of the process and the \\
complexity of the procedures. \\
The educational level of the professionals involved, the possibilities for \\
further education, the use of protocols and standards in the process, the \\
availability of information about assistive technology, the possibility to le- \\
arn from users feedback. \\
A service delivery system needs to be well-coordinated at three levels: wi- \\
thin the primary process of service delivery (micro-level); during the va- \\
rious steps of the service delivery system process (meso-level) and within \\
other policies and processes involving assistive technology (macro-level). \\
Complexity of procedures and regulations, duration of the process, con- \\
trol of the system over the process, mechanisms able to control costs and \\
effectiveness, allocation of decision-making power to the appropriate level \\
of competence between the various actors involved. \\
A service delivery system is flexible when it is able to respond to the diffe- \\
rent needs of individuals. \\
The presence and strength of user organizations, the availability of juridical \\
protection of the users rights, the involvement of users at a policy level, \\
the user empowerment during the individual assessment, communication \\
with the user in the service delivery process and the influence of the user \\
on decisions in the process
\end{tabular}

Notes: Indicators taken from the AAATE Position Paper on AT service delivery systems ${ }^{4}$ 
Table 3. Measures and related instruments employed by the CAT for AT service delivery outcomes assessment

\begin{tabular}{lll}
\hline Outcome level & Outcome measure & Instrument \\
\hline Micro level & $\begin{array}{l}\text { Effectiveness of the AT solution } \\
\text { Users' satisfaction with the AT so- }\end{array}$ & $\begin{array}{l}\text { Individual Prioritised Problem Asses- } \\
\text { sment (IPPA) 27,28 }\end{array}$ \\
lution & $\begin{array}{l}\text { Quebec User Evaluation of Sati- } \\
\text { sfaction with Assistive Technology } \\
\text { (QUEST 2.0) 29 }\end{array}$ \\
Users' compliance with CAT recom- & $\begin{array}{l}\text { Questionnaire developed ad hoc by } \\
\text { the CAT service }\end{array}$ \\
mendations level & $\begin{array}{l}\text { Users' satisfaction with the CAT } \\
\text { service }\end{array}$ & $\begin{array}{l}\text { Questionnaire developed ad hoc by } \\
\text { the CAT service }\end{array}$ \\
User's satisfaction with the AT ser- & KWAZO30,31 \\
vice delivery & $\begin{array}{l}\text { Social costs savings for the healthca- } \\
\text { re system }\end{array}$ & $\begin{array}{l}\text { SIVA Cost Analysis Instrument } \\
\text { (SCAI)24,25 }\end{array}$ \\
\hline
\end{tabular}

In table 3, we provide a list of AT outcome measures which have been incorporated into CAT quality assessment procedure.

- Though not represented in the framework depicted in figure 3, demographic, personal and psychosocial factors related to children, families and other stakeholders may act also as mediating and moderating factors in the measurement of specific AT service delivery quality assessment categories (e.g., outcomes $^{25,17,13,21}$ ). For this reason, these variables should always be considered in the interpretation of the quality assessment results. 


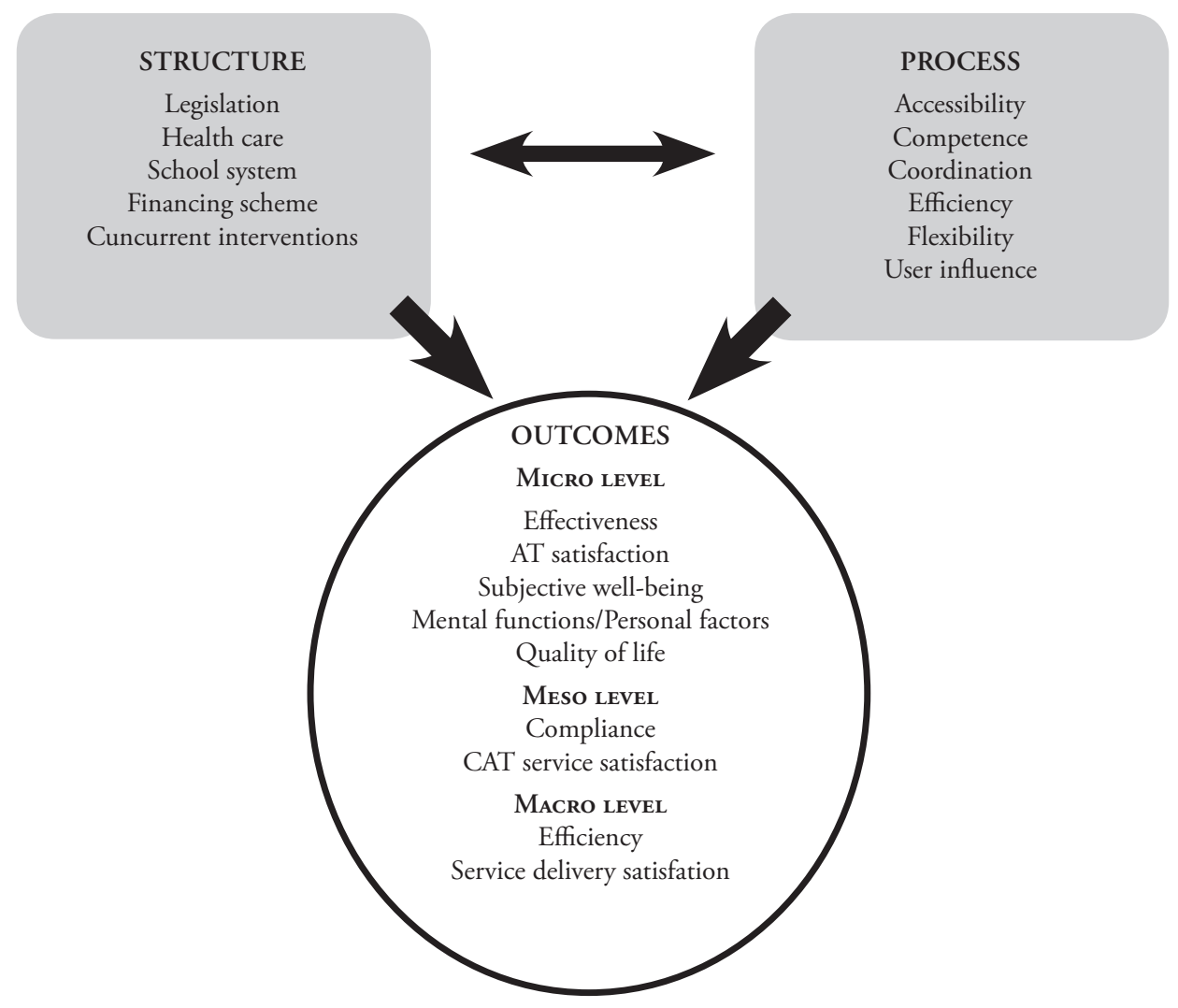

Figure 3. Framework for AT service delivery quality assessment

\section{Conclusion}

Although several limitations can be found in the present case study in terms of generalizability of the model and the framework described, the present contribution represents the first study reporting a model of AT assessment for children with multiple disabilities together with clear strategies and instruments for evaluating the effects of the AT intervention at any level of the service delivery process ${ }^{14}$.

The work described here is an attempt to translate into practice the recommendations made by the AAATE Position Paper on Service Delivery System 4 from an AT professional perspective. Further work will be conducted by the authors in order to develop an evidence-base evaluation of the validity of the CAT model for AT assessment and the effectiveness of the framework for the evaluation of the quality of the service delivery. 


\section{References}

1. Copley J, Ziviani J. Barriers to the use of assistive technology for children with multiple disabilities. Oc-cupational Therapy International 2004, 11(4): 229-243.

2. Østensjø I. Assistive Devices for Children with Disabilities. In: Söderback I, editor. International Hand-book of Occupational Therapy Interventions. New York: Springer; 2009. p. 141-146.

3. Elsaesser LJ, Bauer SM. Provision of assistive technology services method (ATSM) according to evi-dence-based information and knowledge management. Disability \& Rehabilitation: Assistive Technolo-gy 2011, 6(5): 386-401.

4. Association for the Advancement of Assistive Technology in Europe (AAATE). Service Delivery Systems for Assistive Technology in Europe: Position Paper [Internet]. 2012 [cited 19 June 2015]. Available from: http://www.aaate.net/sites/default/files/ATServiceDelivery_PositionPaper.pdf

5. Steel EJ, de Witte, LP. Advances in European Assistive Technology service delivery and recommenda-tions for further improvement. Technology and Disability 2011, 23(3): 131-138.

6. Research on the provision of Assistive Technology in Ireland and other countries to support independ-ent living across the life cycle [Internet]. 2012 [cited January 2013]. Available from: http://www.nda.ie/ cntmgmtnew.nsf/0/797AD755B56A82A580257A4D0031A2B6?OpenDocument

7. Donabedian A. An introduction to quality assurance in health care. New York: Oxford University Press; 2003.

8. Donabedian, A. The quality of care. JAMA 1988, 260(12): 1743-1748.

9. Hoenig H, Sloane R, Horner RD, Zolkewitz M, Duncan PW, Hamilton BB. A taxonomy for classification of stroke rehabilitation services. Arch Phys Med Rehab 2000, 81(7):853-862.

10. Hoenig H, Lee J, Stineman M. Conceptual overview of frameworks for measuring quality in rehabilita-tion. Top Stroke Rehabil 2010, 17(4): 239-251.

11. Sund T, Iwarsson S, Andersen MC, Brandt A. Documentation of and satisfaction with the service deliv-ery process of electric powered scooters among adult users in different national contexts. Disability and Rehabilitation: Assistive Technology 2012, (00): 1-10.

12. Lenker JA, Shoemaker LL, Fuhrer MJ, Jutai JW, Demers L, Tan CH, DeRuyter F. Classification of assistive technology services: Implications for outcomes research. Technology and Disability 2012, 24(1): 59-70.

13. Fuhrer MJ, Jutai JW, Scherer MJ, DeRuyter F. A framework for the conceptual modelling of assistive technology device outcomes. Disabil Rehabil 2003, 25(22): 1243-1251

14. Desideri L, Roentgen U, Hoogerwerf EJ, de Witte L. Recommending assistive technology (AT) for children with multiple disabilities: A systematic review and qualitative synthesis of models and instruments for AT professionals. Technology and Disability 2013, 25(1): 3-13.

15. Scherer MJ, Glueckauf R. Assessing the Benefits of Assistive Technologies for Activities and Participa-tion. Rehabil Psychol 2005, 50(2): 132-141.

16. World Health Organization (WHO). International Classification of Functioning, Disability and Health: Children \& Youth version: ICF-CY. World Health Organization, 2007.

17. Demers L, Fuhrer MJ, Jutai J, Lenker J, Depa M, \& De Ruyter F. A conceptual framework of outcomes for caregivers of assistive technology users. Am J Phys Med Rehab 2009, 88(8): 645-655.

18. Demers L, Weiss-Lambrou R, Ska B. The Quebec User Evaluation of Satisfaction with Assistive Technolo-gy (QUEST 2.0): an overview and recent progress. Technology and Disability 2002, 14(3): 101-105.

19. Henderson S, Skelton H, Rosenbaum P. Assistive devices for children with functional impairments: impact on child and caregiver function. Dev Med Child Neurol 2008, 50(2): 89-98.

20. King S, Teplicky R, King G, Rosenbaum P. Family-centered service for children with cerebral palsy and their families: a review of the literature. Semin Pediatr Neurol 2004, 11(1):78-86.

21. Wessels R, Dijcks B, Soede M, Gelderblom GJ, de Witte L. Non-use of provided assistive technology de-vices, a literature overview. Technology and disability 2003, 15(4): 231-238.

22. Warren CG. Cost effectiveness and efficiency in assistive technology service delivery. Assistive Technol-ogy 1993, 5(2): 61-65.

23. Harris F, Sprigle S. Cost analyses in assistive technology research. Assistive Technology 2003, 15(1): 16-27. 
24. Andrich R. The SCAI instrument: Measuring costs of individual assistive technology programmes. Tech-nology and Disability 2002, 14(3): 95-99.

25. Andrich R. Cost analysis of assistive technology [internet]. [cited 5 March 2013]. Available from: http:// portale.siva.it/files/a16_1_Andrich_Cost_analysis.pdf

26. Scherer MJ, Sax C, Vanbiervliet A, Cushman LA, Scherer JV. Predictors of assistive technology use: The importance of personal and psychosocial factors. Disability \& Rehabilitation 2005, 27(21): 1321-1331.

27. Wessels R, Persson J, Lorentsen O, Andrich R, Ferrario M, Oortwijn W et al. IPPA: Individually prioritised problem assessment. Technology and Disability 2002, 14(3): 141-145.

28. Individual Prioritised Problem Assessment (IPPA) [internet]. [cited January 2013]. Available from: http://portale.siva.it/files/ippa_manuale.pdf

29. Demers L, Weiss-Lambrou R, Ska B. The Quebec User Evaluation of Satisfaction with Assistive Technolo-gy (QUEST 2.0): an overview and recent progress. Technology and Disability 2002, 14(3): 101-105.

30. Desideri L., Bitelli C, Brandan V, de Witte L. The employment of KWAZO with parents of children with disabilities in an Italian region: Preliminary data on scale adaptation and validation. Paper submitted to AAATE 2013 Conference.

31. Dijcks BP, Wessels RD, de Vlieger SL, Post MW. KWAZO, a new instrument to assess the quality of ser-vice delivery. Disabil Rehabil 2006 15,28(15):909-14. 

Chapter 4 Development of a team-based method for assuring the quality of assistive technology documentation

This Chapter was published as: Desideri, L., Ioele, F., Roentgen, U., Gelderblom, G.J., \& de Witte, L. (2014). Development of a team-based method for assuring the quality of assistive technology documentation, "Assistive Technology", 26(4), 175-183. 


\begin{abstract}
Good practice in assistive technology (AT) service delivery targeting children with disabilities has come increasingly to include providing AT stakeholders with a final text record that documents the rationale and procedures behind the recommendations made during the AT assessment process (AT documentation). In the present case study of one AT service provider, we developed a team based approach for conducting an evaluation of the quality of the AT documentation. A service-specific scale for the evaluation of AT documentation was developed following a 5-step approach. The scale was employed to review AT documentation utilizing specific review criteria in order to evaluate the quality of AT documentation practices with regard to the service investigated. Two independent reviewers examined the AT documentation for 130 cases of AT service provision. Weighted kappa and Intraclass correlation coeffcients were employed as a measure of inter-rater agreement. The results of the documentation evaluation allowed AT professionals to objectively assess the quality of the AT documentation produced by the service under investigation, identify shortcomings in the documentation process and making related corrections. AT services may benefit from the employment of strategic approaches for the evaluation of service provision. Possible applications to other AT service providers are discussed.
\end{abstract}




\section{Introduction}

As in any process involving care, effective communication between the user and those providing assistive technology (AT) services is vital to the success of the AT intervention $^{1,2}$. Communication can take different forms, including, of course, written documentation $^{3}$. In the present paper, we will focus on written communication practices as a critical component in the AT service delivery process. In particular, we will focus on written communication practices following the assessment of the child's needs and resources, and the selection of the most appropriate AT solution for learning, play and communication activities (e.g., access solutions for computers and toys; educational software; communication aids). AT assessment represents a critical component in any AT service delivery process targeting children with disabilities ${ }^{4}$. The models and instruments adopted by AT professionals in the course of AT assessment and the collection of data may differ ${ }^{5}$, but presumably all AT service providers, regardless of differences in service delivery systems (e.g. private/public), need to write a summary of their final recommendations.

In the present study, the term "AT documentation" refers to a final text record for the use of AT stakeholders (e.g., the child, the child's family, health and school professionals, suppliers, or other third parties) that documents any stage in the AT service delivery process, from referral to AT assessment, and that reports the user's needs, the rationale behind the recommendations made by the AT team and the procedures underlying them. AT documentation in this sense is important not only for accessing funding for AT purchases but also for guiding AT stakeholders in the process of implementing and using the recommended AT solution.

\section{AT documentation within the service delivery process}

The importance of AT documentation in the AT service delivery process is widely recognized. Cook and $\operatorname{Polgar}^{6}$ (p. 57) highlight the importance of report writing within the AT service delivery process and recognize that writing AT recommendations represents a "unique challenge" for AT professionals. The authors ${ }^{6}$ point out that such reports need to include a variety of information: from a description of the AT assessment process to a definition of needs and goals. The report should include an evaluation of the consumer's capacities with reference to using the proposed AT device and recommendations for developing necessary AT skills before purchase ${ }^{6}$, as well as strategy recommendations for implementing the AT device in the individual's context. AT device specifications, such as part numbers if applicable, the manufacturer's name, required modifications, and $\operatorname{costs}^{6}$, should also be included. Finally, with regard to the implementation of its recommendations, the documentation should identify sources of funding and the person who will take the responsibility for implementing the recommendations ${ }^{6}$.

The Rehabilitation Engineering and Assistive Technology Society of North America (RESNA) has published several documents aimed at guiding AT professionals in the process of AT service delivery. Most notably, the Practical Guide for Rehabilitation 
Technology Service Delivery ${ }^{2}$ insists on the importance of written recommendations in the relationship between the AT provider and AT stakeholders (e.g., clients, referral sources, third-parties) and invites AT professionals to produce AT documentation of a kind which reflects, among other aspects, the quality of the AT assessment process (e.g., by providing photographs and other testimonial documentation) and user involvement (e.g., by describing the needs and concerns expressed by the user). More recently, in the specific case of wheelchair provision, the authors of the RESNA Wheelchair Service Provision Guide ${ }^{7}$ recommend that applications for funding include an account of the clinical rationale for recommended solutions and report findings on the products evaluated, including those ruled out.

Less information is available regarding documentation focusing on AT solutions for learning, play and communication activities when children are concerned. The Quality Indicators for Assistive Technology Consortium has made an attempt to develop quality indicators for AT service provision in school settings. It recommends providing AT stakeholders with: "a written rationale [...] for any recommendations that are made [...]. Recommendations may include assessment activities and results, suggested devices and alternative ways of addressing needs, services required by the student and others, and suggested strategies for implementation and use" ${ }^{\prime \prime}$ (p. 2).

Blischak and $\mathrm{Ho}^{9}$ provide speech-language pathologists with writing guidelines specifically aimed at reporting the results of alternative and augmentative communication (AAC) assessment for school-aged children. The authors ${ }^{9}$ recommend to include a detailed description of the background information (e.g., purpose of the evaluation, referral source, and reasons for referral); the AAC assessment process (e.g., the environment in which the assessment was conducted; who was present; seating and positioning accommodations; the student's response); the results of the assessment (e.g., the student's behaviors); the recommendations (e.g., procedures for implementing and evaluating AAC use). Sample reports are provided together with a detailed description of the terminology to employ.

\section{Rationale and purpose of the study}

AT documentation practices may differ according to a number of variables. The organization, format and content of AT documentation may vary in relation to each local healthcare system and funding policies. Further, the writing process may be different according to the agency from which the report originates (e.g., AT centre, rehabilitation clinic, school). However, despite variances in AT documentation practices, this process is considered a fundamental aspect of any AT service delivery. For this reason, AT providers should be committed to ensure its quality regardless the peculiarities of the AT service delivery systems and models in which they operate. Increasingly, AT professionals are required to adopt evidence-based practices and in particular to evaluate quality with respect to all aspects of the AT service delivery process ${ }^{10,11,12}$. Despite several guidelines are available to AT professionals concerning what specific information should be reported in AT written recommendations, strategies as to how to ensure the quality of the AT documentation are lacking. 
Here we assume that having clear and well-structured methods for assuring the quality of the AT documentation produced by AT providers will improve the whole AT service delivery process and thus benefit all AT stakeholders. With this objective in mind, this study was undertaken to develop a methodology that would assure AT documentation quality in an objective manner. We define quality assurance applied to AT documentation as assessing the quality of the AT documentation produced by AT professionals involved in the AT service delivery targeting children, identifying shortcomings in the documentation process, and making related corrections. This study aims to provide AT professionals and other health and social work professionals involved in the AT service delivery process with a well-structured strategy for reviewing their AT documentation practices in order to improve the overall quality of the AT service delivery.

\section{Study context}

The current study was conducted at the Centre for Assistive Technology (CAT) in Bologna, Italy. The CAT operates as a public funded AT provider managed by a non-profit organization. Its interdisciplinary team works on behalf of the Local Health Authority in close collaboration with other public health services targeting children. Its catchment area covers the whole of Italy. The CAT service delivery process comprises of four phases (for a detailed description see ${ }^{13}$ ): (1) Activation; (2) Assessment; (3) Documentation; and, (4) Post-assessment. Briefly, the CAT service is activated ("Activation" phase) when a request is received from the child's family or a health or educational professional for an assessment in order to determine the most adequate assistive solution for the child in question. The CAT provides an assessment with respect to the following AT categories: access solutions (e.g., mechanical switches, alternative keyboards, joysticks, alternative mouse, eye trackers) for information and communication technology devices (e.g., computer) and toys (e.g., toys adaptations); educational software (e.g., software to create personalized activities such as "ClickerTM"); and, AAC aids (e.g., communication boards, speech generating devices). The CAT AT assessments are centre-based ("Assessment" phase). They are conducted in a customizable setting and last approximately half a working day. The assessment process involves an interdisciplinary team recruited from members of the CAT core team whose composition varies according to the characteristics of the user and includes, in some cases, professionals from other health services (e.g., child psychiatrist, neuropsychologist). A few days after the AT assessment, the CAT provides the child's family with a written report (the "Documentation" phase) detailing its recommendations which can be used by health and social service professionals to support an application for public funding. Once the AT stakeholders have obtained the recommended AT solution, the CAT may also be involved in supporting the correct implementation of the AT solution in the child's home or learning environment ("Post-assessment" phase). However, this last phase is available only for those users that come from the municipality of Bologna. The CAT core team has recently started an evaluation exercise reviewing the quality of each of the four stages in the CAT service delivery process. The present study focuses on assessing the quality of the Documentation phase. Since the CAT does not play an active role in purchasing the AT solution 
and stakeholder access to funding depends on recommendations in AT documentation, the quality of AT documentation is of vital importance. Moreover, AT documentation often represents a fundamental source of information for those who cannot benefit from the post-assessment service provided by the CAT at municipal level. For these users, who represent a significant portion of the users referred to the CAT service, the AT documentation represents an important guide for AT implementation and use. For these reasons, assuring the quality of the reports produced by the CAT core team may be of fundamental importance for the success of the whole AT service delivery process.

\section{Methodology}

\section{Participants and setting}

The current study was conducted by the members of the CAT core team (Figure 1) which includes eight AT professionals: three AT technicians, two physiotherapists with an additional specialization in occupational therapy (hereafter, PT/OT), one psychologist, and two social educators. AT reports are usually drawn up by integrating contributions from the AT professionals who have participated in the AT assessment process. During the assessment, each AT professional records observational data using specific instruments developed within the CAT service (for details about the instruments employed $\left.\operatorname{see}^{13}\right)$. At the end of the AT assessment, the AT team meets to discuss the case and the data collected by each team member is pooled, compared and assessed in order to arrive at agreement on the structure of the AT report that is to be provided to the AT stakeholders. Each professional then writes his/her own part of the report and sends it to the case manager (the social educator) who is responsible for integrating the different contributions into a single document. The resulting AT documentation is thus the work of one member of the AT team who attempts to integrate the contributions of professionals from different theoretical backgrounds. The aim of the AT documentation produced by the CAT is to provide the child, his/her family and other stakeholders with a summary of the rationale that guided the final AT decision, with a definition of objectives, as well as with information concerning AT acquisition and its implementation in the child's everyday environments. The methodology we developed for assuring the quality of the AT documentation produced in this way consisted in a five step procedure (see Figure 1). 


\begin{tabular}{|c|c|c|c|}
\hline \multicolumn{2}{|c|}{ Psychologist } & \multicolumn{2}{|c|}{ PT/OT/1 } \\
\hline \multicolumn{4}{|c|}{ Step 2 - Conceptualization of the scale } \\
\hline AT technician/1 & Social educator/1 & PT/OT/1 & $\begin{array}{l}\text { Psychologist } \\
\text { (coordinator) }\end{array}$ \\
\hline
\end{tabular}

\section{Step 3 - Validity (CAT core team discussion)}

CAT core team (psychologist as coordinator)

\begin{tabular}{ccccc}
\multicolumn{4}{c}{} & \\
\hline \multicolumn{4}{c}{ Step 3 } \\
\hline $\begin{array}{c}\text { AT } \\
\text { technician/1 }\end{array}$ & $\begin{array}{c}\text { Social } \\
\text { educator/1 }\end{array}$ & PT/OT/1 & PT/OT/2 & Psychologist \\
& & & & \\
\hline
\end{tabular}

Step 3 - Reliability (second pilot test)

\begin{tabular}{llll}
\hline AT technician/1 & Social educator/1 & PT/OT/1 & \\
\hline \multicolumn{3}{c}{ Step 4 - Documentation evaluation } \\
\hline Psychologist & PT/OT/1 \\
& & \\
\hline
\end{tabular}

Step 4 - Interpretation of results

CAT core team (psychologist as coordinator)

Figure 1. Schematic illustration of the steps for the development of the AT documentation quality assurance process and the members of the CAT core team involved in each step. The CAT core team is composed of: 3 AT technicians; 2 social educators; 2 PT/OT; and 1 psychologist. 


\section{Step 1. Literature overview}

For the purpose of the study, a tool for conducting a critical evaluation of the written documentation produced by the CAT was needed. The tool needed to be concise, easy to complete, and moreover usable in a busy clinical setting. We searched the MEDLINE database using the free PubMed search engine (last updated November 2013) for anything useful concerning evaluating quality of documentation related to AT service delivery. MeSH terms and free text words related to documentation in clinical settings were combined with MeSH terms and free text words related to the AT field. The search terms were combined by means of two Boolean logical operators (AND, OR) in order to reduce the number of non-pertinent results. The terms employed were: Medical Records/ standards; Medical Records/organization and administration; Documentation/standards; documentation; Delivery of Health Care; service delivery; Self-Help Devices; assistive technology; assistive device; Forms and Records Control; Process Assessment (Health Care); Health Care Quality, Access, and Evaluation; assessment; evaluation; appraisal.

In all, 995 results were found. We focused on studies describing models or AT service delivery practices. What the literature provided were studies describing different types of service delivery models ${ }^{14}$; conceptual service delivery models ${ }^{15,16}$; the development of service delivery models in different contexts ${ }^{17,18}$ and for specific AT solutions ${ }^{19,20}$. One study, performed in the context of wheelchair service delivery ${ }^{19}$ stresses the need to provide proper documentation to AT stakeholders in order to secure product approval. Importantly, the authors also point out that AT documentation is influenced by the quality of the assessment and selection processes. Since we could find no other information suitable for our purposes in the literature, we set out to develop an appropriate operational tool matching the prerequisites above.

\section{Step 2. Conceptualization and development of the scale}

The informativeness of the documentation was taken as an indicator of the quality of the documentation provided to AT stakeholders. We defined the informativeness of the documentation as the degree to which the documentation provided by the AT team satisfied service-specific review criteria. Review criteria "retrospectively assess care provided on a case-by-case basis to individuals or population of patients" ${ }^{21}$ (p. 358). An experience-driven (inductive) approach ${ }^{22}$ was employed in order to identify appropriate review criteria. Our first step was a discussion group which involved four members of the CAT core team (see figure 1, step 2). These front-line professionals, all working in interdisciplinary rehabilitation settings, were asked to describe what they do and to agree on what factors should be addressed in the AT documentation, and then to provide clear definitions for each factor. Each member of the group described his/her practices for producing the AT documentation and provided a description of the information to be reported in the documentation, in accordance with their field of expertise. The group coordinator then organized the information gathered so as to create a list of review criteria relevant to the assessment of the AT documentation produced by the CAT. The discussion group 
lasted approximately two hours and was coordinated by the principal investigator who also took part in the discussion. A previously published review article ${ }^{23}$ helped the discussion group to move beyond specifics and to formulate review criteria of more general significance. These were then incorporated into a scale for AT documentation evaluation.

\section{Step 3. Validation of the scale}

\section{Validity}

A second discussion group was conducted in order to assess the face and content validity of the first draft of the scale. Face validity is defined as the items or questions in the instrument that appear to be measuring what the instrument is supposed to measure ${ }^{24}$, while content validity is defined as having enough items to cover the domains under investigation ${ }^{24}$. The CAT core team took part in the discussion group. In this discussion group, a consensus-driven method was used. The discussion was guided by open-ended questions asked by the coordinator in order to trigger discussion of three main topics: (i) concerning the attitudes of the CAT operators towards the criteria identified; (ii) the wording and definition of the criteria; and, (iii) the number of criteria. Discussion continued until consensus was reached i.e. until there were no significant disagreements about the topics under discussion.

\section{Reliability}

To ensure the reproducibility of the scale scores among reviewers, the scale was pilot-tested in two rounds (see Figure 1). In the first round, five raters with different expertise scored 20 reports each; while in the second round four raters scored 10 further reports. Between the first and second rounds, the reviewers who participated in the first pilot test met to discuss the results and proposed changes to the scale in order to improve its reliability. The second round of pilot testing was conducted after having $a$ ) reduced the number of items; $b$ ) clarified the definitions of each criterion; and $c$ ) reached agreement between reviewers on the scoring for each criterion. Agreement between reviewers was employed as a measure of reliability. Weighted kappas were calculated criterion by criterion while intraclass correlation coefficients [ICC $(2,1)]$ using an absolute agreement definition were calculated for the total (summed) scale scores. Kappa statistics were interpreted as recommended by Landis \& $\mathrm{Koch}^{25}$ : kappa values greater than .80 were considered almost perfect, .61-.80 substantial, .41-.60 moderate, .21-.40 fair and <.20 poor. ICC results were interpreted according to the guidelines proposed by Fleiss ${ }^{24}$ with ICC values of $>.75, .40-.75$ and $<.40$ taken as corresponding respectively to 'excellent', 'fair to good' and 'poor'. The scale was considered reliable if all the kappas fell into the range of .40-.60, and into an ICC above .75 (single measures) for the summed score. 


\section{Step 4. Documentation evaluation}

\section{Sample selection}

The documentation comprised of reports on children who: (i) were assessed by the CAT team in the period 2004-2011; and, (ii) were under 18 at the time of the consultation.

\section{Documentation evaluation procedure and data analysis}

Once the final version of the scale was ready, two members of the AT service who had not participated in the writing of the documentation but who had taken part in the development of the scale (see Figure 1) independently scored the total documentation. Weighted kappas and ICCs were calculated using MedCalc 12.4.026 software. The results were analyzed by the first author of the present study who took part in both the pilot-testing of the scale and the whole documentation evaluation.

\section{Scale scoring procedure}

Reviewers were requested to rate the extent to which reports satisfied the review criteria on a 5 -point scale ranging from not at all $($ score $=1)$ to little $($ score $=2)$ to a lot $($ score $=4)$ or maximal (score $=5)$, with an intermediate level of acceptable (score $=3$ ). Descriptors were developed for scores 1, 3 and 5 in order to guide the raters. Scores below the acceptable level were taken to indicate that the documentation reviewed did not satisfy the review criterion.

\section{Step 5. Interpretation of results}

Two indicators of AT documentation quality were employed. The overall quality of the AT documentation reviewed was calculated by adding the ratings of the review criteria divided by the total number of the criteria. The overall quality score thus obtained ranged from 1.0 to 5.0 , with a score 3.0 indicating the lowest acceptable level. The percentage of reports scoring below the acceptable level was calculated. We decided in advance that an average score of (at least) 3.0 in more than $75 \%$ of the reports reviewed was necessary in order for the documentation to be deemed acceptable. This threshold was chosen as it represents a widely used measure of accuracy in the scientific literature (see for example ${ }^{27}$ ). According to this threshold, if more than $25 \%$ of the reports reviewed scored below the acceptable level $(<3.0)$, the overall quality of the documentation should be considered unsatisfactory.

The second method we used to interpret the results was to perform a criterion-by-criterion analysis, which enabled the CAT core team to identify those criteria where improvement should be made in order to improve the overall quality of the documentation. In order to do this we calculated score frequency distributions for each review criterion. The same threshold was adopted as for the measure of overall quality, whereby if more than $25 \%$ of the reports reviewed scored below the acceptable level (scores $<3$ ) in any of the criteria identified, it meant that the criterion was not satisfied. 
The results of the documentation evaluation were then discussed during a final discussion group involving the CAT core team. The group proposed operative solutions for instances in which the documentation failed to meet the review criteria and drew up a standardized form for AT documentation that attempted to remedy previous shortcomings.

\section{Results}

\section{Pilot-testing and final version of the scale}

The results of the first round yielded low to moderate weighted kappa values for each item while ICC $=.717$ (95\% CI: .54-.86). In the second round, agreement between raters improved with moderate to substantial weighted Kappa values while ICC $=.82$ (95\% CI:.63-.94). Validated by these results, the final version of the scale consisted in ten review criteria (see Appendix 1).

\section{Final documentation evaluation}

In all, 157 reports were retrieved from the CAT database. Twenty-seven reports were discarded because of incomplete information (e.g., where there was no record of those involved in the AT assessment; $n=7$ ) or because they were only a synthesis of the assessment written for internal communications $(\mathrm{n}=20)$ and never sent to AT stakeholders. The final documentation appraisal was conducted on 130 reports. The scoring took about twenty minutes for each report reviewed. The characteristics of the sample reviewed are described in Table 1. As shown in Table 2, agreement between the two raters confirmed the reliability of the scale with weighted kappa values ranging from .43 to .8 and ICC= .9 (95\% CI: .64-.95). 
Table 1. Characteristics of the users in the AT documentation reviewed

\begin{tabular}{|c|c|c|}
\hline Variables & Value (SD) & $\%(n=130)$ \\
\hline Age & $10.2(4.2)$ & - \\
\hline \multicolumn{3}{|l|}{ Gender } \\
\hline Males & 49 & 38 \\
\hline Females & 81 & 62 \\
\hline \multicolumn{3}{|l|}{ Diagnosis } \\
\hline \multicolumn{3}{|l|}{ Cerebral Palsy } \\
\hline Hemiplegia & 3 & 2 \\
\hline Diplegia & 7 & 5 \\
\hline Diskinetic & 4 & 3 \\
\hline Tetraplegia & 55 & 43 \\
\hline Other not specified & 16 & 13 \\
\hline \multicolumn{3}{|l|}{ Muscular Dystrophy } \\
\hline Duchenne & 8 & 6 \\
\hline \multicolumn{3}{|l|}{ Other } \\
\hline SMA & 3 & 2 \\
\hline PDD & 2 & 1.5 \\
\hline Other not specified & 32 & 24.5 \\
\hline \multicolumn{3}{|l|}{ AT solutions recommended* } \\
\hline $\begin{array}{l}\text { Solutions for communica- } \\
\text { tion }\end{array}$ & 59 & - \\
\hline Access solutions for PC & 63 & - \\
\hline Adapted toys & 10 & - \\
\hline Technical support & 40 & - \\
\hline
\end{tabular}

* The sum is larger than the number of the documentation reviewed because commonly the users have more than one objective for AT assessment; Abbreviations: SD, standard deviation; SMA, Spinal muscular atrophy; PDD, Pervasive Developmental Disorder. 


\section{Overall documentation quality}

An overall quality score was calculated for each rater. With a mean score of 2.9 for rater 1 and 3.1 for rater 2, the overall quality of AT documentation appeared to lie in the middle of the scale. The percentage of reports below the satisfactory level were respectively $45.3 \%$ and $36 \%$ for rater 1 and rater 2 (see Figure 2). These results showed that the percentage of reports scoring less than 3.0 exceeded the threshold of $25 \%$ and that hence that the overall quality of the documentation reviewed had to be deemed unsatisfactory.

\section{Criterion-by-criterion analysis}

On examining the review criteria in detail it was found that half of them were not satisfied (see Figure 2). Table 3 shows the frequency distribution of scores for each reviewer, while Figure 2 shows the distribution of scores below the satisfactory level for each criterion. Evaluation of child's body functions and abilities (functional assessment) was rated as being below the satisfactory level in $50.7 \%$ of the reports by rater 1 and in $49.2 \%$ of the reports by rater 2; Environmental factors for implementation was rated below the satisfactory level in $36.1 \%$ of the reports by rater 1 and $37.6 \%$ by rater 2; Goal setting was rated below the satisfactory level by rater 1 in $27.6 \%$ of the reports; Information was rated below the satisfactory level in $72.2 \%$ of the reports by rater 1 and $82.3 \%$ of the reports by rater 2; and Monitoring was rated below the satisfactory level in $66.1 \%$ of the reports by rater 1 and $53.7 \%$ by rater 2 . 
Table 2. Review criteria and weighted kappas

\begin{tabular}{lll}
\hline & Review criteria & Weighted kappa (95\% CI) \\
\hline First version of the scale & Final version of the scale & \\
Interdisciplinary approach & Interdisciplinary ap-proach & $.7(.6-.7)$ \\
User-centeredness & User-centeredness & $.4(.3-.5)$ \\
Initial request & Initial request & $.7(.6-.8)$ \\
Functional assessment & Functional assessment & $.8(.7-.8)$ \\
Context analysis & Environmental factors & $.7(.7-.8)$ \\
Resources analysis & & \\
Solutions explored & Solutions explored & $.6(.5-.7)$ \\
Trials & & \\
Goals & Goal setting & $.7(.6-.7)$ \\
Availability & & $.6(.5-.6)$ \\
Implementation & Information & $.7(.6-.8)$ \\
Documentation & Monitoring & \\
Monitoring & Readability & \\
Readability & & \\
\hline
\end{tabular}




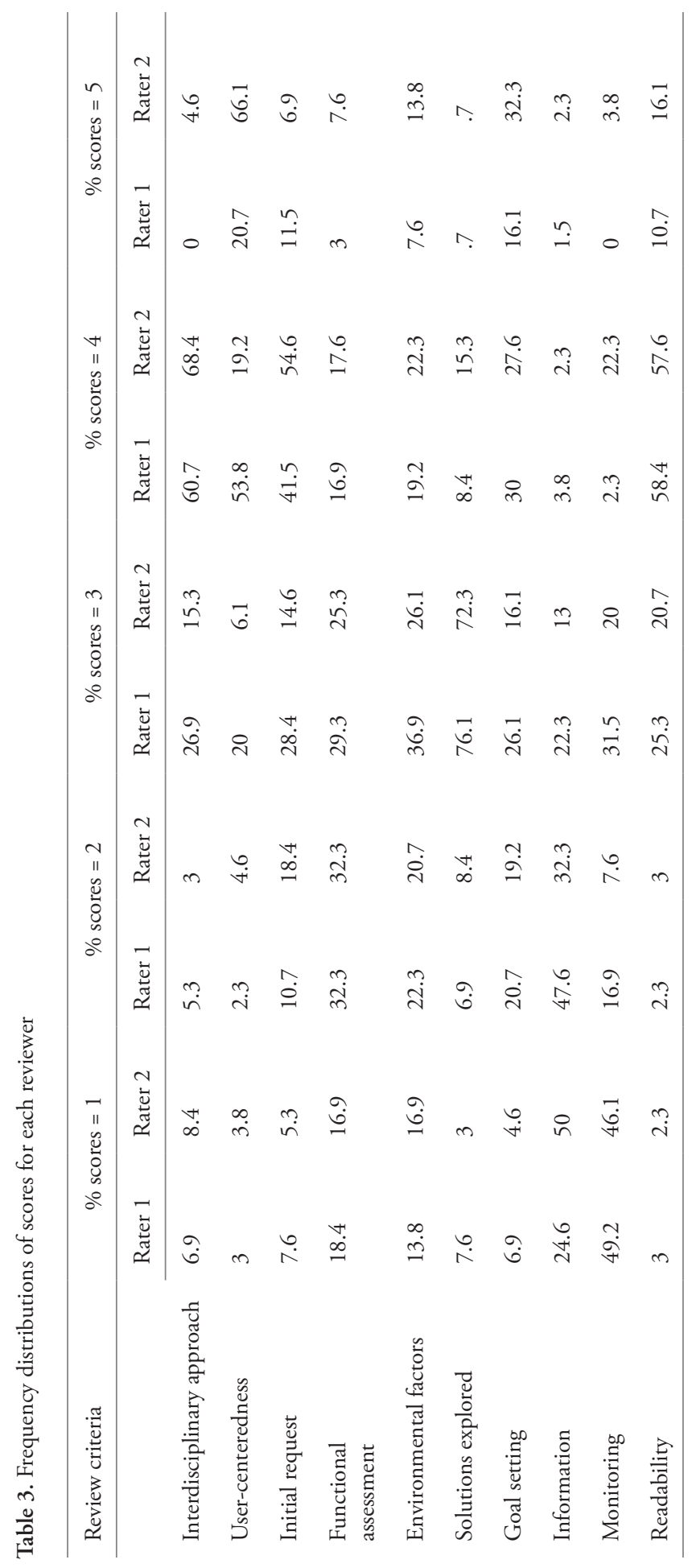




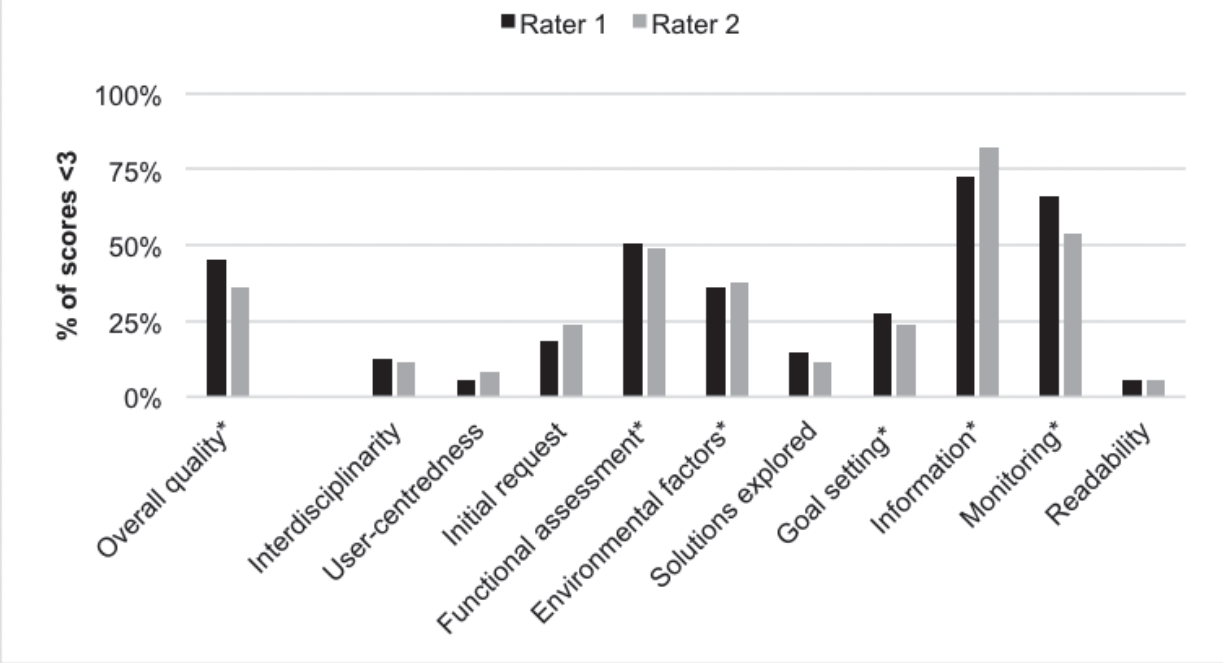

Figure 2. Frequencies of scores rated below the satisfactory level $(<3)$ by the two raters for the overall quality of the documentation reviewed and for each review criterion. The asterisks indicate the measures that exceeded the threshold set at $25 \%$.

\section{Conclusive discussion group}

The CAT core team met in two final discussion groups in order to consider the results of the documentation evaluation. Both lasted approximately three hours and sought to come up with strategies for improving documentation in the case of the five criteria that had not achieved a satisfactory rating. At the end of the second discussion group, the information collected during the review study and the strategies developed for improving the reporting of information in these cases were incorporated into a standard CAT form for AT documentation (see Appendix 2). A summary of the discussion about the criteria that yielded unsatisfactory results is presented below:

- Evaluation of child's body functions and abilities refers to all the activities performed by the interdisciplinary AT team in order to gain a global picture of the child's body functions and abilities before proposing any AT intervention. What emerged in the course of the discussion group was that the complex interaction of different disabilities which usually characterizes the children assessed for AT by the CAT team often makes it impossible to adopt validated strategies or instruments (especially when evaluating intellectual functioning ${ }^{28}$. The assessment is thus performed using clinical observations and this is reflected in the unstructured nature of the AT documentation and in variations in the terminology adopted. For these reasons, there is clearly a need to better identify which domains of the child's functioning are usually 
investigated by which members of the interdisciplinary team and to provide a shared terminology. To this end, we introduced terminology from the International Classification of Functioning - Children and Youth version ${ }^{29}$ both in the scale for AT documentation quality evaluation (Appendix 1) and in the standard CAT form for AT documentation (Appendix 2). This may help AT professionals not only in the writing of the AT documentation but also in the process of selecting or developing specific instruments for AT assessment. Environmental factors for AT implementation refers to the activities proposed by the CAT team to AT stakeholders for introducing the recommended AT solution in the child's context. The AT proposal requires a careful analysis of the environmental factors that could facilitate or obstruct the implementation of the AT solution. The AT solutions recommended by the CAT team are usually mainly used in the school settings. Since in Italy all students with disabilities, even those with severe or multiple disabilities, are included into the general educational system and are members of the same classes as other students, such things as the structure and composition of the class, the technological expertise of teachers and teachers' aides and their attitudes towards AT solutions represent environmental factors to be considered during the AT assessment. Only when information of this kind is available is it possible to develop effective and user-centred strategies to introduce the recommended AT solution into the child's context. Yet evaluation of the documentation revealed that in about $40 \%$ of the reports little attention had been paid in the reporting of such information. During the discussion group it was decided to report information about environmental factors collected during the AT assessment in a more systematic way in the AT documentation, and to link such information to specific courses of action to be undertaken when the child starts using the recommended AT solution.

- Information refers to the information provided to stakeholders about the AT solution. As defined in the scale presented in this study (see Appendix 1), this includes not only information about the technical aspects of the recommended AT solutions but also information about how to obtain funding for AT acquisition. Information of the latter kind was found to be inadequate in the AT documentation. This failing can be attributed, at least in part, to the fact that access to funding for AT solutions for communication and learning in Italy often depends on local policies (see for more information ${ }^{30}$ and it is difficult for AT professionals working in one region to be informed about procedures for obtaining funding in another. However, users would clearly benefit from having some basic information about funding and for this reason, after the present review study, the CAT team decided to include in the documentation references to resources which can help AT stakeholders find funding and orientate themselves in the AT acquisition process.

- Monitoring and Goal setting should be treated as distinct but related aspects of the same process. This study found that the documentation was inadequate when it came to both describing the goals for AT use, that is the descrip- 
tion of activities to perform with the technology, and outlining strategies for monitoring the AT provision process and its outcomes. These two aspects are related in so far as goal setting is a fundamental prerequisite for AT outcome evaluation. In most of the reports no mention was made of planned follow up or of outcome assessment. One reason for this is the fact that the CAT, like many other AT providers across Europe (Association for the Advancement of Assistive Technology in Europe ${ }^{31}$, is part of a complex AT service delivery system, and the responsibility for the evaluation of the AT intervention is shared with other health and school professionals and services involved in the child's care. This complex situation makes it difficult for AT professionals to monitor the state and consequences of AT provision and use. However, one way to overcome this problem is to start using shared instruments for the assessment of AT outcomes which could lead to better coordination between the different professionals involved in the AT service delivery process. For the purposes of the CAT service, it has been decided to employ the Individual Prioritized Problem Assessment scale ${ }^{32}$ (IPPA) at the end of every AT assessment conducted by the CAT team. This tool is particularly suitable for our purposes in that it is AT specific and it is designed as a pre- and post-assessment tool which investigates the user's perception of reduced difficulties in the performance of self-identified activities. A detailed description of the procedure for IPPA administration and scoring is provided by Wessels ${ }^{32}$. For the scope of the present study it is important to note the use of the IPPA questionnaire during the AT assessment. The user (the child or the child's family) is asked to list up to seven problematic activities and to rate each of them on a 1-5 scale both in relation to the importance of the problem and in relation to the difficulty of performing the related activity. The problematic activities listed by the user can be then considered the goals of the AT intervention. By using IPPA, the CAT team is able to define and document specific goals, and to identify expected outcomes for AT use and plan the next follow up together with users.

\section{Discussion}

This study focused on assuring the quality of AT documentation. The rationale behind the study is that the provision of concise but informative and readable documentation to AT stakeholders is a fundamental aspect of the AT provision process and has a positive impact on the quality of AT service delivery. Though AT documentation is recognized as an important component of the AT service delivery process ${ }^{6}$, no instruments or strategies were available to AT professionals that would enable them to critically assess the quality of the AT documentation. In this study, we attempted to fill this research gap by developing and applying a systematic methodology for objectively assessing the quality of the AT documentation, identifying shortcomings in the documentation process and making corrections.

In order to evaluate the documentation produced by the CAT, a scale for assessing the quality of the AT documentation produced was developed. The scale was composed 
of ten review criteria developed by a team of AT experts. The scale proved to be valid and reliable. After a brief training session, the raters achieved a good measure of agreement. Overall, results from the documentation review indicated that the reports produced by the CAT did not achieve a satisfactory level of quality. In particular, five of the ten criteria were unmet. In the final discussion groups in which the results of the entire review process were discussed, members of the AT team proposed ways of remedying the information shortfall in these areas.

One important way of assuring the quality of health service providers is to develop systematic strategies for reviewing the service delivery processes ${ }^{33,34}$. In this regard, the HEART study contained important recommendations for AT professionals and flagged up the need for AT service delivery systems: "[to] develop systems or procedures for self-correcting quality control of the process and the outcome. Procedures should be developed for each phase of the process as well as for the process as a whole"10 (p. 27). The methodology here developed will allow the CAT service to plan such procedures for AT documentation quality monitoring. Our scale for AT documentation quality evaluation represents a mode of internal monitoring and evaluation and will be used by the CAT team to periodically review the quality of the documentation produced. The new form for AT documentation has been already been incorporated into the CAT's practice. Further, this scale may be used also as a strategy for external quality monitoring. To this regard, the CAT team plans to ask to AT stakeholders, AT and health professionals not related to the CAT service to assess the quality of the documentation produced by the CAT with the methodology and the instrument developed in the present study.

The authors were aware of the limitations of the methodological approach of the study. The single case research design here employed, though providing in-depth information about the quality of the service under investigation, may limit the generalizability of this study to other AT providers working in different contexts and clinical settings. Further, we are aware that AT service provision varies broadly and occurs across a variety of service delivery systems and models. In this sense, the fact that this study was conducted in Italy may be seen as a limitation. In particular, the review criteria and the form for AT documentation developed in this study may only partially reflect the issues faced by AT professionals in other countries.

To overcome these issues, we invite AT professionals to follow the methodology starting from the step 2 in order either to develop their own AT documentation quality review process, or to adapt the scale for documentation quality evaluation and the form for AT documentation appended to this article to the peculiarities of their systems and models of AT service delivery.

Another possible application of the methodology developed here is that it may serve as a guide for AT professionals in the development of regional or national AT documentation guidelines from the bottom up. AT professionals from different services and systems may employ this methodology to compare and review their current practices, with the goal of developing a standard and shared form for AT documentation. Professionals from other related contexts (e.g., rehabilitation, schools, users' associations) could be included in this process as well. 


\section{Conclusions}

The increasing demand for data concerning AT service provision has obliged AT professionals to adopt evidence-based practices with respect to all aspects of the AT service delivery process ${ }^{10,11,12}$. This study has responded to growing demands for evidence and greater quality assurance by reporting on a strategy that focuses on AT documentation practices. This approach is intended to help AT professionals who work in interdisciplinary clinical settings to develop more effective practices for documenting AT assessment in order to both improve the communication between AT professionals and stakeholders and create a reliable source of information for linking the process of AT service delivery with AT outcomes. We invite AT researchers and professionals to consider this study a "bottom-up" contribution to stimulate international discussion about the importance of assuring the quality of AT documentation for the benefit of all AT stakeholders. 


\section{References}

1. Besio S. The counseling process in assistive technology evaluation and selection. In: Scherer M, ed. by. Assistive Technology: Matching device and consumer for successful rehabilitation. 1st ed. Washington, DC: American Psychological Association; 2002. p. 231-252.

2. Perlman L, Enders A. Rehabilitation Service Delivery: A Practical Guide. Washington, DC: RESNA; 1987.

3. Braaf S, Manias E, Riley R. The role of documents and documentation in communication failure across the perioperative pathway. A literature review. Int J Nurs Stud 2011, 48(8): 1024-1038.

4. Østensjø I. Assistive Devices for Children with Disabilities. In: Söderback I, editor. International Handbook of Occupational Therapy Interventions. New York: Springer; 2009. p. 141-146.

5. Bernd T, Van Der Pijl D, de Witte LP. Existing models and instruments for the selection of assistive tech-nology in rehabilitation practice. Scand J Occup Ther 2009, 16(3): 146-158.

6. Cook AM, Polgar JM. Essentials of Assistive Technologies. St. Louis, MO: Mosby; 2012.

7. Arledge S, Armstrong W, Babinec M, Dicianno BE, Digiovine C, Dyson-Hudson T, Pederson J, Piriano J, Plummer T, Rosen L, Schmeler M, Shea M, \& Stogner J. RESNA Wheelchair Service Provision Guide [in-ternet]. 2011. Available from from http://www.resna.org/dotAsset/22485.pdf

8. QIAT. Quality Indicators for Assessment of Assistive Technology Needs [internet]. 2012. Available from http://indicators.knowbility.org/docs/2\%20QIs\%20for\%20Assessment.pdf

9. Blischak DM, Ho KM. School-based Augmentative and Alternative Communication evaluation reports. Contemporary Issues in Communication Science and Disorders 2000, 27: 70-81.

10. HEART. European Service Delivery System in Rehabilitation Technology: A Comprehensive Description of Service Delivery Systems of 16 European Countries. HEART (Horizontal European Activities of Reha-bilitation Technology) Line C [Internet]. 1994 [cited 19 June 2015]. Available from: http://portale. siva.it/files/doc/library/a416_1_ATServiceDelivery_HEART_ReportC51.pdf

11. Lenker JA, Fuhrer MJ, Jutai JW, Demers L, Scherer MJ, DeRuyter F. Treatment theory, intervention spec-ification, and treatment fidelity in assistive technology outcomes research. Assistive Technology 2010, 22(3): 129-138.

12. Lenker JA, Shoemaker LL, Fuhrer MJ, Jutai JW, Demers L, Tan CH, DeRuyter F. Classification of assistive technology services: Implications for outcomes research. Technology and Disability 2012, 24(1):59-70.

13. Desideri L, Mingardi A, Stefanelli B, Tanzini D, Bitelli C, Roentgen U, de Witte L. Assessing children with multiple disabilities for assistive technology: A framework for quality assurance. Technology and Disa-bility 2013, 25(3): 159-166.

14. Adya M, Samant D, Scherer MJ, Killeen M, Morris MW. Assistive/rehabilitation technology, disability, and service delivery models. Cognitive Processing 2012, 13(1): 75-78.

15. Elsaesser LJ, Bauer SM. Provision of assistive technology services method (ATSM) according to evidence-based information and knowledge management. Disability \& Rehabilitation: Assistive Technolo-gy 2011, 6(5): 386-401.

16. Scherer MJ, Jutai J, Fuhrer M, Demers L, Deruyter F. A framework for modelling the selection of assis-tive technology devices (ATDs). Disability \& Rehabilitation: Assistive Technology 2007, 2(1): 1-8.

17. Craddock G, McCormack L. Delivering an AT service: a client-focused, social and participatory service delivery model in assistive technology in Ireland. Disability \& Rehabilitation 2002, 24(1-3), 160-170.

18. Ripat J, Booth A. Characteristics of assistive technology service delivery models: stakeholder perspec-tives and preferences. Disability \& Rehabilitation 2005, 27(24), 1461-1470.

19. Eggers SL, Myaskovsky L, Burkitt KH, Tolerico M, Switzer GE, Fine MJ, Boninger ML. A preliminary model of wheelchair service delivery. Arch Phys Med Rehab 2009, 90(6): 1030-1038.

20. Greer N, Brasure M, Wilt TJ. Wheeled mobility (wheelchair) service delivery: scope of the evidence. Ann Intern Med 2012, 156(2), 141-146.

21. Campbell S, Braspenning J, Hutchinson A, Marshall M. Research methods used in developing and apply-ing quality indicators in primary care. Qual Saf Health Care 2002, 11(4): 358-364.

22. Dejong G, Horn SD, Gassaway JA, Slavin MD, Dijkers MP. Toward a taxonomy of rehabilitation interven-tions: using an inductive approach to examine the "black box" of rehabilitation. Arch Phys Med Rehab 2004, 85(4): 678-686. 
23. Desideri L, Roentgen U, Hoogerwerf EJ, de Witte L. Recommending assistive technology (AT) for children with multiple disabilities: A systematic review and qualitative synthesis of models and instruments for AT professionals. Technology and Disability 2013, 25(1): 3-13.

24. Streiner D, Norman G. Health Measurement Scales.4th edition. London, UK: Oxford University Press; 2008.

25. Landis JR, Koch GG. The measurement of observer agreement for categorical data. Biometrics 1977, 33(1): 59-174.

26. MedCalc Statistical Software. MedCalc Software bvba; 2013.

27. Demers L, Weiss-Lambrou R, Ska B. Quebec User Evaluation of Satisfaction with Assistive Technology: QUEST version 2.0 [Internet]. 2000 [cited 24 June 2015]. Available from: http://www.midss.org/sites/ default/files/questmanual_final_electronic20version_0.pdf

28. Stachowiak JR, Mayo JL, Levine SP, Hilker DH. The Role of Assistive Technology in Cognitive Testing of Students with Severe Disabilities [internet]. 2004. Available from: http://resna.org/conference/proceedings/2004/Papers/Research/OTH/CognitiveTesting.html

29. WHO. International Classification of Functioning, Disability, and Health: Children and Youth. Geneva: World Health Organization; 2001.

30. Research on the provision of Assistive Technology in Ireland and other countries to support independ-ent living across the life cycle [Internet]. 2012 [cited January 2013]. Available from: http://www.nda.ie/ cntmgmtnew.nsf/0/797AD755B56A82A580257A4D0031A2B6?OpenDocument

31. Association for the Advancement of Assistive Technology in Europe (AAATE). Service Delivery Systems for Assistive Technology in Europe: Position Paper [Internet]. 2012 [cited 19 June 2015]. Available from: http://www.aaate.net/sites/default/files/ATServiceDelivery_PositionPaper.pdf

32. Wessels R, Persson J, Lorentsen $\varnothing$, Andrich R, Ferrario M, Oortwijn W, Van Beekum T, Brodin H, de Wit-te L. IPPA: Individually prioritised problem assessment. Technology and Disability 2002, 14(3): 141-145.

33. Bengoa R, Kawar R, Key P, Leatherman S, Massoud R, Sturno P. Quality of Care: A Process for Making Strategic Choices in Health Systems [internet]. 2006. Available from http://www.who.int/management/ quality/assurance/QualityCare_B.Def.pdf.

34. Donabedian A. An introduction to quality assurance in health care. New York: Oxford University Press; 2003. 


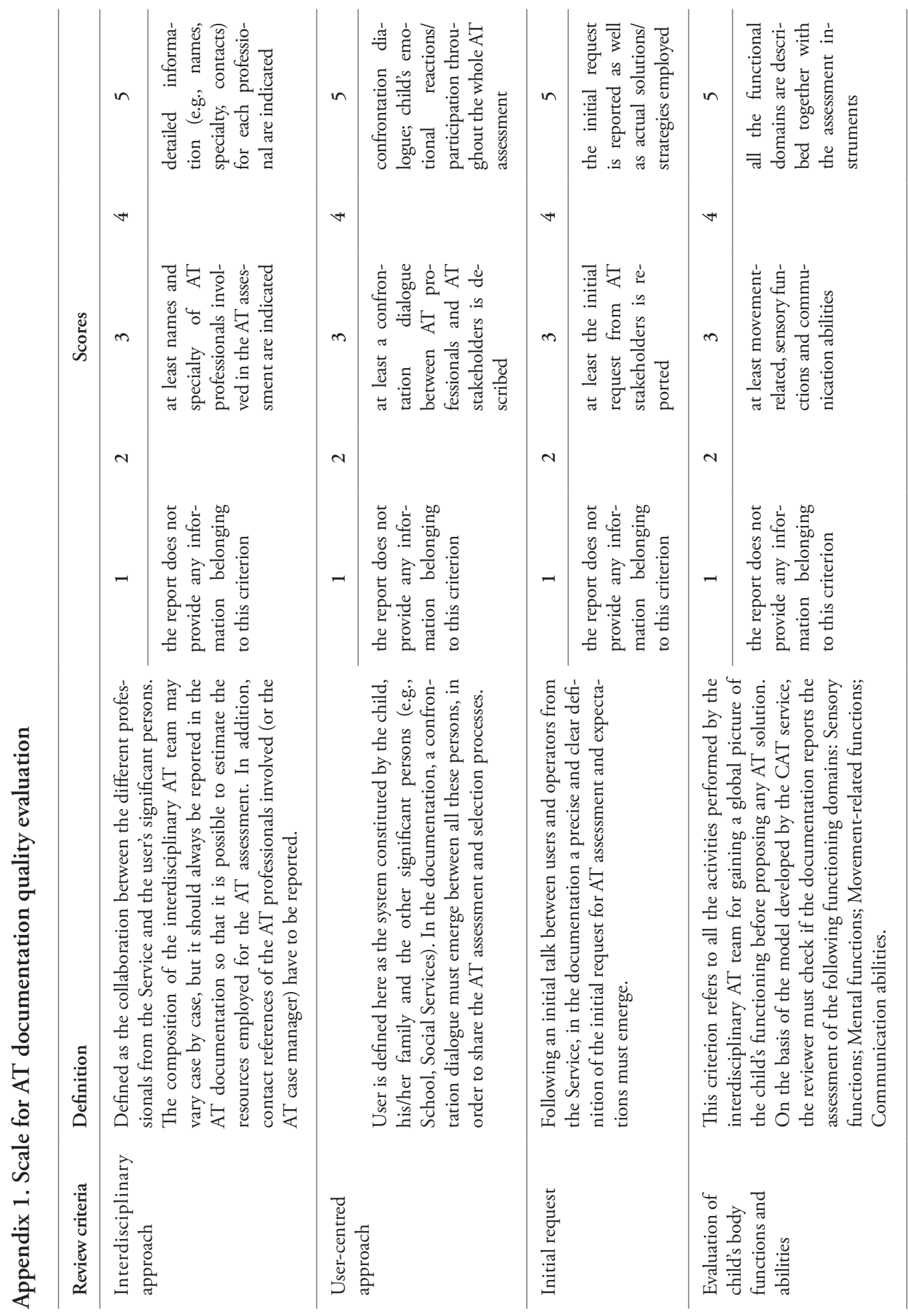




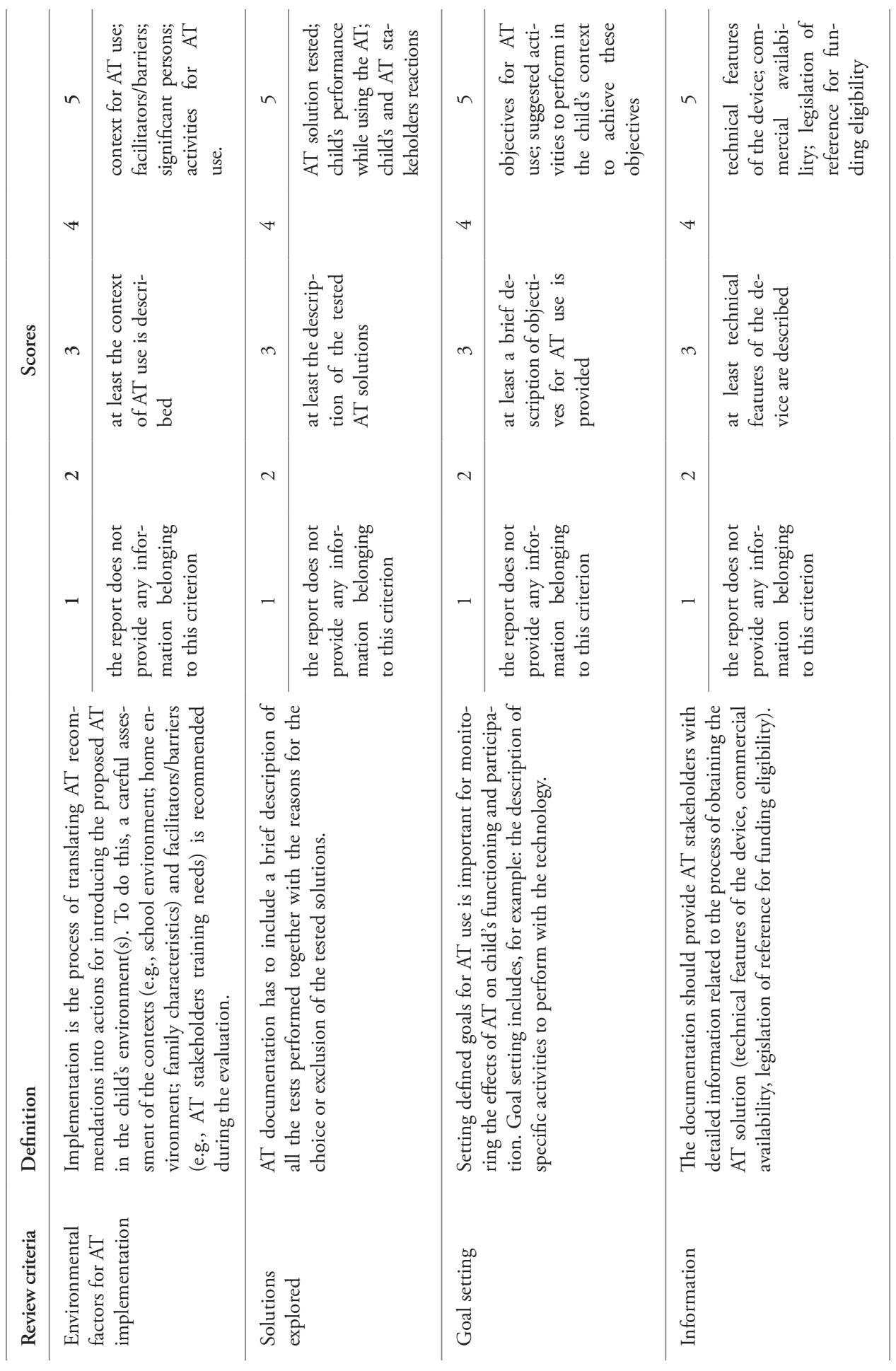




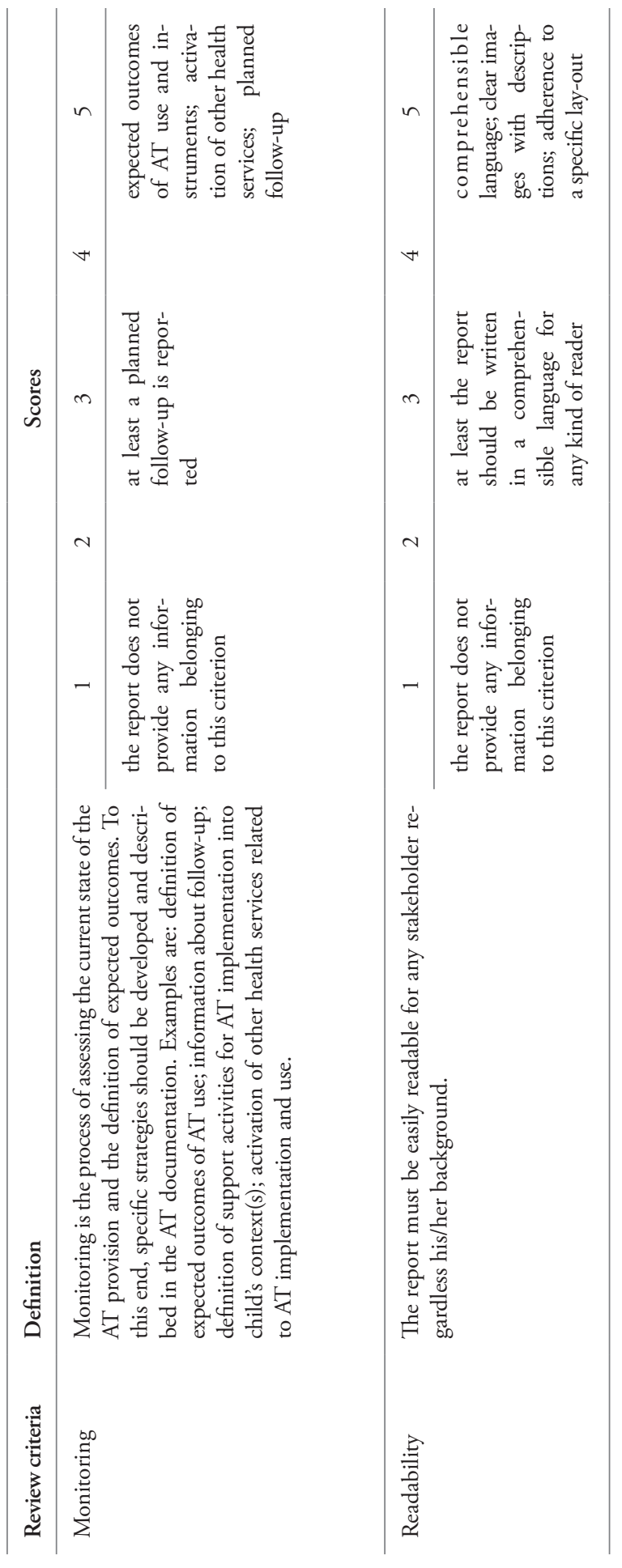




\section{Appendix 2. Standard CAT form for AT documentation}

The criteria developed in the scale illustrated in Appendix 1 were implemented in the standardized form for AT documentation of the CAT service. The table below illustrates the order of the different sections composing the AT documentation and the content required for each section.

\begin{tabular}{|c|c|}
\hline Report section & Section content* \\
\hline Access information & $\begin{array}{l}\text { Description of: } \\
\text { ASL** services activated for the consultation; pro- } \\
\text { fessionals and other people participat-ing at the } \\
\text { consultation; general child's information (e.g., age, } \\
\text { pathology, place of origin) }\end{array}$ \\
\hline \multirow[t]{2}{*}{ Definition of the request } & Description of: \\
\hline & $\begin{array}{l}\text { Child's and family life contexts; activities of daily } \\
\text { living; the child's, family and school past experien- } \\
\text { ce with AT; the child's interests; the child's, family's } \\
\text { and other stakeholders' mo-tives for AT use and } \\
\text { expectations }\end{array}$ \\
\hline \multirow[t]{2}{*}{ Preliminary observations } & Description of (observed/assessed): \\
\hline & $\begin{array}{l}\text { Movement-related functions, Mental Functions, } \\
\text { and Communication abilities*** }\end{array}$ \\
\hline \multirow[t]{2}{*}{ Synthesis of the AT trials and ob-servations } & Description of: \\
\hline & $\begin{array}{l}\text { The confrontation dialogue between operators and } \\
\text { any AT stakeholder; setting predispo-sition for AT } \\
\text { trial (e.g., workstation; room isolation); the AT } \\
\text { solutions proposed and trialed; identification of } \\
\text { the most consistent gesture, AT positioning and } \\
\text { workstation for the AT solution identified (inclu- } \\
\text { ding photos of the child interacting/using the AT } \\
\text { solution) }\end{array}$ \\
\hline \multirow[t]{2}{*}{ Proposed solutions } & Description of: \\
\hline & $\begin{array}{l}\text { the activities to perform for starting using the AT so- } \\
\text { lution proposed in different contexts (home, school, } \\
\text { other living contexts important for the child); The } \\
\text { expected goals for AT use (e.g., IPPA scale); evalua- } \\
\text { tions of AT stakeholders training needs }\end{array}$ \\
\hline \multirow[t]{2}{*}{ Conclusions } & Description of: \\
\hline & $\begin{array}{l}\text { the strategies and instruments for follow-up; pos- } \\
\text { sible proposals for any other specific as-sessment } \\
\text { (e.g., neuropsychological assessment or any other } \\
\text { service related to AT use); strategies for support the } \\
\text { AT implementation in child's contexts }\end{array}$ \\
\hline
\end{tabular}




\section{Report section}

Appendix 1

Appendix 2

\section{Section content*}

Summary list of the AT solutions proposed

Technical, commercial, basic legislative information, and any other information useful for the obtaining/implementation of the AT solution

Notes: * An example of a written report involving a 5 year old child from the municipality of Bologna is in appendix 3; ${ }^{* *}$ ASL, Local Health Authority; ${ }^{* *}$ Mobility-related functions include: Seating and positioning, gestures at the beginning of the consultation; Mental functions include: Sustained attention/distraibility, intentionality, situation awareness, comprehension of specific requests, emotional functions, non-verbal behaviors, cause-effect understanding, symbols/images discrimination; Communication includes: Repertoires of communicative functions, modalities/strategies employed for communicating with family/other caregivers (including use of AAC solutions). 


\title{
Appendix 3. Example of CAT report
}

\author{
Bologna, Italy, November \#\#\# \\ To the kind attention of Mr. and Mrs. \#\#\#
}

\section{Access Information}

On October \#, an evaluation on young C.G. was performed by our Centre, with the aim to identify gaming and communicational assistive technology (AT) devices. The request has been forwarded by physiotherapist E.D. On the user's side, the parents and the following operators were present: E. D., physiotherapist, S.C., speech therapist, A.P., teacher, S.S., teacher, I.V., learning support teacher and E.D., educator.

\section{Definition of the request}

C., 5 years old, comes to the evaluation with a diagnosis of dystonic quadriplegia. The objectives of the request are the access to toys, and the identification of communicational devices to utilize in different life contexts, in particular at school and at home where no assistive solutions are available. Her parents and operators report that $\mathrm{C}$. is well integrated in the classroom; she is highly motivated in engaging in communication activities with her peers and others significant persons (teachers and parents), but actually has no means of communication other than her gaze and grimaces. Currently, C. uses the posture-system "Abbraccio" ("Hug").

\section{Preliminary observations}

At the beginning of the assessment, C. was involved by the CAT operators in several communication activities in order to observe her communication strategies. She resulted motivated and responsive. C.'s communication resulted complex to interpret for the CAT operators. The "yes" and "no", "stop" and "again" are not yet consolidated. However, she is able to focus her look when she is asked where a familiar object or a known person is. The smile is sometimes contextual, she laughs in the presence of cheerful situations and communicates emotions in a showier way with her familiar persons. The binary choice is not always evident, but results more intelligible when she is proposed an alternative related to food. It is essential to motivate her, in order to involve her in the activities.

\section{Synthesis of the AT trials and observations}

The tests have been performed utilizing the posture-system in use by C. The observations took place in the assessment room of the CAT service. In a first trial, a pressure sensor of medium size was utilized to activate the toys, and was placed over the surface, 
on the left, and pushed with the left hand (Figure 1). In order to ease the toy activation, the sensor was placed on a sloping stand. Nevertheless, the difficulty in releasing the sensor remains. From this trial it was possible to ascertain that the concept of cause-effect was consolidated. In a second trial, the access site identified next was represented by a backhanded rotation movement of the head to activate the sensor (Figure 2). The sensor was fixed to a support arm, in correspondence to the left parietal region. The choice of the action, depending on the head, was determined by the necessity to identify an activation modality to be repeatable with the least possible reduction of accessory movements. In addition, the visual field functions (which appear to be appropriate, regarding both fixation and positioning) were more spendable while utilizing the head than while utilizing the left hand, which is often followed by a fall of the head.

With the activation of the sensor through the head, C. also started a toy train on a closed circuit. The pressure on the button had to be continuous, in order to keep the toy on, and the task was to stop on a specific point of the circuit, signaled by some objects. C. managed to find her own modality to make the toy advance (with pressure and short and repeated releases). The results were encouraging, but the toy was not interesting enough for C., to allow a more decisive test. We proposed a single message communicator. Acting on the aforementioned sensor, the child could play the following recorded phrase: "mom, give me a kiss!". The results were better than the previous tests, given the child's greater motivation. By activating the communicator, C. anticipated the mother's action by looking in her direction and waiting for her mom's kiss.

Finally, we performed tests on the identification of images through a selection by the look: utilizing two big pictures, the verbal request was to look at the flowers or the apple; C. tended to distract herself (the context was not optimal), but after a stronger solicitation she pointed at the requested images with discreet ability, even if through a very fast and little persistent glance. With smaller images $(4 \times 4 \mathrm{~cm})$ the result was similar, as well as with simple PCS symbols of the same dimensions.

Proposed solutions

The following modifications were considered useful to optimize the postural control and the functional action, avoiding the loss of spatial relation:

- $\quad$ to fix the pelvic belt (by sowing some velcro);

- $\quad$ to fix the seat corner;

- during the sensor activation, C. showed hyperactivation with the setting of extensor hypertonus, it is thus necessary to guarantee an appropriate control of the pelvis, to be also verified in the postural system in use at school.

Overall, C. showed to have good competences regarding the concept of direct operational causality, and good working perspectives for what concerns waiting times, observance of turns and of rules, but it is important to support the child's motivation with activities and with the involvement of well-accepted persons. It is necessary to identify cause-effect activities, exploiting the resources offered by a single message communicator (very appreciated by the child) and with modified toys, which should utilize, for the activation, a pressure sensor fixed to a support arm, as described in the tests. Toys must 

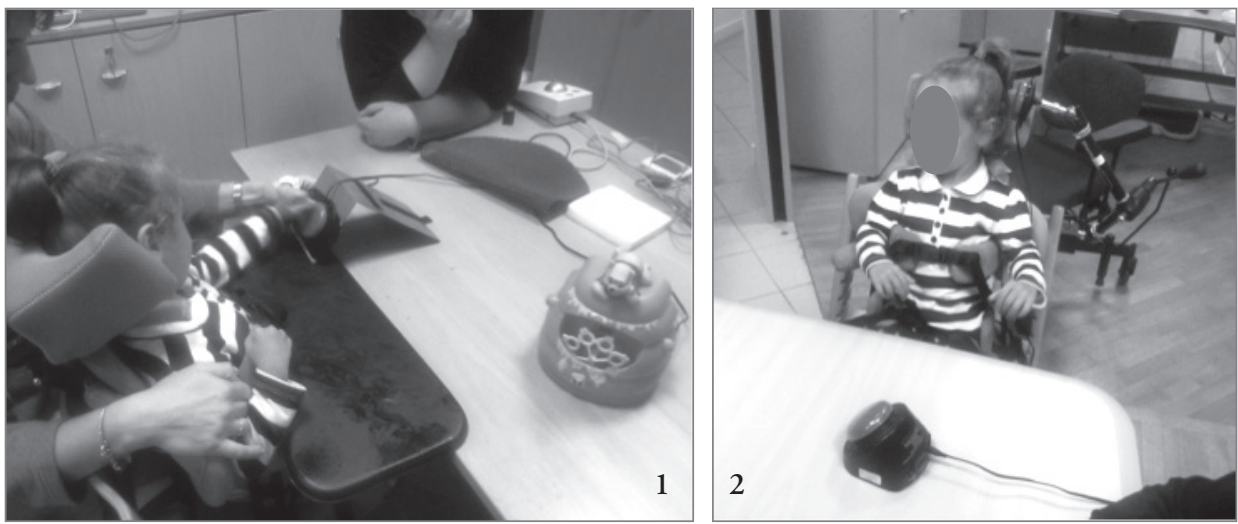

Figure 1. Access to switch by hand.

Figure 2. Positioning of the switch activated by head movements.

be identified according to C.'s taste, but also to the possibility of creating motivating situations, possibly involving her playmates. During the tests for the images identification, which took place at the end of the morning, C. looked rather tired. The verification should be repeated in a time of lesser fatigue. In order to monitor the effective use of the proposed assistive solution, at the end of the assessment the IPPA interview was administered to C.'s mother. Two main objectives for AT use were identified:

- $\quad$ to increase C.'s autonomy in gaming activities;

- to improve C.'s abilities to communicate with peers and adults in different life situations.

\section{Conclusions}

Support from CAT operators for implementing the proposed assistive solutions in C.'s contexts is available once the solution will be available (see Appendix 2 for list of companies and other information related to AT acquisition [not included in this sample report]). Our service will contact the operators of reference for a first appointment. In this occasion, a follow-up strategy for the evaluation of the effectiveness of the assistive solution will be planned.

Best regards,

D.T.

(Social educator) contact person:

name@usilioteca.org
A.M.

(IT Technician)
A.C

Child psychiatrist
A. G.

Physiotherapist 


\section{Appendix 1. List of proposed solutions}

- Middle-sized pressure sensor (models such as "Jelly Bean" or "Buddy Button" result appropriate).

- Support arm for sensor, model "Magic Arm", with a fixing plate appropriate to the chosen sensor.

- $\quad$ Single message communicator with sequential functions (models such as "Step by Step" or "Helpitalker" result appropriate).

- $\quad$ Already modified toys such as bubble gun, toy train (which can be found in the list of companies in Appendix 2 [not included in this sample report]), or commercial toys to be modified. 

Chapter 5

Satisfaction of users with assistive technology service delivery: An exploratory analysis of experiences of parents of children with physical and multiple disabilities

This Chapter was accepted by Developmental Neurorehabilitation as: Desideri, L., Stefanelli, B., Bitelli, C., Roentgen, U., Gelderblom, G-J., de Witte, L. Satisfaction of users with assistive technology service delivery: an exploratory analysis of experiences of parents of children with physical and multiple disabilities. 


\begin{abstract}
Objective: To describe experience of assistive technology service delivery (ATSD) by parents of children with physical or multiple disabilities (aged 3-18 years). Method: Forty-seven of 115 parents participated in a postal survey assessing satisfaction with the ATSD process, employing the QUEST 2.0 and the KWAZO scales. Six of these participated in two focus groups. Descriptive statistics were used for satisfaction scores. The focus group transcripts were coded and combined with survey results by two independent researchers. Results: Low satisfaction scores were reported for follow-up, AT delivery, maintenance services, access to services, coordination, and efficiency of ATSD. Several barriers to and facilitators of ATSD were mentioned and solutions to improve ATSD quality were identified. Conclusion: Evaluation of parents' service experience is central for identifying shortcomings in ATSD. Health professionals are advised to utilize validated instruments and strategies to assess effectiveness of technological interventions and to assure ATSD quality.
\end{abstract}




\section{Introduction}

Child development is the result of reciprocal interactions between the child's maturational processes and the individual's active participation in the environment ${ }^{1}$. Children with cerebral palsy or other developmental disabilities may lack opportunities to participate in their social and physical environments ${ }^{2}$, a limitation that may hinder development of the child's skills and competences, social relationships, and mental and physical health ${ }^{2-4}$. Assistive technology (AT) represents environmental interventions aimed at promoting participation of children in order to foster their social, psychological and cognitive development ${ }^{3}$. AT is an umbrella term indicating any product or technology-based service that enables people of all ages with activity limitations to participate in their daily life, education, work or leisure ${ }^{5}$. AT solutions for children include both low-tech devices such as switches, adapted equipment and picture boards, and high-tech devices such as electronic communication devices, educational software, powered mobility and environmental controls ${ }^{6}$.

While the literature demonstrates that the employment of AT solutions can produce beneficial outcomes for children in terms of participation (for a review see ${ }^{7}$ ) and cognitive and communication development ${ }^{8-10}$, the use of this type of technology is not always successful ${ }^{11,12}$. Frequently, unsuccessful outcomes are associated with abandonment of AT solutions or inadequate adaptation to the child's situation and routines ${ }^{11,13}$, failings which are considered the consequence of ineffective AT service delivery (hereafter ATSD) ${ }^{11-16}$.

ATSD is defined as 'the complexity of processes that act as an intermediate between the needs of an individual with a disability or impairment and existing resources and $[\ldots]$ assistive technology' (p.7 $)^{17}$. ATSD for children, in particular, is a complex process ${ }^{18}$ and a breakdown at any point might adversely affect benefits from the AT intervention ${ }^{11}$. ATSD organization and mechanisms vary broadly within and across countries and may vary in relation to disability policy, socio-economic context and history ${ }^{5}$, thus resulting in a variety of service delivery systems (e.g. private/public) and models ${ }^{19}$.

ATSD itself can be considered as a determinant of children's health. A recent study of children with cerebral palsy in six European countries documented considerable variation across the study regions, in the intensity and nature of the child's participation in daily activities and in children's social roles ${ }^{20}$. A substantial portion of this variation resulted from variation in state policies addressing the use of AT solutions among children ${ }^{21}$. In Italy, where the current study was conducted, AT solutions are provided through public funding, ATSD is organized at regional level and delivered primarily by centres for technical aid, where a team of experts, usually in collaboration with professionals from the Local Health Authority (Azienda Sanitaria Locale - ASL), conducts an assessment to match the person with a disability with the most appropriate AT solution ${ }^{22,23}$. From the available data, it is estimated that rates of AT non-use or abandonment in the Italian context mirror those in other Western countries, with approximately $25 \%$ to $37 \%$ of AT non-use ${ }^{23}$.

The first attempt to cope with this global issue at a European level dates back to the 1993-1994 period, when the Horizontal European Activities in Rehabilitation Technology (HEART) study was conducted ${ }^{17}$. Within HEART, which involved 12 countries, 
important recommendations for AT professionals were produced, including the need for ATSD systems to develop systematic strategies for reviewing the ATSD process. More recently, the outcomes of the HEART study were discussed and reviewed during a workshop organized by the Association for the Advancement of AT in Europe (AAATE) and the European AT Information Network (EASTIN) ${ }^{5}$. It was concluded that most of the recommendations and results of the HEART study are still valid today, while others were reformulated according to the present day context. These latter included, among others, the need to introduce quality assurance procedures for self-correcting quality control of the ATSD process 5 .

In this vein, the HEART study brought about two main contributions that may help AT professionals in the development of shared strategies for ATSD quality assurance. First, the study identified a series of common steps in any ATSD process (figure 1) which may be used to describe every ATSD system in Europe ${ }^{5,17}$. Second, in order to assess ATSD process quality, the HEART study identified six quality criteria that are still considered valid today ${ }^{5,17,24}$ : Accessibility, referring to information on ATSD-related service access (e.g. waiting times, ATSD process duration); Competence, referring to information on professionals' AT-related know-how (e.g. education of the professionals involved in the ATSD process, AT training offered); Coordination, referring to information on AT-related service integration (e.g. contact between the professionals involved in the ATSD process); Efficiency, referring to information on control of the ATSD process (e.g. complexity of procedures, availability of mechanisms able to control costs and process effectiveness); Flexibility, referring to information on ATSD-related service ability to respond to different user needs (e.g. use of a multidisciplinary approach); and, User influence, referring to information on user involvement (e.g. user presence at any stage of the ATSD process). Taken together, these contributions provide AT professionals with a common frame of reference in organizing an ATSD quality assurance process.

Increasingly, the involvement of stakeholders in health-care evaluation is considered as a judgment of quality ${ }^{25,26}$, and negative evaluations from stakeholders can be regarded as an indicator of a need for improvements $\mathrm{s}^{25}$. Key stakeholders in the ATSD process are those who play a significant role in the identification, prescription and use of the AT solution ${ }^{27}$; in the case of the ATSD process targeting children, these include several individuals other than the child him/herself. Although AT and health professionals have a main role in the identification and prescription of the AT solution, teachers and school support staff are mainly involved in AT solution use on a daily basis ${ }^{27}$. Parents, however, are those AT stakeholders that play a key role at any stage of the ATSD process ${ }^{28}$, and may represent an invaluable source of information for AT providers regarding the quality of the whole ATSD process ${ }^{29}$.

A growing number of studies have been conducted reporting on the impact on parents of AT solutions provided to children (for a review see and $^{30}$ ), and specific outcome measures focusing on the child's family caregivers have recently been developed ${ }^{31}$. Recent studies that have attempted to address parents' experience of the ATSD process include investigations conducted in the US ${ }^{32,33}$, Australia ${ }^{27,34}$, Israe ${ }^{135}$ and the $\mathrm{UK}^{36,37}$. However, to date no studies have been published concerning the Italian system and little is known about Italian parents' experience of the ATSD process. 
Thus, this study is aimed at contributing to the research knowledge base regarding the quality assessment of ATSD systems by exploring parent experience of the ATSD process in the Italian context. In more detail, the purpose of this study was to:

- $\quad$ explore the quality of the ATSD process as perceived by parents of children who are current users of AT solutions;

- $\quad$ understand the factors that may facilitate or hinder the ATSD process from a parent's perspective;

- $\quad$ identify the ATSD-related aspects in need of improvement.

\section{Methodology}

\section{Study design}

Given the exploratory nature of the study, a mixed methods research design was undertaken. Mixed methods research draws on the strengths of both qualitative and quantitative research design $s^{38}$. Two approaches were taken: quantitative followed by qualitative. A self-administered set of questionnaires was used in a postal survey in order to collect quantitative information about users' overall experience of the ATSD process. The results of the survey helped the researchers to gain quantitative data about users' perception of ATSD quality. Focus groups were then held for more detailed exploration of the barriers to and facilitators of the ATSD process as experienced by parents. The focus groups also served both to follow up survey results and to strengthen the conclusions drawn from the principal investigation ${ }^{39}$. From this standpoint, the data collected using the different research methods were complementary and formed a more complete and coherent picture of the parents' experience of the ATSD process ${ }^{39}$.

\section{Context for the research}

The current study was conducted by the Centre for Assistive Technology (CAT) in Italy, in the Emilia-Romagna region (E-R). The CAT operates as a public-funded AT provider managed by a non-profit organization in collaboration with professionals from the Local Health Authority (Azienda Sanitaria Locale - ASL; for a detailed description $\left.\operatorname{see}^{40,41}\right)$. Its catchment area covers the whole of Italy, but for the purposes of the present study we focused on users from E-R.

The conceptual model that guided the present study was derived from the Donabedian triadic model of quality of care ${ }^{40,42}$. This model encompasses three aspects of care: structure, process and outcomes. Its structure refers to attributes of the setting in which health care is delivered and received ${ }^{40}$. In the context of ATSD, the domains of structure include types of financing schemes, legislation, and school and health system regulations for obtaining and implementing AT devices ${ }^{42}$. The care process refers to what is actually done in the delivery and receipt of care ${ }^{40}$. In the ATSD context, the domains of process include the activities performed during the different ATSD stages ${ }^{17,42,43}$. Figure 1 sche- 
matically illustrates the contributions by the different stakeholders during any phase of the ATSD process considered in the present study. Lastly, outcomes are conceived as a consequence of care and may be directly or indirectly influenced by both ATSD structure and process ${ }^{40}$. The domain of outcomes within the ATSD process includes 1) child and family changes in activity/participation, and 2) user perception (e.g. satisfaction) of the AT solution as well as the ATSD process 5 . In the present study, we focused on ATSD outcomes in terms of parents' satisfaction with the ATSD process.

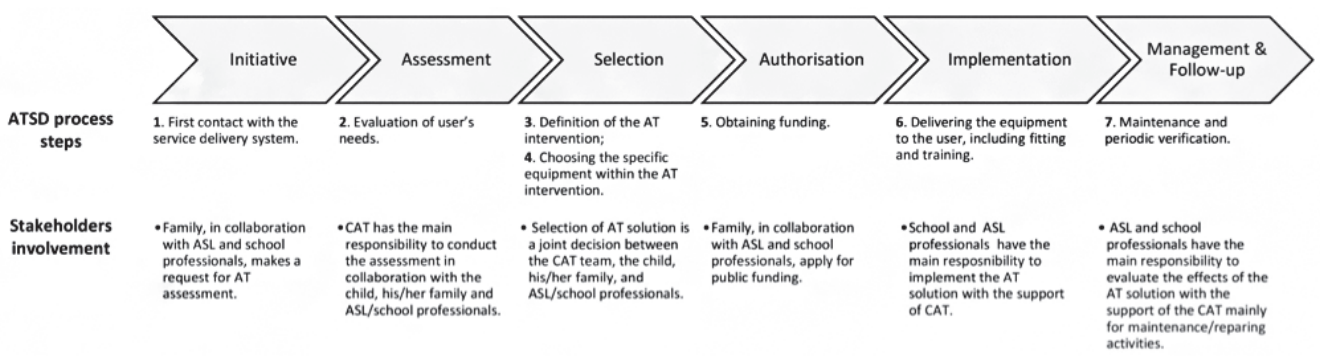

Figure 1. Steps in the AT service delivery process and stakeholders' involvement. CAT, Centre for Assistive Technology; ASL, Local Health Authority.

\section{Quantitative study}

\section{Participants and procedure}

Participants were identified from the CAT database. The database contains the demographic information (age, gender, date of birth, diagnosis, and nationality) of all the children who have had contact with the CAT service, and information on the AT recommendations provided. We selected database children aged between 3 and 18 years with diverse health conditions and diagnoses leading to physical or multiple disabilities, assessed by the CAT team during the 2007-2012 period and residing in the E- $\mathrm{R}$ region.

Parents were contacted by telephone in order to inform them of the purpose of this study. Interested parents were then given the opportunity to provide informed consent to participate. Participants could complete the survey either online or in its paper-based form. Participating parents were sent a personalized cover letter (or email) together with the survey and the instructions for its completion. A reminder was sent twice to non-respondents (once every two weeks after the first questionnaire was sent). This multimode approach was adopted in order to enhance representativeness and to increase response number ${ }^{44}$. It was emphasized during the preliminary telephone contact that participation was entirely voluntary. The study was carried out in accordance with the principles of the Declaration of Helsinki.

From the CAT database, a total of 115 children from the E-R region were eligible for inclusion in the survey. Seven users lacked contact information while 5 users refused to participate. In total, 103 out of 115 eligible users were contacted and agreed to participate. 
Questionnaires were returned by 49 respondents (42.6\%). Two questionnaires were completed without information about the respondents and were excluded from analysis. In all, questionnaires from 47 respondents were included, resulting in a response rate of $40.8 \%$. Respondents and non-respondents did not differ in terms of place of origin, nationality, geographical area, and age range. The characteristics of the sample included in the survey are illustrated in table 1.

\section{Survey design}

The survey was conducted from October 2012 to June 2013 (9 months) and consisted of a combination of forced choice and open-ended questions related to the child's background, ATSD process information and ATSD outcomes.

The background section included the child's place of origin (urban, intermediate, rural) and information on users' compliance with CAT recommendations. 'Urban' users were defined as those living in a town or city with more than 50,000 inhabitants; 'intermediate' users were defined as those living in a town with less than 50,000 inhabitants but close (less than $50 \mathrm{~km} / 31$ miles) to a larger town; and, 'rural' users were defined as those living in a town or village with less than 20,000 inhabitants and at a height of more than 500 metres $/ 1640 \mathrm{ft}$. Compliant users were defined as those who acquired and used the AT solution recommended by the CAT service ${ }^{45}$. Use of AT solution was self-identified by respondents. ATSD-related process information included 9 questions covering the ATSD process stages illustrated in figure 1: Initiative (question 1); Assessment and Selection (questions 2, 3 and 4); Authorization (questions 5, 6 and 7); and Implementation (questions 8 and 9). Yes/No questions (questions 2, 3, and 5) were followed by an open-ended question: "If yes, could you please specify?".

Information on parents' satisfaction with the ATSD process was assessed using the 'service' subscale of the Italian version of the QUEST 2.046 and the KWAZO ('Kwaliteit van Zorg'; 'Quality of Care') ${ }^{47}$ scale. The QUEST 2.0 consists of four items assessing different dimensions of the ATSD process (Service delivery; Maintenance and Repair services; Professional services; Follow-up services). The responder is invited to rate his/ her satisfaction on a 5 -point Likert scale ( $1=$ not satisfied at all; $5=$ very satisfied) and to write a comment to justify any rating below the score 5 .

Developed in the Netherlands, the KWAZO is composed of 7 questions each covering specific quality indicators of the ATSD process, mostly belonging to those identified by the HEART study (see appendix and47). The responder is requested to rate his/her degree of satisfaction with each indicator on a 3 -point Likert scale ( $1=$ 'insufficient'; $2=$ 'sufficient'; $3=$ 'good'). In our study, we utilized the Italian version of the KWAZO, which had been previously pilot-tested in the Italian context with a sample of parents of children with physical or multiple disabilities ${ }^{48}$. The scale was found to be valid and reliable with a Cronbach's alpha of 0.848 . 


\section{Quantitative data analysis}

Frequency distributions were used to describe the sample and the information related to the ATSD process. Survey response rate was calculated as the percentage of valid returned questionnaires among the eligible sample. To assess potential non-response error $^{50}$, Chi-square was used to test differences between respondents and non-respondents according to geographical area (urban, intermediate, rural), nationality (Italian, non-Italian), and age range (3-5 yr, 6-10 yr, 11-17 yr). Item-by-item analyses were conducted on the QUEST 2.0 and scores were grouped into two categories: 'Satisfied' (scores 4 and 5 combined) and 'Not fully satisfied' (scores 3, 2 and 1 combined). This method is recommended when the evaluator seeks to identify those areas where improvements should be made 51. As for the QUEST, in order to make the results from the two scales comparable, KWAZO scores were also grouped into two categories: 'Satisfied' (score 3) and 'Not fully satisfied' (scores 1 and 2 combined). For each item of both the QUEST 2.0 and KWAZO, a threshold of $33 \%$ was used ( $>33 \%$ of the respondents resulting 'Not fully satisfied'), as recommended by 1 for identifying those dimensions related to ATSD in need of improvement. Data were collected and organized using the software Microsoft Excel. Statistical analyses were conducted utilizing the software SPSS version 17.

\section{Qualitative study}

All the parents who completed the survey were invited to participate in the focus groups. In all, six parents from the survey cohort participated in two focus groups (November 2013). Table 3 provides information on group composition and participant characteristics. All the participants mentioned had been involved in every aspect of the ATSD process. Some stated that the recommended AT solution that involved them in the study was not currently in use due to changes in the child's needs. Focus groups were conducted by a trained psychologist who served as moderator, and one co-moderator (a social educator with over 20 years of experience in ATSD), who facilitated discussion, took notes and made audio recordings of the sessions. At the beginning of each focus group, the purpose of the study was explained and written informed consent was obtained. A semi-structured questioning route was used. This method was employed as it ensures consistency in questions asked across the groups while allowing for some flexibility in accordance with topics raised within the groups 49 . Questions were developed by the research team and reviewed by the members of the CAT for content validity and comprehensibility, and were primarily aimed at assessing barriers and facilitators affecting ATSD as perceived by the parents (see appendix). Groups ran for approximately 1.5 hours and were conducted in Italian.

\section{Qualitative data analysis}

The whole qualitative data set comprised focus group transcripts, answers to the survey's open-ended questions and comments in response to QUEST 2.0. In total, 11 answers to open-ended survey questions ( 1 in question 2, 1 in question 3, and 9 in 
question 5) and 7 comments regarding QUEST 2.0 items (3 in the 'maintenance' item and 4 in the 'follow-up' item) were collected. The moderator and co-moderator of the focus groups served as analysts of the qualitative data set. As a first step, the two analysts read in full the whole data set in order to comprehend the meaning of the data in their entirety ${ }^{52}$. Analysis began by using a line-by-line open coding technique ${ }^{53}$. Codes identify a feature of the data that appears interesting to the analyst, and is defined as 'the most basic segment, or element, of the row data or information that can be assessed in a meaningful way regarding the phenomenon' (p.88) ${ }^{54}$. The data set was read in full by one analyst (psychologist), who assigned a conceptual code to each segment of text related to either a barrier or a facilitator as experienced by the family caregivers during the ATSD process. During this phase, the analyst followed an inductive approach, which consists of reading the text and assigning the codes that reflect the emerging concepts without using a preconceived framework. This approach allowed the code structure to evolve 'inductively', thus reflecting the participants' experience ${ }^{52}$. A constant comparison of text segments assigned to the same codes was performed in order to refine dimensions of existing codes and identify new codes. As more data were reviewed, the specifications of codes were developed and refined to fit the data. The involvement of one analyst is considered sufficient during this phase of text analysis. Once the qualitative data set was coded line by line and the codes were saturated, the principal analyst met with the second analyst to discuss the emerged codes. Each code was reviewed and any alternative interpretation was discussed until consensus was achieved. The qualitative analyses were conducted utilizing the software ATLAS.ti version 7 (http://www.atlasti.com).

\section{Data triangulation}

Integration between the quantitative and qualitative data sets was performed during a second step in qualitative analysis. During this phase, the QUEST 2.0 and KWAZO questionnaire items served as pre-defined categories for grouping the codes emerged. The two analysts independently linked the barriers and facilitators emerging in the previous phase to the items of the two questionnaires in order to achieve a better understanding of the users' experience and opinions. As an example of this process, the following is a quote from one parent during the first focus group and was coded in the previous step as a barrier to ATSD:

'Everything [needs to be] monitored... just like at the beginning of a job. If you load a software on a computer, then you should check if the child uses it or not, if it's appropriate, if it's still going to be appropriate after a year, or forever, or for all the years of primary and secondary school. ... How can you not monitor how it worked out?'

Due to its reference to the monitoring activities after implementation of the AT solution in the classroom, the quote was grouped as belonging to the QUEST 2.0 item concerning follow-up activities. The QUEST 2.0 and KWAZO questionnaire items uti- 
lized as grouping categories were sufficient for grouping all the codes produced from the transcripts in the first step and there was no need to create new categories.

During this step, the two analysts met several times in order to match their results and to refine the barriers and facilitators assigned to each item. The involvement of two independent analysts was introduced to assure result reliability and credibility.

\section{Results}

\section{Participants' characteristics}

As illustrated in table 1, most of the families had been recommended with more than one AT solution. In total, 35 users $(74 \%)$ were compliant with the CAT recommendations, including those who both acquired the AT solution and currently use it (57\%), and those who no longer use it due to a change in the child's needs (17\%). Notably, most of the respondents used the web-based response method (72\%). There were strong links between the Local Health Authority (ASL) and the CAT service for the initial phase, with the majority of the participants (74\%) having activated the CAT through a request made by the ASL professionals. Few respondents reported any problem in the activation of the CAT $(13 \%)$ or the AT assessment phases (11\%), and most found the documentation provided by the CAT either clear (47\%) or very clear (30\%). Looking at the post-assessment phases, a low percentage (14\%) had found it difficult to obtain the AT solution after the AT assessment. The acquisition phase was undertaken in more than half of the cases by schools and ASL professionals (respectively $57 \%$ and $60 \%$ ), usually with the involvement of the child's family caregivers. In over one third of the cases, the AT solution was obtained $3(14 \%), 6(11 \%)$, or even $12(11 \%)$ months after the AT assessment. Unsurprisingly, the AT solutions employed by the participants included in the survey were most frequently used at home and at school. 
Table 1. Demographics of survey sample $(n=47)$.

n

Survey responder

Child

Parent

Other (e.g., teacher assistant; educator)

Survey mode

Web-based

Paper-based

13

28

Child gender

Male

Female

23

Child age

$$
\text { 3-5 y }
$$

6-10y 18 38

11-17 y

23

Health condition

Cerebral palsy 30 64

Spina bifida

Muscular Dystrophy

Other diagnosed syndromes

Other conditions

Place of origin

Urban

Intermediate

20

Rural

6

13

Has been the AT solution acquired and used?

Yes

Yes, it has been acquired but no longer in use

8

17

Yes, it has been acquired/obtained but never used

1

11

$\%$ 6 83

No, it hasn't been never acquired/obtained 


\begin{tabular}{lcc}
\hline & $\mathbf{n}$ & $\%$ \\
\hline Type of AT intervention $^{1}$ & & \\
ICT access solutions & 37 & 79 \\
AAC & 23 & 49 \\
Adapted toys & 8 & 17 \\
\hline
\end{tabular}

${ }^{1}$ More than one response allowed

Table 2. Responses to the ATSD process questions

\begin{tabular}{|c|c|c|}
\hline ATSD stage & Questions & n (\%) \\
\hline \multirow{7}{*}{ Initiative } & Who referred you to the CAT service? & \\
\hline & None & $1(2)$ \\
\hline & Local Health Authority (ASL) & $35(74)$ \\
\hline & School & $5(11)$ \\
\hline & Social services & $0(0)$ \\
\hline & Other & $4(4)$ \\
\hline & Don't remember & $2(9)$ \\
\hline \multirow{12}{*}{ Assessment \& Selection } & $\begin{array}{l}\text { Did you encounter any problem for activating } \\
\text { the CAT service? }\end{array}$ & \\
\hline & Yes & $6(13)$ \\
\hline & No & $41(87)$ \\
\hline & $\begin{array}{l}\text { Did you encounter any problem during the AT } \\
\text { assessment? }\end{array}$ & \\
\hline & Yes & $5(11)$ \\
\hline & No & $42(89)$ \\
\hline & $\begin{array}{l}\text { How would you rate the AT documentation pro- } \\
\text { vided? }\end{array}$ & \\
\hline & Not clear & $0(0)$ \\
\hline & Little clear & $3(6)$ \\
\hline & Sufficiently clear & $8(17)$ \\
\hline & Clear & $22(47)$ \\
\hline & Very clear & $14(30)$ \\
\hline
\end{tabular}




\begin{tabular}{|c|c|c|}
\hline \multirow{16}{*}{ Authorization } & \multicolumn{2}{|c|}{$\begin{array}{l}\text { Did you encounter any problem for acquiring } \\
\text { the AT solution?a }\end{array}$} \\
\hline & Yes & $9(14)$ \\
\hline & No & $36(86)$ \\
\hline & \multicolumn{2}{|c|}{$\begin{array}{l}\text { Who helped you during the acquisition of the } \\
\text { AT solution? } ?^{\mathrm{b}, \mathrm{c}}\end{array}$} \\
\hline & Local Health Authority & $20(57)$ \\
\hline & Social services & $4(11)$ \\
\hline & School & $21(60)$ \\
\hline & Voluntary associations & $1(3)$ \\
\hline & Family & $19(54)$ \\
\hline & User him/herself & $2(6)$ \\
\hline & \multicolumn{2}{|c|}{ How long did it take obtaining the AT solution? } \\
\hline & $<1$ month & $5(15)$ \\
\hline & Between 1 and 3 months & $15(43)$ \\
\hline & Between 3 and 6 months & $5(14)$ \\
\hline & Between 6 and 12 months & $4(11)$ \\
\hline & $>12$ months & $4(11)$ \\
\hline \multirow{10}{*}{ Implementation } & $\begin{array}{l}\text { Who helped in the implementation of } t \\
\text { solution? } ?^{\mathrm{b}, \mathrm{c}}\end{array}$ & \\
\hline & Local Health Authority & $17(48)$ \\
\hline & CAT & $23(66)$ \\
\hline & School & $25(71)$ \\
\hline & Family & $19(54)$ \\
\hline & \multicolumn{2}{|c|}{ In which context(s) the AT was implemented? $?^{\mathrm{b}, \mathrm{c}}$} \\
\hline & Home & $23(51)$ \\
\hline & School & $38(84)$ \\
\hline & Work & $0(0)$ \\
\hline & Daycare centre/ Occupational centre & $3(7)$ \\
\hline
\end{tabular}

\footnotetext{
a 2 missing responses

${ }^{\mathrm{b}}$ More than one response allowed

c Compliant users only ( $\mathrm{n}=35)$
} 
Table 3. Focus groups composition and participants characteristics.

\begin{tabular}{|c|c|c|c|c|c|c|c|}
\hline Group & Participant & $\begin{array}{l}\text { Child's } \\
\text { age }\end{array}$ & $\begin{array}{l}\text { Child's } \\
\text { gender }\end{array}$ & $\begin{array}{l}\text { Place of } \\
\text { origin }\end{array}$ & $\begin{array}{l}\text { Health } \\
\text { condition }\end{array}$ & $\begin{array}{l}\text { Type of AT } \\
\text { intervention }\end{array}$ & $\begin{array}{l}\text { Current } \\
\text { use of AT } \\
\text { solution }\end{array}$ \\
\hline \multirow{3}{*}{ First } & P1 (father) & 19 & Female & Rural & $\mathrm{CP}$ & $\begin{array}{l}\text { ICT access } \\
\text { solution }\end{array}$ & No \\
\hline & P2 (mother) & 14 & Female & $\begin{array}{l}\text { Inter - } \\
\text { mediate }\end{array}$ & $\mathrm{CP}$ & $\begin{array}{l}\text { ICT access } \\
\text { solution }\end{array}$ & No \\
\hline & P3 (mother) & 6 & Female & $\begin{array}{l}\text { In ter - } \\
\text { mediate }\end{array}$ & GD & Adapted toys & Yes \\
\hline \multirow{3}{*}{ Second } & P4 (mother) & 13 & Female & Urban & $\mathrm{CP}$ & $\begin{array}{l}\text { ICT access } \\
\text { solution; } \\
\text { AAC }\end{array}$ & Yes \\
\hline & P5 (mother) & 13 & Male & Urban & $\mathrm{CP}$ & $\begin{array}{l}\text { ICT access } \\
\text { s ol ut i o n ; } \\
\text { AAC }\end{array}$ & Yes \\
\hline & P6 (mother) & 7 & Male & $\begin{array}{l}\text { Inter- } \\
\text { mediate }\end{array}$ & $\mathrm{CP}$ & $\mathrm{AAC}$ & Yes \\
\hline
\end{tabular}

$\mathrm{CP}=$ Cerebral Palsy; $\mathrm{GD}=$ Genetic Disorder; $\mathrm{AAC}=$ Alternative and Augmentative Communication.

\section{Parents' experience with the ATSD process}

Overall negative results emerged through both the QUEST 2.0 and the KWAZO. Results from the outcome measures used in the survey were integrated with the qualitative data set in order to achieve a deeper understanding of the users' experience of the ATSD process (see tables 4 and 5).

Satisfaction with the ATSD process: QUEST 2.0 results

\section{Maintenance}

In $47 \%$ of cases respondents reported that they were not fully satisfied with maintenance services. Looking in detail at focus group discussions, the long time it took AT professionals to adapt the AT solutions (mainly toys) was considered one of the most 'unpleasant' barriers to the ATSD process:

'It takes a long time to receive customized toys, and this can be a bit of a handicap, since once a solution's been found [...], a toy might have been right for the child at that time, but if it takes you six months to alter it to suit his or her needs, you hope the child will have made progress in those six months, so the new toy is probably useless.'(P6) 
A facilitator identified by one participant was the family caregivers' active involvement in those maintenance and adaptation procedures that require non-expert skills:

'Give me some input so I can do the job for you [...]. If a mother makes her time available, she should be taken up on her offer, because she does it for her child' (P4).

\section{Follow-up}

Verification activities were rated as unsatisfactory in $47 \%$ of cases. This ATSD dimension was discussed in depth during focus groups, from which it emerged that the absence of a 'systematic' and 'cyclic' evaluation of the effectiveness of the AT solutions recommended was considered as a main barrier to ATSD and perceived as a discontinuity in the ATSD process. This concern also emerged from all the comments left in the 'follow up' item of the QUEST 2.0. Two focus group participants (P1 and P2) explicitly declared they felt a sense of 'abandonment' after the AT assessment, as no one from the AT-related services contacted them to at least find out 'how things are going' (P2). A facilitator identified by focus group participants as possibly improving perception of ATSD process continuity is the timely and well-planned AT re-assessments at least when the child has to face school transitions.

\section{AT delivery}

This item was rated as unsatisfactory in 39\% of cases. Focus group participants identified the lengthy waiting times necessary to obtain the recommended AT solution as the main barrier to the ATSD process related to this quality dimension. Furthermore, difficult access to funding was experienced by the majority of the focus group participants $(n=5)$. As stated by one participant in the first focus group:

'I spent loads of money on buying the computer and the AT solutions, because if I'd waited for the local council to provide them... It would have taken me four years just to get a small desk!' (P2).

A strategy to overcome these barriers mentioned by focus group participants is represented by the possibility of borrowing the AT solution as soon as it has been recommended, thus covering the period until the family caregivers access funding and acquire the AT solution. This service is already offered by the CAT, but does not fulfil the needs of all users, due to the limited resources available.

\section{Professional services}

This item was the only one that did not exceed the chosen threshold. Nevertheless, it was negatively rated in $25 \%$ of cases. To this regard, a lack of 'initiative' from AT professionals in guiding families through the complexities of the ATSD process was mentioned by participants as a barrier during the discussion in both focus groups. 


\section{Satisfaction with the ATSD process: KWAZO results}

\section{Accessibility}

Barriers to ATSD process access as assessed on the KWAZO scale concern the ease with which users could reach AT professionals. In this sense, $51 \%$ of the respondents had been dissatisfied with ATSD accessibility. However, this aspect was not mentioned during the focus groups. The aspects related to ATSD process access that were discussed as barriers to ATSD included accessing funding for acquiring the AT solutions, and the costs of some AT solutions. The latter aspect was also highlighted by respondents to open-ended survey questions $(n=6)$. A facilitator to face the costs of AT solutions (especially educational software) as identified by participants in both focus groups and open-ended survey questions $(n=2)$ would be to recommend free or low-cost solutions.

\section{Coordination}

This item was rated as unsatisfactory in $34 \%$ of all cases. Two facilitators relating to coordination between ATSD team members were identified from focus group discussions in particular. The first occurred when team members had clearly identified roles, and felt part of a stable support network. The second involved frequent exchange of information on the child's ever-changing needs. However, as highlighted in both focus group discussions, this is rarely possible, in particular due to the frequent turn-over in teacher assistants who are usually in charge of ensuring that the recommended AT solutions are correctly adopted and used in schooling. In this context, the second focus group participants in particular complained about fragmentation of services (e.g. AT centre, school, health and social services), which leads to frequent 'communication interruptions' (P5) between professionals who should be working as a team:

'So I think this aspect should also be improved, i.e. there should be more shared moments involving the school, the family, the child and the CAT' (P5).

Furthermore, a lack of shared AT objectives was identified as a barrier to coordinating services and professionals. In some AT interventions, one focus group participant found:

'[In some cases] there's no connection, no programme, no shared vision for getting things done [...], and this is, in my opinion, the fault of both the school and the CAT' (P1).

Effective coordination is also influenced by child's age at the start of AT intervention. Parents in the first focus group defined late AT interventions as those interventions that begin when the child is in primary school (6 yr or older) or even in secondary school, and therefore 'a long time after the child's need emerges' (P1). Conversely, early intervention starts before the beginning of primary school and the participants deemed this 'fundamental for the correct adoption of the AT recommendations' (P3). In the participants' 
opinion, teachers working in kindergartens have more positive attitudes towards the introduction of AT solutions in activities than their counterparts in primary schools, and it is easier for the parents 'to interact with the kindergarten staff (P1) and create a partnership. This positive relationship, in the opinions of participants, seems to make the correct adoption of AT recommendations more likely to happen.

\section{Efficiency}

$53 \%$ of cases rated this item as unsatisfactory. Focus group participants clarified this low satisfaction rate by mentioning efficiency issues mainly concerning long waiting times in relation to different aspects of the ATSD process, including waiting lists for obtaining an AT assessment and the time usually needed to receive the documentation from AT professionals following the AT assessment.

\section{Participation}

Satisfaction results for the 'participation' indicator were slightly below the threshold (32\% of respondents not fully satisfied). Focus group participants as well as some respondents to open-ended survey questions $(n=3)$ considered parental involvement in any aspect of the ATSD process as fundamentally important for the success of the AT intervention. In particular, focus group participants and one respondent to survey questions mentioned their experiences related to having played a secondary role in the AT intervention, due to an 'expert' approach often adopted by the majority of the professionals involved in the ATSD process:

'[...] Therefore, I'm organizing, or I'm trying to organize, all these people so they understand the need to work in this direction. But I've noticed a certain degree of difficulty, I mean, they say "yes, yes, of course", and then nothing happens' (P4).

'During the whole of primary school, [my daughter] hardly ever got to use a computer... She used it very little at secondary school [...], and the school replied: "We make [your daughter] write [by hand] because the computer shows her up as a disabled person, and so she doesn't want [a computer]"' (P2).

A possible strategy to facilitate parental involvement in the ATSD process was proposed by one participant who expressed the need to create user groups 'where all the parents could be gathered together' (P6). These groups may be useful for 'exchanging experiences and materials' (P6):

'So yes, shared moments would be useful [...]. It would also be nice to establish collaborative moments with the parents [...], especially regarding the adapted books, which are a real wealth for children like ours. But yes, having parents take part more, and making them more united - I think that would be a great idea' (P6). 
Participants in both focus groups agreed that a careful consideration of the child's desires and of the family's characteristics represent facilitators for the ATSD process. In this sense, participants recommended that AT interventions should be planned taking into account the complexities related to the family context and routines, otherwise interventions that could appear to be matching the child's needs from an expert perspective may contrast with his/her family's cultural and educational approaches:

'This is a very important aspect: the parents really should be spoken to before talking to the child $[\ldots]$ because maybe different messages are given, and giving a child different messages is terrible' (P1).

\section{Know-how}

Relatively positive judgments resulted from the 'know-how' item (17\% of respondents not fully satisfied). Focus group participants identified lack of school staff's AT competence as a barrier to ATSD. In the opinions of participants in both focus groups, lack of teachers' competence in using technology in general, and AT solutions in particular, prevent schools from including AT solutions in their educational activities. Thus, in some cases, AT non-use may be due to teachers' poor training and expertise in using AT solutions. The availability of periodic free AT training courses for teachers, social educators and family members have been identified as a facilitator of the ATSD process, and some positive experiences were reported by participants during the focus groups.

\section{Information}

Although below the threshold, the 'information' item was negatively rated by a significant percentage of respondents (29\%). Unclear information from AT professionals as included in the AT documentation, such as objectives for AT use and expected outcomes, were deemed barriers to the ATSD process by one focus group participant (P3) and one survey respondent.

\section{Instructions}

This item was rated below the satisfactory level in $21 \%$ of cases. It emerged during focus group discussions that one barrier related to this dimension was a lack of clear activities to perform with the AT solution in order to achieve the goals established during the AT assessment, and this - in the participants' opinions - may prevent the teachers and other professionals from developing useful activities for including the AT solution within the child's routines. 


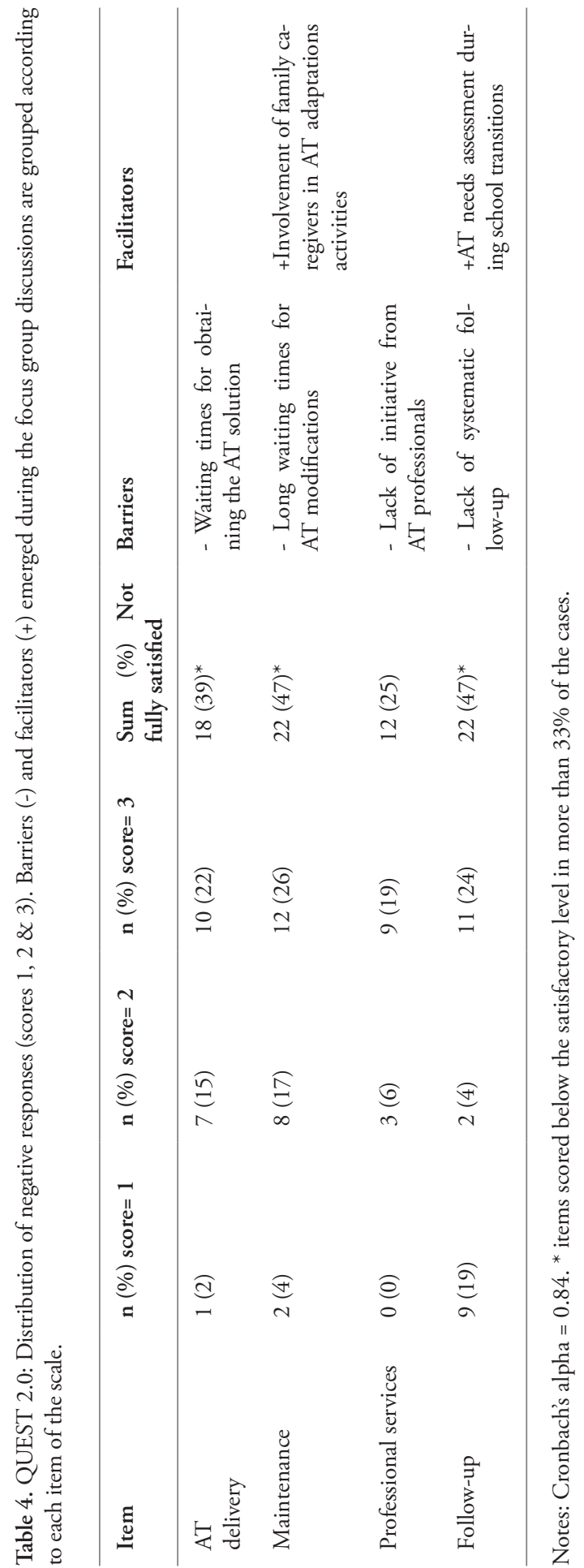




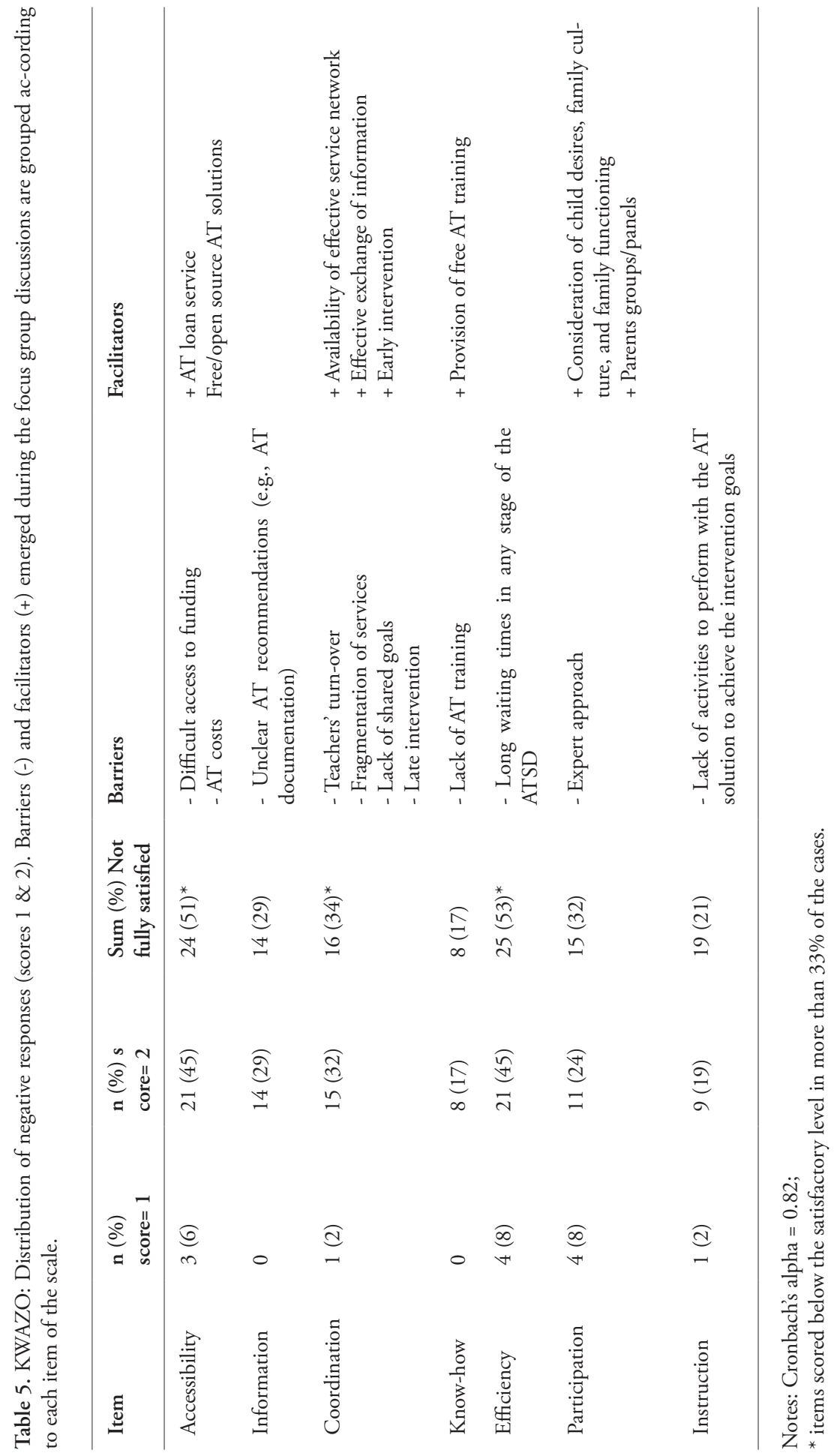




\section{Discussion}

The purpose of this study was to explore parents' experience with the ATSD process in an Italian region, with a view to understanding factors related to the ATSD process that may facilitate or hinder the AT interventions targeting children, and to identify the ATSD-related aspects in need of improvement. Results from this study are consistent with the notion that the ATSD process may be perceived by AT stakeholders as 'complex and tedious, fragmented and uncoordinated, or problematic' (p. 1461) ${ }^{55}$, and suggest that experience of the ATSD process may be affected by numerous factors. Overall, our results mirror those from previous investigations conducted on different ATSD systems, and many of the themes emerging here are reported in other literature in relation to the ATSD process ${ }^{27,32,34,36}$. However, the literature revealed no studies that both prioritized aspects of the ATSD process in need of improvement using internationally validated instruments and investigated possible solutions from a parents' perspective. In the present study, we investigated parents' experiences through a combination of quantitative and qualitative methods: while the quantitative approach allowed us to prioritize dimensions related to the ATSD process in need of improvement, the focus groups allowed us to conduct in-depth exploration into the reasons (barriers) for such ratings and to identify possible solutions (facilitators). Here we discuss the six dimensions identified as needing improvement and provide recommendations to address the issues raised, based on the proposals made by the participants in our study and in relation to the existing literature.

\section{AT delivery}

Waiting times for obtaining the recommended AT solution may be lengthy due to bureaucratic procedures. A similar finding was described by Newton and colleagues ${ }^{36}$ who interviewed parents of children recommended for communication aids. Parents in our study did not report possible solutions to address this issue. Parents in Newton and colleagues' study ${ }^{36}$, however, suggested that an estimation of a probable timescale, from AT assessment to delivery, would be useful for them. In addition, parents propose that AT professionals, when recommending AT solutions, support the use of existing technology in school and/or introduce or improve the use of low-tech systems ${ }^{36}$.

\section{Maintenance}

Maintenance and reparation services rarely satisfy parents' expectations. Telfer and colleagues $^{37}$, for example, worry that $47 \%$ of the surveyed parents carried out repairs to their child's seating system themselves, and most parents were dissatisfied about the time taken to repair and replace the system. Similarly, participants in our study found particularly problematic the activities mainly concerning toy adaptations (e.g. adding a switch to an electronic toy) or programming educational software. The focus group discussions highlighted the difficulty for AT professionals to keep pace with the child's continuously changing needs, and sometimes adaptations to AT solutions are delivered when the child 
no longer needs them. This delay may lead to parents' dissatisfaction with the ATSD process and potentially compromise the success of the whole AT intervention ${ }^{37}$. To overcome this issue, one parent suggested involving family members in this activity, instead of relying on experts' work alone. Nevertheless, a parent's capacity to take an active role varies from family to family ${ }^{32}$, and for this reason we do believe that the involvement of AT professionals is always recommended in this kind of activity. However, offering parents the opportunity to play an active role in adaptation interventions may reduce the 'knowledge gap' between parents and health or AT professionals often reported by other studies $^{34}$. To this end, it is necessary to provide parents with both accessible training activities and continuous support from AT and health professionals. In this way, AT and health professionals may empower parents by shifting them from passive observer roles to those of active participants in the AT intervention ${ }^{34}$.

\section{Follow-up}

Implementing follow-up procedures is commonly recognized as a strategy to reduce the risk of AT non-use or abandonment ${ }^{56}$. However, the AT professionals' poor attention to the follow-up step in practice is widely recognized ${ }^{24}$. In our study, a general dissatisfaction with the follow-up services was found. According to the focus groups, this may be due to a lack of follow-up strategies offered by AT professionals. A recent survey conducted in the Italian context involving an adult population found that the users tend not to utilize the AT if the follow-up provided is unsatisfactory ${ }^{23}$. Thus, to improve the quality of the ATSD process and to reduce the rate of AT non-use, it is vital that routine clinical practice be supplemented with validated and periodic user-centred evaluation strategies, ones capable of providing meaningful information to all stakeholders about the effectiveness of AT solutions ${ }^{24,57}$ and of allowing AT and health professionals to plan possible corrective actions within the current AT intervention ${ }^{24}$. User-centred instruments available for AT and health professionals to evaluate the effectiveness of AT interventions are, for example, the Individually Prioritized Problem Assessment ${ }^{58}$ and the Goal Attainment Scaling ${ }^{15}$.

\section{Accessibility}

Generally, barriers to health service access include, for instance ${ }^{26}$ : geographical barriers (location of services), financial barriers (cost of obtaining care), organizational barriers (lack of appointments, transportation), and cultural barriers (differing languages). In our study, barriers to ATSD access reported by parents included difficulties in reaching AT professionals easily, difficult access to public funding, and the costs of certain AT solutions. These access issues may be found in other systems ${ }^{18}$, and may challenge the quality of the ATSD process because they increase the likelihood of producing unfavourable outcomes for the AT intervention (e.g. AT non-use) and heighten the burden on family members ${ }^{59}$. In particular, the ease with which AT stakeholders could reach AT professionals seems to be a common problem ${ }^{28,37}$, and strategies to improve this issue 
have been proposed. For example, Anderson and colleagues ${ }^{34}$ suggested the use of technological solutions (e.g. telehealth) for easier contact with AT professionals, especially in remote and rural areas, even if the authors recognize that the effectiveness of this strategy requires further evidence ${ }^{34}$.

Access to funding and costs of AT solutions are also well recognized in many ATSD systems as issues for which it is difficult to introduce definitive solutions ${ }^{59}$. In our study, we found that the employment of AT loan services, where possible, and recommending the use of free or low-cost educational software, where appropriate, may reduce the risk of AT non-use.

\section{Coordination}

As noted by one study participant, a lack of coordination may lead to 'an interruption in AT intervention', and the parents in our study often reported experiencing the 'dark side' of multidisciplinary interventions, this being fragmentation of services. Our results mirrored those from other systems. For instance, a recent study conducted in Australia involving parents of children recommended for speech-generating devices found that parents 'called for improved communication and coordination of services within and across organizations, settings and stakeholders' (p.7 $)^{34}$. ATSD is usually a multidisciplinary process which requires the integration of different expertise and services $^{5}$ including the child and his/her family ${ }^{28}$, and effective coordination is key for integrating the services and professionals involved in the ATSD process ${ }^{55}$. As emerges from the available literature - which also reflects the opinions of the participants in our focus groups - developing structured communication strategies as well as establishing a solid network through a partnership between all stakeholders, and in particular parents and school staff ${ }^{27,60}$, are both required for an effective coordination of the ATSD process. The literature reports that early interventions (i.e. those interventions targeting infants and toddlers) may produce several benefits to the ATSD process targeting children ${ }^{6}$, and our results suggest that beginning the AT interventions early may also be particularly useful for establishing a partnership between the school staff and the child's parents due to appropriate environmental conditions (i.e. teachers' positive attitudes towards technology use in the classroom). In addition, following the recommendation from Anderson and colleagues $^{34}$, appointment of an ATSD case manager may help to avoid the 'communication interruptions' identified by participants in our study by facilitating cohesion between the AT stakeholders.

\section{Efficiency}

From the definition provided by the AAATE', an ATSD process is efficient when 'it is able to achieve the best solution, for the highest number of users, using the available resources in the shortest time and at lowest cost' (p. 15). In particular, both parents and health professionals are aware that the success of the AT intervention targeting children depends especially on a timely delivery of AT-related services ${ }^{6}$. Lengthy waiting times in 
any aspect of the ATSD process might delay the AT intervention and thus compromise the achievement of important developmental and learning goals ${ }^{6,61}$. Participants in our study place particular emphasis on barriers related to the time needed to perform an AT assessment and to receive the AT documentation after the AT assessment. However, improving ATSD efficiency is a complex task which depends on the specific organization of each ATSD system. A recent study on AT documentation ${ }^{41}$, for example, suggests that employing structured and validated strategies for writing the AT reports after the technological assessment may contribute to reducing the time required to produce the AT documentation for stakeholders, thus speeding up the whole ATSD process.

\section{Study strengths and limitations}

This is the first study conducted in the Italian context addressing parents' experience of the ATSD process. Some limitations of the study should be noted. Although the focus group and the survey participants were well spread in terms of demographic characteristics (e.g. age, geographic location, type of AT solution) - which is to be considered a strength of the current study - the results are based on a relatively small sample size, especially in the case of the focus group participants, and this factor may hamper the generalizability of our findings. We are also aware that our results do not reflect the perspectives of all AT stakeholders usually involved in the ATSD process (e.g. teachers, children), and are restricted to a population living in one Italian region. For these reasons, the results of the present study should be used with caution.

However, future studies conducted in the Italian context - but also on other ATSD systems - may take advantage of the methodology employed here, which is relatively easy to replicate due to the use of internationally validated instruments. Indeed, as highlighted by Grol and colleagues ${ }^{25}$ : 'Differences or similarities in patients' views [...] may - if an internationally standardised and validated instrument is used - be helpful in the debate about specific strengths and weaknesses of care provision in a particular country'(p. 882). The utilization of validated measures may also allow researchers to find associations between satisfaction ratings and users' characteristics (e.g. demographics, functional status, type of AT intervention); this area of research was not addressed in the present study, but needs to be explored in more detail in future studies with a larger sample size.

In conclusion, this study raises some important points in relation to the ATSD process for children. Health professionals involved in rehabilitation interventions including the use of AT solutions should be aware that failings in the ATSD process may have detrimental consequences both for the developing child, in terms of missed opportunities to benefit from increased participation, and for the community, in terms of costs sustained for the provision of the AT solution. This study particularly underlines the importance of AT delivery, maintenance services, follow-up strategies, accessibility of the ATSD process, coordination between stakeholders, and general efficiency of the ATSD process as key dimensions of ATSD quality. In addition, this study highlights the value of including standardized instruments when collecting information about stakeholders' experiences of the ATSD process. 


\section{References}

1. Karmiloff-Smith A, D'Souza D, Dekker T, Van Herwegen J, Xu F, Rodic M, Ansari D. Genetic and environmental vulnerabilities in children with neurodevelopmental disorders. Proceedings of the National Academy of Sciences 2012;109(Supplement 2):17261-17265.

2. Law M, King G, King S, Kertoy M, Hurley P, Rosenbaum P, Young N, Hanna, S. Patterns of participation in recreational and leisure activities among children with complex physical disabilities. Developmental Medicine \& Child Neurology 2006;48:337-342.

3. Bøttcher L. Children with spastic cerebral palsy, their cognitive functioning, and social participation: a review. Child Neuropsychology 2010:16:209-228.

4. Bøttcher L, Dammeyer, J. Disability as a risk factor? Development of psychopathology in children with disabilities. Research in Developmental Disabilities 2013;34:3607-3617.

5. Association for the Advancement of Assistive Technology in Europe [AAATE]. Service Delivery Systems for Assistive Technology in Europe; 2012 - [cited 2014 Jul 8]. Available from: http://www.aaate.net/sites/ default/files/ATServiceDelivery_PositionPaper.pdf

6. Dugan L, Campbell P, Wilcox M. Making decisions about assistive technology with infants and toddlers. Topics in Early Childhood Special Education 2006;26:25-32.

7. Henderson S, Skelton H, Rosenbaum P. Assistive devices for children with functional impairments: impact on child and caregiver function. Developmental Medicine \& Child Neurology 2008;50:89-98.

8. Lancioni G, O'Reilly M, Singh N, Sigafoos J, Oliva D, Baccani S, Bosco A, Stasolla F. Technological aids to promote basic developmental achievements by children with multiple disabilities: evaluation of two cases. Cognitive Processing 2004;5:232-238.

9. Cook A, Adams K, Encarnaçấo P, Alvarez L. The role of assisted manipulation in cognitive development. Developmental Neurorehabilitation 2012;15:136-148.

10. Rispoli M, Franco J, van der Meer L, Lang R, Camargo S. The use of speech generating devices in communication interventions for individuals with developmental disabilities: A review of the literature. Developmental Neurorehabilitation 2010;13:276-293.

11. Copley J, Ziviani J. Barriers to the use of assistive technology for children with multiple disabilities. Occupational Therapy International 2004;11:229-243.

12. Østensjø I. Assistive Devices for Children with Disabilities. In: Söderback I, editor. International Handbook of Occupational Therapy Interventions. New York: Springer; 2009. pp 141-146.

13. Judge $S$. Family-centered assistive technology assessment and intervention practices for early intervention. Infants \& Young Children 2002;15:60-68.

14. Desideri L, Roentgen U, Hoogerwerf E, de Witte L. Recommending assistive technology (AT) for children with multiple disabilities: A systematic review and qualitative synthesis of models and instruments for AT professionals. Technology and Disability 2013;25:3-13.

15. Mumford L, Lam R, Wright V, Chau T. An access technology delivery protocol for children with severe and multiple disabilities: A case demonstration. Developmental Neurorehabilitation 2013;17:232-242.

16. Warren C. Cost effectiveness and efficiency in assistive technology service delivery. Assistive Technology 1993;5:61-65.

17. de Witte L, Knops H, Pyfers L, Röben P, Johnson I, Andrich R., Paganin A, Parker M, Forsberg S. European Service Delivery System in Rehabilitation Technology: A Comprehensive Description of Service Delivery Systems of 16 European Countries. HEART (Horizontal European Activities of Rehabilitation Technology) Line C. 1994. iRv, Institute for Rehabilitation Research: Hoensbroek. Available from http:// portale.siva.it/files/doc/library/a416_1_ATServiceDelivery_HEART_ReportC51.pdf [last accessed 20 Nov 2014].

18. Lee H, Templeton R. Ensuring equal access to technology: Providing assistive technology for students with disabilities. Theory into Practice 2008;47:212-219.

19. Adya M, Samant D, Scherer M, Killeen M, Morris M. Assistive/rehabilitation technology, disability, and service delivery models. Cognitive Processing 2012;13:75-78.

20. Fauconnier J, Dickinson H, Beckung E, Marcelli M, McManus V, Michelsen S, Parkes J, Parkinson K, Thyen U, Arnaud C, Colver A. Participation in life situations of 8-12 year old children with cerebral palsy: cross sectional European study. BMJ: British Medical Journal 2009;338:b1458

21. Wise PH. Emerging technologies and their impact on disability. The Future of Children 2012;22:169-191. 
22. Cullen K, McAnaney D, Dolphin C, Delaney S, Stapleton P. Research on the provision of Assistive Technology in Ireland and other countries to support independent living across the life cycle. 2012 - [cited 2014 Jul 10]; Available from http://www.nda.ie/cntmgmtnew. nsf/0/797AD755B56A82A580257A4D0031A2B6?OpenDocument.

23. Federici S, Borsci S. The use and non-use of assistive technology in Italy: Preliminary data. 11th AAATE Conference: Everyday technology for independence and care; 2011 Aug 31-Sep 2; Maastricht. Amsterdam: IOS Press; 979 p.

24. Steel E, de Witte L. Advances in European Assistive Technology service delivery and recommendations for further improvement. Technology and Disability 2011;23: 131-138.

25. Grol R, Wensing M, Mainz J, Jung H, Ferreira P, Hearnshaw H, Hjortdahl P, Olesen F, Reis S, Ribacke M, Szecsenyi J, European Task Force on Patient Evaluations of General Practice Care (EUROPEP). Patients in Europe evaluate general practice care: an international comparison. British Journal of General Practice 2000; 50:882-887.

26. Lawthers A, Pransky G, Peterson L, Himmelstein J. Rethinking quality in the context of persons with disability. International Journal for Quality in Health Care 2003;15:287-299.

27. Priest N, May E. Laptop computers and children with disabilities: Factors influencing success. Australian Occupational Therapy Journal 2001;48:11-23.

28. Parette H, Brotherson M. Family-centered and culturally responsive assistive technology decision making. Infants \& Young Children 2004;17:355-367.

29. MacKean G, Thurston W, Scott C. Bridging the divide between families and health professionals' perspectives on family-centred care. Health Expectations 2005;8:74-85.

30. Nicolson A, Moir L, Millsteed J. Impact of assistive technology on family caregivers of children with physical disabilities: a systematic review. Disability and Rehabilitation: Assistive Technology 2012;7:345-349.

31. Ryan S, Campbell K, Rigby P. Reliability of the Family Impact of Assistive Technology Scale for families of young children with cerebral palsy. Archives of Physical Medicine and Rehabilitation 2007;88:1436-1440.

32. Bailey R, Parette H, Stoner J, Angell M, Carroll K. Family members' perceptions of augmentative and alternative communication device use. Language, Speech, and Hearing Services in Schools 2006; 37:50-60.

33. Kling A, Campbell P, Wilcox J. Young children with physical disabilities: Caregiver perspectives about assistive technology. Infants \& Young Children 2010; 23:169-183.

34. Anderson K, Balandin S, Stancliffe R. Australian parents' experiences of speech generating device (SGD) service delivery. Developmental Neurorehabilitation 2013;17:75-83.

35. Hetzroni O. Augmentative and alternative communication in Israel: results from a family survey. Augmentative and Alternative Communication 2002;18:255-266.

36. Newton C, Clarke M, Donlan C, Wright J, Lister C, Cherguit J. Parents' expectations and perceptions concerning the provision of communication aids by the Communication Aids Project (CAP). Child Language Teaching and Therapy 2007; 23:47-65.

37. Telfer S, Solomonidis S, Spence W. An investigation of teaching staff members' and parents' views on the current state of adaptive seating technology and provision. Disability \& Rehabilitation: Assistive Technology 2010;5:14-24.

38. Ivankova N, Creswell J,Stick S. Using mixed-methods sequential explanatory design: From theory to practice. Field Methods 2006;18:3-20.

39. Morgan D. Practical strategies for combining qualitative and quantitative methods: Applications to health research. Qualitative health research 1998; 8:362-376.

40. Desideri L, Mingardi A, Stefanelli B, Tanzini D, Bitelli C, Roentgen U, de Witte L. Assessing children with multiple disabilities for assistive technology: A framework for quality assurance. Technology and Disability 2013;25:159-166.

41. Desideri L, Ioele F, Roentgen U, Gelderblom GJ, de Witte L. Development of a team-based method for assuring the quality of assistive technology documentation. Assistive Technology, in press.

42. Donabedian A. The quality of care: How can it be assessed? JAMA 1988;260:1743-1748.

43. Sund T, Iwarsson S, Andersen M, Brandt A. Documentation of and satisfaction with the service delivery process of electric powered scooters among adult users in different national contexts. Disability and Rehabilitation: Assistive Technology 2013;8:151-160. 
44. Yun G, Trumbo C. Comparative response to a survey executed by post, e-mail, \& web form. Journal of Computer-Mediated Communication 2000, 6.

45. Wessels R, Dijcks B, Soede M, Gelderblom GJ, de Witte L. Non-use of provided assistive technology devices, a literature overview. Technology and Disability 2003;15:231-238.

46. Demers L, Weiss-Lambrou R, Ska B. The Quebec User Evaluation of Satisfaction with Assistive Technology (QUEST 2.0): an overview and recent progress. Technology and Disability 2002;14:101-105.

47. Dijcks B, Wessels R, De Vlieger S, Post M. KWAZO, a new instrument to assess the quality of service delivery in assistive technology provision. Disability \& Rehabilitation 2006;28:909-914.

48. Desideri L, Bitelli C, Brandan V, de Witte L. The Employment of KWAZO with Parents of Children with Disabilities in an Italian Region: Preliminary Data on Scale Adaptation and Validation. Proceedings of the 12th biennial European conference of the Association for the Advancement of Assistive Technology in Europe, AAATE 2013, p. 1059 - 1063.

49. Krueger R, Morgan D, King J. Focus group kit. Thousand Oaks, CA, US: Sage; 1998.

50. MacDonald S, Newburn-Cook C, Schopflocher D, Richter S. Addressing nonresponse bias in postal surveys. Public Health Nursing 2009;26:95-105.

51. Demers L, Weiss-Lambrou R, Ska B. Quebec User Evaluation of Satisfaction with Assistive Technology: QUEST version 2.0; 2000 - [cited 2014 Jul 14] Available at http://www.midss.org/sites/default/files/ questmanual_final_electronic20version_0.pdf .

52. Bradley E, Curry L, Devers K. Qualitative data analysis for health services research: developing taxonomy, themes, and theory. Health Services Research 2007;42:1758-1772.

53. Miles M, Huberman, A. Qualitative data analysis: An expanded sourcebook. Sage Publications. 1994.

54. Braun V, Clarke V. Using thematic analysis in psychology. Qualitative Research in Psychology 2006;3:77-101.

55. Ripat J, Booth A. Characteristics of assistive technology service delivery models: stakeholder perspectives and preferences. Disability \& Rehabilitation 2005; 27:1461-1470.

56. Phillips B, Zhao H. Predictors of assistive technology abandonment. Assistive Technology 1993;5:36-45.

57. Fuhrer M, Jutai J, Scherer M, DeRuyter F. A framework for the conceptual modelling of assistive technology device outcomes. Disability \& Rehabilitation 2003;25;1243-1251.

58. Wessels R, Persson J, Lorentsen $\varnothing$, Andrich R, Ferrario M, Oortwijn W, VanBeekum T, Brodin H, de Witte L. IPPA: Individually prioritised problem assessment. Technology and Disability 2002;14:141-145.

59. Judge S. Accessing and funding assistive technology for young children with disabilities. Early Childhood Special Education 2000;28:125-131.

60. Angelo D, Jones $S$, Kokoska $S$. Family perspective on augmentative and alternative communication: Families of young children. Augmentative and Alternative Communication 1995;11:193-202.

61. Parette H, Peterson-Karlan G. Facilitating student achievement with assistive technology. Education and Training in developmental Disabilities 2007;42:387-3. 


\section{Appendix. Questions included in the KWAZO scaling and the focus groups}

\section{KWAZO*}

1. Could you always reach the service delivery professionals easily? (accessibility);

2. How clear was the information about the application and the possible solutions that the service delivery professionals gave you? (information);

3. How well was the cooperation and the communication between the different service delivery professionals? (coordination);

4. Did the service delivery professionals have sufficient know-how? (know-how);

5. Was your application handled quickly and efficiently? (efficiency);

6. Were your own opinion and wishes considered in choosing an assistive device? (participation);

7. Was the use of the assistive device well-explained to you? (instruction)

\section{Focus groups questions}

1. How would you describe your experience with the CAT service?

2. How would you describe your experience with the assistive solution?

3. What elements would make you say the ATSD is poor?

4. What elements would make you say the ATSD is excellent?

5. Which barriers did you encounter during the AT process?

6. What do you think could make the AT process easier?

7. Thinking about what we have said today, what are the most urgent things to be done in order to improve ATSD?

*From [47] (Italian version in [48]). 
Chapter 6 Implementing a routine outcome assessment procedure to evaluate the quality of assistive technology service delivery for children with physical or multiple disabilities: Perceived effectiveness, social cost, and user satisfaction

This Chapter was accepted by Assistive Technology as: Desideri, L., Bizzarri, M., Bitelli, C., Roentgen, U., Gelderblom, G-J., de Witte, L. Implementing a routine outcome assessment procedure to evaluate the quality of assistive technology service delivery for children with physical or multiple disabilities: Perceived effectiveness, social cost, and user satisfaction. 


\begin{abstract}
There is a lack of evidence on the effects and quality of AT service delivery (ATSD). This study presents a quasi-experimental 3-months follow-up using a pre-test/post-test design aimed at evaluating outcomes of AT interventions targeting children with physical and multiple disabilities. A secondary aim was to evaluate the feasibility of the follow-up assessment adopted in this study with a view to implement the procedure in routine clinical practice. Forty-five children aged 3-17 years were included. Parents were asked to complete the IPPA for AT effectiveness; KWAZO and QUEST 2.0 for satisfaction with ATSD; SCAI for estimating the social cost of AT interventions. At follow-up, 25 children used the AT recommended. IPPA effect sizes ranged from 1.4 to 0.7 , showing a large effect of $A T$ interventions. Overall, parents were satisfied with ATSD, but Maintenance, Professional services, and AT delivery were rated not satisfactory. SCAI showed more resources spent for AT intervention compared to human assistance without technological supports. AT may be an effective intervention for children with disabilities. Issues concerning responsiveness and feasibility of the IPPA and the SCAI instruments are discussed with a view to inform routine clinical practice.
\end{abstract}




\section{Introduction}

Evidence exists demonstrating that assistive technology (AT) solutions may reduce children's activity limitations, improve their participation ${ }^{1,2}$, and may have a positive socio-economic effect by improving access to education and increasing achievement ${ }^{3}$.

The effectiveness of AT service delivery is crucial for the integration of AT solutions in children's everyday life ${ }^{4}$. AT service delivery may be defined as 'the complexity of processes that act as an intermediate between the needs of an individual with a disability or impairment and existing resources and [...] assistive technology ${ }^{5}$ (p. 17).

Little evidence is available concerning the effectiveness of various AT service delivery systems ${ }^{6,7}$, even if empirical research has documented that children with disabilities are often less likely to access AT than adults ${ }^{8}$, and that non-use rates of provided AT are reported up to $23 \%$ among children ${ }^{4}$.

The recent emphasis on evidence-based practice highlights the importance of evaluating the effectiveness and efficiency of all aspects of health care in order to take corrective actions aimed at improving the overall quality of the health care system?

A careful monitoring of the progress toward the desired outcome is an essential aspect of the AT service delivery process ${ }^{4,10,11}$. In particular, adopting a structured and user-centred procedure to document outcomes of the AT service delivery in everyday practice may represent a strategy to gain beneficial outcomes from AT interventions ${ }^{12}$.

In the current study, we assume that a lack of data concerning outcomes of AT service delivery may result from the often scarce attention paid by AT professionals towards documenting the effects of their AT interventions. Indeed, it is widely recognized in various service delivery systems, including Europe and North America, that the documentation of the outcomes of AT service delivery is still in an infant state of development; as a consequence, AT professionals may lack procedures and instruments to evaluate the outcomes of their AT interventions in routine clinical practice ${ }^{13,14}$.

The current study was primarily aimed at contributing to fill this research gap by documenting the outcomes of an Italian AT service delivery process performed by an Italian AT centre.

To our knowledge, no studies are available documenting the outcomes of AT service delivery targeting children in the Italian context. AT service delivery in Italy is a complex process, which involves different providers and professionals. AT solutions are generally provided through public funding, and service delivery is organized at the regional level and delivered primarily by AT centres, where a team of experts, usually in collaboration with professionals from the Local Health Authority, conducts an assessment to match the person with a disability with the most appropriate AT solution. Professionals from the Local Health Authority, together with the child's family and school staff, are then responsible to apply for funding and to acquire the recommended AT solution.

Research concerning the relationship between the delivery of AT services and AT outcomes has a long history. Several instruments have been developed over the last two decades ${ }^{15,16,17}$ addressing different dimensions of AT outcomes. For the purposes of the current study, we focused on specific dimensions of outcomes selected on the basis of 
the recent recommendations by the Association for the Advancement of the Assistive Technology in Europe ${ }^{18}$, which stated that:

'there is an increasing demand for evidence of the cost-effectiveness of any public support system for the users' personal needs. Information should be available on the effectiveness of an AT service delivery system in meeting the citizens' needs, on how much its social cost is, and how much it performs against appropriate quality indicators' (p. 3).

Attempts to document outcomes of AT service delivery targeting children are limit$\mathrm{ed}^{19-22}$, and none of the studies available in literature documents the attempt to implement evaluation strategies for AT service delivery outcomes in everyday practice. Thus, a secondary aim of the current study was to evaluate AT professionals' and users' perception of the outcomes measurement instruments used in the current study, in order to provide recommendations for the actual use of the instruments when children are involved. In more details, the purpose of this study was to answer the following research questions:

- What are the effects of AT interventions on the child's activities, service delivery satisfaction, and social cost?

- $\quad$ Are the instruments here employed suitable to assess the outcome of AT intervention targeting children with physical and multiple disabilities?

\section{Methodology}

\section{Study design}

We conducted a quasi-experimental study with a pre-test/post-test design and each AT user was also considered as his/her own control. Parents in particular are those AT stakeholders who play a key role at any stage of AT service delivery, and may represent an invaluable source of information for AT providers regarding the quality of the whole AT service delivery and AT outcomes ${ }^{23}$. In addition, proxy assessment was chosen since all children in our sample had a certain degree of cognitive impairment, difficult to test with the available instruments, which prevented them to complete the instruments used independently. In this case, proxy assessment may provide more comprehensive information than the child him- or herself ${ }^{4}$. The study was conducted in accordance with the principles of the Declaration of Helsinki.

\section{Study participants and context}

All the referrals of the Centre for Assistive Technology (CAT) were included in the study over a 10 months period. Participants were sequentially recruited among either parents or teachers of children (aged 3-17 years old) with various health conditions leading to either physical or multiple disabilities (e.g., cerebral palsy). 
The CAT operates as a publicly funded AT provider managed by a non-profit organization in collaboration with the Local Health Authority, and its catchment area covers the whole country. The CAT service delivery process comprises of four phases: (1) Activation; (2) Assessment; (3) Documentation; and, (4) Post-assessment. Briefly, the CAT service is activated ("Activation" phase) when a request is received from the child's family or a health or educational professional for an assessment in order to determine the most adequate assistive solution for the child in question. The CAT provides an assessment with respect to the following AT categories: access solutions (e.g., mechanical switches, alternative keyboards, joysticks, alternative mouse, eye trackers) for information and communication technology devices (ICT; e.g., personal computer) and toys (e.g., toys adaptations); educational software (e.g., software to create personalized activities such as "Clicker ${ }^{\mathrm{TM}}$ "); and, alternative and augmentative communication devices (AAC; e.g., communication boards, speech generating devices). The CAT assessments are centre-based ("Assessment" phase). They are conducted in a customizable setting and last approximately half a working day. A few days after the AT assessment, the CAT provides the child's family with a written report (the "Documentation" phase) detailing its recommendations which can be used by health and social service professionals to support an application for public funding. The CAT does not play an active role in purchasing the AT solution. Once the AT stakeholders have obtained the recommended AT solution, the CAT may also be activated for supporting the correct implementation of the AT solution in the child's home or learning environment ("Post-assessment" phase) through a direct (e.g., on site) or remote (e.g., phone, e-mail) support. Direct support is available only for users from the municipality of Bologna.

\section{Outcome measurement instruments}

The outcomes of the AT service delivery were assessed by employing a set of specific AT instruments covering three distinct outcome dimensions: a) perceived AT effectiveness; b) users' satisfaction with the AT service delivery process; and, c) social cost. A description of the characteristics of the instruments and the rationale for their use follows.

\section{Perceived AT effectiveness}

The effectiveness of AT interventions was measured through subjective perceptions by means of the Individual Prioritised Problem Assessment ${ }^{25}$ (IPPA). With this tool, the user is asked to list up to 7 problematic activities he/she considers would benefit from the AT intervention, and to rate each of them on a 5-point scale both in relation to the importance of the problem, and in relation to the difficulty of performing the related activity ${ }^{25}$. Thus, importance scores and difficulty scores are multiplied, resulting in a baseline score between 1 and 25 for each problem. These can then be added up and divided by the number of problems, ultimately resulting in the total IPPA baseline score. In a follow-up interview respondents are asked to repeat the IPPA rating only in relation to the difficulty of performing the same activities listed in the baseline interview. The effectiveness of 
the intervention is calculated by subtracting the follow-up score from the baseline score, either per problem or per total score, thus resulting in a change score ${ }^{25}$. Before the study started, each AT professional involved in the follow-up administered at least two IPPA interviews in order to practice with the tool and identify any possible issue.

\section{Satisfaction with ATSD process and services}

For the purpose of the present study, we distinguished between AT service delivery process and AT services. Quality indicators to evaluate the AT service delivery process have been produced within the Horizontal European Activities in Rehabilitation Technology (HEART; de Witte et al., 1994), and on the basis of these a user-centred questionnaire was recently developed, termed KWAZO'26 ('Kwaliteit van Zorg'; 'Quality of Care'). Developed in the Netherlands, the KWAZO is composed of 7 questions, each covering the HEART related quality indicators of the AT service delivery process (Accessibility, Information, Coordination, Know-how, Competence, Efficiency, Participation, Instruction). Here we used the Italian version of the KWAZO, which has been validated through a series of studies ${ }^{27}$. The responder is requested to rate his/her degree of satisfaction with each indicator on a 5 -point Likert scale ( $1=$ insufficient; $2=$ modest; $3=$ sufficient; $4=$ good; $5=$ =very good) and to write a comment to justify any rating below score 5 .

The AT service delivery process embraces a series of AT services, including assessment of the child's developmental and learning needs, the selection of the AT solution, the modification and fitting of the product to the child and his/her environment, the training of the child and of family members, the follow-up, the maintenance of the AT solution and repairs. To assess users' satisfaction with the AT service delivery related services, we employed the service subscale of the Quebec User Evaluation of Satisfaction with Assistive Technology ${ }^{28}$ (QUEST 2.0). It consists of four items assessing ATSD-related services (Service delivery; Maintenance and Repair services; Professional services; Follow-up services). The responder is invited to rate his/her satisfaction on a 5-point Likert scale ( $1=$ not satisfied at all; $5=$ very satisfied $)$ and to write a comment to justify any rating below score 5 .

\section{Social cost of the AT intervention}

The analysis of social costs associated to the AT intervention was performed using the SIVA Cost Analysis Instrument ${ }^{29,30}$ (SCAI). Social cost is defined as the sum of the costs incurred by all the actors in a given situation ${ }^{29,31}$. For the purposes of the present study, SCAI was employed to compare the social costs generated by the intervention performed with the help of an AT solution (AT intervention) against the social cost generated by the same intervention performed with the help of human assistance alone. AT intervention includes social cost related to investment, maintenance, human assistance, and cost of the AT service; while costs associated to human assistance alone were calculated according to the expertise of the caregiver involved in the activity for which the AT solution was provided ${ }^{32}$. Assistance provided either by a professional (e.g., health professional, teacher) or by family caregivers was estimated with reference to standard contract costs, according to national labour contracts for health and social care workers ${ }^{31}$. 
The social cost of each individual AT intervention and human assistance was estimated over a predefined period of time (1,2, and 3 years) according to the estimated clinical duration of the solution. For the scope of the present study and on the basis of a previous study ${ }^{31}$ we decided to use the SCAI only for those children: (a) who used one AT device (ICT access solutions for accessing personal computers) with one clear AT objective (e.g., writing); (b) for whom it was realistic to consider the same intervention without an AT solution. This decision was taken since it appeared difficult to have the respondent provide detailed and reliable information about, i.e., the level of human assistance required to the child during communication and playing activities. The AT professional responsible for administering the SCAI and estimating the social cost (C.B.) received specific training by the Italian author of the tool.

\section{Follow-up procedure}

The battery of instruments was employed following a 3-step follow-up procedure (Figure 1). In step 1, at the end of the assessment conducted by the CAT, one member (either a social educator or psychologist) of the CAT team administered the IPPA interview. In step 2, one member of the CAT team, other than who conducted the first interview in step 1, carried out a follow-up consisting of a structured interview with open questions, to ascertain that the child received and used the recommended AT solution for at least 3 months. Parents were contacted after 6 months from the AT assessment. Respondents, parents of children both with and without the AT solution, were asked to complete the IPPA follow-up interview. Parents of children who did not obtain the AT solution were asked to indicate the reasons. The SCAI interview was also conducted where applicable in step 2 . At the end of the telephone interview, in step 3 only parents of children with the AT were further asked to complete an online questionnaire comprising the QUEST 2.0 and KWAZO scales.

\section{Feasibility}

To evaluate the feasibility of the follow-up procedure in clinical practice, judgments from both AT professionals and AT stakeholders were collected. The time spent by AT professionals for each interview was recorded. In addition, each professional involved in the follow-up procedure was asked to respond to a questionnaire comprising five close-ended questions: (1) Overall, do you think that the follow-up procedure is suitable for evaluating the effectiveness of the ATSD process? (Italian: In generale, pensa che la procedura di verifica sia adeguata a valutare l'efficacia del percorso ausili?); (2-5) Do you think that the IPPA/QUEST/KWAZO/SCAI is a useful tool for evaluating the outcome of the AT intervention? (Italian: Pensi che IPPA/QUEST/KWAZO/SCAI sia uno strumento utile per valutare gli effetti dell'intervento ausili?). Respondents were asked to answer using a 10-point Likert scale ( $1=$ 'totally disagree'; $10=$ 'totally agree').

Concerning users' feedback, response rates to online questionnaires were calculated. In addition, a general question about the respondents' perception of the follow-up over- 
all usefulness, identical to question (1) mentioned earlier for AT professionals, was asked at the end of step 3, after the completion of the online questionnaires.

\section{Data analyses}

To assess potential sample bias between children with and without AT solutions, Chi-square was used to test differences according to place of origin (Bologna; Emilia-Romagna; Rest of Italy), gender (male; female), and diagnosis (cerebral palsy; genetic syndrome and other not specified); while t-test was used to assess differences according to chronological age.

Descriptive statistics were used to analyse IPPA results. Mean $(M)$, standard deviations $(S D)$, and frequencies were used to describe the data collected. To explore in detail the impact of the AT solution on the different child's activities, IPPA problems were also grouped according to the domains of the Activity and Participation components of the International Classification of Functioning - Children and Youth Version ${ }^{33}$ (ICF$\mathrm{CY}$ ). To this regard, two researchers (a psychologist and an occupational therapist) independently grouped IPPA problems according to the ICF-CY classification, then met to discuss differences and achieve a consensual classification. At the end of this process, five ICF-CY dimensions resulted suitable to group the IPPA problems: Learning and Applying Knowledge; Communication; General Tasks and Demands; Interpersonal Relations; Community, Social, and Civic life. To quantify the amount of change measured, the responsiveness index by Cohen ${ }^{34}$ was applied (as used by ${ }^{35}$ ), for which IPPA effect sizes were calculated as the ratio of the mean change to the standard deviation of the change scores. Further, according to Wessels and colleagues ${ }^{36}$, to assess responsiveness of IPPA and the individual problems categorized according to the ICF-CY, the change scored for each problem was divided by the standard deviation of the baseline scores for all the problems in the ICF-CY domain concerned. Cohen ${ }^{34}$ has provided benchmarks that serve to guide the interpretation of effect sizes: 0.20 is considered small, 0.50 moderate and 0.80 or more is defined as large.

Item-by-item analyses were conducted both on the QUEST 2.0 and on the KWAZO. Scores were grouped into two categories: 'Satisfied' (scores 4 and 5 combined) and 'Not fully satisfied' (scores 3, 2 and 1 combined). For each item of both questionnaires, a threshold of $33 \%$ was used ( $>33 \%$ of the respondents resulting 'Not fully satisfied') ${ }^{37}$.

Intervals (lowest, highest) were used to report data from SCAI. Descriptive statistics were used for feasibility questions.

Data were collected and organized using the software Microsoft Excel. Statistical analyses were conducted utilizing the software SPSS version 17. 


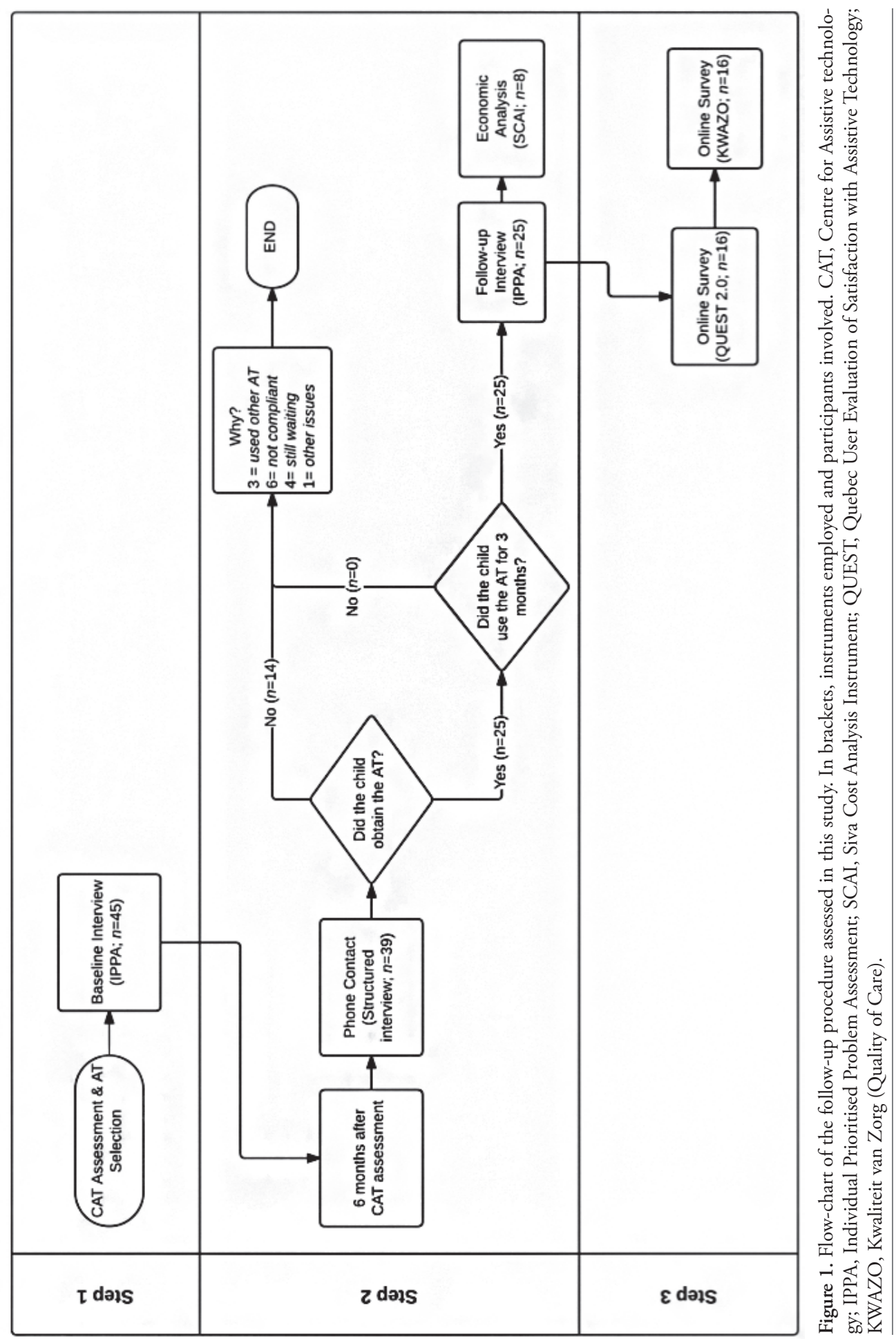




\section{Results}

\section{Participants}

A cohort of 45 consecutive children with physical or multiple disabilities referred to the CAT were included in the study (Table 1). At follow-up, 39 proxies (87\%) were interviewed. Of those included in the follow-up, 25 children (64\%) acquired/obtained and used the AT solution, while 14 children (36\%) did not acquire/obtain the recommended AT solution. Of those children without AT $(n=14), 3(21 \%)$ did use an AT solution which was available in their schools but different from the one recommended by the CAT; 6 (43\%) did not follow the CAT recommendations; and, 5 (36\%) never acquired/obtained the AT solution due to either long waiting times for obtaining the device through public funding $(n=4)$ or bureaucratic issues $(n=1)$. Children who obtained and used the AT solution and those who did not differed by place of origin, Chi square $(2, \mathrm{~N}=39)=3.40$, $\mathrm{p}=0.1$; diagnosis, $\mathrm{c}^{2}(1, \mathrm{~N}=39)=.094, \mathrm{p}=.7$; gender, Chi square $(1, \mathrm{~N}=39)=.001, \mathrm{p}=.9$; and chronological age, $\mathrm{t}(37)=0.64, \mathrm{p}=0.5$.

\section{Perceived effectiveness (IPPA)}

On average, at group level, the change in IPPA score was $4.72(S D=3.74)$ with an effect size of 1.2 which, according to Cohen's criterion, should be considered large. For Communication, General Tasks \& Demands, and Interpersonal Interactions a large effect was surveyed, with effect sizes respectively of 1.4, 1, and 1.5 (Table 2). Problems afferent to Learning \& Applying knowledge and Community, Social, \& Civic Life were solved moderately with an equal effect size of 0.7 . Further, looking at Table 2 , it could appear that most problems were solved well $(67 \%, n=51)$. However, a substantial number of problems $(30 \%, n=23)$ show no effect at all $(n=20)$ or even a negative effect $(n$ $=3)$. Only very few problems $(3 \%, n=2)$ show a moderate effect. 
Table 1. Participants' baseline information.

\begin{tabular}{|c|c|c|c|c|}
\hline & $\begin{array}{l}\text { All participan- } \\
\text { ts }(n=45)\end{array}$ & $\begin{array}{l}\text { Participants } \\
\text { with AT } \\
(n=25)\end{array}$ & $\begin{array}{l}\text { Participants } \\
\text { without AT } \\
(n=14)\end{array}$ & $\begin{array}{l}\text { Participants } \\
\text { without fol- } \\
\text { low-up } \\
(n=6)\end{array}$ \\
\hline Mean age (SD) & $10,5(4,5)$ & $10,4(3,6)$ & $10,8(3,8)$ & $12(6,9)$ \\
\hline \multicolumn{5}{|l|}{ Gender (\%) } \\
\hline Male & $23(51)$ & $11(44)$ & $7(50)$ & $5(83)$ \\
\hline Female & $22(49)$ & $14(56)$ & $7(50)$ & $1(17)$ \\
\hline \multicolumn{5}{|l|}{ Place of origin (\%) } \\
\hline Bologna & $8(18)$ & $1(4)$ & $3(21)$ & $4(66)$ \\
\hline E-R & $13(29)$ & $8(32)$ & $5(36)$ & $0(0)$ \\
\hline Rest of Italy & $24(53)$ & $16(64)$ & $6(43)$ & $2(34)$ \\
\hline \multicolumn{5}{|l|}{ Diagnosis (\%) } \\
\hline Cerebral palsy & $36(80)$ & $19(76)$ & $12(86)$ & $5(83)$ \\
\hline Hemiplegia & $3(8)$ & - & $2(16)$ & - \\
\hline Diplegia & $3(8)$ & - & - & $2(40)$ \\
\hline Diskinetic & $1(4)$ & $1(5)$ & - & $2(40)$ \\
\hline Tetraplegia & $21(58)$ & $12(63)$ & $8(68)$ & $1(20)$ \\
\hline Other not specified & $8(22)$ & $6(32)$ & $2(16)$ & - \\
\hline GS & $5(11)$ & $3(12)$ & $1(7)$ & $1(17)$ \\
\hline Other not specified & $4(9)$ & $3(12)$ & $1(7)$ & - \\
\hline \multicolumn{5}{|l|}{ Type of AT* $(\%)$} \\
\hline Communication & $21(46)$ & $11(44)$ & $8(57)$ & $2(33)$ \\
\hline ICT access solution & $28(62)$ & $19(76)$ & $8(57)$ & $2(33)$ \\
\hline Adapted toys & $4(9)$ & $2(8)$ & $1(7)$ & $1(17)$ \\
\hline Educational software & $9(20)$ & $5(20)$ & $3(21)$ & $1(17)$ \\
\hline
\end{tabular}

* The sum is larger than the number of users included because in some cases the users were recommended for more than one AT device; SD, standard deviation; E-R, Emilia-Romagna region; GS, genetic syndrome; ICT, information and communication technologies. 


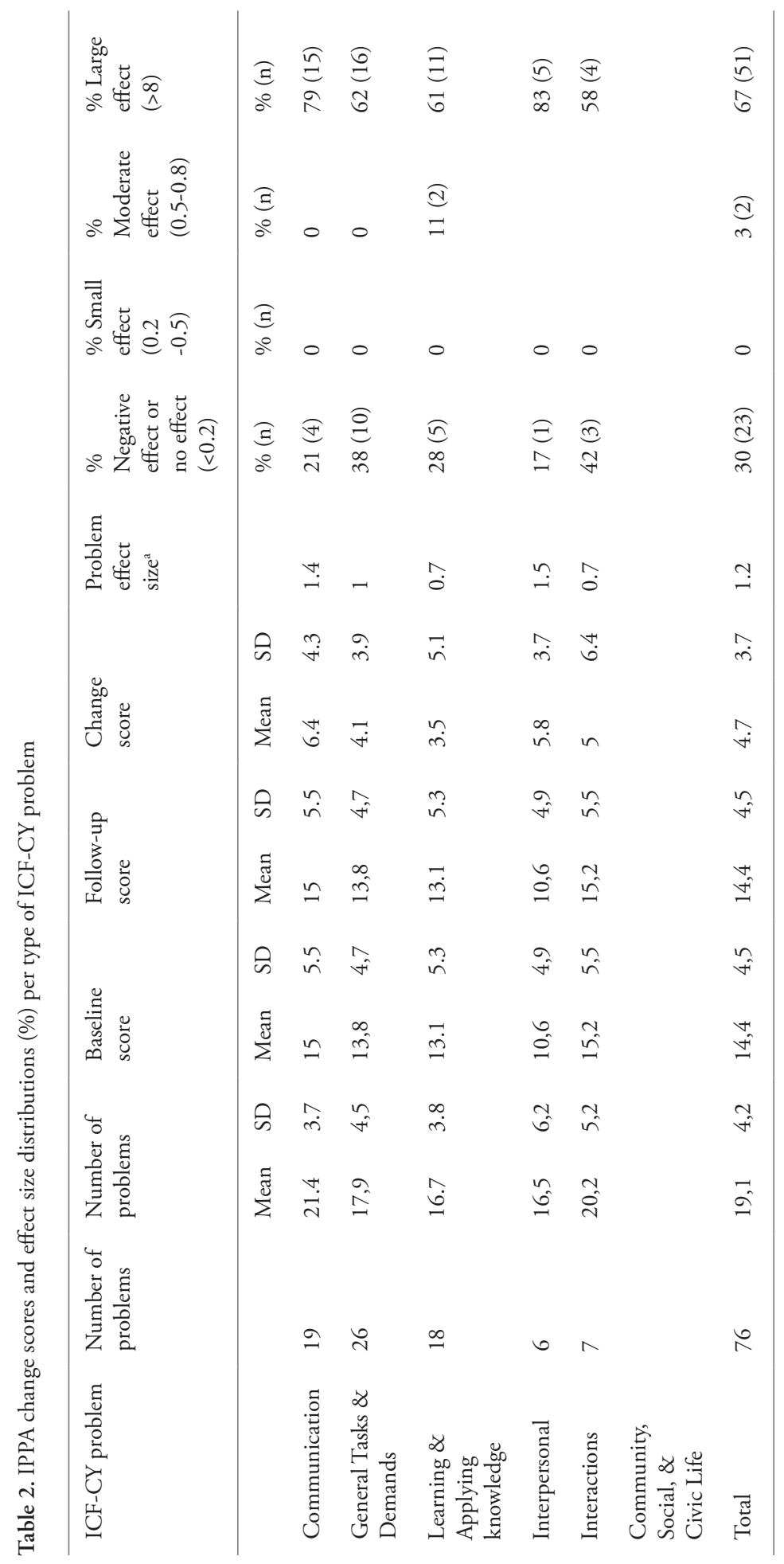




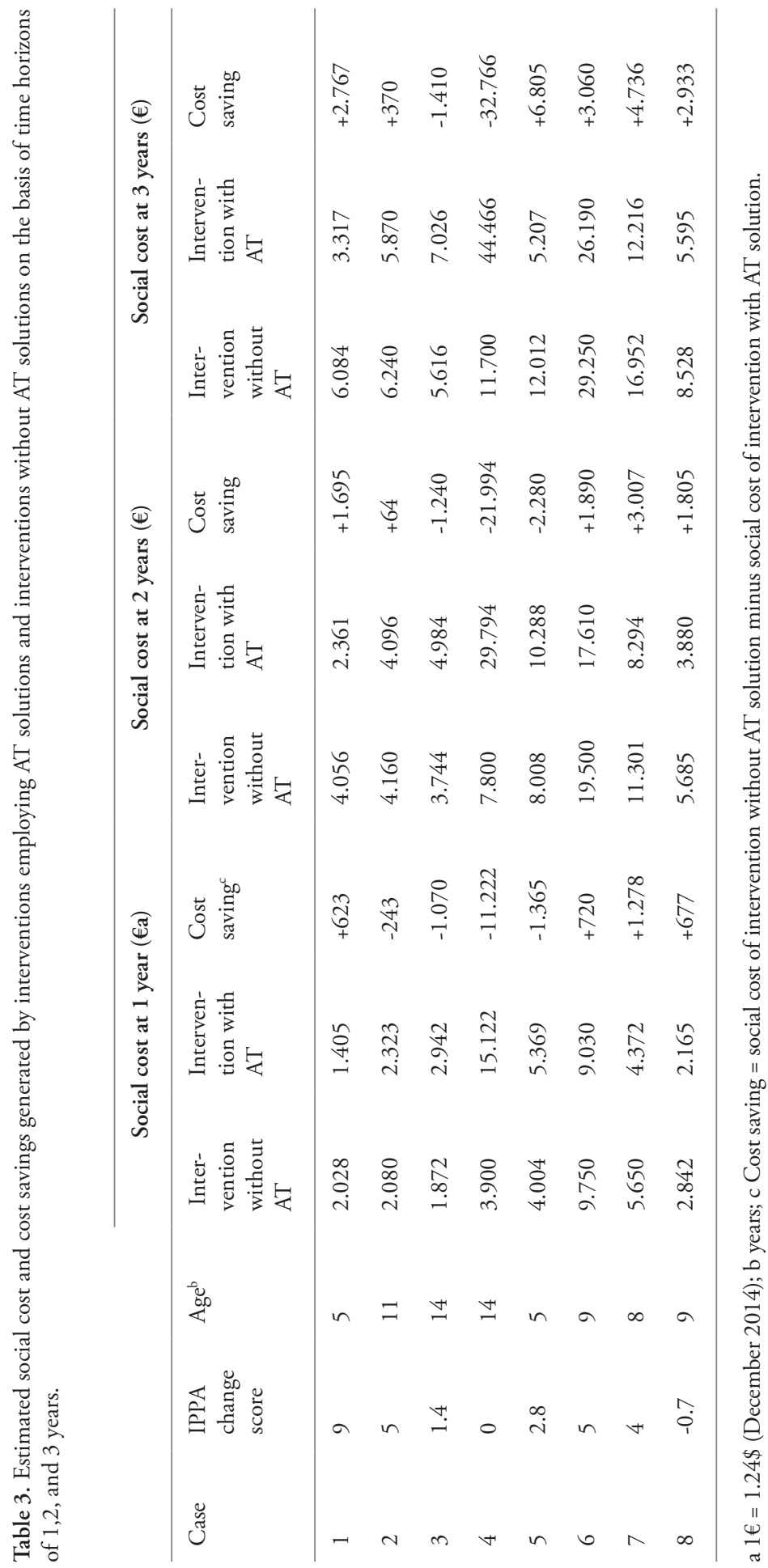




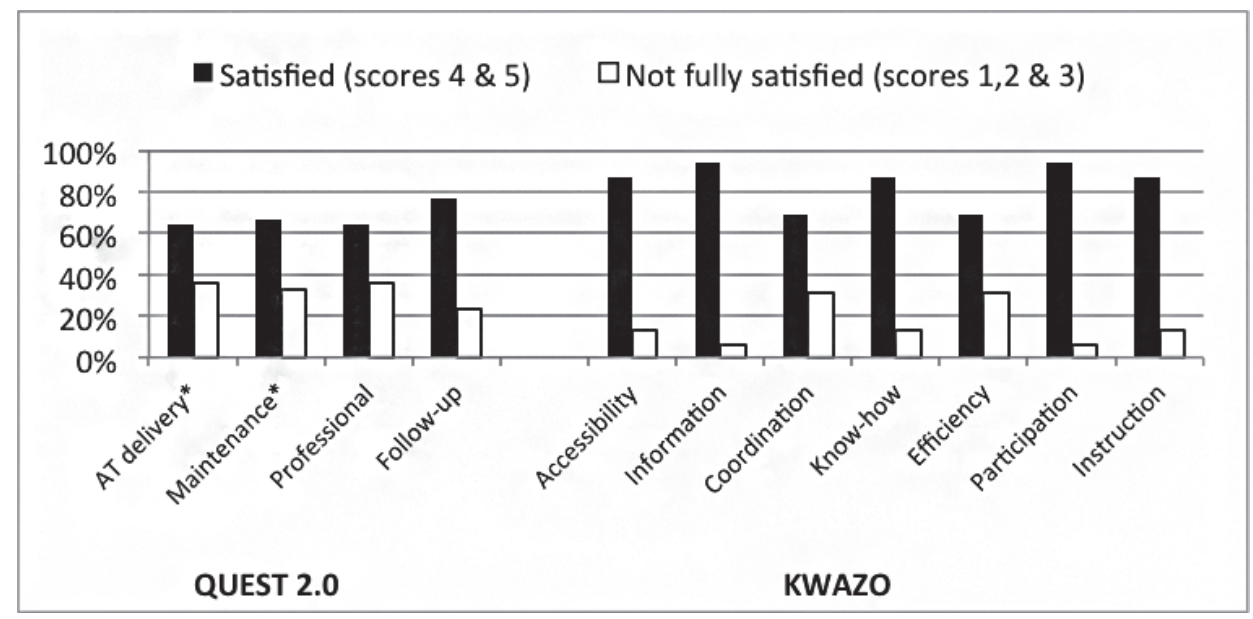

Figure 2. Satisfaction with ATSD. The asterisks indicate the items scored below the satisfactory level (scores $1,2 \& 3)$ in more than $33 \%$ of the cases.

\section{AT service delivery satisfaction (QUEST 2.0 and KWAZO)}

In total, 16 out of $25(64 \%)$ parents of children who used the AT solution completed the online survey. The results (Figure 2) clearly highlight the dimensions of the AT service delivery that resulted as not satisfying the users' requirements. Maintenance, Professional services, and AT delivery were rated not satisfactory in 36\%, 33\%, and $36 \%$ of cases respectively. Follow-up services, instead, were positively rated by $77 \%$ of cases. Notably, all items of the QUEST 2.0 had some missing responses, 5 (31\%) for AT delivery; 10 (62\%) for Maintenance; 2 (12\%) for professional services; and, 3 (19\%) for Follow-up. Although below the threshold, efficiency and coordination items of the KWAZO were rated as not satisfactory in $31 \%$ of all cases. No missing responses were recorded for the KWAZO.

In all, 10 comments were left, 7 in the KWAZO and 3 in the QUEST 2.0. A summary of the comments left by AT professionals and parents is shown in Table 4. Comments regarding the KWAZO refer mainly to problems in obtaining the AT solution due to bureaucratic issues related to healthcare professionals $(n=2)$ and to coordination between healthcare and school professionals $(n=2)$. Lack of competence was highlighted in 3 comments both on the healthcare and on the school side. In the comments regarding the QUEST 2.0, two respondents complained about a lack of verification of the AT use on the side of the healthcare professionals, while one respondent reported that he himself performed maintenance activities and thus was unable to provide a score to the related item.

\section{Social cost}

In all, 8 children ( $M=9.37$ years, $S D=3.50$ years) using ICT access solutions were included in economic analyses. In Table 3 , the estimated social cost of the AT intervention 
is shown together with the corresponding estimation of the resources that could have been spent if the intervention did not employ an AT solution. For AT interventions, social cost ranged from $€ 1.405$ to $€ 15.122$ after one year of AT use; from $€ 2.361$ to $€ 29.794$ after two years; and, from $€ 3.317$ to $€ 44.466$ after three years. For the same intervention without AT solution, social cost ranged from $€ 1.872$ to $€ 9.750$ in year 1; from $€ 3.744$ to $€ 19.500$ in year 2 ; and, from $€ 5.616$ to $€ 29.250$ in year 3 . It must be noted that, from data shown in Table 3, the resources estimated to be spent for using an AT solution exceed those estimated for human assistance alone in 4 cases in year one, in 3 cases in year 2 , and in 2 cases in year 3 .

\section{Feasibility}

Seventy-two attempts were needed $(M=1.84, S D=1.13)$ to contact the users $(n=45)$. The average time spent to conduct follow-up interviews $(n=39)$ was 17.89 minutes $(S D=$ 7.36). Six AT professionals (one psychologist, one physiotherapist, one occupational therapist, two AT technicians, and one social educator) were involved in the baseline and follow-up interviews and answered to the feasibility questions. Table 4 shows ratings given by professionals to each instrument employed in this study. An overall positive attitude towards the instruments employed was found except for the SCAI $(M=3.25$, $S D=3.30$ ) which resulted not suitable for the CAT follow-up procedure. Main concerns about the SCAI were related to its applicability to a limited set of AT interventions and to the reliability of the information collected, on the basis of which cost estimates are calculated. IPPA also elicited some concerns, though it was, in general, well accepted ( $M$ $=6, S D=2.23)$. Concerns about IPPA mainly relate to the reliability of the information collected, due to the difficulties encountered by respondents in attributing a score to both importance and difficulty values. Despite some critical aspects related to the instruments employed, both AT professionals and users considered the AT follow-up procedure feasible and acceptable with an overall score of $7.33(S D=2.51)$ for the former and $8.81(S D=1.27)$ for the latter. Some issues, however, still remain to be fixed, as for example the exigency to shorten the time needed to perform the whole interview. 
Table 4. Follow-up procedure feasibility evaluations from AT professionals and users.

\begin{tabular}{|c|c|c|c|}
\hline & $\begin{array}{l}\text { AT } \\
\text { professionals }^{1} \\
(n=6)\end{array}$ & $\begin{array}{l}\text { Users }^{1} \\
(\mathrm{n}=16)\end{array}$ & Comments \\
\hline IPPA (SD) & $6(2.2)$ & - & $\begin{array}{l}\text { - In general, easy to administer. Respondents } \\
\text { experience some difficulties in provid-ing an exact } \\
\text { score; } \\
\text { - Problems described by parents are often too ge- } \\
\text { neral, so it is difficult to detect whether something } \\
\text { has changed; } \\
\text { - The problems identified may come from AT } \\
\text { professionals and not from stakehold-ers. This is } \\
\text { a potential risk that AT professionals should be } \\
\text { aware of. }\end{array}$ \\
\hline QUEST 2.0 (SD) & $8(1.4)$ & - & - No comments. \\
\hline KWAZO (SD) & $7.3(3)$ & - & $\begin{array}{l}\text { - Sometimes respondents have some difficulties } \\
\text { in thinking about the ATSD as a pro-cess invol- } \\
\text { ving other AT providers other than CAT, so their } \\
\text { responses are biased by their opinions about CAT. }\end{array}$ \\
\hline SCAI (SD) & $3.2(3,3)$ & - & $\begin{array}{l}\text { - Useful tool, but not for any type of AT inter- } \\
\text { vention; } \\
\text { - In certain cases, Some concerns about consi- } \\
\text { stency of the information collected; }\end{array}$ \\
\hline $\begin{array}{l}\text { Overall follow-up } \\
\text { procedure }(S D)\end{array}$ & $7.3(2.5)$ & $\begin{array}{l}8.8 \\
(1.2)\end{array}$ & $\begin{array}{l}\text { - It is still time consuming both for the professio- } \\
\text { nal and for the respondent }(\mathrm{P}) \text {; } \\
\text { - Follow-up should be cyclic and not limited to a } \\
\text { single contact after the AT imple-mentation and } \\
\text { initial use }(\mathrm{U}) \text {; }\end{array}$ \\
\hline
\end{tabular}

1 Range 1-10; $(\mathrm{P})=$ AT Professional; $(\mathrm{U})=$ User; CAT, Centre for Assistive Technology 


\section{Discussion}

The current study focused on outcomes of AT service delivery targeting children with physical and multiple disabilities in the attempt to document its perceived effectiveness, users' satisfaction and social cost. A secondary aim was to evaluate the feasibility of the procedure adopted to follow-up the AT service delivery, in order to implement it in routine clinical practice.

Implications of the results from the current study for research and AT practice are discussed in the following sections.

\section{Rate of AT non-use}

From the current study, it resulted that almost one in three children assessed by the CAT service did not obtain the AT solution. There are no data available concerning AT non-use in the Italian context regarding children. In general, non-use rates may differ between countries due to factors such as funding, organization of AT service delivery, and professional training ${ }^{4}$. From the few data available internationally, non-use rates of AT provided among children are reported from $10 \%$ up to $23 \%$, depending on the type of $\mathrm{AT}^{4}$. Thus, the results of the current study (36\%) seem to mirror or even exceed those found in other contexts. Although the specific causes for such a high rate of AT non-use after the AT assessment have not been carefully analysed, the organization and efficiency of the AT service delivery may have played a pivotal role in reducing the number of children who obtained an AT. In detail, obtaining the most adequate AT solution may be problematic for a number of factors. We shall consider, for example, the AT service delivery phase between the AT assessment and the obtaining of the AT solution (namely, Authorization phase). From responses of parents who intended to use the AT solution recommended but did not obtain it $(n=5)$, it emerged that in this phase, the family is usually alone and has to face several challenges including bureaucratic issues and a lack of coordination between healthcare and school professionals who, in some cases, had not even participated in the AT assessment. Again, coordination and the active involvement of all stakeholders seems to be crucial for the adoption of the AT solution. In addition, little attention towards the child's context and the family needs may also explain why more users did not obtain the recommended AT $(n=9)$. Together, these last results point to the need for AT professionals to conduct a complete assessment of the child's needs in terms of both functions to be increased through the employment of an AT solution, and complexities associated with the context in which the solution will be implemented. . Further, these findings also indicate that changes in the social and political environments may benefit children, specifically reducing bureaucratic barriers and improving coordination between professionals and agencies.

\section{Perceived AT effectiveness (IPPA)}

To our knowledge, this is the first study documenting the use of IPPA with a paediatric population. In the current study we found that provision of AT solutions reduced 
parents' perceived difficulty for the children to perform important activities. This result is consistent, in particular, for activities related to the dimensions of the ICF-CY of Communication, and of Learning and Applying Knowledge. On average, in the shortterm, the majority of children's difficulties were addressed rather well, with $67 \%$ of effect sizes showing a large effect. However, a substantial proportion of AT solutions provided (30\%) did not address properly the difficulties experienced by children, resulting in either no effect or a negative effect. This latter result calls AT service delivery towards a more structured and family-oriented approach and, most importantly, towards a structured and continuous evaluation of the effect of the AT interventions.

Data on perceived effectiveness here presented, however, should be considered with caution. In general, there are numerous challenges implied in the interpretation of outcome measures in AT practice. One relates to the variability of the population considered in this study. Although the heterogeneity of the population here involved reflected the variability that usually CAT professionals face in their daily practice, however, to assess effectiveness of AT intervention, further research is needed, controlling a number of factors in terms of, i.e., types and degrees of disabilities, socioeconomic status, and children's age.

Further, the paucity of research available makes it difficult for clinicians to determine whether the sample of users with an AT solution has moved from a dysfunctional to a more functional sample of scores. Literature provides no information on the degree of change on the IPPA score that could be considered as a significant change ${ }^{38}$. It follows that the overall average change score of 4.7 , found in this study for children who obtained and used the AT solution, does not provide any information about the clinical significance of the change. Change scores found in other studies, in which the IPPA was employed to assess effectiveness, range, on average, from $17.5(S D=12.8)^{39}$ to 19.8 ( $S D$ $=13.3)^{36}$. These studies, however, investigated the effects of mobility devices and involved an adult sample, two differences that, in our opinion, make it impossible to draw any firm conclusion about the clinical significance of the change found in our study. To face with these limitations, for both research and clinical purposes, IPPA may be integrated within a battery of tools aimed at assessing the outcome of AT interventions from a multidimensional perspective. Such a battery may include the measurement, other than the reduction in the child's activity limitations as assessed by IPPA, also of AT effects on the child's participation ${ }^{40}$, achievement of educational and developmental goals ${ }^{13,41}$, and family well-being ${ }^{42}$.

Regarding the applicability of IPPA in clinical practice, two main problems were experienced by AT professionals. The first concerns the lack of clarity of the problems listed by respondents; while the second concerns the lack of reliability of the difficulty scores. In some cases, when asked to provide a list of problematic activities, parents proposed activities either indefinite (e.g., "autonomy") or unrealistic (e.g., "she doesn't communicate like her peers do"). In our opinion, the lack of clarity may be due not to the characteristics of the tool itself, but may depend on the strategies adopted by the AT team during the AT assessment. To fully capitalize on the potential of IPPA, the AT assessment phase should be structured in such a way to derive clear objectives for AT use. This would require AT professionals to employ instruments along the whole 
assessment process, once they have been capable of allowing professionals, children and their parents to clearly identify only those problematic activities that could benefit from an AT solution and to define quantifiable objectives of the AT use ${ }^{43}$. This would simplify the employment of the IPPA and, in turn, would make the scoring provided by parents more accurate as well. In this view, the implementation of IPPA may positively feed-back on the whole AT service delivery by motivating professionals to adopt validated instruments or strategies in any aspect of the AT service delivery, and not only for assessing its outcomes ${ }^{44}$.

Overall, however, IPPA has been perceived by AT professionals as an easy and straightforward tool, and only a minority of users found some difficulties in completing it. It follows that, on the basis of our results, for the purposes of documenting outcomes from a proxies' perspective, and for a variety of AT users and AT interventions, IPPA may be a useful tool also for children.

\section{Satisfaction with ATSD (QUEST 2.0 and KWAZO)}

Most respondents were satisfied by the service delivery process. Data on parents'satisfaction with AT service delivery found here partially mirror those found in an earlier study focusing on the same AT service. Desideri and colleagues ${ }^{45}$ investigated the experience of children's parents with AT service delivery in an Italian region employing the QUEST 2.0 and the KWAZO scales. Six of them participated in two focus groups. In that study, relatively negative ratings were reported for AT delivery, maintenance services, and follow-up strategies as measured with the QUEST 2.0; and, accessibility, coordination between stakeholders, and general efficiency of AT service delivery as measured with the KWAZO. Similarly, in the current study both AT delivery and maintenance services were rated as not satisfying by the users involved in the survey, probably due to long waiting times for, respectively, obtaining the recommended AT solution and receiving modifications to the AT solution. The previous study ${ }^{45}$ was conducted when the AT service under investigation did not provide a structured and systematic AT follow-up. From the data collected, it emerged that users (47\%) felt a 'sense of abandonment' due to a lack of a systematic follow-up of the AT intervention. In the current study, however, the follow-up services were in general positively rated (77\% of satisfied users). This result may reflect a positive outcome of the follow-up procedure here employed, and may be interpreted as a reduction of the sense of abandonment found in the previous study.

Again, further research is needed involving a larger sample of users to confirm the positive trend found in the current study.

The utility of QUEST 2.0 and KWAZO for documenting user satisfaction with ATSD is widely recognized $27,28,46$. The relatively high response rate found in this study (64\%), supports the feasibility of implementing such instruments in clinical routine outcome assessment. The relatively high percentage of missing responses in the QUEST 2.0 found in this study, in our opinion, may be due to the fact that some respondents did not receive certain services and thus did not answer to the related items. 


\section{Social cost (SCAI)}

Economic evaluation in the field of AT presents several challenges to AT professionals $s^{32}$. Among these, there are the complexities associated to the multiple variables that are specific to each child and that may change rapidly ${ }^{31}$. In addition, another challenge lies in configuring general tools to make them useful across the AT solutions and contexts in which the ATSD is provided ${ }^{32}$. To face these challenges, on the basis of previous experience ${ }^{31}$, the social cost analysis here presented was conducted in a very prudent way, targeting only those children for whom there was a single AT solution tackling a single AT objective. In the present study, we found an increase in resources spent when the AT solution is included in the child's context. Given the population under investigation, these results are not surprising. Negative cost savings indicate that the AT solutions do not eliminate or even reduce the need for assistance. On the contrary, in certain cases the introduction of an AT solution may require more resources. This is particularly evident, for example, in case 4 (see Table 3), for whom new professional assistance is needed due to the introduction of an ICT solution in the classroom which may lead, after 3 years, to an amount of resources spent of $€ 44.466$ in comparison with $€ 11.700$ cost of human assistance alone. The analysis of social cost, in our opinion, becomes meaningful only when a multidimensional approach is used. For this reason, in Table 5 we showed IPPA change scores together with SCAI estimates for each case considered in the social cost analysis. Following the previous example, looking at IPPA change scores, the resources to be spent in case 4 seem to be not justified after 3 months of AT use. On the basis of this evaluation, AT professionals may activate a reassessment of the child's situation in order to identify shortcomings in the AT intervention with the aim to increase the benefit for the child. In this view, the estimate of the social cost may serve as a useful monitoring tool to document the resources that would have been spent without changes in the AT intervention after the assessment of its effectiveness.

Concerns however remain about the employment of the SCAI in routine clinical practice when children and AT interventions employing AT solutions for communication, play and learning activities are considered. In this study SCAI was applied in a restricted way. Although the SCAI requires to be completed for each AT device recommended, usually children are recommended with more than one AT device (e.g., a personal computer with an access solution and educational software). From a pilot-test conducted by CAT professionals before the current study and involving 10 children $^{31}$, it resulted that the SCAI took too long (30-45 minutes) to be administered when more than one technological device is considered. The long time needed to administer the tool and the necessity to compile the SCAI for each AT solution identified may represent obstacles for the widespread use of this instrument in clinical practice. 


\section{Conclusions}

Findings from the current study show that AT solutions represent an investment which may lead to a reduction of children's activity limitations, thus increasing their opportunities to communicate, learn, and play.

In this study we assumed that without information about evidence of AT interventions and strategies to collect outcomes through proper instruments, the AT field will struggle to substantiate and guide practice ${ }^{47}$. To face this issue, AT professionals are required to adopt evidence-based practices and in particular to evaluate quality with respect to all aspects of AT service delivery ${ }^{5,48,49}$. Results from this study, other than documenting the effectiveness of AT interventions targeting children with physical and multiple disabilities, demonstrate the feasibility of implementing a routine outcome assessment in clinical practice employing existing AT specific instruments. Thanks to this study, the outcome tools have been implemented in the routine CAT clinical activities, and will serve to develop an evidence base which will help CAT professionals monitor the quality of AT, their interventions and the whole AT service delivery process from a family perspective. 


\section{References}

1. Anttila H, Samuelsson K, Salminen AL, Brandt Å. Quality of evidence of assistive technology interventions for people with disability: An overview of systematic reviews. Technology and Disability 2012, 24(1): 9-48.

2. Henderson S, Skelton H, Rosenbaum P. Assistive devices for children with functional impairments: impact on child and caregiver function. Developmental Medicine \& Child Neurology 2008, 50(2): 89-98.

3. Parette H, Peterson-Karlan G. Facilitating Student Achievement with Assistive Technology. Education and Training in Developmental Disabilities 2007, 42(4): 387-397.

4. Østensjø I. Assistive Devices for Children with Disabilities. In: Söderback I, editor. International Handbook of Occupational Therapy Interventions. New York: Springer; 2009. p. 141-146.

5. de Witte L, Knops H, Pyfers L, Röben P, Johnson I, Andrich R., Paganin A, Parker M, Forsberg S. European Service Delivery System in Rehabilitation Technology: A Comprehensive Description of Service Delivery Systems of 16 European Countries. HEART (Horizontal European Activities of Rehabilitation Technology) Line C [internet]. 1994 [cited June 2015]. Available from http://portale.siva.it/files/doc/ library/a416_1_ATServiceDelivery_HEART_ReportC51.pdf

6. Lee H, Templeton R. Ensuring equal access to technology: Providing assistive technology for students with disabilities. Theory into practice 2008, 47(3): 212-219.

7. Wise PH. Emerging technologies and their impact on disability. The Future of Children 2012, 22(1), 169-191.

8. Lindsay S, Tsybina I. Predictors of unmet needs for communication and mobility assistive devices among youth with a disability: the role of socio-cultural factors. Disability \& Rehabilitation: Assistive Technology 2011, 6(1): 10-21.

9. Campbell SM, Roland MO, Buetow SA. Defining quality of care. Social Science \& Medicine 2000, 51(11): 1611-1625.

10. Edyburn DL, Smith RO. Creating an assistive technology outcomes measurement system: Validating the components. Assistive Technology Outcomes and Benefits 2004, 1(1): 8-15.

11. Fuhrer MJ, Jutai JW, Scherer MJ, DeRuyter F. A framework for the conceptual modelling of assistive technology device outcomes. Disab \& Rehabil 2003, 25(22): 1243-1251.

12. Phillips B, Zhao H. Predictors of assistive technology abandonment. Assistive Technology 1993, 5(1): 36-45.

13. Parette HP, Peterson-Karlan GR, Smith S, Gray T, Silver-Pacuilla H. The State of Assistive Technology: Themes from an Outcomes Summit. Assistive Technology Outcomes and Benefits 2003, 3(1): 15-33.

14. Steel EJ, de Witte, LP. Advances in European Assistive Technology service delivery and recommendations for further improvement. Technology and Disability 2011, 23(3): 131-138.

15. RESNA. Volume I: RESNA Resource Guide for Assistive Technology Outcomes: Measurement Tools. Arlington, VA; 1998.

16. Gelderblom GJ, de Witte LP. The assessment of assistive technology outcomes, effects and costs. Technology and Disability 2002, 14(3): 91-94.

17. Federici S, Scherer M. Assistive technology assessment handbook. Boca raton, FL: CRC Press; 2012

18. Association for the Advancement of Assistive Technology in Europe (AAATE). Service Delivery Systems for Assistive Technology in Europe: Position Paper [Internet]. 2012 [cited 19 June 2015]. Available from: http://www.aaate.net/sites/default/files/ATServiceDelivery_PositionPaper.pdf

19. Benedict RE, Lee JP, Marrujo SK, Farel AM. Assistive devices as an early childhood intervention: Evaluating outcomes. Technology and Disability 1999, 11(1): 79-90.

20. Clarke M, McConachie H, Price K, Wood P. Speech and language therapy provision for children using augmentative and alternative communication systems. European journal of special needs education 2001, 16(1): 41-54.

21. Murchland S, Kernot J, Parkyn H. Children's satisfaction with Assistive technology solutions for schoolwork using the QUEST 2.1: Children's version. Assistive Technology 2011, 23(3): 162-176.

22. Salminen AL, Petrie H. Impact of computer augmented communication on the daily lives of speech-impaired children. Part II: Services to support computer augmented communication. Technology and Disability 2004, 16(3): 169-177. 
23. Parette P, VanBiervliet A, Hourcade JJ. Family-centered decision-making in assistive technology. Journal of Special Education Technology 2000, 15(1): 45-55.

24. Pickard AS, Knight SJ. Proxy evaluation of health-related quality of life: a conceptual framework for understanding multiple proxy perspectives. Medical care 2005, 43(5): 493.

25. Wessels R, de Witte L, Andrich R, Ferrario M, Persson J, Oberg B, Oortwijn W, VanBeekum T, Lorentsen $\varnothing$. IPPA: Individually prioritised problem assessment. Technology and Disability 2002, 14(3): 141-145.

26. Dijcks BP, Wessels RD, De Vlieger SL, Post MW. KWAZO, a new instrument to assess the quality of service delivery in assistive technology provision. Disab Rehabil 2006, 28(15): 909-914.

27. Desideri L, Bitelli C, Brandan V, de Witte L. The Employment of KWAZO with Parents of Children with Disabilities in an Italian Region: Preliminary Data on Scale Adaptation and Validation. 12th biennial European conference of the Association for the Advancement of Assistive Technology in Europe. Amsterdam: IOS Press; 2013. p. 1059 - 1063.

28. Demers L, Weiss-Lambrou R, Ska B. The Quebec User Evaluation of Satisfaction with Assistive Technology (QUEST 2.0): An overview and recent progress. Technology and Disability 2002, 14(3): 101-105.

29. Andrich R. The SCAI instrument: Measuring costs of individual assistive technology programmes. Technology and Disability 2002, 14(3): 95-99.

30. Andrich R, Caracciolo, A. Analysing the cost of individual assistive technology programmes. Disability \& Rehabilitation: Assistive Technology 2007, 2(4): 207-234.

31. Bensi N, Bitelli C, Hoogerwerf E. Assistive technologies and other solutions for independence: cost or investment?. 11th European Conference of the Association for the Advancement of Assistive Technology in Europe. Amsterdam: IOS Press; 2011. p. 270 - 277.

32. Harris F, Sprigle S. Cost analyses in assistive technology research. Assistive Technology 2003, 15(1): 16-27

33. World Health Organization. International Classification of Functioning, Disability, and Health: Children \& Youth Version: ICF-CY. Geneva: World Health Organization; 2007.

34. Cohen J. Statistical Power Analysis for the Behavioral Sciences. (2nd ed.), New York, NY: Academic Press; 1988.

35. Jedeloo S, Witte LD, Linssen BAJ, Schrijvers AJP. Client satisfaction with service delivery of assistive technology for outdoor mobility. Disabil Rehabil 2002, 24(10): 550-557.

36. Wessels RD, De Witte, LP, Jedeloo S, van den Heuvel WP, van den Heuvel WJ. Effectiveness of provision of outdoor mobility services and devices in The Netherlands. Clinical Rehabilitation 2004, 18(4): 371-378.

37. Demers L, Weiss-Lambrou R, Ska B. Quebec User Evaluation of Satisfaction with Assistive Technology: QUEST version 2.0 [internet]. 2000. Available from: http://www.midss.org/sites/default/files/questmanual_final_electronic20version_0.pdf .

38. Tam C, Archer J, Mays J, Skidmore G. Measuring the outcomes of word cueing technology. Canadian Journal of Occupational Therapy 2005, 72(5): 301-308.

39. Jedeloo S, De Witte L, Schrijvers G. A user-centred approach to assess the effectiveness of outdoor mobility devices and services. Int J Rehabil Res 2002, 25(2):137-41.

40. Besio S, Salminen AL. Children and youngsters and technology. Technology and Disability 2004, 16(3): 115-117.

41. Mumford L, Lam R, Wright V, Chau T. An access technology delivery protocol for children with severe and multiple disabilities: A case demonstration. Developmental neurorehabilitation 2013, 17(4): 232-242.

42. Nicolson A, Moir L, Millsteed J. Impact of assistive technology on family caregivers of children with physical disabilities: a systematic review. Disability and Rehabilitation: Assistive Technology 2012, 7(5): 345-349.

43. Desideri L, Roentgen U, Hoogerwerf EJ, de Witte L. Recommending assistive technology (AT) for children with multiple disabilities: A systematic review and qualitative synthesis of models and instruments for AT professionals. Technology and Disability 2013 25(1): 3-13.

44. Desideri L, Ioele F, Roentgen U, Gelderblom GJ, de Witte L. Development of a team-based method for assuring the quality of assistive technology documentation, Assistive Technology 2014, 26(4): 175-183.

45. Desideri L, Stefanelli B, Bitelli C, Roentgen U, Gelderblom GJ, de Witte L. Satisfaction of users with 
assistive technology service delivery: an exploratory analysis of experiences of parents of children with physical and multiple disabilities. Developmental Neurorehabilitation in press.

46. Ahtola S, Heinonen A, Haikonen K, Anttila H. Adaptation and validation of the modified KWAZO and EATS-2D instruments into Finnish circumstances. 11th European Conference of the Association for the Advancement of Assistive Technology in Europe Amsterdam. Amsterdam: IOS Press; 2011. p. 300-307.

47. Watson AH, Smith RO. Comparison of two school-based assistive technology outcome instruments. Technology and Disability 2012, 24(1): 83-92.

48. Lenker JA, Fuhrer MJ, Jutai JW, Demers L, Scherer MJ, DeRuyter F. Treatment theory, intervention specification, and treatment fidelity in assistive technology outcomes research. Assistive Technology 2010, 22(3): 129-138.

49. Lenker JA, Shoemaker LL, Fuhrer MJ, Jutai JW, Demers L, Tan CH, DeRuyter F. Classification of assistive technology services: Implications for outcomes research. Technology and Disability 2012, 24(1), 59-70. 
Chapter 7

General Discussion 

It has been widely documented in the field of assistive technology (AT) that many people, and in particular children with disabilities, struggle to obtain AT solutions due to organizational, financial or bureaucratic issues ${ }^{1}$. Furthermore, once the AT solution is obtained, its appropriateness and effects are seldom evaluated ${ }^{2,3}$. In this thesis, it has been assumed that these issues relate to the broader concept of quality of AT service delivery (ATSD). In general, care quality is a complex, multi-perspective, and multi-dimensional concept ${ }^{4}$. Increasingly, healthcare providers express a need to define and measure quality so that better programmes can be developed, better quality of care delivered, and programmes and quality evaluated ${ }^{5}$. Although ATSD is usually part of the healthcare system, surprisingly little research has been conducted into how AT professionals could measure ATSD-related quality.

The position paper published by the Association for the Advancement of Assistive Technology in Europe ${ }^{6}$ strongly recommends that a 'common way to describe the service delivery process and measure its quality should be found' (p. 13). The aim of the research project here described was to translate this recommendation into practice by developing and implementing a structured procedure to assure quality and estimate the cost associated with a specific ATSD process. Furthermore, particular attention has been given to the use of the instruments and conceptual tools elaborated by the AT community, active in the European Union since the Horizontal European Activities in Rehabilitation Technology study ${ }^{7}(\mathrm{HEART}$.

To achieve this objective, the research project was split into different research actions, described in Chapters 2 to 6 . The scope of this present Chapter is to provide critical analysis of the main findings of each research action. Following this, implications for AT professionals and health policy are discussed. Lastly, perspectives for future research are outlined.

\section{Main Findings}

\section{Available Evidence on Service Delivery Practices}

A systematic review was conducted in order to identify the models and instruments specifically developed in the AT field for guiding AT professionals in the selection of the most adequate technological solution for children with multiple disabilities ${ }^{8}$. The focus on AT assessment was chosen as this represents one of the main activities by the Centre for AT (CAT). In addition, AT assessment is a fundamental step in the process of linking the child's needs with the outcomes of the AT intervention. In this view, it was assumed that the adoption of evidence-based practice for AT assessment targeting children with multiple disabilities could serve to develop the theoretical basis for the development of a strategy for measuring ATSD quality.

However, the review revealed a scarcity of research into this topic, and data on the effectiveness of most of the models and instruments was found to be lacking. In addition, information about follow-up after the AT implementation was also absent, and the reviewed work did not clarify what factors should be considered in evaluating the effectiveness of AT interventions in the case of children with multiple disabilities. 
These results are not surprising. AT professionals' resistance towards standardizing their practice is a well-recognized issue ${ }^{9}$. One possible reason why this happens also for AT interventions targeting children may be related to the variability of three inter-related factors: the child and his/her context, the technology, and the ATSD system. Firstly, variability in children and their contexts is the norm rather than the exception. The same diagnosis (e.g. tetraplegia due to cerebral palsy) may lead to extremely different developmental patterns. In addition, children change rapidly and so do their needs, along with those of their families. Secondly, there exists no AT solution with the scope to provide a standard answer to a problem or a class of problems. The AT device must almost always be chosen, adapted and personalized according to the child's (continuously changing) characteristics and needs, to his/her residual abilities, as well as to the utilization environment of the device itself. Thirdly, ATSD systems vary within and between countries, for which each provider needs to consider the unique social, cultural, educational, financial and political environment in which it operates. What works in one context may not work in a different one.

Added together, these factors may contribute to reducing the likelihood that AT professionals standardize the modality under which an AT solution is chosen ${ }^{10}$, and thus also impinge upon standard evaluation of both its effects on the final users and, more in general, ATSD quality.

Nevertheless, the emphasis on evidence-based practice pushes AT professionals to frame their work within a model that allows documentation of their operational methodology, and results, by means of a language shared by a community of operators which is ever vaster and from diverse cultural backgrounds.

\section{Identifying Targets for Change}

Following collection of (lacking) available evidence on models and instruments developed in the AT field to guide professionals in the selection of AT solutions and evaluation of AT interventions, Chapter 3 presented a study which provides a description of the role of the CAT within its specific service delivery system ${ }^{11}$. In this study, a model of AT assessment targeting children with multiple disabilities is described in detail, together with the instruments employed and the professionals involved. In addition, this study proposes the incorporation of a quality assurance model within AT practice in order to document ATSD quality and outcomes. The framework was based on the Donabedian triadic model for the evaluation of healthcare quality ${ }^{12}$. According to this model, information on ATSD quality may be collected from three information sources: structure, process and outcome. Although applied to the specific characteristics of the CAT service, two important factors make the proposed quality assurance framework generalizable to other contexts and systems. Firstly, it is based on the well-known quality-of-care model developed by Donabedian, which has proven valid for a wide variety of healthcare settings $^{12}$. Secondly, the instruments proposed for measuring the different quality facets have been developed specifically for AT solutions and validated in different contexts.

Improving the care process has been described as the primary objective of quality measurement and evaluation ${ }^{12,13}$. The ATSD quality assurance framework described in 
Chapter 3 was developed to allow AT professionals to understand and describe the actual care delivered. This was in order to identify ATSD-related aspects that needed to be changed or improved ${ }^{14}$. To this end, two studies were conducted, aimed at evaluating ATSD quality from the perspective of both AT professionals and parents to children with multiple disabilities.

\section{The Perspective of Assistive Technology Professionals}

To stimulate AT professionals in self-evaluating the quality of their own work, the study presented in Chapter 4 focused on an element of ATSD that usually receives scarce attention - at least as far as the Italian system is concerned - this being the written report provided to AT stakeholders at the end of the AT assessment ${ }^{15}$. In designing this study, it was assumed that the written report represents a synthesis of the different perspectives participating in the AT assessment. As such, it may reflect practical and theoretical issues that might emerge during ATSD from the AT professional's perspective. Reviewing the quality of the AT reports was considered a way to let professionals evaluate the quality of their own work and to set benchmarks for their performance in a manner that was perceived by the AT professionals as non-critiquing. From this study, a set of ten quality indicators was developed; these served to define, in an indirect way, what constitutes quality in the AT assessment process from an AT professional's perspective. The review, conducted by two independent raters, led to the identification of shortcomings related mainly (but not limited) to the AT assessment process. The results showed that the overall quality of the entire documentation reviewed had to be deemed unsatisfactory. The percentages of reports below the satisfactory level were $45.3 \%$ and $36 \%$ respectively for rater 1 and rater 2 . This negative result derived from five points - out of the ten quality indicators developed - emerging as not satisfied (Functional assessment, Environmental factors, Goal setting, Information, and Monitoring). Notable is that Information and Monitoring were the indicators that most frequently were not satisfied by the documentation reviewed. In detail, the quality of information provided to AT stakeholders on how to obtain the AT solution after assessment (Information) was rated below the satisfactory level in $72.2 \%$ of the reports by rater 1 and $82.3 \%$ of the reports by rater 2 ; the quality of the follow-up activities planned after AT implementation (Monitoring) was rated below the satisfactory level in $66.1 \%$ of the reports by rater 1 and $53.7 \%$ by rater 2 .

This result may be interpreted as a lack of attention posed by AT professionals towards the ATSD process activities that, to use the terminology adopted in Chapter 3, belong to the post-assessment phase. This phase in particular includes the application for funding, the implementation of the AT solution in the child's contexts and the eventual assessment of the effects of the AT solution.

\section{The Perspective of Parents}

The study presented in Chapter 5 was complementary to that presented in Chapter 4. A mixed-method research approach allowed in-depth investigation of parents' experi- 
ences of ATSD and identification of shortcomings in the ATSD process from their perspectives ${ }^{16}$. In detail, as regards the QUEST 2.0 (service subscale) results, low satisfaction scores were reported for follow-up services ( $47 \%$ of respondents were not fully satisfied), AT delivery (39\%), and maintenance services (47\%). KWAZO results showed low satisfaction scores in particular for access to AT services (51\%), coordination (34\%) and efficiency (53\%) of ATSD. Two focus-groups were conducted to follow up the results of the survey. To summarize the discussions, it clearly emerged that health services for children are too driven by the needs of health and AT professionals. More precisely, the health system seemed to focus disproportionally on acute services and less on long-term processes, which can too easily fragment service delivery and diminish quality. In particular, the long-term care system appeared to be characterized by high fragmentation in terms of responsibility management (e.g. who is in charge of evaluating the effectiveness of the AT intervention?). This may discourage a comprehensive child- and family-centred approach to health, with adverse consequences for the continuity of AT interventions.

\section{Implementing Change}

The study presented in Chapter 6 had the primary aim of evaluating the outcome of ATSD targeting children with multiple disabilities. Outcome may be measured at different conceptual levels, ranging from functional performance to quality of life ${ }^{17}$. The quality assurance framework developed in this thesis helped to further define such conceptual levels. In detail, AT outcomes have been classified in relation to the person (micro-level) and the health and social system in which the AT intervention takes place (macro-level). This distinction allowed the researchers to account for the specific type of information addressed by the instruments already available to AT professionals to assess AT solution outcome.

In this view, a structured follow-up procedure was developed and a battery of validated instruments was employed, covering different facets of ATSD outcome: AT effectiveness, ATSD user evaluation, and cost associated to AT intervention. Furthermore, since the studies presented in Chapters 4 and 5 provided converging evidence about shortcomings within the ATSD process, associated with the lack of a timely and well-structured follow-up service, a secondary aim of the study presented in Chapter 6 was to evaluate the feasibility of the strategy adopted to assess AT outcome with a view to implementing it in routine clinical practice.

\section{Cost-Outcome Analysis of Assistive Technology Service Delivery}

At follow-up, 25 children (64\%) had acquired/obtained and used the AT solution, while 14 children (36\%) had not acquired/obtained the recommended AT solution. There are no data available concerning AT non-use in the Italian context regarding children. From the few data available internationally, utilization of AT solutions greatly differs between countries due to factors such as funding, organization of ATSD and professional training $^{18}$. Non-use rates of AT provided among children are reported as from $10 \%$ up to $23 \%$, depending on the type of $\mathrm{AT}^{18,19}$. Thus, the results of the study conducted by the CAT seem to mirror those found in other contexts. 
The Individually Prioritized Problem Assessment ${ }^{20}$ (IPPA) was used as a tool to evaluate AT intervention effectiveness. The results indicate that, in the short term and at population level, AT interventions are perceived by the children's parents as effective in reducing children's activity limitations. In detail, difficulties experienced by children who used an AT solution systematically decreased for all ICF-CY domains considered, with effect sizes ranging from 0.7 to 1.5 .

From the results of the Quebec User Evaluation of Satisfaction with Assistive Technology-service subscale (QUEST 2.0), AT delivery and maintenance services were rated as not satisfactory by the users involved in the survey. This result may be due to long waiting times for, respectively, obtaining the recommended AT solution and receiving modifications to the AT solution. As regards the KWAZO results, none of the seven quality indicators was rated on average below the threshold (set at 33\%). However, 'coordination' and 'efficiency' received negative ratings more frequently (both $31 \%$ ).

Lastly, the Siva Cost Analysis Instrument ${ }^{21}$ (SCAI) was used to document the outcome of the AT solution in terms of social cost associated to a selected series of individual AT interventions $(n=8)$. In detail, SCAI was utilized to estimate the total amount of resources spent for each AT intervention considered, in relation to three time horizons (after one, two and three years of AT use). Cost ranged from $€ 1,405$ to $€ 15,122$ after one year of AT use; from $€ 2,361$ to $€ 29,794$ after two years; and from $€ 3,317$ to $€ 44,466$ after three years. The resources estimated as spent for using an AT solution exceed those estimated for human assistance alone in 4 cases in year 1, in 3 cases in year 2, and in 2 cases in year 3. This latter result highlights how AT interventions targeting children may be considered an investment which should be monitored while taking into account different aspects of outcome. In particular, it emerged in one case that the very high social cost did not correspond with any perceived benefit from AT intervention as assessed by IPPA. The combination of economic analysis with measurement of AT effectiveness helped AT professionals to identify an AT intervention that required further support and modifications to the original objectives.

\section{Feasibility of Assistive Technology Follow-up Procedure}

Overall, it resulted that adopting a structured follow-up procedure and using validated instruments in daily practice may be feasible and well-accepted by both AT professionals and children's parents. An overall positive attitude towards the instruments employed was found. Despite some critical aspects related to the instruments adopted, which will be discussed in more detail in the next sections, both AT professionals and users considered the follow-up procedure feasible and acceptable even if time-consuming. 


\section{Research Implications}

\section{Assistive Technology Professionals}

The data collected in the present research project show that good quality of ATSD means that service choices should be appropriate to the child and his/her parents, the results effective and satisfying the users' needs and expectations, and the services delivered in a timely manner. Furthermore, lack of coordination between health and school professionals and fragmentation of services may reduce the likelihood that the child will benefit from the AT solution.

Notably, most of the factors which appeared problematic for CAT service users mirrored those found in other studies conducted in different contexts ${ }^{16}$. In this view, it may be assumed that, despite variability in the organization of ATSD between and within healthcare systems, there may be less variation between ATSD systems for what constitutes quality of ATSD from a parent's perspective.

It follows that - by collecting data on ATSD quality by using validated instruments and well-structured strategies - insights can be gained and lessons learned from a greater understanding of how other countries have attempted to solve similar problems.

The comparative assessment of ATSD systems within and between countries has received growing interest, especially since publication of the latest AAATE Position Paper ${ }^{6}$. To this end, this thesis proposes an approach combining process and outcome measures to yield a more comprehensive description and evaluation of ATSD quality.

\section{Process Measures}

\section{Documenting Quality of the Assistive Technology Service Delivery Process}

Under the quality assurance framework described in Chapter 3, process relates to the activities performed by AT professionals and providers throughout ATSD. To describe ATSD process quality, it may be helpful to first identify the specific steps making up the ATSD process under investigation. As a starting point, it could be useful to follow the distinction proposed by the HEART study, which listed seven steps in any ATSD: Initiative, Assessment, Selection, Authorization, Implementation, Management and Follow-up ${ }^{6,7}$. In the studies carried out in the context of the present project, for instance, the steps identified by the HEART study were taken as a starting point to categorize and define the steps reflecting the peculiar organization of the ATSD system under investigation (see Chapters 3 and 5). The resulting steps varied slightly from those proposed by the HEART study (Activation/Initiative; Assessment, Selection \& Documentation; Authorization/Post-assessment), but the difference in the terminology adopted simply reflects ATSD organization variations and the importance of specific tasks (e.g. Documentation) generated by the context under investigation.

Once the steps within the ATSD process have been identified, quality dimensions may be used to describe actual care provided. In the study presented in Chapter 5, which focused on the whole ATSD process from a parent's perspective, information on qual- 
ity was collected using questions formulated on the basis of the domains of indicators outlined by the HEART study (see Chapter 5, table 2). Its authors ${ }^{7}$ distinguished six domains, which comprise: Accessibility, Competence, Coordination, Efficiency, Flexibility, and User influence. In this view, for example, the question 'How long did it take to obtain the AT solution?' refers to a specific step in the ATSD process (Authorization), and was formulated to collect data useful to documenting ATSD efficiency.

\section{Measuring Quality of the Assistive Technology Service Delivery Process}

In general, process measuring is used to determine the extent to which health providers consistently give users specific services that are compliant with recommended care guidelines. In the AT field, such guidelines are lacking, mainly due to the high variability in ATSD practices and systems between and within countries. The study described in Chapter 4, for example, showed how AT professionals may try to compensate for the lack of such guidelines to measure ATSD performance by developing process-related quality indicators. Quality indicators then served to benchmark their performance in a specific aspect of ATSD (documentation). Although the quality indicators developed in this study were service- and process-specific, the methodology adopted could easily be extended at national (and international) level, involving AT professionals and AT users from different systems, in order to develop guidelines or best practices for AT documentation.

\section{Outcome Measures}

\section{Parents' Experience with the Assistive Technology Service Delivery Process}

The surveys usually address what is valued by users and AT stakeholders in general. Standardized surveys may measure specific domains of patient experience and satisfaction. QUEST 2.0 (services subscale) and KWAZO have been used in this research project to assess the parents' overall experience of the service delivery system. However, a clear distinction should be made between these two instruments. While KWAZO may be considered a tool for measuring user experience with the ATSD process, QUEST 2.0 (services subscale) may be considered as measuring user experience with the ATSD-related services. The distinction between quality of ATSD process and services is important since some users may not receive certain services simply because they do not need them (e.g. maintenance services) but nevertheless are able to express their views about the interpersonal aspects of care received, such as information clarity and ATSD process accessibility and efficiency. Taken together, therefore, KWAZO and QUEST 2.0 (services subscale) may yield a comprehensive picture of AT user experience regarding the whole ATSD system. 


\section{Documenting Effectiveness of Assistive Technology Interventions for Children}

Prior to the study described in Chapter 6, there were no studies utilizing IPPA with children and adolescents. Moreover, little research has been conducted into attempting to evaluate the effectiveness of AT solutions at population level, considering the whole ATSD process and using instruments that could be applied in different ATSD systems ${ }^{3}$. Indeed, to evaluate effectiveness of AT interventions targeting children, most of the literature available to date reports data collected in controlled settings, usually involving case studies and instruments created $a d h o c^{2}$. From the results of the study presented in Chapter 6, two main considerations should be made regarding use of IPPA in clinical practice.

IPPA has been perceived by AT professionals as an easy and straightforward tool, and only a minority of parents found difficulties in completing it. From these results it follows that, for the purposes of documenting outcomes at population level from the proxies' perspective, the IPPA may be a useful tool also for children.

Some concerns remain, however, about interpretation of the clinical significance of the change scores. A possible first solution to overcome this issue would be to adopt a multi-dimensional approach to evaluating the AT effects on the child. Indeed, it has been assumed in this thesis that AT interventions targeting children should not only compensate for functional impairments, but also stimulate skill development ${ }^{8}$. In this view, measuring AT outcome may benefit from the combination of measures that assess the reduction of the child's difficulties in performing specific activities, as evaluated by IPPA, with measures that focus on his/her achievements regarding specific developmental and learning goals. Goal Attainment Scaling ${ }^{22}$, for example, may be used in addition to IPPA, to assess AT outcome, providing a more comprehensive picture of the AT intervention outcome. Furthermore, non-disease-specific measures of disability and health may also provide useful information on AT outcome. The World Health Organization Disability Assessment Schedule II (WHO-DAS 2.0), for instance, resulted as responsive in detecting domain-specific changes over a short-term period after an AT intervention in an adult population ${ }^{23}$. Once a version of the WHO-DAS 2.0 is available for children and adolescents ${ }^{24}$, this tool may be tested for its usefulness in detecting changes also in children with (multiple) disabilities.

It is also important to highlight that the term 'user' employed in this thesis does not refer to the child alone. User was defined here as the system composed of the child, his/ her family and the other significant persons (see Chapter 4). This definition points to the importance of focusing also on the family when assessing AT outcome ${ }^{25}$.

A final consideration concerns QUEST 2.0 (device subscale), which measures the user's satisfaction with several aspects of a device. Since most of the children involved in the studies here presented used more than one AT device, it was decided not to employ this tool. However, QUEST 2.0 may be administered to children and adolescents to directly assess their experience with a specific AT solution ${ }^{26,27}$. 


\section{Estimating Social Cost of Assistive Technology Interventions}

Economic evaluations are included in the field of outcome research ${ }^{28}$. Two considerations make the measurement of cost associated to AT intervention an important aspect of the AT outcome ${ }^{21}$ : first, there is an increasing demand for evidence of the cost-effectiveness of AT interventions; second, healthcare professionals are nowadays - more than ever - expected to be accountable for the economic implications of their decisions or prescriptions.

The most simple and logical way to estimate the costs associated with an AT intervention may be to consider the purchase price of the AT solution. Though informative, this method immediately reveals its limitations since it does not allow the taking into account of other costs which may derive from long-term use of the AT device. Particularly in the case of children with (multiple) disabilities, such additional costs may come in the form of the human assistance needed as a consequence of the introduction of an AT solution that enables the child to perform new activities which were previously hindered by his/her functional limitations ${ }^{29}$. Such additional costs refer to social $\cos ^{21}$, and may be defined as the sum of all the resources spent by all the actors involved in the ATSD process $^{30,31}$.

To date, the SCAI tool is the only instrument available to AT professionals to estimate social cost associated to AT interventions. SCAI is primarily aimed at supporting the user and the clinician in estimating the economic impact of an individual AT intervention by comparing the social cost involved when different options are available to solve a specific problem ${ }^{21}$. In the research project here described, however, SCAI was included in the battery for assessing AT solution outcome in terms of social cost and not to compare alternative interventions during $\mathrm{AT}$ assessment. Indeed, there may frequently be no alternatives to a specific AT intervention capable of leading to the same outcome for children with multiple disabilities.

Economic analysis and the estimation of social cost associated to AT interventions may raise a number of theoretical and practical issues. Theoretical issues include, for instance, the adoption of precise financial-mathematical models and the cost to include when estimating resources employed for non-interventions ${ }^{21,29}$. Practical issues, instead, were faced by AT professionals involved in the present research project when trying to estimate the cost associated to AT interventions targeting children. Such issues deserve careful attention since they may prevent the use of SCAI in routine clinical practice. In more detail:

- Children's needs as well as their capabilities vary within relatively short periods of time. Thus, providing a realistic estimate of the clinical duration of the AT intervention as requested by SCAI may be challenging for AT professionals;

- In most cases, the achievement of one goal may require the use of more than one AT at the same time (e.g. a mechanical switch combined with specific software). Adding the cost of each AT to the next may result in a non-realistic estimate of the social $\operatorname{cost}^{31}$; 
- $\quad$ The same AT device may allow the child to achieve different goals (e.g. a mechanical switch for both communication and play). Furthermore, the activities performed to achieve different goals are sometimes intertwined (e.g. activities conducted to stimulate both the child's communication and his/her play). These issues make the quantification of certain parameters (e.g. human assistance) problematic to estimate;

- For certain activities (e.g. communication), a realistic estimation of human assistance needed in relation to the device is - again - problematic for AT professionals.

Nevertheless, evidence regarding cost associated to AT interventions is needed more than ever ${ }^{6,21,29}$. A first solution to promote the use of social cost evaluation in clinical practice may be to start using SCAI to evaluate the cost associated to 'simple' AT interventions, i.e. those including one AT device (e.g. an adapted keyboard) that is used to achieve one measurable goal (e.g. writing). As illustrated in the study described in Chapter 6, this would allow AT professionals to first familiarize with SCAI, then to adopt it at least for some AT interventions.

\section{Health Policy}

ATSD in many European countries comprises a series of complex processes which are embedded within broader healthcare and social processes ${ }^{6}$. Integration of ATSD processes and services within healthcare, in particular, is vital for the success of any AT intervention. One of the main findings of the research project described in this thesis is that, in the opinion of the AT stakeholders surveyed, eliminating fragmentation of health services may have a positive impact also on ATSD. However, as emerged in the studies described in Chapter 5, and to some extent in Chapter 6, health services at national, regional and local levels are all designed to manage individual diseases and are mostly pathology-oriented. As such, services may often be experienced as troublesome and inefficient due to little integrated and poorly coordinated care ${ }^{32}$. In this context, issues emerge when children experience multiple disabilities, in which case the child is requested to attend multiple specialists and professionals that rarely communicate because they lack the procedures to do so. Reducing fragmentation and improving coordination among health providers and professionals may thus also lead to better ATSD quality.

Integrating services has become a key policy focus in many European countries, including Italy, with the aim to improve best practices around the provision of continued well-coordinated person-centred care for individuals ${ }^{33}$. Focusing on the context in which the present research project took place, in recent years the healthcare system in the local authority area of Bologna, in line with similar changes in most of the Italian regions and other European countries ${ }^{34}$, has started to move from specialized (and fragmented) care, dedicated to treating specific pathologies (separate health departments), to a more integrated model of assistance. This new care model is termed Percorsi Diagnostici Terapeutici Assistenziali (Diagnostic Therapeutic Assistive Pathways; PDTA). The definition 
of PDTA picks up on that of 'clinical pathway' (also termed integrated care pathways)', which is a structured multi-disciplinary care plan that details essential steps in the care of patients with a specific clinical problem ${ }^{35}$. The innovative aspect of the PDTA approach is that it promotes a comprehensive approach to health care. PDTAs are developed by multi-professional teams, composed of all types of physicians, nurses and social workers, who manage the disease processes and are responsible for the care of the person ${ }^{36}$. In this view, caring for a person with a specific pathology means taking into account all the factors that may impact on the individual's health, from the body structures and functions to the context in which the individual lives. The development of specific PDTAs means that, for each specific disease, practitioners from different specializations and services are required to collaborate in order to develop a single care process where any single operator is aware of the progress of the intervention plan, from diagnosis through to follow-up, and shares the various information on the specific user utilizing common instruments and organizational procedures. In doing so, the objective is to deal with the increasing proportion of individuals requiring treatment for more than one disease, for which it is necessary to integrate several interventions at different levels (medical, psychological, social and technological).

Currently, some PDTAs targeting children with complex health conditions have been developed within the Bologna area and are in the pilot phase. One in particular, named PDTA for children at risk of developing multiple disabilities, has been developed and implemented by the Maternal and Paediatrics Department of 'Maggiore' Hospital in the Bologna local authority area. This PDTA targets infants with various complex health conditions that may cause multiple disabilities and might require long-term care (e.g. very premature birth, cerebral palsy, genetic syndromes). The aim of the PDTA is to activate an integrated network of health and social professionals from the child's birth to late adolescence. The network integrates the activities of a wide range of health professionals from different health departments usually operating individually (e.g. Maternal and Paediatrics Department; Mental Health Department; Unit of Rehabilitation Medicine), and includes social as well as CAT services.

Moving from a deficit-centred care model, which locates the problem within the child, towards a model that considers the child in relation to his/her needs in terms of activities and participation may have important implications for the ATSD. For example, AT interventions may expand beyond being considered only when rehabilitative interventions are no longer useful, and may play a role from the beginning of the care process. In this view, AT interventions that begin early in the child's life and involve multiple health and social professionals, as well as the child and his/her family, may help build the foundations for the successful adoption of any AT solution that is needed as the child grows.

Although it is too early to evaluate the effectiveness of the PDTA targeting children at risk of developing multiple disabilities, the results of the studies described in the present thesis give some indications concerning possible improvements on the PDTA as regards the provision of AT solutions to children with multiple disabilities.

Firstly, the PDTA approach still adopts a strong medical perspective on health care. It emphasizes coordination among healthcare providers and is strongly focused on the 
pathology. In contrast, it places less emphasis on the child's broader social context and resources, in particular the school system. Indeed, as emerged from parents' ATSD experiences, other than the gap existing between the different healthcare providers, parents and AT professionals experience a gap between the healthcare and the school systems, the latter representing a fundamental context for the achievement of the child's developmental and learning goals. To be effective, any PDTA targeting children with multiple disabilities needs to also include the school system within its network. Italy has a fully-inclusive school system ${ }^{37}$, and most of the individual's life from childhood to late adolescence is spent at mainstream school. As documented in the study described in Chapter 5, children usually use AT solutions at school, and school teachers as well as teacher aides are responsible for the correct implementation and use of the AT solution within the child's activities. This ascribes to the teachers, or, in general, the professionals working at school, a pivotal role within the ATSD, and could make a substantial difference between the correct use of an AT solution and its abandonment. However, looking at parents' experiences, a huge gap currently seems to exist between the healthcare system, on one side, and the school system, on the other, with the CAT service working as mediator between the two 'worlds' and the child's family. This role seems somewhat unsuccessful, given the frequent 'communication interruptions' between all stakeholders ${ }^{16}$.

To avoid communication interruptions and improve coordination between all stakeholders, appointment of a PDTA-case manager may facilitate cohesion between the child and his/her family and all stakeholders, which include AT professionals, health professionals and the school system.

\section{Methodology Considerations}

The present research project adopted a practice-oriented approach, for which the experience and insight of AT stakeholders were collected in order to improve AT practice. By gathering these experiences through rigorous research methods, this project attempted to promote the adoption of an evidence-based culture within the AT service under investigation. In this view, the knowledge generated in this thesis was not only useful to implementing a change in the same environment where the research was applied, but may be immediately transferable to AT professionals working in different ATSD systems.

Overall, from this research project experience, it emerged that introducing a research approach within daily clinical activities presents a number of opportunities for service improvement. Of fundamental importance is the direct involvement and collaboration of the different AT stakeholders. In particular, the involvement of AT professionals was considered important when planning the introduction of new practices in the ATSD in so far that, without their contribution, the implementation of change would unlikely have significant and sustainable impact on ATSD. For instance, it was assumed that introducing measures for quality assessment without understanding the organizational context in which these measures are going to be used would lead AT professionals to develop work-arounds, tools could be improperly used or, more likely, not used at $\mathrm{all}^{38}$. On the other hand, user involvement and evaluation of the parents' ATSD experi- 
ence was considered important for two reasons. Firstly, as already mentioned in Chapter 1 , the family-centred approach employed in this study emphasizes the importance of considering parents' opinions as a driver of service delivery planning, implementation and evaluation ${ }^{39}$. Secondly, before implementation of any change in ATSD practice, a detailed assessment of the actual quality of care provided, from a user perspective, is considered important to creating a sense of urgency in the target audience (mainly AT professionals) - an awareness that service provision should be improved and a feeling of responsibility for such change ${ }^{40}$. Indeed, what has been noted by Davis and colleagues may be considered valid for any care provider, including AT professionals: 'they overestimate the quality of their work and are usually (often unhappily) surprised when they see the 'facts', the actual metrics describing their performance' 40 (p. 48).

In conclusion, this approach to ATSD, which integrates clinical and research activities, contributed to creating a unique context where AT professionals and AT users collaborated in the quest for answers that lead to the improved delivery of AT solutions. Further efforts should be spent in the future to make this collaboration a permanent element of the service delivery process.

\section{Recommendations for Further Research}

The research that has been undertaken for this thesis has highlighted a number of topics on which further studies would be beneficial.

In this thesis, the link between ATSD process and the AT outcome has only been assumed on the basis of the Donabedian framework for healthcare quality. Further research is needed to demonstrate that a direct link exists between specific aspects of the ATSD process (e.g. regular follow-up services) and AT solution outcome (e.g. adoption and use of the AT solution; increased effectiveness of the AT solution; parents' satisfaction with ATSD).

On the basis of the follow-up procedure developed in this research project, future research should be aimed at demonstrating a link between AT solutions and outcomes, by involving a larger sample of children and controlling for a number of factors. The latter point is of fundamental importance. The research project described in this thesis did not focus on the role of demographic, personal and psycho-social factors related to children, families and other stakeholders in mediating the measurement of specific dimensions of quality of the ATSD process and AT outcome. In particular, the heterogeneity of the population involved in this research project in terms of type and degree of disabilities reflected the variability that AT professionals routinely face in their daily practice. However, this variability may limit inference regarding AT solution outcome and ATSD quality. Future studies conducted in clinical settings may draw advantage from the use of internationally recognized measures to document the severity of the disability (e.g. Gross Motor Function Classification System ${ }^{19}$ ) or, more in general, adaptive behaviour and degree of autonomy in different life areas (Vineland Adaptive Behaviour Scale ${ }^{41}$ ). In view of better integration between the CAT and other health services within the PDTA, reliable data on family functioning and well-being collected through validated tools (e.g. Parent Stress Index ${ }^{42}$ ) may also serve for better interpretation of the AT solution outcome. 
The study on AT outcome presented in Chapter 6 focused on AT effects while considering a relatively short period of AT use (about three months). Although this was enough to document a possible effect of the AT intervention, replicating the follow-up over multiple time points (e.g. after 6,12 and 18 months) would provide more detailed information on AT effectiveness.

\section{General Conclusion}

In Italy as well as in the rest of the EU, the role and importance of specialized AT services within the healthcare systems seems to be far from well-consolidated'. A possible reason may be the lack of data on effectiveness of such services and, more in general, on ATSD quality in different countries. For this reason, assuring and improving ATSD quality is increasingly becoming a priority both at European and regional levels $s^{6,9}$. The research project presented in this thesis showed that adopting a research approach to service delivery may help AT professionals improve their practices and, in turn, the quality of their services. 


\section{References}

1. The State of the World's Children 2013 - Assistive technology for children [Internet]. 2015 [cited 19 June 2015]. Available from: http://www.unicef.org/sowc2013/focus_assistive_technology.html

2. Henderson S., Skelton H., Rosenbaum P. Assistive devices for children with functional impairments: impact on child and caregiver function. Dev Med Child Neurol 2008;50(2):89-98.

3. Anttila H, Samuelsson K, Salminen AL, Brandt Å. Quality of evidence of assistive technology interventions for people with disability: An overview of systematic reviews. Technology and Disability. 2012;24(1):9-48.

4. Lawthers A, Pransky G, Peterson L, Himmelstein J. Rethinking quality in the context of persons with disability. International Journal for Quality in Health Care 2003;15:287-299.

5. Campbell S, Roland M, Buetow S. Defining quality of care. Social Science \& Medicine. 2000;51(11):1611-1625.

6. Association for the Advancement of Assistive Technology in Europe (AAATE). Service Delivery Systems for Assistive Technology in Europe: Position Paper [Internet]. 2012 [cited 19 June 2015]. Available from: http://www.aaate.net/sites/default/files/ATServiceDelivery_PositionPaper.pdf

7. HEART. European Service Delivery System in Rehabilitation Technology: A Comprehensive Description of Service Delivery Systems of 16 European Countries. HEART (Horizontal European Activities of Rehabilitation Technology) Line C [Internet]. 1994 [cited 19 June 2015]. Available from: http://portale. siva.it/files/doc/library/a416_1_ATServiceDelivery_HEART_ReportC51.pdf

8. Desideri L, Roentgen U, Hoogerwerf EJ, de Witte L. Recommending assistive technology (AT) for children with multiple disabilities: A systematic review and qualitative synthesis of models and instruments for AT professionals. Technology and Disability 2013, 25(1): 3-13.

9. Steel E, de Witte L. Advances in European Assistive Technology service delivery and recommendations for further improvement. Technology and Disability. 2011;23:131-138.

10. Friederich A, Bernd T., de Witte LP. Methods for the selection of assistive technology in neurological rehabilitation practice. Scand J Occup Ther. 2010;17(4):308-18.

11. Desideri L, Mingardi A, Stefanelli B, Tanzini D, Bitelli C, Roentgen U, de Witte L. Assessing children with multiple disabilities for assistive technology: A framework for quality assurance. Technology and Disability. 2013;25(3):159-166.

12. Donabedian A. An introduction to quality assurance in health care. New York: Oxford University Press; 2003.

13. Campbell S, Braspenning J, Hutchinson A, Marshall M. Improving the quality of health care: Research methods used in developing and applying quality indicators in primary care. BMJ. 2003;326(7393):816-819.

14. Braspenning J, Hermens R, Calsbeek H, Westert G, Campbell S, Grol R. Quality and safety of care: the role of indicators. In: Grol R, Wensing M, Eccles M, Davis D, ed. by. Improving Patient Care: The Implementation of Change in Health Care. 2nd ed. Chichester, West Sussex: Wiley-Blackwell/BMJ Books; 2013. p. 115-136.

15. Desideri L, Ioele F, Roentgen U, Gelderblom GJ, de Witte L. Development of a team-based method for assuring the quality of assistive technology documentation, Assistive Technology. 2014;26(4):175-183.

16. Desideri L, Stefanelli B, Bitelli C, Roentgen U, Gelderblom GJ, de Witte L. Satisfaction of users with assistive technology service delivery: an exploratory analysis of experiences of parents of children with physical and multiple disabilities. Developmental Neurorehabilitation. in press.

17. Gelderblom GJ, de Witte LP. The assessment of assistive technology outcomes, effects and costs. Technology and Disability. 2002;14(3):91-94.

18. Østensjø S. Assistive Technology Devices for Children with Disabilities. In: Söderback I, ed. by. International Handbook of Occupational Therapy Interventions. 2nd ed. New York: Springer International Publishing; 2015. p. 311-322.

19. Østensjø, S, Carlberg E, VÁs llestad N. The use and impact of assistive devices and other environmental modifications on everyday activities and care in young children with cerebral palsy. Disabil Rehabil. 2005;27(14):849-861.

20. Wessels R, Persson J, Lorentsen O, Andrich R, Ferrario M, Oortwijn W et al. IPPA: Individually prioritised problem assessment. Technology and Disability. 2002;14(3):141-145. 
21. Andrich R. Cost analysis of assistive technology [internet]. [cited June 2015]. Available from: http:// portale.siva.it/files/a16_1_Andrich_Cost_analysis.pdf

22. Isabelle S, Bessey SF, Dragas KL, Blease P, Shepherd JT, Lane SJ. Assistive technology for children with disabilities. Occupational Therapy in Health Care. 2003;16(4):29-51.

23. Raggi A, Albanesi F, Gatti V, Andrich R, Leonardi M. Detecting changes following the provision of assistive devices: utility of the WHO-DAS II. International Journal of Rehabilitation Research. 2010;33(4):306-310.

24. Üstün T, Chatterji S, Kostanjsek N, Rehm J, Kennedy C, Epping-Jordan J et al. Developing the World Health Organization Disability Assessment Schedule 2.0. Bulletin of the World Health Organization. 2010;88(11):815-823.

25. Ryan S, Campbell K, Rigby P. Reliability of the Family Impact of Assistive Technology Scale for families of young children with cerebral palsy. Archives of Physical Medicine and Rehabilitation 2007;88:1436-1440.

26. Demers L, Weiss-Lambrou R, Ska B. The Quebec User Evaluation of Satisfaction with Assistive Technology (QUEST 2.0): an overview and recent progress. Technology and Disability 2002;14:101-105.

27. Murchland S, Kernot J, Parkyn H. Children's satisfaction with Assistive technology solutions for schoolwork using the QUEST 2.1: Children's version. Assistive Technology 2011, 23(3): 162-176.

28. Harris F, Sprigle S. Cost analyses in assistive technology research. Assistive Technology. 2003;15(1):16-27

29. Schraner I, de Jonge D, Layton N, Bringolf J, Molenda A. Using the ICF in economic analyses of Assistive Technology systems: Methodological implications of a user standpoint. Disabil Rehabil. 2008;30(12-13):916-926.

30. Andrich R. The SCAI instrument: Measuring costs of individual assistive technology programmes. Technology and Disability. 2002;14(3):95-99.

31. Andrich R, Caracciolo, A. Analysing the cost of individual assistive technology programmes. Disability \& Rehabilitation: Assistive Technology. 2007;2(4):207-234.

32. Schoen C, Osborn R, Squires D, Doty M, Pierson R, Applebaum S. New 2011 Survey Of Patients With Complex Care Needs In Eleven Countries Finds That Care Is Often Poorly Coordinated. Health Affairs. 2011;30(12):2437-2448.

33. Hofmarcher M, Oxley H, Rusticelli E. Improved Health System Performance through better Care Coordination. Paris: OECD; 2007.

34. Vanhaecht K, Bollmann M, Bower K, Gallagher C, Gardini A, Guezo J et al. Prevalence and use of clinical pathways in 23 countries - an international survey by the European Pathway Association. International Journal of Care Pathways. 2006;10(1):28-34.

35. Rotter T, Kinsman L, James E, Machotta A, Willis J, Snow P et al. The Effects of Clinical Pathways on Professional Practice, Patient Outcomes, Length of Stay, and Hospital Costs: Cochrane Systematic Review and Meta-Analysis. Evaluation \& the Health Professions. 2011;35(1):3-27.

36. Panella M, Marchisio S, Di Stanislao F. Reducing clinical variations with clinical pathways: do pathways work?. International Journal for Quality in Health Care. 2003;15(6):509-521.

37. European-agency.org. Italy - Legal System | European Agency for Special Needs and Inclusive Education [Internet]. 2015 [cited 26 June 2015]. Available from: https://www.european-agency.org/ country-information/italy/national-overview/legal-system

38. Carayon P, Wetterneck T, Rivera-Rodriguez A, Hundt A, Hoonakker P, Holden R et al. Human factors systems approach to healthcare quality and patient safety. Applied Ergonomics. 2014;45(1):14-25.

39. Parette P, VanBiervliet A, Hourcade J. Family-centered decision-making in assistive technology. Journal of Special Education Technology. 2000;15(1):45-55

40. Grol R, Wensing M, Eccles M, Davis D. Improving patient care. Chichester, West Sussex: Wiley-Blackwell/BMJ Books; 2013.

41. Msall M. Measuring functional skills in preschool children at risk for neurodevelopmental disabilities. Mental Retardation and Developmental Disabilities Research Reviews. 2005;11(3):263-273.

42. Abidin R. Parenting Stress Index. Odessa, FL: Psychological Assessment Resources; 1995. 
Chapter 8

Valorization of Research Results 

The research project presented in this thesis describes the development of a framework to assure quality of the AT service delivery process, and to assess AT intervention outcome and the social cost associated to the provision of AT solutions for children with multiple disabilities. The framework for assuring ATSD quality, the methodologies developed and the knowledge gained regarding AT professionals' and parents' experience of the ATSD process may be considered the foundations to a more evidence-based AT provision in which quality of the entire ATSD process is continuously monitored and improved according to a family-centred approach. The results from this research project, in particular, may be relevant for a number of stakeholders.

\section{Healthcare System}

The research project described in this thesis has substantially contributed to integrating the CAT service activities within any possible Diagnostic Therapeutic Assistive Pathway (hereafter, PDTA) targeting children with complex health conditions and multiple disabilities as described in Chapter 7. Firstly, it formalized the CAT service procedures and methodologies to such a level of detail as to facilitate integration of the CAT activities within those of the other health professionals involved in the PDTA (see study Chapter 3). Secondly, since the quality of any PDTA - and of any service provided within a PDTA - is thus periodically evaluated, the quality assurance framework developed and described in Chapter 3 will serve as a standard in assessing ATSD quality and outcomes. Thirdly, the CAT model for AT documentation developed on the basis of the experience described in Chapter 4 may be used as an additional element for integrating the ATSD within the child's broader healthcare process. Integrated documentation is in fact a key strategy for enhancing multi-professional collaboration. The work of having established a clear set of essential dimensions and related information to be considered and collected for effective AT identification, selection, implementation and use may help AT professionals to coordinate their activities with those of other health professionals and to reduce the risk of developing conflicting goals within the rehabilitative/assistive intervention. The employment of ICT-based management systems for sharing such information would be helpful in improving the integration and coordination of the care process. The CAT model for AT documentation as developed in this thesis could be easily implemented in a digital format. However, the role of ICT in supporting management of the care process within the PDTA has only been theorized so far, and has still not been translated into practice due to a lack of technological resources and competences related to ICT and health. Lastly, estimation of costs associated to AT interventions may help in the process of evaluating the resources spent within the whole PDTA and, in turn, its overall efficiency.

\section{Assistive Technology and Rehabilitation Professionals}

Enabling quality comparisons of different ATSD systems is one of the main goals of the present research project. The results of this project as well as the methodology 
employed may constitute the basis upon which AT professionals working in different Italian regions could develop strategies for collecting comparable information regarding the quality of their ATSD systems, starting from the measuring of the ATSD process and outcome. In this view, common instruments should be employed, and the results of this project have clearly shown that instruments already available for assessing AT intervention outcome could be used also with children.

The strategies proposed in this thesis may also be helpful in describing and measuring ATSD process quality. For example, the CAT service performed a two-day training course to update professionals working at the Montecatone Rehabilitation Institute, in the Imola local authority area (in the Emilia-Romagna region), to replicate the methodology developed in the study presented in Chapter 4. The scope was to develop clearer and more informative reports to support prescription of AT solutions for patients with spinal cord and traumatic brain injuries. Such an experience may be replicated, for example, with AT providers within the GLIC, the Italian association of independent AT centres described in Chapter 1.

\section{Researchers}

Further research is needed to refine the instruments employed in this research project and to advance knowledge regarding the quality of ATSD targeting children with multiple disabilities. The Italian version of the KWAZO scale to assess ATSD process outcome was adapted to the Italian context for the purposes of this thesis. Further research is already ongoing within the AT Area of the Corte Roncati Centre for Disabilities to evaluate the psychometric properties of this scale in relation to a larger sample of participants (children, adults, and elderly; $n=98$ ) who use different types of AT solutions.

In addition, AT professionals working at the CAT service have started to use the SCAI and IPPA tools at the end of any AT assessment. To facilitate data entry, a digital version of the SCAI tool has already been developed and included for the CAT users' database. Similarly, development of a digital version of the IPPA is currently ongoing. Through the systematic collection of information on AT intervention outcome, a clearer picture of the effects of AT solutions on the child's activities may emerge in the near future. After a first pilot-test conducted by professionals at the CAT, AT professionals working in different ATSD systems might also implement these tools in their daily practice.

\section{Children and Their Families}

This thesis clearly highlighted that children and their families should have a stronger role throughout the ATSD process. This is possible only by creating the conditions for increasing their involvement in the ATSD process in a manner that is feasible both for AT professionals and users. The focus-groups conducted for the purposes of this project and discussed in Chapter 5 were considered, both by AT professionals working at the CAT service and by some of the parents involved, as an experience worth repeating. In this view, focus-groups may be organized regularly to evaluate the AT service delivery 
and to discuss any possible issue regarding the provision of AT solutions to children. People involved in the focus-groups may be users living in the Bologna local authority area, but also those from other areas within the Emilia Romagna region.

Furthermore, the creation of a repository where parents and teachers could share their experiences and materials (especially adapted books and other material related to augmentative and alternative communication) was suggested during one of the two focus-groups described in Chapter 5 to improve parent participation in AT intervention. The repository could be hosted by the CAT and managed by the CAT professionals together with the children's parents or, hopefully, by the children themselves. 

Summary 

Children living in Europe are surviving more than ever, and the diseases and disabilities they suffer from are changing. The focus of this thesis is on children with multiple problems such as eating, breathing, mobility, congenital malformations and intellectual disabilities, and on interventions aimed at creating developmental and learning opportunities by modifying the context in which they live. These types of interventions are denoted under the umbrella term assistive technology (AT). The increased probability of survival even among children with multiple disabilities means that adequate services and interventions, including AT, will need to be provided for children at any point of their life. Therefore, this thesis focuses on the development and implementation of a quality assurance approach that can support AT professionals measuring and assessing the quality of AT service delivery (ATSD) provided to children and their families.

The position paper published by the Association for the Advancement of Assistive Technology in Europe (AAATE) strongly recommends that a 'common way to describe the service delivery process and measure its quality should be found'. The aim of the research project here described was to translate this recommendation into practice by developing and implementing a structured procedure to assure quality and estimate the cost associated with a specific ATSD process. Furthermore, particular attention has been given to the use of the instruments and conceptual tools elaborated by the AT community, active in the European Union since the Horizontal European Activities in Rehabilitation Technology study (HEART). To achieve this objective, the research project here described focuses on the activities of one AT centre, the Centre for AT (hereafter, CAT), which is located in the city of Bologna, in Italy.

Chapter 2 was aimed at collecting available evidence on AT service delivery practices. It presents a systematic literature review of AT assessment models and instruments specifically developed for children with multiple disabilities. Only one model for structuring the AT assessment process and four instruments developed to support decisions about AT solutions for children with multiple disabilities were found. What emerges from the work reviewed is that assessing children is a complex process which involves several tasks, including: adopting both interdisciplinary- and family-centred approaches, establishing shared goals for AT use, evaluating family and contextual resources, and assessment of both access and functions. The role of the family is central at all stages in the assessment process and the main goal of AT professionals is to empower family members so as to enable them to make the final decision regarding the AT solutions proposed. However, due to the lack of reliable information on the effectiveness of the models and the instruments reviewed, it is impossible to draw any evidence-based conclusions concerning key factors that could guide the design of models and instruments able to address in the best possible way the complexities related to the AT assessment of children with multiple disabilities in different conditions and contexts and thus to evaluate their applicability in interdisciplinary rehabilitation. Moreover, the work reviewed here leaves it unclear what factors should be considered in evaluating the effectiveness of AT interventions in case of children with multiple disabilities.

Following collection of (lacking) available evidence on models and instruments developed in the AT field to guide professionals in the selection of AT solutions and evaluation of AT interventions, Chapter 3 presents a study which provides a description of 
the role of the CAT within its specific service delivery system. In this study, a model of AT assessment targeting children with multiple disabilities is described in detail, together with the instruments employed and the professionals involved. In addition, this study proposes the incorporation of a quality assurance model within AT practice in order to document ATSD quality and outcomes. According to this model, information on ATSD quality may be collected from three information sources: structure, process and outcome. The ATSD quality assurance framework was developed to allow AT professionals to understand and describe the actual care delivered. This was in order to identify ATSD-related aspects that needed to be changed or improved. To this end, two studies were conducted, aimed at evaluating ATSD quality from the perspective of both AT professionals working at CAT and parents to children with multiple disabilities assessed by CAT professionals. These studies are presented in Chapters 4 and 5 respectively.

To stimulate AT professionals in self-evaluating the quality of their own work, the study presented in Chapter 4 focuses on an element of ATSD that usually receives scarce attention - at least as far as the Italian system is concerned - this being the written report provided to AT stakeholders at the end of the AT assessment. From this study, a set of ten quality indicators was developed; these served to define, in an indirect way, what constitutes quality in the AT assessment process from an AT professional's perspective. The review, conducted by two independent raters, led to the identification of shortcomings related mainly (but not limited) to the AT assessment process. The results showed that the overall quality of the entire documentation reviewed had to be deemed unsatisfactory. This negative result derived from five points - out of the ten quality indicators developed - emerging as not satisfied. Notable is that "Information" and "Monitoring" were the indicators that most frequently were not satisfied by the documentation reviewed. This result may be interpreted as a lack of attention posed by AT professionals towards the ATSD process activities that belong to the post-assessment phase. This phase in particular includes the assessment of the effects of the AT solution.

In the study presented in Chapter 5, a mixed-method research approach was used to conduct an in-depth investigation of parents' experiences of ATSD. Forty-seven of 115 parents participated in a postal survey assessing satisfaction with the ATSD process, employing the Quebec User Evaluation of Satisfaction with Assistive Technology-service subscale (QUEST 2.0) and the KWAZO scales. Two focus groups involving six parents served both to follow up survey results and to strengthen the conclusions drawn from the survey. As regards the QUEST 2.0 results, low satisfaction scores were reported for follow-up services ( $47 \%$ of respondents were not fully satisfied), AT delivery (39\%), and maintenance services (47\%). KWAZO results showed low satisfaction scores in particular for access to AT services (51\%), coordination (34\%) and efficiency (53\%) of ATSD. From the focus groups, it clearly emerged that health services for children are too driven by the needs of health and AT professionals. More precisely, the health system seemed to focus disproportionally on acute services and less on long-term processes, which can too easily fragment service delivery and diminish quality. This may discourage a comprehensive child- and family-centred approach to health, with adverse consequences for the continuity of AT interventions. 
The study presented in Chapter 6 had the primary aim of evaluating the outcome of ATSD targeting children with multiple disabilities. In this view, a structured follow-up procedure was developed and a battery of validated instruments was employed, covering different facets of ATSD outcome: AT effectiveness, ATSD user evaluation, and cost associated to AT intervention. Furthermore, since the studies presented in Chapters 4 and 5 provided converging evidence about shortcomings within the ATSD process, associated with the lack of a timely and well-structured follow-up service, a secondary aim of the study presented in Chapter 6 was to evaluate the feasibility of the strategy adopted to assess AT outcome with a view to implementing it in routine clinical practice.

The Individually Prioritized Problem Assessment (IPPA) was used as a tool to evaluate AT intervention effectiveness. The results indicate that, in the short term and at population level, AT interventions are perceived by the children's parents as effective in reducing children's activity limitations. In detail, difficulties experienced by children who used an AT solution systematically decreased for all ICF-CY domains considered, with effect sizes ranging from 0.7 to 1.5. From the results of the QUEST 2.0, AT delivery and maintenance services were rated as not satisfactory by the users involved in the survey. This result may be due to long waiting times for, respectively, obtaining the recommended AT solution and receiving modifications to the AT solution. As regards the KWAZO results, none of the seven quality indicators was rated on average below the threshold (set at 33\%). However, 'coordination' and 'efficiency' received negative ratings more frequently (both 31\%). Lastly, the Siva Cost Analysis Instrument (SCAI) was used to document the outcome of the AT solution in terms of social cost associated to a selected series of individual AT interventions $(n=8)$. In detail, SCAI was utilized to estimate the total amount of resources spent for each AT intervention considered, in relation to three time horizons (after one, two and three years of AT use). Cost ranged from $€ 1,405$ to $€ 15,122$ after one year of AT use; from $€ 2,361$ to $€ 29,794$ after two years; and from $€ 3,317$ to $€ 44,466$ after three years.

The combination of economic analysis with measurement of AT effectiveness helped AT professionals to identify an AT intervention that required further support and modifications to the original objectives. Further, it resulted that adopting a structured follow-up procedure and using validated instruments in daily practice may be feasible and well-accepted by both AT professionals and children's parents. An overall positive attitude towards the instruments employed was found.

Chapter 7 provides a critical analysis of the main findings presented in this thesis. Implications for AT professionals and health policy are discussed. Lastly, Chapter 8 discusses the relevance of the research project here described for a number of possible stakeholders.

In Italy as well as in the rest of the EU, the role and importance of specialized AT services within the healthcare systems seems to be far from well-consolidated. A possible reason may be the lack of data on effectiveness of such services and, more in general, on ATSD quality in different countries. For this reason, assuring and improving ATSD quality is increasingly becoming a priority both at European and regional levels. The research project presented in this thesis showed that adopting a research approach to service delivery may help AT professionals improve their practices and, in turn, the quality of their services. 

Samenvatting 

De overlevingskans van kinderen in Europa is hoger dan ooit en de ziektes en beperkingen die zij ondervinden, veranderen. In dit proefschrift ligt de focus op kinderen met meervoudige problemen zoals moeilijkheden op het gebied van eten, ademhaling, mobiliteit, aangeboren afwijkingen en intellectuele beperkingen en interventies die bedoeld zijn om leer- en ontwikkelingsmogelijkheden te creëren door de context te veranderen waarin de kinderen leven. Deze interventies worden ondergebracht binnen het containerbegrip 'assistive technology' (AT). De hogere overlevingskans, zelfs van kinderen met een meervoudige beperking, betekent dat passende dienstverlening en interventies, inclusief AT, op ieder moment van hun leven verstrekt moet kunnen worden. Om die reden richt dit proefschrift zich op de ontwikkeling en implementatie van een benaderingswijze voor kwaliteitsborging die professionals op het gebied van AT kan ondersteunen bij het meten en beoordelen van het hulpmiddelenverstrekkingsproces voor kinderen en hun families.

Een door de vereniging ter bevordering van hulpmiddelen en ondersteunende technologie in Europa - 'Association for the Advancement of Assistive Technology in Europe' (AAATE) - uitgebrachte nota raadt ten zeerste aan, dat een 'gezamenlijke weg voor de beschrijving van het proces van de hulpmiddelenverstrekking en het meten van de kwaliteit daarvan gevonden dient te worden'. Het doel van het hier beschreven onderzoeksproject was deze aanbeveling naar de praktijk te vertalen door een gestructureerde procedure voor het meten van de kwaliteit en het schatten van de kosten die met een specifiek verstrekkingsproces samenhangen te ontwikkelen en te implementeren. Verder werd bijzondere aandacht besteed aan het gebruik van instrumenten en conceptuele tools die door de AT gemeenschap uitgewerkt en sinds de 'Horizontal European Activities in Rehabilitation Technology' (HEART) studie in gebruik zijn. Om dit doel te bereiken, richt het hier beschreven onderzoeksproject zich op één instituut voor hulpmiddelen, het 'Centre for AT' (in het volgende CAT) in Bologna, Italië.

Hoofdstuk 2 had tot doel het beschikbare wetenschappelijk bewijs omtrent de praktijken van het hulpmiddelenverstrekkingsproces te verzamelen. Er wordt een systematische review van AT assessment modellen en instrumenten gepresenteerd die specifiek ontwikkeld zijn voor de doelgroep van kinderen met een meervoudige beperking. Er werd alleen één model om het AT assessment proces te structureren en vier instrumenten die ontwikkeld zijn om de besluitvorming op het gebied van AT voor kinderen met een meervoudige beperking te ondersteunen, gevonden. Uit de artikelen die gelezen en beoordeeld zijn, wordt duidelijk dat het gericht onderzoeken van kinderen een complex proces is. Hierbij komen verschillende taken aan de orde, waaronder: het hanteren van zowel interdisciplinaire als ook familie-gecentreerde benaderingswijzen, het opstellen van gezamenlijke doelen voor het gebruik van AT, het boordelen van de (ondersteunings-)mogelijkheden van familie en omgeving en het onderzoeken van mogelijkheden voor toegang en functies. De rol van de familie staat in alle fases van het assessment proces centraal. Het hoofddoel van professionals op het gebied van AT is dan ook om familieleden te empoweren, zodat zij in staat zijn om een definitief besluit omtrent de voorgestelde AT oplossingsmogelijkheden te nemen. Echter, door een gebrek aan betrouwbare informatie over de effectiviteit van de gereviewde modellen en instrumenten is het niet mogelijk om op wetenschappelijk bewijs gebaseerde conclusies te trekken met betrekking tot sleutelfactoren die voor de ontwikkeling van modellen en instrumenten leidend kunnen zijn. Dit zou een voorwaarde zijn om 
op de meest optimale manier de complexiteit die met het assessment van kinderen met een meervoudige beperking in verschillende condities en omgevingen samenhangt, in acht te nemen. Door dit gebrek aan evidentie is het tevens niet mogelijk hun toepasbaarheid in de interdisciplinaire revalidatie te evalueren. Verder blijft het ook na de review onduidelijk welke factoren voor het evalueren van de effecten van AT voor kinderen met een meervoudige beperking overwogen moeten worden.

$\mathrm{Na}$ het verzamelen van het (ontbrekende) beschikbare wetenschappelijk bewijs omtrent modellen en instrumenten die in het domein van AT ontwikkeld werden om professionals bij de selectie van AT oplossingsmogelijkheden en het evalueren van AT interventies te leiden, presenteert Hoofdstuk 3 een studie die de rol van het CAT en zijn specifieke dienstverleningssysteem beschrijft. In deze studie wordt een model voor AT assessment gericht op kinderen met een meervoudige beperking samen met de gebruikte instrumenten en de betrokken professionals gedetailleerd beschreven. Daarnaast stelt deze studie het inpassen van een kwaliteitsborgingsmodel voor de praktijk van de hulpmiddelenverstrekking voor om de kwaliteit en de uitkomsten van het verstrekkingsproces vast te leggen. Volgens dit model kan informatie over de kwaliteit van het verstrekkingsproces uit drie verschillende bronnen verzameld worden: informatie over de structuur, het proces en de uitkomsten. Het raamwerk voor de kwaliteitsborging van het verstrekkingsproces werd ontwikkeld om AT professionals in staat te stellen de daadwerkelijk geboden zorg te begrijpen en te beschrijven. Dit was noodzakelijk om de aan het verstrekkingsproces gerelateerde aspecten te identificeren die veranderd of verbeterd moesten worden. Om dit te kunnen bereiken, werden twee studies verricht. Zij beoogden de kwaliteit van het verstrekkingsproces vanuit het perspectief van zowel AT professionals in dienst bij het CAT als ook van ouders van kinderen met een meervoudige beperking die door CAT professionals onderzocht werden, te achterhalen. Deze studies worden in respectievelijk Hoofdstuk 4 en 5 gepresenteerd.

Om AT professionals te stimuleren de kwaliteit van hun eigen werk te evalueren, staat in Hoofdstuk 4 een element van het verstrekkingsproces centraal, dat normaal gesproken, tenminste binnen het Italiaanse systeem, weinig aandacht verkrijgt. Dit is de schriftelijke rapportage die alle betrokkenen aan het eind van het AT assessment ontvangen. Op basis van de resultaten uit deze studie is een lijst met tien kwaliteitsindicatoren ontwikkeld. Deze dienen ervoor om - op een indirecte manier - te definiëren wat er vanuit het perspectief van AT professionals aan kwaliteit in het hulpmiddelenverstrekkingsproces van belang is. De evaluatie die door twee onafhankelijk beoordelaars uitgevoerd werd, heeft tot het identificeren van tekortkomingen geleid. Deze tekortkomingen hadden voornamelijk (maar niet alleen) met het AT assessment proces te maken. De resultaten lieten zien, dat de kwaliteit van de gehele documentatie als ontoereikend kon worden beschouwd. Dit negatieve resultaat kwam tot stand doordat vijf van de tien kwaliteitsindicatoren onvoldoende beoordeeld zijn. Het valt op dat "Informatie" en "Monitoring" de indicatoren waren die voornamelijk met onvoldoende beoordeeld zijn in de getoetste documentatie. Dit resultaat kan geïnterpreteerd worden als een gebrek aan aandacht die door AT professionals besteed wordt aan activiteiten binnen het verstrekkingsproces die in de na-assessment fase behoren. Deze fase houdt vooral het in kaart brengen van de effecten van een hulpmiddelen verstrekking in. 
In de studie die in Hoofdstuk 5 gepresenteerd wordt, werd een mixed-method benadering gebruikt om een diepgaand exploratief onderzoek naar de ervaringen van ouders met het verstrekkingsproces uit te voeren. Aan een schriftelijke enquête over hun tevredenheid met het verstrekkingsproces namen 47 van 115 ouders deel. De enquête werd per post verstuurd en maakte gebruik van de 'Quebec User Evaluation of Satisfaction with Assistive Technology'(QUEST 2.0) - services sub schaal en de KWAZO schalen. Twee focus groepen met zes ouders dienden zowel voor het voortbouwen op de resultaten van de enquête als ook voor het onderbouwen van de conclusies die uit de enquête getrokken zijn. De QUEST 2.0 resultaten toonden lage tevredenheidsscores voor de dienstverlening in het kader van nazorg ( $47 \%$ van de respondenten was niet helemaal tevreden), levering van het hulpmiddel (39\%) en dienstverlening op het gebied van onderhoud (47\%). Ook de resultaten uit KWAZO laten lage tevredenheidsscores zien, vooral voor de toegankelijkheid van AT services (51\%), coördinatie (34\%) en efficiëntie $(53 \%)$ van het verstrekkingsproces. Uit de focusgroepen kwam duidelijk naar voren dat de geboden zorg voor kinderen te veel vanuit de behoeften van professionals op het gebied van gezondheidszorg en AT ingegeven wordt. Meer in het bijzonder leek de zorg onevenredig gericht te zijn op acute zorg en dienstverlening en minder op lange-termijn processen, waardoor de dienstverlening te gemakkelijk gefragmenteerd raakt en de kwaliteit vermindert. Dit zou een omvattende kind- en familie-gecentreerde benaderingswijze van gezondheid in de weg kunnen staan met nadelige gevolgen voor de continuïteit van AT interventies.

Het voornaamste doel van de in Hoofdstuk 6 gepresenteerde studie was het achterhalen van de uitkomsten van het verstrekkingsproces voor kinderen met een meervoudige beperking. Om dit doel te kunnen bereiken, werd een gestructureerde follow-up procedure ontwikkeld en een set van gevalideerde instrumenten toegepast. Deze set omvatte verschillende facetten van de uitkomsten van het verstrekkingsproces: effectiviteit van AT, gebruikerstevredenheid met het verstrekkingsproces en kosten die aan de AT interventie verbonden zijn. Verder was een tweede doelstelling van de in Hoofdstuk 6 gepresenteerde studie het evalueren van de haalbaarheid van de gebruikte strategie om de uitkomsten van AT te onderzoeken met het oog op de implementatie in de dagelijkse klinische praktijk. Dit omdat de studies die in Hoofdstuk 4 en 5 gepresenteerd worden convergent bewijs leverden van de tekortkomingen in het verstrekkingsproces die in verband gebracht worden met het gebrek van een tijdige en goed gestructureerde nazorg.

Het "Individually Prioritized Problem Assessment" (IPPA) werd gebruikt als instrument voor de evaluatie van de effectiviteit van de AT interventie. De resultaten tonen dat, op de korte termijn en op groepsniveau, de AT interventies door de ouders als effectief beschouwd worden voor het verminderen van de beperkingen in activiteiten van hun kinderen. Meer in het bijzonder verminderden de ervaren moeilijkheden bij de kinderen die gebruik makkten van AT systematisch in alle ICF-CY domeinen die bekeken werden. De effectgrootte reikte van 0,7 tot 1,5. De resultaten van QUEST 2.0 laten zien dat de deelnemers aan de survey over de levering van AT en dienstverlening ten behoeve van onderhoud niet tevreden waren. Dit resultaat zou verklaard kunnen worden door de lange wachttijden voor zowel het verkrijgen van de aanbevolen AT oplossing als ook voor het verkrijgen van vereiste individuele aanpassingen voor de AT oplossingen. Wat de resulta- 
ten van KWAZO betreft, werd geen van de zeven kwaliteitsindicatoren gemiddeld lager beoordeeld dan de drempelwaarde (die op 33\% vastgelegd werd). Echter, 'coördinatie' en 'efficiëntie' werden vaker negatief beoordeeld (beiden 31\%). Ten slotte werd het 'Siva Cost Analysis Instrument' (SCAI) gebruikt om de uitkomst van de AT oplossing in termen van sociale kosten die met een reeks van geselecteerde individuele AT interventies in verband gebracht worden, te documenteren $(n=8)$. SCAI werd gebruikt om de totale hoeveelheid van resources te schatten die aan iedere nader bekeken AT interventie besteed werd. Dit in verhouding tot drie tijdshorizonnen (na één, twee en drie jaar gebruik van AT). De kosten reikten van $€ 1.405$ tot $€ 15.122$ na één jaar gebruik van AT; van $€ 2.361$ tot $€ 29.794$ na twee jaren; en van $€ 3.317$ tot $€ 44.466$ na drie jaren.

De combinatie van een economische analyse en het meten van de effectiviteit van AT heeft AT professionals geholpen te identificeren dat een AT interventie verdere ondersteuning en een bijstelling van de oorspronkelijke doelstellingen vereist. Bovendien werd duidelijk dat het aanvaarden van een gestructureerde procedure voor follow-up en nazorg en het gebruik van gevalideerde instrumenten in de dagelijkse praktijk zowel haalbaar is als ook door AT professionals en ouders geaccepteerd wordt. Er bleek een algeheel positieve attitude met betrekking tot de gebruikte instrumenten te zijn.

Hoofdstuk 7 biedt een kritische analyse van de voornaamste resultaten die in dit proefschrift gepresenteerd worden. Daarnaast worden implicaties voor AT professionals en gezondheidsbeleid uiteengezet. Ten slotte wordt in Hoofdstuk 8 de relevantie van het hier beschreven onderzoeksproject voor een aantal mogelijke stakeholders besproken.

In Italië lijkt, zoals in de hele EU, de rol en het belang van gespecialiseerde AT services binnen de gezondheidszorgsystemen verre van goed geconsolideerd. Een mogelijke reden hiervoor zou gelegen kunnen zijn in het gebrek van data over de effectiviteit van dergelijke services en, meer in het algemeen, over de kwaliteit van het verstrekkingsproces in verschillende landen. Om deze reden wordt het bewaken en verhogen van de kwaliteit van het verstrekkingsproces in toenemende mate een prioriteit, zowel op Europees als op regionaal niveau. Het in dit proefschrift gepresenteerde onderzoeksproject heeft laten zien dat het toepassen van een onderzoekende benaderingswijze in het proces van dienstverlening AT professionals kan ondersteunen hun praktijken en op zijn beurt tevens de kwaliteit van hun dienstverlening te verbeteren. 
Sommario 

In Europa, i bambini hanno una maggiore aspettativa di vita rispetto al passato e le patologie di cui possono soffrire stanno cambiando. Questa tesi si focalizza, da una parte, sui bambini con difficoltà multiple come mangiare, respirare, muoversi, che presentano malformazioni congenite e disabilità intellettiva; dall'altra sugli interventi che hanno come obiettivo il miglioramento delle opportunità di apprendimento e sviluppo di tali bambini attraverso l'adattamento del loro ambiente. Tali interventi vengono definiti utilizzando il termine generico 'tecnologie assistive' (ma anche 'ausili' o 'AT'). L'aumento delle possibilità di sopravvivenza anche tra i bambini con disabilità multiple implica la sempre maggiore necessità di offrire in ogni momento della loro vita servizi per la salute che siano adeguati, ivi compresi interventi che prevedono l'uso di ausili. Per questo motivo, questa tesi si concentra sullo sviluppo ed implementazione di una strategia a garanzia della qualità dei servizi che possa aiutare i professionisti nel campo delle tecnologie assistive nel compito di misurare e valutare la qualità delle prestazioni offerte ai bambini e alle loro famiglie lungo tutto il percorso di valutazione e fornitura degli ausili.

Il Position Paper pubblicato dalla Associazione per l'Avanzamento delle Tecnologie Assistive in Europa (Association for the Advancement of Assistive Technology in Europe; AAATE) raccomanda la necessità di 'trovare una modalità comune per descrivere il percorso ausili e misurare la sua qualità. L'obiettivo del presente progetto di ricerca è quello di trasferire tale raccomandazione nella pratica clinica attraverso lo sviluppo e l'implementazione di una procedura strutturata per la garanzia della qualità del percorso e stimare i costi dell'intero processo di fornitura dei servizi. Inoltre, particolare attenzione è stata data agli strumenti e i modelli elaborati entro la Comunità Europea a partire dallo studio Horizontal European Activities in Rehabilitation Technology study (HEART). Per realizzare tale obiettivo, il progetto di ricerca è stato realizzato focalizzandosi sulle attività cliniche di un centro per le tecnologie assistive (CAT), attivo nella città di Bologna, in Italia.

Il Capitolo 2 aveva l'obiettivo di raccogliere le evidenze a disposizione circa le pratiche di fornitura ausili. Il Capitolo presenta una rassegna sistematica della letteratura e si concentra sui modelli e gli strumenti sviluppati specificamente per i bambini con disabilità multiple. E' stato identificato soltanto un modello di percorso ausili e quattro strumenti per guidare i professionisti nella scelta della soluzione tecnologica che fossero stati sviluppati specificamente per bambini con disabilità multiple. Ciò che emerge chiaramente dal lavoro revisionato è la complessità del processo di valutazione dei bambini al fine di identificare la migliore soluzione possibile. Tale processo include diverse attività: adottare un approccio interdisciplinare centrato sulla famiglia, stabilire obiettivi condivisi per l'utilizzo della soluzione, valutare le risorse a disposizione della famiglia e del suo contesto, valutare le strategie di accesso alla soluzione e il funzionamento del bambino. Il ruolo della famiglia è centrale in ogni aspetto della valutazione, e l'obiettivo primario dei professionisti è quello di rinforzare i membri della famiglia al fine rendere loro in grado di prendere la decisione finale rispetto all'ausilio più adatto da utilizzare. Purtroppo, a causa di una mancanza di informazioni circa l'efficacia dei modelli e degli strumenti revisionati, è stato impossibile valutare quali fattori giocano un ruolo chiave nel percorso di fornitura dell'ausilio in diversi contesti di utilizzo e per diversi bisogni, e pertanto valutare la loro adeguatezza e applicabilità in ambienti clinici interdisciplinari. 
In aggiunta, quanto è stato revisionato non permette di chiarire quali fattori debbano essere tenuti in considerazione nella valutazione dell'efficacia degli interventi ausili per bambini con disabilità multiple.

Successivamente alla raccolta delle informazioni circa i modelli e gli strumenti per guidare la valutazione e selezione degli ausili a disposizione dei professionisti, il Capitolo 3 presenta una descrizione del servizio CAT e del sistema di salute in cui opera. In tale Capitolo, viene descritto minuziosamente il modello di valutazione ausili per bambini con disabilità multiple utilizzato dal CAT, questo insieme agli strumenti utilizzati e i professionisti della salute coinvolti. Inoltre, il Capitolo propone un modello di garanzia della qualità utile al fine di documentare la qualità del percorso ausili e valutare i suoi esiti. Secondo questo modello, le informazioni circa la qualità del percorso ausili provengono da tre fonti distinte: strutture, processi, esiti. Tale modello è stato sviluppato per permettere ai professionisti di comprendere e documentare le prestazioni erogate, questo con l'obiettivo di identificare gli aspetti del percorso ausili da cambiare o migliorare. A tal fine, due studi sono stati condotti, il cui obiettivo era di valutare la qualità del percorso ausili secondo la prospettiva sia dei professionisti nel campo degli ausili, sia dei genitori dei bambini con disabilità multiple afferenti presso il CAT. Questi studi sono stati presentati rispettivamente nel Capitolo 4 e 5.

Per stimolare i professionisti a valutare la qualità del proprio lavoro, lo studio presentato nel Capitolo 4 si concentra su un elemento del percorso ausili solitamente trascurato nella pratica - almeno per quanto riguarda il sistema italiano - vale a dire la redazione di una relazione da inviare a tutti i portatori di interesse in seguito alla valutazione ausili effettuata presso il centro. Questo studio ha permesso di identificare una lista di dieci indicatori di qualità. Tali indicatori sono serviti per definire, in maniera indiretta, cosa costituisce la qualità di una valutazione ausili. La valutazione della documentazione, condotta da due valutatori indipendenti, ha portato all'identificazione dei punti deboli nel processo di valutazione ausili. I risultati hanno mostrato che l'intera documentazione revisionata era da considerare non soddisfacente. Questo risultato negativo era dovuto al fatto che cinque dei dieci criteri utilizzati per la revisione della documentazione non erano stati soddisfatti. In particolare, i criteri definiti "Informazioni" e "Monitoraggio" sono risultati essere quelli più spesso non soddisfatti dalle relazioni revisionate. Tale risultato può essere visto come la conseguenza di una scarsa attenzione da parte dei professionisti verso tutte quelle attività che seguono la valutazione ausili. Questa fase in particolare comprende la valutazione degli esiti della soluzione fornita.

Nello studio presentato nel Capitolo 5 è stato utilizzato un disegno di ricerca misto per investigare in profondità l'esperienza dei familiari rispetto al percorso ausili. Quarantasette di 115 familiari contattati hanno dapprima partecipato a un sondaggio postale per valutare la loro soddisfazione rispetto al percorso ausili. In tale indagine è stata utilizzata la scala Quebec User Evaluation of Satisfaction with Assistive Technology-service subscale (QUEST 2.0) e la KWAZO. Successivamente, sono stati organizzati due focus group con in totale 6 genitori per approfondire i risultati del sondaggio. Per quanto riguarda i risultati alla QUEST 2.0, bassi livelli di soddisfazione sono stati rilevati per quanto riguarda i servizi di verifica ( $47 \%$ dei partecipanti non soddisfatto), fornitura dell'ausilio (39\%), servizi di riparazione (47\%). Per quanto riguarda la KWAZO, i risul- 
tati hanno mostrato bassi livelli di soddisfazione specialmente per quanto riguarda l'accesso ai servizi (51\%), la coordinazione tra professionisti (34\%) e l'efficienza (53\%). Dai focus group è emerso chiaramente che i servizi per la salute sono guidati troppo spesso dai bisogni dei professionisti della salute e degli ausili. Più precisamente, i servizi per la salute sembrano troppo concentrati sulla fase acuta e meno su quella a lungo termine. Questo causa una frammentazione dei servizi a scapito della qualità, portando come conseguenza una scarsa attenzione verso pratiche centrate sul bambino e la sua famiglia e una discontinuità degli interventi.

Lo studio presentato nel Capitolo 7 aveva come obiettivo principale quello di valutare gli esiti del percorso ausili affrontato da bambini con disabilità multiple. A questo proposito, è stato sviluppato un processo strutturato di follow-up in combinazione con una batteria di strumenti validati che coprissero i diversi aspetti della valutazione dell'esito del percorso ausili: efficacia della soluzione, soddisfazione dell'utente, costi associati all'intervento. In aggiunta, dal momento che gli studi presentati nei Capitoli 4 e 5 hanno fornito evidenze convergenti circa le debolezze del percorso ausili, identificabili nella mancanza di una puntuale e strutturata strategia di valutazione dell'intervento AT, un obiettivo secondario dello studio è stato quello di valutare la fattibilità della startegia di follow-up adottata al fine di implementarla nella pratica quotidiana.

La scala Individually Prioritized Problem Assessment (IPPA) è stata utilizzata per valutare l'efficacia. I risultati mostrano che, nel breve periodo e a livello della popolazione coinvolta, le soluzioni fornite sono percepite dai genitori come efficaci nel ridurre le limitazioni funzionali dei bambini. Nel dettaglio, le difficoltà esperite dai bambini sono diminuite in seguito alla fornitura di un ausilio per tutti i domini dell'ICF-CY considerati, con effetti nel range da 0.7 a 1.5. Dai risultati del QUEST 2.0, i servizi di fornitura e di manutenzione non hanno soddisfatto i partecipanti coinvolti nello studio. Questo risultato può essere attribuibile ai lunghi tempi di attesa rispettivamente per ottenere l'ausilio e ricevere gli opportuni adattamenti. Per quanto concerne la scala KWAZO, benchè nessuno dei sette indicatori sia stato valutato sotto la soglia di accettabilità (posta al 33\%), gli item relativi alla 'coordinazione' e l' efficienza' hanno ricevuto più frequentemente punteggi negativi (entrambi nel 31\% dei casi). Infine, lo strumento Siva Cost Analysis Instrument (SCAI) è stato usato per documentare i costi sociali relativi al fornitura di un serie selezionata di casi $(n=8)$. Nel dettaglio, lo SCAI è stato utilizzato per stimare il totale delle risorse spese per ciascun intervento considerato, in relazione a tre orizzonti temporali distinti (dopo 1, 2 e 3 anni). I costi oscillavano tra $€ 1,405$ e $€ 15,122$ dopo un anno di utilizzo dell'ausilio; tra $€ 2,361$ a $€ 29,794$ dopo due anni; da $€ 3,317$ a $€ 44,466$ dopo tre anni.

La combinazione dell'analisi dei costi sociali con la misurazione dell'efficacia dell'intervento ha aiutato i professionisti a identificare un intervento che richiedeva ulteriori modifiche all'obiettivo originale. Inoltre, è risultato che l'adozione di una procedura strutturata per la verifica degli interventi è una pratica accettata sia dai professionisti che dai familiari. E' stato inoltre registrato un atteggiamento generalmente positivo verso gli strumenti impiegati. 
Il Capitolo 7 fornisce una analisi critica dei più rilevanti risultati emersi nel corso del progetto. Vengono descritte le implicazioni di tali risultati per i professionisti nel campo degli ausili e della salute più in generale.

Infine, nel Capitolo 8 viene discussa la rilevanza di tale progetto di ricerca per diversi portatori di interesse.

In Italia così come nel resto d'Europa, il ruolo e l'importanza dei servizi specializzati nel supporto alla fornitura degli ausili non è ancora consolidata. Una possibile motivazione può essere la mancanza di dati circa l'efficacia di tali servizi e, più in generale, sulla qualità dei diversi percorsi ausili. Per questo motivo, assicurare e migliorare la qualità del percorso ausili è diventata una priorità a livello europeo come a livello locale. Il progetto qui presentato ha mostrato come adottare un approccio basato sulla ricerca può aiutare i professionisti nel campo degli ausili a migliorare le proprie pratiche di lavoro e, di conseguenza, la qualità dei servizi offerti. 


\section{Abbreviations}

AAATE $=$ Association for the Advancement of Assistive Technology in Europe

$\mathrm{ASL}=$ Local Health Authority

AT = Assistive Technology

ATSD $=$ Assistive Technology Service Delivery

CAT $=$ Centre for Assistive Technology

Children with $\mathrm{MD}=$ Children with multiple disabilities

GLIC = Italian association of independent AT centres

HEART $=$ Horizontal European Activities in Rehabilitation Technology

ICF-CY= International Classification of Functioning, Disability and Health - Children and Youth Version

IOM= Institute of Medicine

IPPA= Individual Prioritised Problem Assessment

$\mathrm{ISO}=$ International Organization for Standardization

ISTAT = Italian Institute of Statistics

$\mathrm{KWAZO}=$ Quality of Care

PDTA= Diagnostic Therapeutic Assistive Pathway

QUEST 2.0= Quebec User Evaluation of Satisfaction with Assistive Technology

SCAI = SIVA Cost Analysis Instrument

SSN= Italian National Health Service 



\section{Aknowledgments}

This thesis is the result of the continuous support and encouragement of my $\mathrm{PhD}$ advisors, Luc de Witte, Uta Roentgen, and Gert Jan Gelderblom.

Luc, thanks for having trusted in me the first time you came in Bologna. Thanks for your guidance, support, and your ability to transmit your incredible energy: it was a source of motivation over the last four years.

Uta, sincere thanks for your patience: I would have never written this thesis without your support, scientific advice, and the many insightful discussions and suggestions.

Gert Jan, it was a privilege to meet you, receive your guidance and discuss about AT with you. I will always remember you as an inspiring person.

I am also infinitely grateful to my colleagues in Bologna at Area Ausili of Corte Roncati: Evert Jan Hoogerwerf, Claudio Bitelli, Massimiliano Malavasi, Eleonora Ravaglia, Martina Bizzarri, Marcella Ioele, Roberta Agusto, Devis Trioschi, Margherita Borri, Chiara Costa, Matteo Rimondini, Aziz Roume, Gianluca Travaglini, Daniela Tanzini, Alberto Mingardi, Ivan Nanni, Brunella Stefanelli. Without their precious support it would not be possible to conduct this research project. I'm particularly grateful to the vision of Evert for having created a link between Italy and the Netherlands, thus making it possible the realization of this research project.

My sincere thanks goes to the people at the Research Centre for Technology in Care. I'm grateful in particular to Loek van der Heide for her great hospitality the first time I came in Maastricht, and her fundamental contribution to the study described in Chapter 2.

Voglio ringraziare AIAS Bologna onlus per avere creduto in questo progetto fin dall'inizio e avermi dato l'opportunità di portarlo avanti con grande tranquillità. Sono convinto che i risultati di tutto questo lavoro potranno aiutare davvero l'AIAS a crescere e migliorare come servizio.

Un grazie speciale va a tutte le famiglie che hanno offerto il loro contributo rendendo possibile buona parte degli studi qui descritti.

Grazie alla mia famiglia. Grazie di tutto. Giuro che adesso smetto di studiare e mi trovo un lavoro.

A Francesca dico grazie ogni giorno e continuerò a farlo per sempre. 



\section{About the Author}

I was born in Bologna, Italy, in 1983. I have received the Master's degree (with honors) in Applied Cognitive Psychology and the 2nd level specialization degree in Health Psychology from the University of Bologna, Bologna, Italy, in 2007 and 2014 respectively. Currently, I'm working as researcher at Ausilioteca Living Lab at Corte Roncati Centre for Disabilities - Az. USL Bologna, Bologna, Italy.

With a multidisciplinary background in applied psychology, cognitive and behavioral psychotherapy, assistive technology, and health services research, I have working experience in EU funded research projects, academia and public health sector. I have coauthored publications in Brain-Computer Interfaces, user-centred design, eye movements during face processing, and assistive technology service delivery. My research interests are digital technology supporting the cognitive and social development of people with intellectual, language and learning disabilities. 


$$
G
$$

